volume 7

ISSUE 1

2019 gennaio-febbraio

Editor in Chief

Paola Gnerre

Supervisor Editor

Roberto Nardi

\title{
Le urgenze ematologiche
}

Guest Editors: M. Scudeletti, R. Tassara, G. Antonucci

The official journal of the Federation of Associations of Hospital Doctors on Internal Medicine (FADOI)

\section{A Joumal of Hospital \\ and Internal Medicine}

\section{dell'Italian Journal of Medicine}


PRESIDENTE ELETTO

Dario Manfellotto, Roma, Italy

PAST PRESIDENT

Mauro Campanini, Novara, Italy

SEGRETARIO

Micaela La Regina, La Spezia, Italy

SEGRETARIO VICARIO

Andrea Montagnani, Grosseto, Italy

\section{STAFF DI SEGRETERIA}

\begin{tabular}{ll}
\hline Comunicazione & Claudia Tieri, Bari, Italy \\
Ricerca & Roberta Re, Novara, Italy \\
Formazione & Maurizia Gambacorta, Todi $(P G)$, Italy
\end{tabular}

Formazione Maurizia Gambacorta, Todi $(P G)$, Italy

TESORIERE

David Terracina, Roma, Italy

\section{STAFF DI TESORERIA}

Francesco D'Amore, Roma, Italy

\section{PRESIDENTE FONDAZIONE FADOI}

Mauro Campanini, Novara, Italy

COORDINATORE

Giuseppe Augello, Canicattì ( $A G)$, Italy

\section{DIPARTIMENTO PER LA RICERCA CLINICA FADOI}

Direttore Francesco Dentali, Varese, Italy

Supervisor per la Ricerca Giancarlo Agnelli, Perugia, Italy

DIPARTIMENTO PER LA FORMAZIONE

E AGGIORNAMENTO

Direttore Mauro Silingardi, Bologna, Italy

COORDINAMENTO FORMAZIONE

AREA CENTRO-NORD

Francesco Orlandini, La Spezia, Italy

COORDINAMENTO FORMAZIONE

AREA CENTRO-SUD

Generoso Uomo, Napoli, Italy

COORDINATORE COMMISSIONE GIOVANI

Flavio Tangianu, Oristano, Italy

MEMBRO FISM E RESPONSABILE

PER L'INNOVAZIONE IN MEDICINA INTERNA

Antonino Mazzone, Legnano (MI), Italy

ITALIAN JOURNAL OF MEDICINE

Editor in Chief Giorgio Vescovo, Padova, Italy

RESPONSABILE DEI

QUADERNI DELL'ITALIAN JOURNAL OF MEDICINE

Paola Gnerre, Savona, Italy

SUPERVISOR EDITOR DEI

QUADERNI DELL'ITALIAN JOURNAL OF MEDICINE

Roberto Nardi, Bologna, Italy

DELEGATO FADOI ITALIAN STROKE ORGANIZATION

E CONSULTA CARDIOVASCOLARE

Michele Stornello, Siracusa, Italy

\section{RAPPORTI CON EFIM}

Antonio Brucato, Bergamo, Italy

Gualberto Gussoni, Milano, Italy

Ombretta Para, Firenze, Italy

Giorgio Vescovo, Padova, Italy

\section{RESPONSABILE SITO NAZIONALE}

Salvatore Lenti, Arezzo, Italy

RESPONSABILE SISTEMA GESTIONE QUALITÀ

Franco Berti, Roma, Italy

RESPONSABILE CLINICAL COMPETENCE

Antonino Mazzone, Legnano (MI), Italy

RESPONSABILE AREA ECOGRAFIA

Francesco Cipollini, Ascoli Piceno, Italy

Marcello Romano, Catania, Italy

\section{RESPONSABILE MEDICINA DI GENERE}

Cecilia Politi, Isernia, Italy

\section{RESPONSABILE AREA NUTRIZIONE}

Roberto Risicato, Siracusa, Italy

Massimo Rondana, Pordenone, Italy

Luciano Tramontano, Praia a Mare (CS), Italy

RESPONSABILE AREA DI CLINICAL GOVERNANCE

Giovanni Iosa, Cesenatico (FC), Italy

Stefano De Carli, Udine, Italy

\section{AREA SLOW MEDICINE}

Roberto Frediani, Chieri (TO), Italy

Luigi Lusiani, Castelfranco Veneto (TV), Italy

\section{AREA DOLORE}

Domenico Panuccio, Bologna, Italy

Giuseppe Civardi, Piacenza, Italy

\section{AREA CRITICA IN MEDICINA INTERNA}

Carlo Nozzoli, Firenze, Italy

\section{RESPONSABILE AGGIORNA FADOI}

Giuliano Pinna, Asti, Italy 


\section{Italian Journal of Medicine}

A Journal of Hospital and Internal Medicine

\section{PRESIDENTE FONDAZIONE}

Mauro Campanini, Novara, Italy

\section{COORDINATORE}

Giuseppe Augello, Canicattì ( $A G)$, Italy

\section{DIPARTIMENTO PER LA RICERCA CLINICA FADOI}

Direttore $\quad$ Francesco Dentali, Varese, Italy

Supervisor per la Ricerca Giancarlo Agnelli, Perugia, Italy

SEGRETERIA

Grazia Panigada, Pescia (PT), Italy

DELEGATO SIF

Francesco Rossi, Napoli, Italy

DELEGATO ANÍMO

Alberto Dal Molin, Novara, Italy

RESPONSABILE AREA MALATTIE CARDIOVASCOLARI

Paolo Verdecchia, Assisi (PG), Italy

\section{STAFF AREA MALATTIE CARDIOVASCOLARI}

Cecilia Becattini, Perugia, Italy

Pierpaolo Di Micco, Napoli, Italy

Fernando Gallucci, Napoli, Italy

Alessandro Squizzato, Varese, Italy

\section{RESPONSABILE AREA MALATTIE INFETTIVE}

Ercole Concia, Verona, Italy

\section{STAFF AREA MALATTIE INFETTIVE}

Anna Maria Azzini, Verona, Italy

Gianluca Giuri, Castelnovo ne'Monti (RE), Italy

Matteo Giorgi Pierfranceschi, Piacenza, Italy

Carlo Tascini, Pisa, Italy

\section{RESPONSABILE AREA MALATTIE RESPIRATORIE}

Leonardo Fabbri, Reggio Emilia, Italy

\section{STAFF AREA MALATTIE RESPIRATORIE}

Bianca Beghè, Reggio Emilia, Italy

Gaetano Cabibbo, Modica (RG), Italy

Francesco Corradi, Firenze, Italy

Francesco Ventrella, Cerignola $(F G)$, Italy

\section{RESPONSABILE AREA MALATTIE REUMATOLOGICHE}

Carlo Salvarani, Reggio Emilia, Italy

\section{STAFF AREA MALATTIE REUMATOLOGICHE}

Paola Faggioli, Legnano (MI), Italy

Laura Morbidoni, Senigallia (AN), Italy

Nicolò Pipitone, Reggio Emilia, Italy

Tito D'Errico, Napoli, Italy

\section{RESPONSABILE AREA MALATTIE METABOLICHE}

Roberto Vettor, Padova, Italy

\section{STAFF AREA MALATTIE METABOLICHE}

Tiziana Attardo, Agrigento, Italy

Giovanni Gulli, Savigliano (CN), Italy

Ada Maffettone, Napoli, Italy
Maurizio Nizzoli, Forli, Italy

RESPONSABILE AREA ORGANIZZATIVA

IN MEDICINA INTERNA

Antonio Greco, San Giovanni Rotondo ( $F G)$, Italy

\section{STAFF AREA ORGANIZZATIVA IN MEDICINA INTERNA}

Marco Candela, Jesi (AN), Italy

Giovanni Mathieu, Pinerolo (TO), Italy

Valentino Moretti, San Daniele del Friuli (UD), Italy

Filomena Pietrantonio, Brescia, Italy

Elisa Romano, La Spezia, Italy

DIRETTORE DIPARTIMENTO PER LA FORMAZIONE

E AGGIORNAMENTO

Mauro Silingardi, Bologna, Italy

COORDINAMENTO DI AREA FORMATIVA CENTRO-NORD

Francesco Orlandini, La Spezia, Italy

COORDINAMENTO DI AREA FORMATIVA CENTRO-SUD

Generoso Uomo, Napoli, Italy

STAFF DIPARTIMENTO PER LA FORMAZIONE

E AGGIORNAMENTO

Roberto Frediani, Chieri (TO), Italy

Marco Grandi, Sassuolo (MO), Italy

\section{SEGRETERIA DIPARTIMENTO PER LA FORMAZIONE} E AGGIORNAMENTO

Luigi Magnani, Voghera (PV), Italy

\section{BOARD SCIENTIFICO}

Clelia Canale, Reggio Calabria, Italy

Fabrizio Colombo, Milano, Italy

Giuseppe De Matthaeis, Città Sant'Angelo (PE), Italy

Massimo Giusti, Torino, Italy

Luca Masotti, Cecina (LI), Italy

Andrea Montagnani, Grosseto, Italy

Nicola Mumoli, Livorno, Italy

Maurizio Ongari, Porretta Terme (BO), Italy

Ruggero Pastorelli, Colleferro (RM), Italy

Fulvio Pomero, Savigliano (CN), Italy

Roberto Risicato, Siracusa, Italy

Antonio Sacchetta, Treviso, Italy

Giancarlo Tintori, Pisa, Italy

COMMISSIONE TECNICHE E METODICHE INNOVATIVE DI FORMAZIONE E VERIFICA

Responsabile dell'Innovazione in Medicina Interna

Antonino Mazzone, Legnano (MI), Italy

STAFF

Francesco Dentali, Varese, Italy

Andrea Montagnani, Grosseto, Italy

Filippo Pieralli, Firenze, Italy

\section{DIRETTORE SCIENTIFICO FONDAZIONE FADOI}

Gualberto Gussoni, Milano, Italy 


\title{
QUADERNI - Italian Journal of Medicine
}

\author{
LE URGENZE EMATOLOGICHE
}

Guest Editors: M. Scudeletti, R. Tassara, G. Antonucci

INTRODUZIONE

Introduzione

M. Scudeletti

\section{RASSEGNE}

La trombocitopenia immune.

M. Cavalleri, P. Pitto, S. Timitilli, M. Scudeletti

Approccio dell'internista alla leucemia acuta

G.L. Michelis

Sindrome emolitico-uremica atipica

e porpora trombotica trombocitopenica.

M. Brignone

I linfomi aggressivi a rapida crescita

M. Cavaliere

L'emofilia A acquisita .

G.A. Berisso

La gestione delle complicanze acute del paziente

con mieloma multiplo.

R. Goretti

Le complicanze trombo-emboliche nel paziente ematologico. . . . . . .

S. Panarello, C. Fioravanti, F. Raggi, G. Antonucci

Come affrontare il paziente con leucocitosi e linfocitosi

C. Venturino, R. Tassara

Come affrontare il paziente con adenomegalia

P. Gnerre, N. Artom, E. Schiavetta, L. Parodi

Come affrontare il paziente con splenomegalia ............ 52

P. Gnerre, N. Artom, E. Schiavetta, L. Parodi

Come affrontare il paziente con leucopenia

G. Pastori, R. Tassara

Come affrontare il paziente con trombocitosi

L. Rebella, R. Tassara

Policitemia vera o morbo di Vaquez

E. Arboscello

Approccio all'adulto con piastrinopenia

R. Tassara, L. Paris 


\section{QUADERNI - Italian Journal of Medicine}

La gestione delle infezioni nel paziente oncoematologico

A.L. Garlaschelli, F. Artom

La gammopatia di origine indeterminata. . . . . . . . . . .

S. Timitilli, M. Cavalleri, M. Scudeletti

La malattia di Gaucher

M. Cavaliere

APPENDICE

Come affrontare $\mathrm{i}$ pazienti con... . 


\title{
Introduzione
}

\author{
Marco Scudeletti \\ Dipartimento di Medicina Interna, ASL 4 Chiavarese; Presidente FADOI Liguria, Italia
}

L'Ematologia clinica è un settore affascinante e complesso della Medicina Interna caratterizzato dalla coesistenza di una rapida e continua evoluzione tecnologica diagnostica, dalle sempre più mirate terapie target ma ancora dalla tradizionale analisi morfologica sullo striscio di sangue periferico o midollare in microscopia.

Numerose possibilità di approfondimento diagnostico, basate su metodi di citochimica, citogenetica, citofluorimetria, genomica e trascrittomica, sono poi in costante diffusione, contribuendo in maniera significativa alla classificazione, alla diagnosi e al monitoraggio delle patologie ematologiche.

L'introduzione di nuove metodologie e principi analitici per l'analisi cellulare, insieme alla progressiva evoluzione di hardware e software, ha permesso la realizzazione di emocitometri in grado di fornire dati quantitativi (conteggi cellulari e determinazione di indici cellulari) e qualitativi (citogrammi e allarmi morfologici) caratterizzati da sempre maggiori sensibilità e specificità nell'individuazione di anomalie cellulari.

Tutto questo ha portato e porterà sempre di più a ottenere terapie mirate sulla singola patologia e sul singolo paziente.

Questi indubbi progressi hanno, tuttavia, imposto la necessità di conoscenze sempre più specialistiche per poter meglio comprendere le possibili applicazioni cliniche e sviluppare percorsi successivi di appropriatezza. Nell'emato-oncologia si assiste nei grossi centri (Hub) alla sotto-specializzazione di un singolo ematologo per un singolo tumore.
In questo scenario, il medico internista che conosce l'ematologia, svolge comunque e sempre la sua parte nell'impostare una diagnosi, sia di malattie non tumorali quali: anemie citopenie, malattie trombotiche o emorragiche, che dei principali tumori ematologici.

Una volta ottenuta la diagnosi può impostare la terapia specifica se ha i necessari supporti laboratoristici e seguire il paziente inviando ogni volta che sarà necessario il paziente ad un centro di alta specializzazione per terapie altamente specialistiche: trapianto autologo e allogenico, terapie mirate delle leucosi acute nel paziente giovane, linfomi aggressivi del giovane, ecc.

La sfida è mantenersi in costante aggiornamento scientifico, in un settore che propone continue novità in ambito diagnostico e terapeutico, ricordando sempre che una diagnosi importante per la vita di un paziente si può fare strisciando, colorando e leggendo un vetrino di sangue periferico, con pochi euro (meno di 10) e in breve tempo (20 minuti). Poi la diagnosi verrà confermata e inquadrata con le tecniche più sofisticate e appropriate, ma intanto la diagnosi morfologica avrà fatto guadagnare ore preziose al paziente.

L'internista ematologo svolge sostanzialmente due funzioni nell'ospedale: consulente di casi difficili o con aspetti di urgenza ematologica; e medico dell'ambulatorio o del day hospital ematologico. Pertanto lo scopo del lavoro di questa monografia ematologica è quello di mettere a fuoco i principali quadri di urgenze ematologiche e le principali situazioni di patologie ematologiche non tumorali che vengono inviate negli ambulatori.
Corrispondente: Marco Scudeletti, Dipartimento di Medicina Interna, ASL 4 Chiavarese, Italia.

Tel.: +39.0185 .329845 .

E-mail: m.scudeletti@asl4.liguria.it

Articolo pubblicato secondo la Creative Commons Attribution NonCommercial 4.0 License (CC BY-NC 4.0).

(C) Copyright M. Scudeletti, 2018

Licensee PAGEPress, Italy

QUADERNI - Italian Journal of Medicine 2019; 7(1):1 


\title{
La trombocitopenia immune
}

\author{
Maurizio Cavalleri, Paola Pitto, Silvana Timitilli, Marco Scudeletti \\ Medicina Interna I, PO Sestri Levante, ASL 4 Chiavarese, Sestri Levante (GE), Italia
}

\section{Introduzione}

La trombocitopenia immune (ITP) è una piastrinopenia acquisita (definita da una conta $<100 \times 10^{9} / \mathrm{L}$ ) e causata da una distruzione immunomediata delle piastrine. ${ }^{1}$ Intercorre sia negli adulti che nei bambini, con incidenza multimodale, con un primo picco nell'età infantile ed un secondo e terzo picco nei giovani adulti e negli anziani. Il processo patologico sottostante nella ITP infantile e in quella dell'adulto potrebbe essere sostanzialmente diverso, come evidenziato dal fatto che la maggior parte dei bambini presenta una malattia autolimitante mentre negli adulti si tratta più spesso di un disordine cronico. ${ }^{2}$

Tra il 2010 e il 2011, l'American Society of Hematology (ASH) e i report di consenso internazionale hanno pubblicato le linee guida per la diagnosi e il trattamento dell'ITP. Nel 2009 un gruppo di lavoro internazionale sull'ITP (IWG) ha pubblicato le raccomandazioni per standardizzare le definizioni e la terminologia e consentire un'omogeneizzazione degli studi di ricerca e del trattamento. L'IWG ha definito l'abbreviazione di uso comune ITP (non idiopatica nè porpora) perchè la fisiopatologia della malattia è stata compresa meglio e la maggior parte dei pazienti, sia adulti che pediatrici, non si presentano con porpora ma più spesso con petecchie ed ematomi. È stato anche rimosso il termine acuta, in quanto questa definizione si può dare solo retrospettivamente, dopo la guarigione del paziente. Invece, il gruppo ha proposto una terminologia standardizzata, evidenziata nella Tabella 1.

Corrispondente: Maurizio Cavalleri, Medicina Interna I, PO Sestri Levante, ASL 4 Chiavarese, Sestri Levante (GE), Italia. Tel.: +39.0185.329904.

E-mail: mcavalleri.doc@hotmail.it

Articolo pubblicato secondo la Creative Commons Attribution NonCommercial 4.0 License (CC BY-NC 4.0).

CCopyright M. Cavalleri et al., 2019

Licensee PAGEPress, Italy

QUADERNI - Italian Journal of Medicine 2019; 7(1):2-7

\section{Epidemiologia}

L'incidenza dell'ITP primaria negli adulti è di $3,3 / 100.000$ individui per anno con una prevalenza di 9,5 per 100.000 adulti. Si riscontra una prevalenza maggiore tra le femmine, nei giovani adulti mentre è similare tra i due sessi nell'età più avanzata $(>65$ anni). ${ }^{3}$ Una recente metaanalisi si è focalizzata sul rischio di trombosi nei pazienti adulti con ITP e ha concluso che questi pazienti hanno un maggior rischio tromboembolico (TE) dopo la diagnosi di ITP (pari a $1,6)$ basandosi primariamente su due grossi studi di coorte. ${ }^{4}$ La stessa analisi ha anche mostrato in quei pazienti un rischio di TE, precedente alla diagnosi di ITP, con prevalenza circa $8 \%$. L'ITP secondaria ad altri disordini è il $20 \%$ delle totali ed è il motivo per cui alcuni pazienti vengono sottoposti a valutazioni diagnostiche approfondite. La prevalenza di malattia autoimmune nella popolazione affetta da ITP senza segni/sintomi aggiuntivi è risultata abbastanza bassa nello studio di popolazione più grosso, effettuato utilizzando lo United Kingdom General Practice Research Database, dove era 1 ' $8,7 \% .{ }^{5}$ In uno studio epidemiologico francese, l'incidenza della ITP secondaria è risultata il $18 \% .{ }^{6}$ Gli studi di popolazione suggeriscono anche un incremento di mortalità per $\mathrm{i}$ pazienti con ITP rispetto alla popolazione generale e proporzionale alla severità della malattia. Uno studio danese ha riportato un indice di mortalità maggiore di 1,5 rispetto alla popolazione generale, con un incremento significativo del rischio di sanguinamento, di infezione e di malignità ematologica. ${ }^{7}$ Studi successivi non hanno però confermato il rischio aumentato di malignità. ${ }^{8}$

Tabella 1. Terminologia per trombocitopenia immune.

\begin{tabular}{ll}
\hline Nuova diagnosi: & durata $<3$ mesi \\
\hline Persistente: & durata $3-12$ mesi \\
\hline Cronica: & durata 12 mesi \\
\hline Severa: & $\begin{array}{l}\text { sanguinamento clinicamente rilevante tale da ri- } \\
\text { chiedere terapia, interventi aggiuntivi o incre- } \\
\text { mento del dosaggio farmacologico }\end{array}$ \\
\hline Refrattaria: & presenza di ITP severa dopo splenectomia \\
\hline
\end{tabular}




\section{Fisiopatologia}

Negli ultimi anni la comprensione della fisiopatologia dell'ITP è significativamente migliorata. Ora è chiaro come l'ITP primaria sia un disordine immunologico acquisito dove la trombocitopenia è il risultato di anticorpi antipiastrine patologici, megacariocitopoiesi inefficace e distruzione piastrinica Tcell-mediata, con ciascun meccanismo patologico impegnato a giocare vari ruoli in ogni paziente. L'ITP secondaria si associa ad altri disordini sottostanti, come malattie autoimmuni (LES o AR), HIV, Helicobacter pylori, o sindromi da disregolazione immunologica, come l'immunodeficienza comune variabile. La maggioranza degli adulti con ITP (circa l'80\%) ha un'ITP primaria. Il trattamento e la fisiopatologia dell'ITP secondaria sono generalmente basate sul disordine sottostante, sebbene alcuni pazienti con ITP secondaria e malattia principale severa possano richiedere una terapia ITPspecifica per stabilizzare la conta piastrinica durante il trattamento mirato alla patologia di base.

Il $60-70 \%$ dei pazienti con ITP ha anticorpi IgG piastrino-specifici generalmente diretti verso le glicoproteine di superficie GPIIb/IIIa e GP1b/IX/V. ${ }^{9}$ Il tipo di epitopo targato da questi anticorpi autoreattivi potrebbe influenzare il corso della malattia ed alcuni ricercatori hanno suggerito come questi tipi differenti di anticorpi potrebbero alterare la clearance piastrinica, inibendo i megacariociti o inducendone l'apoptosi. ${ }^{10}$ Inoltre, la presenza di anticorpi antipiastrine si associa ad un incremento del rischio trombotico.

Alcuni pazienti che non hanno anticorpi antipiastrine potrebbero avere cellule $\mathrm{T}$ anormali in grado di distruggere le piastrine, ${ }^{11}$ mentre in altri pazienti potrebbe essere la disregolazione delle cellule $\mathrm{T}$ a causare la produzione di autoanticorpi. ${ }^{12}$ In alcuni pazienti sono state ritrovate cellT citotossiche CD8+ capaci di lisare direttamente le piastrine e accumularle nel midollo osseo, danneggiando potenzialmente la produzione di piastrine. I dati suggeriscono inoltre che i pazienti con ITP attiva hanno popolazioni di cellT regolatorie ridotte, citochine anormali, ed un alterato equilibrio del rapporto Thelper1/Thelper2. ${ }^{13}$ Tutto ciò spiegherebbe la disregolazione immunologica sottostante e offrirebbe possibili target per terapie innovative.

Colture cellulari derivate dal plasma dei pazienti hanno messo in evidenza anomalie dell'apoptosi e alterazione della crescita dei megacariociti. I livelli sierici di trombopoietina nei pazienti sono bassi ed il successo dei farmaci TPO mimetici, valida parzialmente queste osservazioni. ${ }^{14}$

Studi recenti si sono anche focalizzati sul ruolo del recettore Ashwell-Morrell (AMR) nel fegato, come un meccanismo aggiuntivo indotto dalla clearance piastrinica, tramite il quale viene regolato il numero delle piastrine. ${ }^{15}$ In condizioni fisiologiche, le piastrine invecchiate perdono l'acido sialico sulla loro superficie, vengono riconosciute dall'AMR ed eliminate dal circolo. Tale clearance effettuata dall'AMR stimola la produzione di TPO-RNA messaggero. L'espressione di superficie dell'acido sialico è regolato dalla sialidasi intrinseca, analogamente a molecole che sono state studiate in altri contesti per il trattamento delle infezioni virali. Un singolo piccolo studio e due case report hanno focalizzato l'attenzione su oseltamivir fosfato (un inibitore della sialidasi sviluppato per curare l'influenza) quale potenziale opzione terapeutica nell'ITP, esaminandone anche il ruolo nel meccanismo della clearance piastrinica nell'ITP. ${ }^{16}$

\section{Diagnosi}

La maggior parte delle ITP dovrebbero essere diagnosticate con un'anamnesi accurata ed un esame obiettivo oltre all'esame dello striscio periferico ed alcuni test. L'IWG ha raccomandato pochi test aggiuntivi per tutti i pazienti con ITP, inclusi la ricerca di $H$. pylori, di HIV e HCV, dell'antiglobulina diretta e la tipizzazione del gruppo sanguigno.

Le lineeguida ASH raccomandano test similari per gli adulti eccetto H. pylori (solo per alcune aree geografiche e se è possibile il trattamento eradicante). La raccomandazione dell'IGW è di effettuare l'esame del midollo osseo nei pazienti $>60$ anni con nuova diagnosi di ITP, mentre le ASH suggeriscono che la BOM non è necessaria in tutte le popolazioni. Il test per la ricerca di Ac antipiastirne non è indicativa per la diagnosi di ITP nella maggioranza dei pazienti e sia ASH che IWG non raccomandano di routine questo test. Lo screening aggiuntivo del test per HIV e per altre malattie autoimmuni è raramente di aiuto in assenza di sintomi negli adulti con ITP non complicata di nuova diagnosi e di fatto una positività per ANA, in assenza di altri segni, è raramente predittiva per lo sviluppo della malattia autoimmune (Figura 1).

Sebbene alcuni studi nei bambini abbiano evidenziato che una positività per ANA potrebbe associarsi ad un rischio incrementato di malattia cronica o refrattaria, gli studi negli adulti sono limitati e non dimostrano una chiara associazione con la risposta al trattamento o con la cronicità. ${ }^{17}$

\section{Rischio di sanguinamento}

Capire il rischio di sanguinamento è importante per riconoscere i pazienti che richiedono terapia farmacologica anche ad una conta piastrinica iniziale più alta. Studi precedenti hanno evidenziato, quali fattori predittivi per maggior rischio emorragico, la bassa conta piastrinica, l'età più avanzata, l'utilizzo di terapie 
concomitanti e il sesso maschile. Uno studio ha esaminato $i$ fattori di rischio in una coorte di pazienti con ITP ed emorragia cerebrale e ha trovato che, in quei pazienti, il 37\% presentava un'emorragia intracranica nel corso dei primi tre mesi dalla diagnosi. ${ }^{18}$ È risultato inoltre che i pazienti con emorragia intracranica avevano più sintomi emorragici, inclusi ematuria ed emorragie viscerali, rispetto al gruppo di controllo con sola ITP ed il $74 \%$ dei pazienti aveva ricevuto la terapia prima dell'evento emorragico cerebrale. Questo studio si somma ad altri che hanno dimostrato come un'emorragia significativa precedente sia un fattore di rischio per la successiva emorragia intracranica. Non è stato trovato un rischio aumentato negli uomini. Gli studi riportano un rischio di 1,5-1,8\% per emorragia cerebrale negli adulti, molto più alto di quello riportato nei bambini che è $<1 \%{ }^{19}$

Si può desumere che i pazienti con sintomi di sanguinamento significativo potrebbero avere piastrine differenti rispetto a quelli che non sanguinano. Questa ipotesi è stata analizzata in uno studio che esaminava la funzionalità piastrinica nei pazienti adulti per provare a determinare come questa si correli col rischio di sanguinamento: ${ }^{20}$ è stato dimostrato che l'incremento della reattività piastrinica, misurata con la citometria a flusso, si associa ad un rischio ridotto di sanguinamento, specie per quei pazienti con la conta piastrinica più bassa.

\section{Terapia di prima linea}

Per molti anni la terapia steroidea a $1 \mathrm{mg} / \mathrm{kg} /$ die è stata la prima linea di riferimento ma negli ultimi anni alcuni studi hanno indagato opzioni alternative. ${ }^{21}$

Un recente RCT ha confrontato l'uso di desametasone ad alte dosi versus prednisone a dosaggi standard. Lo schema del desametasone prevedeva la somministrazione di desam, etasone $40 \mathrm{mg} /$ die per 4 gg q21 per 6 cicli. Il risultato è stato un significativo miglioramento in termini di risposta completa. ${ }^{22}$

Altri due studi hanno valutato l'uso di rituximab in associazione a desametasone versus HDD dimostrando che la percentuale di remissioni era più alta nei pazienti trattati con il regime di combinazione a 6 mesi (63 vs $36 \%$ ) e a 1 anno (58 vs 37\%). ${ }^{23}$ Da prendere in considerazione comunque è il fato che il miglioramento delle percentuali di remissioni si verificava a costo di un aumento di tossicità di grado 3 e 4 .

Un'ulteriore opzione che è in fase di studio negli ultimi anni, è il TPO mimetico: un primo studio analizzò il romiplostin in 75 pazienti con ITP di nuova insorgenza da meno di 6 mesi: ${ }^{24}$ dopo un follow-up di 12 mesi il romiplostin veniva ridotto fino alla sospensione se la conta piastrinica rimaneva stabile sopra le 50.000. Il $32 \%$ dei pazienti arruolati ha raggiunto l'endpoint primario cioè il mantenimento di una conta piastrinica sopra le 50.000 per 24 settimane consecu-

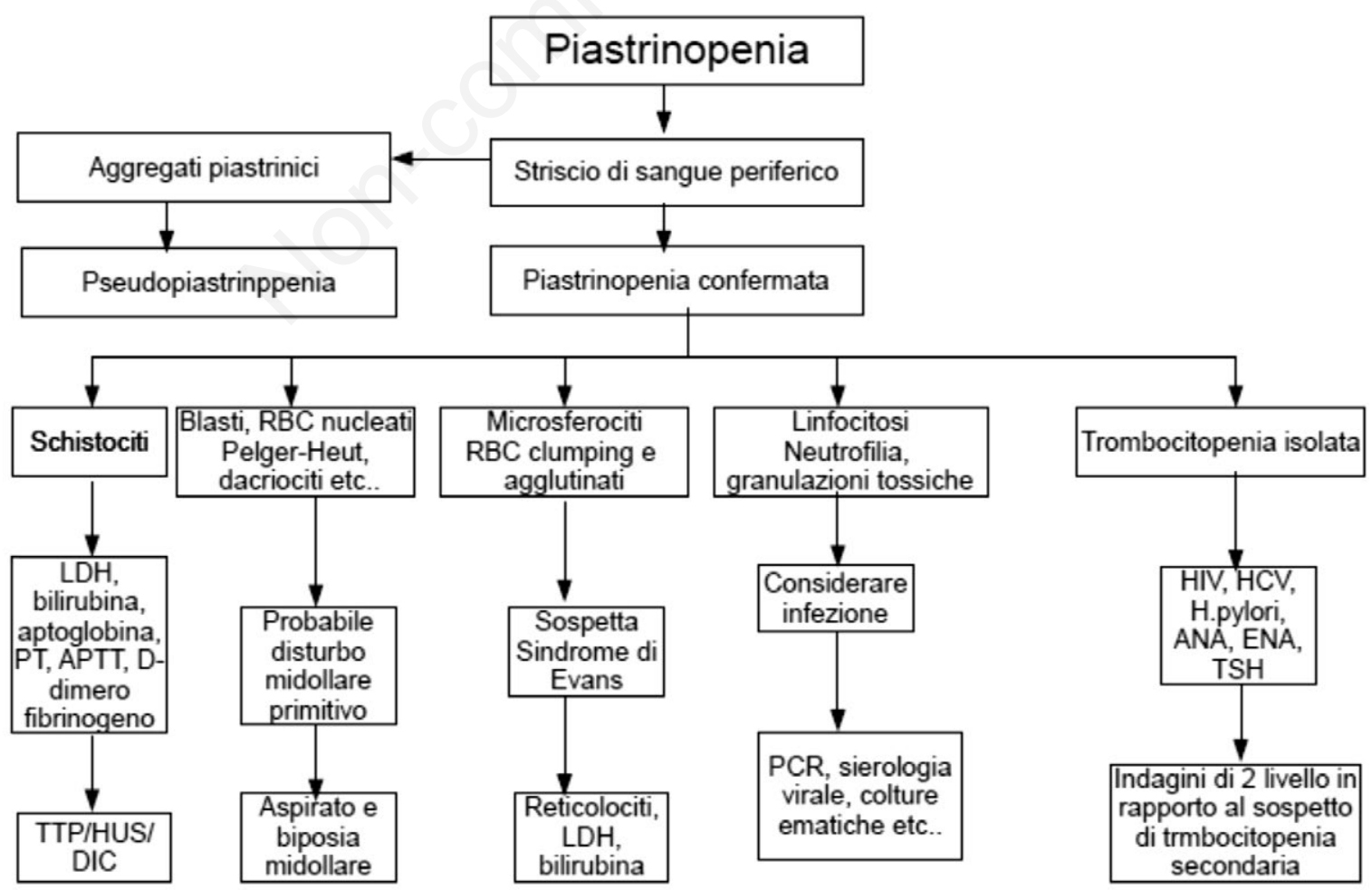

Figura 1. Flow chart diagnostico per la trombocitopenia immune. 
tive dopo la sospensione. Un secondo studio ha valutato la combinazione di HDD per 4 giorni seguito da eltrombopag $50 \mathrm{mg} /$ die nei giorni 5-32. Lo studio era molto esiguo (12 pazienti), in ogni caso la maggior parte dei pazienti ha mantenuto una conta piastrinica accettabile a 6 e 12 mesi. ${ }^{25}$

Ovviamente saranno necessari ulteriori studi di più ampia portata per avvalorare questi risultati e fornire dati di efficacia e sicurezza.

\section{Terapia di seconda linea}

Nelle linee guida dell'ASH del 2011, la principale terapia di seconda linea considerata era la splenectomia con la raccomandazione di tentare di posticiparla se possibile a 6 mesi-1 anno dalla diagnosi. Questo perchè in quel momento non erano ancora disponibili robuste evidenze sulle opzioni terapeutiche alternative, come ad esempio i TPO mimetici.

Per decenni la splenectomia chirurgica ha rappresentato la terapia di seconda linea di scelta ma ad oggi, benchè le percentuali di risposta siano del $60-70 \%$ a 5 anni, meno del $25 \%$ dei pazienti viene sottoposto a splenectomia e questo a causa delle numerose e severe complicanze come il rischio di infezione (aumentato da 5 a 30 volte a 90 giorni e di 1-3 volte per tutta la vita per il rischio di setticemie) e il rischio di trombosi (più del 30 volte la popolazione generale). ${ }^{26,27}$

Numerosi studi hanno analizzato l'efficacia del rituximab in alternativa alla splenectomia. Uno schema di somministrazione standard di $375 \mathrm{mg} / \mathrm{m}^{2} \mathrm{x} 4$ dosi ha dimostrato una risposta iniziale del $40-60 \%{ }^{28}$ tuttavia le percentuali di risposta a 5 anni sono decisamente inferiori rispetto alla splenectomia $(20 \%$ circa $) .{ }^{29} \mathrm{Un}$ recente trial ha persino dimostrato che non ci sono differenze statisticamente significative in termini di remissione completa a 1,5 anni tra rituximab e placebo. ${ }^{30}$

Le più importati novità nel campo della terapia di seconda linea dell'ITP riguardano i TPO-mimetici (romiplostin e eltrombopag).

Una recente metanalisi sull'utilizzo dell'eltrombopag nell'ITP ha confrontato i 6 trial randomizzati controllati su questo tema, dimostrando che questo farmaco migliora significativamente la conta pistrinica (RR: 3,42; CI 95\%: 2,51-4,65) e riduce il rischio di sanguinamento (RR: 0,74, CI95\%: 0,66-0,83). ${ }^{31}$

Nei trial che riguardono sia eltrombopag che romiplostin, più dell $180 \%$ dei pazienti ottiene una conta piastrinica maggiore di $50 \times 10^{9} / \mathrm{L}$ benchè plurirefrettari ad altre linee terapeutiche. ${ }^{32}$

Nella pratica clinica le percentuali di risposta sono in qualche modo inferiori (da 74 a 94\%) forse perchè riflettono una maggiore eterogeneità della popolazione reale non arruolata nei trial.

Nell'ambito del trial EXTEND (Eltrombopag eXTENDed dosing) nel 2013 sono stati pubblicati i dati del follow-up a 3 anni di pazienti con ITP in trattamento con eltrombopag. ${ }^{33}$ La overall response è del $85 \%$ con una conta piastrinica media maggiore di $50 \times 10^{9} / \mathrm{L}$ a 2 settimane e rimasta stabile per tutto il follow-up.

Gli eventi avversi più comuni erano di grado lieve moderato (1-2) ed erano rappresentati da cefalea, nasofaringite, infezioni del tratto respiratorio superiore e astenia. Gli eventi avversi di grado $>3$ erano costituiti da astenia, il rialzo dell'enzima epatico ALT nel $10 \%$ dei casi, la trombocitopenia e episodi tromboembolismo venoso nel 3\% dei casi.

Un recente aggiornamento dei dati di follow-up ha dimostrato a 5 anni una percentuale del $15 \%$ di rialzo delle transaminasi e $6,3 \%$ di eventi tromboembolici.

In 147 pazienti venne valutata l'insorgenza di fibrosi reticulinica alla biopsia osteomidollare: nell' $8 \%$ dei casi alla biopsia osteomidollare era presente una fibrosi reticulinica di grado 2 (in assenza di fibre di collagene).

Cines et al. hanno pubblicato nel 2015 una analisi integrata di sicurezza a lungo termine nei pazienti con ITP trattati con romiplostin. ${ }^{34}$ Sono stati analizzati 994 pazienti da 13 trial.

La durata media dello studio è stata di 75-77 settimane e la dose più frequente del farmaco è stata di 5 $\mathrm{microg} / \mathrm{kg}$ e $4,6 \mathrm{microg} / \mathrm{kg}$ (rispettivamente nei pazienti postsplenectomia e nei non splenectomizzati).

I principali eventi avversi erano la cefalea, ecchimosi, epistassi e nasofaringiti. L'incidenza di fibrosi reticolinica era circa il 3\% con le percentuali maggiori nei pazienti che avevano assunto dosi superiori a quelle raccomandate.

Sono in corso di studio e rappresentano una prospettiva per il prossimo futuro numerosi nuovi target terapeutici, in particolare terapie immunologiche con anticorpi mirati all'interazione CD40-CD154 tra i linfociti B e T ed acne nuovi agenti stimolanti la produzione di piastrine ma questi nuovi agenti necessitano ovviamente ancora di evidenze scientifiche. ${ }^{35,36}$

\section{Trombocitopenia immune in gravidanza}

Approssimativamente il 7\% delle gravidanze sono complicate da trombocitopenia (definita per conta piastrinica $<150 \times 10^{9} / \mathrm{L}$ ), la maggior parte delle quali dovute alla gravidanza stessa (chiamata piastrinopenia gestazionale). L'incidenza dell'ITP è da 1 a $10 \mathrm{su}$ 10.000 gravidanze e richiede terapia nel $30 \%$ dei casi. Come nelle pazienti non gravide, l'ITP può essere primaria o associata a un disordine autoimmune. Può essere il primo episodio o riesacerbato dallo stato di gravidanza ed è la causa più frequente di trombocitopenia nel primo trimestre. Un sanguinamento severo materno o neonatale è raro quando queste gravidanze sono seguite da un team multidisciplinare esperto. 
In un report di donne con ITP era stato consigliato a circa il 28\% (14/50) di non restare incinta. Nonostante la rarità di complicanze emorragiche, le donne malate prima della gravidanza sembrano avere una maggiore incidenza di aborto fetale (11,2 vs 3,9\% delle donne diagnosticate durante la gravidanza) e un basso peso del nascituro per età gestazionale $(17,9 v \mathrm{~s}$ $9,7 \%$ ). È stata riportata anche una maggiore incidenza di nascite premature.

Non sembra che la terapia possa influenzare il rischio neonatale di trombocitopenia e in ogni caso il trattamento è diretto a mantenere una conta soddisfacente di piastrine nella madre, generalmente considerata $30 \times 10^{9} / \mathrm{L}$, fino quasi al termine quando il parto può essere anticipato. La terapia di prima linea raccomandata sia dall'ASH che da IWG è basata su immunoglobuline (IG vena) o cortisone che sembrano avere simile efficacia nell' accrescimento della conta piastrinica. La tossicità materna e fetale è relativamente blanda ma l'aumento di peso, l'iperglicemia e l'ipertensione possono arrecare problemi al corso della gravidanza. In uno studio di 235 gravide con ITP, meno della metà delle pazienti ha richiesto un trattamento. Di 91 gravidanze trattate, 47 sono state sottoposte a IG vena e 51 a steroide. Non ci sono state differenze tra i due gruppi per quanto riguarda la conta piastrinica al momento del parto, emorragie antepartum e postpartum o necessità di trasfusione piastrinica; le donne trattate avevano una maggiore conta piastrinica al parto e meno necessità di trasfusione rispetto al gruppo non trattato. Si sono verificate meno emorragie post-partum nel gruppo trattato rispetto a quello non trattato, mentre non si sono osservate differenze nei neonati di entrambi i gruppi. La terapia materna e la conta piastrinica non sembrano essere fattori predittivi efficaci per la conta piastrinica neonatale.

Le pazienti refrattarie alla prima linea potrebbero beneficiare di un trattamento combinato. Le opzioni per una seconda linea sono limitate dal rischio fetale. L'azatioprina può essere usata moderatamente. La terapia con anti-RhD immunoglobuline, ciclosporina e rituximab da buoni risultati ma non si possono raccomandare di routine. Ci sono parecchi report su romiplostim nella malattia refrattaria severa in gravidanza, ma è richiesta maggiore evidenza della sua sicurezza in gravidanza. Un report recente sull'utilizzo della TPO umana ricombinante in 60 gravidanze è promettente. Non è stata stabilita la conta piastrinica ottimale al momento del parto. Una conta di $75-80 \times 10^{9} / \mathrm{L}$ in assenza di altre anomalie dell'emostasi è generalmente quella raccomandata dalla maggior parte delle linee guida. Per i parti non complicati, una conta pari a $50 \times 10^{9} / \mathrm{L}$ è generalmente adeguata e sicura per un parto cesareo, se dovesse essere necessario.

Il rischio di complicanze con l'utilizzo di analgesia epidurale è correlata al grado di piastrinopenia, ma un recente studio che ha esaminato il rischio in 499 gravide ha dimostrato un livello di sicurezza per una conta di $75-80 \times 10^{9} / \mathrm{L}$. Per contro, nello stesso studio, l'anestesia generale era associata a un $6,5 \%$ di rischio di complicanze. Il tipo di parto si dovrebbe basare sull'indicazione ostetrica, dato che il rischio di emorragia cerebrale è basso, generalmente $<1 \%$.

La maggior parte degli studi ha riportato che una severa piastrinopenia $\left(<50 \times 10^{9} / \mathrm{L}\right)$ nel neonato non è comune, però l'incidenza potrebbe essere superiore al $30 \%$. Il nadir della conta piastrinica generalmente intercorre tra il secondo e il quinto giorno dopo il parto, cosicchè il neonato va monitorato attentamente. Il trattamento per il neonato consiste in Igvena, talvolta associate a trasfusione piastrinica.

\section{Conclusioni}

Lo sviluppo di linee guida per la diagnosi e il trattamento dell'ITP ed i dati emergenti sulle terapie di seconda linea ha determinato una riduzione significativa delle splenectomie. La pratica clinica è orientata all'utilizzo di terapie di seconda linea con minimi rischi e pochi effetti collaterali e che abbiano ragionevoli possibilità di successo. Saranno necessarie nuove linee guida e trial clinici per esaminare le terapie alternative in fase di sviluppo.

\section{Bibliografia}

1. Rodeghiero F, Stasi R, Gernsheimer T, et al. Standardization of terminology, definitions and outcome criteria in immune thrombocytopenic purpura of adults and children: report from an international working group. Blood 2009;113(11): 2386-2393.

2. Schulze H, Gaedicke G. Immune thrombocytopenia in children and adults: what's the same, what's different? Haematologica. 2011; 96(12):1739-1741.

3. Fogarty PF. Chronic immune thrombocytopenia in adults: epidemiology and clinical presentation. Hematol Oncol Clin North Am. 2009;23(6): 1213-1221.

4. Doobaree IU, Nandigam R, Bennett D, Newland A, Provan D. Thromboembolism in adults with primary immune thrombocytopenia: a systematic literature review and meta-analysis. Eur J Haematol. 2016;97(4):321-330.

5. Schoonen WM, Kucera G, Coalson J, et al. Epidemiology of immune thrombocytopenic purpura in the general practice research database. Br J Haematol. 2009;145(2): 235-244.

6. Moulis G, Palmaro A, Montastruc JL, Godeau B, Lapeyre-Mestre M, Sailler L. Epidemiology of incident immune thrombocytopenia: a nationwide populationbased study in France. Blood. 2014; 124(22):3308-3315.

7. Frederiksen H, Maegbaek ML, Nørgaard M. Twentyyear mortality of adult patients with primary immune thrombocytopenia: a Danish population-based cohort study. Br J Haematol. 2014;166(2):260-267.

8. Thai LH, Mahe'vas M, Roudot-Thoraval F, et al. Long- 
term complications of splenectomy in adult immune thrombocytopenia. Medicine (Baltimore). 2016;95(48): e5098.

9. Zhang HY, Hou M, Zhang XH, Guan XH, Sun GZ. The diagnostic value of platelet glycoproteinspecific autoantibody detection in idiopathic thrombocytopenic purpura [in Chinese]. Zhongguo Shi Yan Xue Ye Xue Za Zhi. 2004; 12(2):204-206.

10. Leytin V, Mykhaylov S, Starkey AF, et al. Intravenous immunoglobulin inhibits antiglycoprotein IIb-induced platelet apoptosis in a murine model of immune thrombocytopenia. Br J Haematol. 2006;133(1):78-82.

11. Kuwana M, Kaburaki J, Ikeda Y. Autoreactive T cells to platelet GPIIb-IIIa in immune thrombocytopenic purpura. Role in production of anti-platelet autoantibody. $\mathrm{J}$ Clin Invest. 1998; 102(7):1393-1402.

12. Nishimoto T, Kuwana M. CD41CD251Foxp31 regulatory $\mathrm{T}$ cells in the pathophysiology of immune thrombocytopenia. Semin Hematol. 2013;50(suppl 1):S43-S49.

13. Ware RE, Howard TA. Phenotypic and clonal analysis of T lymphocytes in childhood immune thrombocytopenic purpura. Blood. 1993;82(7): 2137-2142.

14. Makar RS, Zhukov OS, Sahud MA, Kuter DJ. Thrombopoietin levels in patients with disorders of platelet production: diagnostic potential and utility in predicting response to TPO receptor agonists. Am J Hematol. 2013;88(12):1041-1044.

15. Hoffmeister KM. The role of lectins and glycans in platelet clearance. J Thromb Haemost. 2011; 9(suppl 1): 35-43.

16. Shao L, Wu Y, Zhou H, et al. Successful treatment with oseltamivir phosphate in a patient with chronic immune thrombocytopenia positive for anti-GPIb/IX autoantibody. Platelets. 2015;26(5):495-497.

17. Altintas A, Ozel A, Okur N, et al. Prevalence and clinical significance of elevated antinuclear antibody test in children and adult patients with idiopathic thrombocytopenic purpura. J Thromb Thrombolysis. 2007;24(2):163-168.

18. Melboucy-Belkhir S, Khellaf M, Augier A, et al. Risk factors associated with intracranial hemorrhage in adults with immune thrombocytopenia: a study of 27 cases. Am J Hematol. 2016;91(12):E499-E501.

19. Neunert C, Noroozi N, Norman G, et al. Severe bleeding events in adults and children with primary immune thrombocytopenia: a systematic review. J Thromb Haemost. 2015;13(3):457-464.

20. Middelburg RA, Carbaat-Ham JC, Hesam H, Ragusi MA, Zwaginga JJ. Platelet function in adult ITP patients can be either increased or 2834 LAMBERT and GERNSHEIMER BLOOD, 25 MAY 2017xVOLUME 129, NUMBER 21 For personal use only.on April 6, 2018. by guest www.bloodjournal.org From decreased, compared to healthy controls, and is associated with bleeding risk. Hematology. 2016;21(9):549-551.

21. Cuker A, Cines DB, Neunert CE. Controversies in the treatment of immune thrombocytopenia. Curr Opin Hematol. 2016;23(5):479-485.

22. Matschke J, Müller-Beissenhirtz H, Novotny J, et al. A randomized trial of daily prednisone versus pulsed dexamethasone in treatment-na"1ve adult patients with immune thrombocytopenia: EIS 2002 Study. Acta Haematol. 2016;136(2):101-107.

23. Gudbrandsdottir S, Birgens HS, Frederiksen H, et al.
Rituximab and dexamethasone vs dexamethasone monotherapy in newly diagnosed patients with primary immune thrombocytopenia. Blood. 2013;121(11):19761981.

24. Newland A, Godeau B, Priego V, et al. Remission and platelet responses with romiplostim in primary immune thrombocytopenia: final results from a phase 2 study. $\mathrm{Br}$ J Haematol. 2016;172(2):262-273.

25. Gómez-Almaguer D, Herrera-Rojas MA, Jaime-Pérez JC, et al. Eltrombopag and high-dose dexamethasone as frontline treatment of newly diagnosed immune thrombocytopenia in adults. Blood. 2014;123(25):3906-3908.

26. Kumar S, Diehn FE, Gertz MA, Tefferi A. Splenectomy for immune thrombocytopenic purpura: long-term results and treatment of postsplenectomy relapses. Ann Hematol. 2002;81(6):312-319.

27. Ahmed R, Devasia AJ, Viswabandya A, et al. Long-term outcome following splenectomy for chronic and persistent immune thrombocytopenia (ITP) in adults and children: splenectomy in ITP. Ann Hematol. 2016;95(9): 1429-1434.

28. Cuker A, Cines DB, Neunert CE. Controversies in the treatment of immune thrombocytopenia. Curr Opin Hematol. 2016;23(5):479-485.

29. Chugh S, Darvish-Kazem S, Lim W, et al. Rituximab plus standard of care for treatment of primary immune thrombocytopenia: a systematic review and meta-analysis. Lancet Haematol. 2015;2(2):e75-e81.

30. Ghanima W, Khelif A, Waage A, et al. RITP study group. Rituximab as second-line treatment for adult immune thrombocytopenia (the RITP trial): a multicentre, randomised, double-blind, placebocontrolled trial. Lancet. 2015;385(9978):1653-1661.

31. Elgebaly AS, Ashal GE, Elfil M, Menshawy A. Tolerability and efficacy of eltrombopag in chronic immune thrombocytopenia: meta-analysis of randomized controlled trials [published online ahead of print 1 January 2016]. Clin Appl Thromb Hemost. 2016.

32. Provan D, Newland AC. Current management of primary immune thrombocytopenia. Adv Ther. 2015;32 (10):875-887.

33. Saleh MN, Bussel JB, Cheng G, et al. EXTEND Study Group. Safety and efficacy of eltrombopag for treatment of chronic immune thrombocytopenia: results of the long-term, open-label EXTEND study. Blood. 2013;121 (3):537-545.

34. Cines DB, Gernsheimer T, Wasser J, et al. Integrated analysis of long-term safety in patients with chronic immune thrombocytopaenia (ITP) treated with the thrombopoietin (TPO) receptor agonist romiplostim. Int J Hematol. 2015;102(3):259-270.

35. Kuwana M, Nomura S, Fujimura K, et al. Effect of a single injection of humanized anti-CD154 monoclonal antibody on the platelet-specific autoimmune response in patients with immune thrombocytopenic purpura. Blood. 2004;103(4):1229-1236.

36. Bussel JB, Kuter DJ, Aledort LM, et al. A randomized trial of avatrombopag, an investigational thrombopoietin-receptor agonist, in persistent and chronic immune thrombocytopenia. Blood. 2014;123(25):3887-3894. 


\title{
Approccio dell'internista alla leucemia acuta
}

\author{
Gian Luca Michelis \\ SC Medicina 1 ed Ematologia, Ospedale S. Paolo, Savona, Italia
}

\section{Introduzione}

Le leucemie sono malattie neoplastiche del sistema emolinfopoietico. L'etimologia deriva dal greco e significa letteralmente sangue bianco in quanto nacque dal fatto che molti pazienti mostravano un'elevata concentrazione di leucociti tale che lo strato di queste cellule, solitamente non visibile in provetta, uguagliava quello dei globuli rossi. In seguito tale dizione venne estesa a molte patologie neoplastiche ematologiche, originanti dalle cellule staminali, indipendentemente dalla quota di cellule leucemiche circolanti. Per tale motivo si preferisce il termine più generale di sindrome mieloo linfo-proliferativa. ${ }^{1}$ Negli anni, sebbene il termine leucemia sia rimasto inalterato (comprendendo così anche forme croniche), si è capito come le forme acute siano un gruppo di neoplasie ematologiche a prognosi variabile caratterizzate da accumulo, nel midollo osseo e spesso anche nel sangue periferico, di cellule indifferenziate, i blasti, con conseguente riduzione di cellule ematiche mature. È dunque intuitivo che una leucemia acuta possa manifestarsi sia con una o più citopenie (fino alla pancitopenia) sia con la più caratteristica leucocitosi blastica. Nelle leucemie, come avviene per quasi tutte le malattie tumorali, la trasformazione neoplastica origina da un'unica cellula la cui progenie prolifera in modo relativamente illimitato e autonomo: si dice infatti che esse hanno carattere clonale. Il tipo di leucemia è determinato dal fenotipo della cellula infetta. La leucemia mieloide acuta si verifica quando la cellula interessata origina da una cellula staminale pluripotente $\mathrm{o}$, più raramente, da un progenitore granulo-monocitopoietico. Nella leucemia linfoblastica acuta, invece, la

Corrispondente: Gian Luca Michelis, SC Medicina 1 ed Ematologia, Ospedale S. Paolo, Savona, Italia.

Tel.: +39.019.8404551.

E-mail: glmic@libero.it

Articolo pubblicato secondo la Creative Commons Attribution NonCommercial 4.0 License (CC BY-NC 4.0).

CCopyright G.L. Michelis, 2019

Licensee PAGEPress, Italy

QUADERNI - Italian Journal of Medicine 2019; 7(1):8-10 cellula interessata è un progenitore $\mathrm{B}$ o $\mathrm{T}$ linfocitario o più raramente una cellula staminale pluripotente. Sono stati individuati nel tempo alcuni fattori di rischio predisponenti la genesi di leucemie acute, ma va detto che nessuno è stato dimostrato come certo in assoluto. ${ }^{2} \grave{\mathrm{E}}$ infatti frequente riscontrare tali patologie, che per definizione sono ad insorgenza rapida e improvvisa, in soggetti con anamnesi familiari, patologiche o professionali non particolarmente espressive. In ogni caso tra i fattori patogenetici (Tabella 1) vanno sicuramente menzionati le radiazioni ionizzanti, precedenti chemio- e/o radioterapie, pregresse malattie ematologiche con rischio di trasformazione leucemica (es. sindromi mielodisplastiche, sindromi mieloproliferative), sindromi genetiche predisponenti (es. sindrome di Down), esposizione ad agenti chimici (benzene, antiparassitari, ecc.). Come già detto, non essendo nota una causa specifica ed essendo l'insorgenza improvvisa e a rapido sviluppo, è praticamente impossibile attuare un piano di prevenzione. Non esistono dunque, come per altri tipi di neoplasia, indagini di screening da poter effettuare. L'unica eccezione va riferita alle malattie ematologiche a possibile evoluzione leucemica che andranno tenute strettamente sotto controllo per individuare il più rapidamente possibile un'eventuale trasformazione. Non esiste tuttavia un modo per impedire che questa tragica storia naturale verso la leucosi acuta si possa verificare.

\section{Segni e sintomi}

Il corredo sintomatologico (Tabella 2) può essere più o meno caratteristico, ma spesso è aspecifico riguardando soprattutto astenia, febbre, sudorazioni anomale, calo ponderale, pallore mucocutaneo, sindrome emorragica (da piccole ecchimosi a emorragie più importanti: di solito epistassi e gengivorragie) e algie ossee. Tali sintomi sono da ricondurre all'anemia, alla leucopenia, alla piastrinopenia, alla liberazione di citochine e all'espansione del clone blastico a livello midollare (il dolore osseo, perlopiù pulsante, sarà soprattutto localizzato a livello delle ossa piatte: bacino, sterno, coste e rachide). Di fronte a un paziente con petecchie, ecchimosi ed ematomi spontanei, in particolare se associati a pallore cutaneo, andrebbe sempre sospettata una malattia ematologica e mai esclusa una forma leucemica 
acuta. Proprio per questo insieme di sintomi e segni piuttosto generici il paziente potrà dapprima rivolgersi al medico di famiglia o in caso di eventi acuti al pronto soccorso ospedaliero. Diventa quindi fondamentale che nel clinico, anche non ematologo, si possa instaurare un sospetto reale.

\section{Diagnosi}

Come per tutte le patologie, anche per le leucemie acute, la diagnosi va sospettata seguendo un percorso preciso. L'anamnesi è fondamentale e riguarderà in particolare la presenza di precedenti chemio- o radioterapie, l'esposizione a fattori di rischio mutageno (da approfondire sempre l'anamnesi professionale), la presenza di altre patologie ematologiche a rischio di evoluzione, la tempistica di comparsa dei segni e sintomi caratteristici. In seconda battuta dovrà essere effettuato un attento esame clinico: utile indagare la presenza di adenomegalie superficiali, di epato- e/o spleno-megalia, di ematomi e/o petecchie spontanee, di ipertrofia gengivale e/o tonsillare. A questo proposito va ricordato come molte malattie, anche comuni e a eziologia virale, possano mimare una leucemia acuta: tra queste la mononucleosi, le infezioni da citomegalovirus o da HIV, per citarne solo alcune. Diventa quindi d'obbligo eseguire alcuni esami ematochimici mirati: emocromo con formula leucocitaria, VES, PCR, LDH, coagulazione completa, indici di funzionalità renale ed epatica e, nel sospetto di una delle virosi suddette, andranno effettuate le relative sierologie (Tabella 3). Se possibile dovranno essere rapidamente eseguite una radiografia del torace e un'ecografia dell'addome (esami strumentali a cui di solito vengono sottoposti pazienti che accedono al pronto soccorso). Là dove i risultati pongano un effettivo sospetto di leucosi acuta sarà buona norma far eseguire uno striscio di sangue periferico (per valutare la presenza di blasti) e inviare un campione al più vicino laboratorio di citofluorimetria per l'esame dell'immunofenotipo. Questo ci permetterà non solo di confermare eventualmente la diagnosi, ma anche di poter individuare il fenotipo interessato (mieloide o linfoide). A questo punto dovrà essere necessariamente coinvolto lo specialista di riferimento, cioè l'ematologo, che dovrà procedere con il resto delle indagini specifiche (in particolare l'aspirato midollare e, se ritenuta necessaria, anche la biopsia ossea) e indirizzare il paziente verso il reparto (se presente nello stesso ospedale) o il centro di riferimento. Tale scelta verrà effettuata anche in base alla tipologia del paziente e alle possibilità terapeutiche prospettate. È buona norma nel caso di pazienti giovani, quindi potenzialmente candidati al trapianto allogenico, trasferire il paziente in centri specializzati. Invece va ricordato che molte recenti terapie rivolte al paziente anziano (es. agenti demetilanti come azacitidina o decitabina) possono essere effettuate in regime di day hospital anche in strutture ematologiche che afferiscono alla medicina interna. Naturalmente devono essere presenti medici esperti nell'uso di tali farmaci e nella gestione di questi pazienti.

Tabella 1. Fattori di rischio che possono concorrere nella genesi di leucemia acuta.

Precedente chemio-e/o immunoterapia

Precedente malattia ematologica con rischio di evoluzione leucemica

Sindromi genetiche predisponenti con rischio di presentazione leucemica

Esposizione a radiazioni ionizzanti

Esposizione ad agenti chimici e antiparassitari

Tabella 2. Segni e sintomi potenzialmente correlati a leucemia acuta.

Astenia, pallore, cefalea, tachicardia, acufeni, lipotimie e sincopi (legati all'anemia)

Infezione o febbre persistente

Sindrome emorragica

Flogosi e ipertrofia gengivale, ulcerazioni del cavo oro-faringeo

Algie ossee (soprattutto a livello delle ossa piatte)

Calo ponderale

Sudorazioni anomale 
Tabella 3. Esami ematochimici e strumentali da eseguire nel sospetto di leucemia acuta.

Emocromo con formula ed esame dello striscio di sangue periferico (in caso di forte sospetto di malattia anche immunofenotipo su sangue periferico)

Indici di flogosi: PCR, VES, ferritina

Coagulazione completa

Indici di funzionalità epatica e renale

LDH

Dosaggio delle vitamine emoattive (B12, Acido folico)

Sierologia per EBV, CMV, Toxoplasma, HIV

Elettroforesi delle proteine sieriche

Radiografia del torace standard

Ecografia dell'addome e, se possibile, delle principali stazioni linfonodali

\section{Approccio terapeutico}

L'approccio terapeutico a carico dell'internista dovrà coprire esclusivamente quel lasso di tempo necessario per ultimare le indagini e arrivare a una diagnosi definitiva. Poiché in caso di leucemia acuta il paziente dovrà essere affidato alle cure dello specialista ematologo e trasferito nel più breve tempo possibile in un centro specializzato. In ogni caso, nell'attesa di una diagnosi definitiva, sarà importante supportare il paziente con trasfusioni di emazie concentrate (per valori di $\mathrm{Hb}$ uguali o inferiori a $8 \mathrm{~g} / \mathrm{dL}$ ), di concentrati piastrinici (per valori inferiori alle $5000 \mathrm{plt} / \mathrm{mm}^{3}$ o per valori inferiori a $10.000 / \mathrm{mm}^{3}$ se presente sindrome emorragica). Si ricorda che per pazienti che possano essere candidati a trapianto allogenico sarà necessario trasfondere concentrati irradiati. In caso di severe alterazioni della coagulazione, come può verificarsi per esempio nella leucemia promielocitica acuta, si valuterà la necessità dell'uso di plasma. In caso di febbre sarà opportuno eseguire emocolture e intraprendere una terapia antibiotica a largo spettro. Utile idratazione per via infusionale continua e supporto con ossigeno terapia in caso di insufficienza respiratoria.

\section{Conclusioni}

Le leucemie acute sono patologie ematologiche a insorgenza rapida, ma che possono verificarsi de novo (senza precedenti ematologici) o possono essere secondarie a precedenti patologie (sindromi mielodisplastiche o sindromi mieloproliferative per esempio). Di solito le forme de novo colpiscono per la maggior parte una popolazione più giovane che non si sta sottoponendo a controlli periodici ematologici. Sono i casi in cui la rapidità d'azione e l'esecuzione di un percorso diagnostico-terapeutico corretto sono fondamentali, soprattutto per gestire eventuali complicanze che potrebbero mettere a rischio la vita del paziente nell'immediato. Sono questi i pazienti a cui va rivolta la massima attenzione. Le forme secondarie, insorgendo in pazienti più anziani e con una patologia ematologica già in monitoraggio, sono più facilmente diagnosticabili e, nel caso specifico di pazienti con età avanzata, non essendo candidabili al trapianto allogenico, possono essere gestiti anche in strutture non di riferimento che non prevedano un centro trapianti.

\section{Bibliografia}

1. Tura $\mathrm{S}$, et al. Lezioni di Ematologia, Società editrice Esculapio, 2003.

2. AAVV. PDTA del paziente con leucemia mieloide acuta e linfoblastica, Azienda Ospedaliera S. Luigi Gonzaga di Orbassano. 


\title{
Sindrome emolitico-uremica atipica e porpora trombotica trombocitopenica
}

\author{
Marcello Brignone \\ SC Medicina 1 ed Ematologia, Ospedale San Paolo, Savona, Italia
}

\section{Introduzione}

La trombocitopenia e l'anemia emolitica microangiopatica sono i segni distintivi delle microangiopatie trombotiche (MAT): la porpora trombotica trombocitopenica (PTT) e la sindrome emolitico-uremica (SEU). In queste malattie si ha una infiammazione e occlusione ubiquitaria di piccoli vasi con consumo di piastrine e anemia emolitica. Esistono due forme di SEU: una di origine infettiva e l'altra di origine genetica. La prima è causata da una tossina batterica liberata da particolari ceppi del batterio Escherichia coli (Shiga-tossina) e viene definita Seu Shigatossina-associata (o anche SEU tipica). È più frequente nei bambini ed è caratterizzata da gastroenterite con diarrea emorragica. Il danno renale di vario grado è presente in tutti i pazienti, mentre un'insufficienza renale acuta coinvolge il $55-70 \%$ dei pazienti. Focolai epidemici possono manifestarsi sia in ambito familiare che in comunità (asili nido, scuole, ecc.). La forma non infettiva di origine genetica (SEU atipica) è più rara $\mathrm{e}$ rappresenta meno del $10 \%$ della totalità dei casi di SEU. La prognosi, per quanto riguarda l'insufficienza renale, è molto spesso sfavorevole: più del $50 \%$ dei casi va incontro a dialisi cronica.

Distinguere una PPT da una SEUa può essere difficile solo con i dati clinici e i comuni dati di laboratorio. Una diagnosi differenziale più accurata ha implicazioni cliniche, in quanto la plasmaferesi (il trattamento di prima scelta nella PTT) è molto meno efficace nella SEU atipica, che mostra notevoli benefici

Corrispondente: Marcello Brignone, SC Medicina 1 ed Ematologia, Ospedale S. Paolo, Savona, Italia.

Tel.: +039.019.8404467.

E-mail: marcello.brignone58@gmail.com

Articolo pubblicato secondo la Creative Commons Attribution NonCommercial 4.0 License (CC BY-NC 4.0).

(C) Copyright M. Brignone, 2019

Licensee PAGEPress, Italy

QUADERNI - Italian Journal of Medicine 2019; 7(1):11-14 terapeutici a breve e lungo termine con eculizumab, un anticorpo monoclonale che inibisce l'attivazione del complemento.

\section{Epidemiologia}

L'incidenza della SEUa è stimata in 1-2 casi/milione/anno, circa il $20 \%$ a carattere familiare. Mortalità o insufficienza renale acuta terminale si verificano fino al $40 \%$ dei casi non trattati al primo episodio. La PTT circa 4 casi/milione/anno, 80-90\% idiopatia/acquisita, $10 \%$ ereditaria. La mortalità arriva al $95 \%$ dei casi se non trattata.

\section{Sindrome emolitico-uremica atipica}

La sindrome emolitica uremica è una microangiopatia trombotica complemento-mediata con prevalente interessamento del parenchima renale. Si caratterizza per anemia emolitica, piastrinopenia e occlusione trombotica dei piccoli vasi (microangiopatia trombotica), con segni di prevalente coinvolgimento renale. Clinicamente il paziente presenterà insufficienza renale acuta, segni di emolisi intravascolare massiva con insufficienza del microcircolo e interessamento multiorgano (encefalo, frequente, polmoni e apparato cardiovascolare). La SEUa è una malattia rara, scatenata da stress infettivi, chirurgici ecc. ma spesso senza nessun fattore individuabile. È gravata da complicanze come l'insufficienza renale uremica nel $50 \%$ dei casi, recidiva frequentemente ed ha un'elevata mortalità (>25\% a 5 anni).

Il complemento rappresenta una componente del sistema immunitario ed è costituito da proteine solubili e di membrana che interagiscono reciprocamente.

È composto da 3 vie di attivazione con una sequenza effettrice finale comune:

- via classica;

- via della lectina;

- via alternativa.

I componenti delle prime due vie sono indicati con la lettera $\mathrm{C}$ seguita da un numero.

I componenti della via alternativa vengono indicati con le lettere B e D. 
Nella Figura 1 è mostrata la cascata del complemento.

Il sistema del complemento è sempre attivo per consentire una rapida risposta a diversi tipi di stimolazione (immune, traumatica, da stress generico) che ne inducono un'amplificazione che porta a potenti e distruttive reazioni immunitarie.

L'amplificazione del complemento è tenuta sotto controllo da multipli meccanismi di inibizione e regolazione per prevenirne l'attivazione incontrollata. Quando gli inibitori sono assenti o mal funzionanti il sistema del complemento rimane cronicamente non controllato.

Nella SEUa l'attivazione del complemento contro gli endoteli è provocata da:

- deficit congenito di proteine di regolazione del complemento;

- produzione di anticorpi contro le proteine di regolazione del complemento.
L'attivazione cronica incontrollata del complemento provoca attivazione piastrinica, endoteliale e leucocitaria con conseguente infiammazione, trombosi e occlusione sistemica dei piccoli vasi. La diagnosi di SEUa non è legata all'identificazione di una mutazione genetica (non identificata nel $30-50 \%$ dei pazienti) né la sua severità è correlabile alla presenza di una data mutazione.

In Tabella 1 sono presentati i segni e sintomi di esordio.

\section{Porpora trombotica trombocitopenia}

La microangiopatia trombotica è caratterizzata da: piastrinopenia, anemia emolitica e trombosi micro vascolare che si accompagna a disfunzioni neurologiche ( $90 \%$ dei casi), insufficienza renale acuta $(50 \%$ dei casi) e febbre ( $25 \%$ dei casi).

Tabella 1. Sintomi e segni di esordio della sindrome emolitico-uremica atipica.

Insufficienza renale acuta

Anemia emolitica Coombs negativa

Schistocitosi frequente

Piastrinopenia da consumo $(>25 \%)$

Insorgenza improvvisa e violenta

Possibili segni di sofferenza neurologica (stato confusionale, convulsioni)

Possibili sintomi gastrointestinali (vomito, diarrea, dolore)

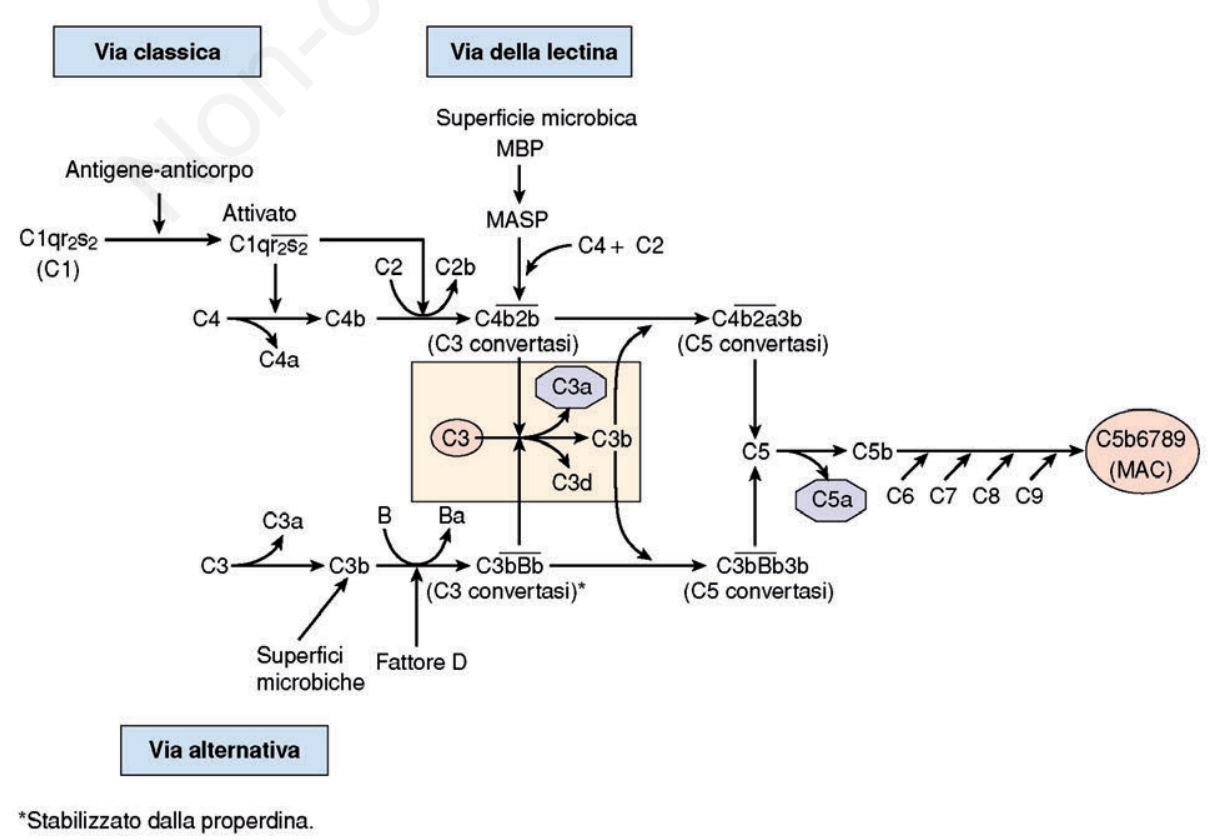

Figura 1. Cascata del complemento. 
La PTT è causata dal deficit di ADAMTS 13 ( $a$ disintegrin and metalloprotease with thrombo-spondin type 1 repeat, member 13), una metalloproteasi con attività $\mathrm{Zn}^{++} \mathrm{Ca}^{++}$dipendente.

In individui sani, in risposta ad un danno vascolare, viene rilasciato il Fattore di von Willebrand immagazzinato nell'endotelio. L'ADAMTS 13 elabora e cliva il vWF evitando la formazione di multimeri ultra large che attivano e aggregano le piastrine causando trombosi intravascolare.

La deficienza di ADAMTS13 determina pertanto la formazione incontrollata di questi multimeri di grandi dimensioni.

Esistono due differenti forme di PTT: una forma acquisita e una forma ereditaria. La forma acquisita si caratterizza per la presenza di anticorpi antiADAMTS 13 che: o inibiscono l'attività proteolitica dell'enzima o ne accelerano la clearance.

In Tabella 2 sono mostrate le caratteristiche delle due forme.

In Tabella 3 sono mostrati i sintomi neurologici e i dati di laboratorio presenti nel paziente con PTT.

\section{Diagnosi differenziale tra sindrome emolitico-uremica atipica e porpora trombotica trombocitopenica}

La presentazione clinica, molto simile per SEUa e PTT, non consente di identificare facilmente la causa di una microangiopatia trombotica. I pazienti infatti, in entrambi i quadri clinici presentano piastrinopenia, anemia emolitica e danno d'organo (sistema neurologico centrale, reni, apparato gastroenterico). Inoltre ogni età può essere colpita da entrambe le patologie.

D'altra parte però una precoce diagnosi differenziale diagnostica è essenziale per il corretto approccio terapeutico, in quanto le due patologie riconoscono etiologie e strategie terapeutiche, ad oggi, diverse.

Esiste un singolo test che può, con specificità $>90 \%$, discriminare tra SEUa e PTT: la determinazione della attività di ADAMTS 13 e il riscontro di autoanticorpi.

Una attività di ADAMTS $13<5 \%$ è diagnostica di PTT.

Una attività $>5 \%$ è sufficiente a prevenire la formazione di trombi piastrinici nel microcircolo. In Figura 2 è mostrata la diagnosi differenziale tra SEUa e PTT.

\section{Terapia}

Nel paziente affetto da PTT il cardinale della terapia è rappresentato dalla plasmaferesi che rimuove gli anticorpi anti ADAMTS 13.

Nel paziente affetto da SEUa il cardine di trattamento è rappresentato dall'utilizzo dell'anticorpo anti$\mathrm{C} 5$, Eculizumab che legandosi con alta affinità a $\mathrm{C} 5$ ne blocca l'attività impedendo la via terminale litica del complemento. È indicato in tutte le forme di SEUa in-

Tabella 2. Porpora trombotica trombocitopenica acquisita ed ereditaria.

\begin{tabular}{ll}
\hline Acquisita & Ereditaria \\
\hline $90 \%$ & $10 \%$ \\
\hline Femmina $70 \%$ & Maschi=femmine \\
\hline Picco tra 30-40 anni & Picco tra nascita e 4 anni \\
\hline $30 \%$ di recidive & $20 \%$ 20-30 anni \\
\hline Talora scatenata da infezioni o gravidanza & Recidive frequenti \\
\hline Presenza di auto-anticorpi vs ADAMTS 13 & Conosciuta come sindrome di Upshaw-Schulman \\
\hline
\end{tabular}

Tabella 3. Sintomi neurologici e dati di laboratorio PTT.

\begin{tabular}{ll}
\hline Sintomi neurologici più frequentemente presenti & Dati di laboratorio \\
\hline Cefalea & Piastrinopenia spesso severa $(<50.000)$ \\
\hline Disturbi visivi & Anemia \\
\hline Deficit motori & Presenza di schistociti \\
\hline Convulsioni & LDH elevato \\
\hline Alterazione dello stato mentale & Reticolociti elevati \\
\hline Atassia & Coombs negativo \\
\hline Coma & Aptoglobina ridotta \\
\hline
\end{tabular}




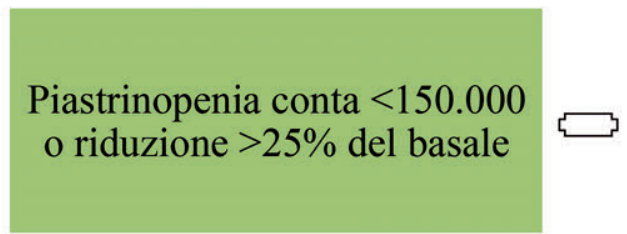

Sintomi neurologici
Emolisi microangiotatica schistociti, LDH elevato, anemia, Coombs negativo

\section{Insufficienza renale}

Sintomi gastrointestinali

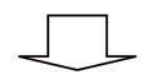

\section{Determinazione attività ADAMTS 13}
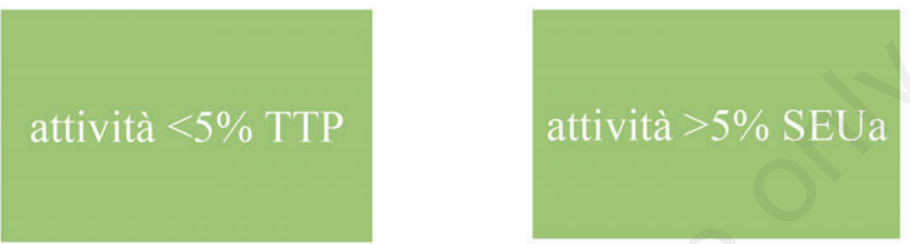

Figura 2. Diagnosi differenziale SEUa - PTT.

dipendentemente dalla presenza di mutazione genica e può essere utilizzato nei pazienti in dialisi. La dose iniziale è di 900 mg iv ogni 7 giorni per il primo mese. Secondo la risposta si potrà proseguire con dosi bisettimanali o mensili. La terapia andrà continuata sine die. Tutti i pazienti devono essere vaccinati contro il meningococco almeno 2 settimane prima del trattamento con eculizumab. I pazienti trattati in emergenza devono essere sottoposti a profilassi antibiotica appropriata fino a due settimane dopo l'avvenuta vaccinazione.

\section{Conclusioni}

Nel management di entrambe le patologie, è essenziale la diagnosi precoce e la corretta gestione successiva che deve prevedere la diagnosi differenziale tra le due forme.

Ogni paziente con sospetto clinico-laboratoristico di microangiopatia trombotica deve essere sottoposto a prelievo ematico per determinazione dell'attività di ADAMTS 13 e deve iniziare la plasmaferesi, che sarà sospesa in caso di diagnosi di SEUa dove è indicata la somministrazione di eculizumab. 


\title{
I linfomi aggressivi a rapida crescita
}

\author{
Marina Cavaliere \\ SC Medicina 1 ed Ematologia, Ospedale San Paolo, Savona, Italia
}

\section{Introduzione}

I linfomi sono neoplasie del sistema immunitario che originano da linfociti maturi in diverse fasi della loro differenziazione. In base alla classificazione più recente esistono oggi più di 60 tipi di linfoma maligno, ognuno associato a specifiche caratteristiche patologiche e cliniche. In maniera schematica i linfomi possono essere di tipo B, T o NK in base al fenotipo della cellula di origine e possono presentare un decorso clinico di tipo indolente o aggressivo.

\section{Epidemiologia}

I linfomi maligni rappresentano il quinto tipo di tumore per frequenza nel mondo occidentale, con un'incidenza pari a circa $19-20$ casi per 100.000 abitanti.

L'incidenza dei linfomi è ampiamente influenzata da fattori geografici, razziali e temporali ed è superiore nei paesi industrializzati, nei soggetti di sesso maschile e di razza bianca.

Dopo una fase epidemica che nei paesi occidentali ha portato ad un incremento dei casi di linfoma del $50 \%$ circa dagli anni ' 70 agli anni ' 90 , numerosi studi concordano sul fatto che l'incidenza delle malattie linfoproliferative si sia attualmente stabilizzata o registri solo incrementi minori.

Le cause del notevole incremento del passato sono sicuramente da ascrivere al miglioramento

Corrispondente: Marina Cavaliere, SC Medicina 1 ed Ematologia, Ospedale San Paolo, Savona, Italia.

Tel.: +39.019.8404551 - Fax: +39.019.8404583.

E-mail: marinacavaliere@libero.it

Articolo pubblicato secondo la Creative Commons Attribution NonCommercial 4.0 License (CC BY-NC 4.0).

CCopyright M. Cavaliere, 2019

Licensee PAGEPress, Italy

QUADERNI - Italian Journal of Medicine 2019; 7(1):15-22 diagnostico, e almeno in alcune realtà, alla pandemia di infezione da HIV registrata negli anni ' 80. In Italia si stima che ogni anno vengono diagnosticati circa 16.000 nuovi casi di linfoma con un incremento annuo pari all' $1,3 \%{ }^{1}$

Recentemente anche gli studi epidemiologici sulle malattie linfoproliferative stanno acquisendo la filosofia dei sistemi classificativi REAL/WHO che considerano i linfomi come un insieme di entità clinico-biologiche distinte. Sono pertanto disponibili dati epidemiologici più precisi per singolo istotipo. I linfomi a cellule B sono largamente predominanti in ogni indagine epidemiologica.

\section{Linfomi aggressivi}

Termine utilizzato per indicare quei tumori linfoidi che esordiscono con una sintomatologia importante e che, non trattati, riconoscono una rapida progressione.

\section{Linfomi aggressivi a cellule B}

Sono rappresentati da neoplasie dei precursri B (leucemia/linfoma linfoblastico B NOS e la leuce$\mathrm{mia} /$ linfoma linfoblastico B con anomalie genetiche ricorrenti) e da numerose neoplasie derivanti da cellule B mature, come il linfoma mantellare, il linfoma di Burkitt, il Primary Effusion limphoma, il linfoma diffuso a grandi cellule con i suoi numerosi sottotipi, il linfoma a cellule B inclassificabile con caratteristiche tra il linfoma diffuso a grandi cellule e il linfoma di Burkitt e una nuova variante del linfoma di Burkitt-like con alterazione del cr 11q.

\section{Linfomi aggressivi a cellule T/NK}

Ovviamente tra i linfomi aggressivi si annoverano anche neoplasie derivanti dai linfociti T/NK (rappresentano circa il 15\% dei linfomi aggressivi), sia dai precursori che dalle cellule mature (dei precursori: leucemia/linfoma linfoblastico, dei linfociti $\mathrm{T}$ maturi: leucemia prolinfocitica $\mathrm{T}$, leucemia a cellule NK, aggressiva, leucemia/linfoma T dell'adulto HTLV-1, linfoma T/NK, tipo nasale, linfoma $\mathrm{T}$ enteropatico, linfoma $\mathrm{T}$ epatosplenico, linfoma $\mathrm{T}$ si- 
milpanniculitico, linfoma T, NAS, linfoma T, angioimmunoblastico, linfoma a grandi cellule anaplastico).

Data la rarità dei linfomi a cellule $\mathrm{T}$ (circa il 5$10 \%$ di tutti i linfomi non-Hodgkin), orienterò la relazione sui linfomi a cellule $\mathrm{B}$ aggressivi più noti: i) linfoma diffuso a grandi cellule B (DLBCL, diffuse large B cell lymphoma); ii) linfoma mantellare (MCL, Mantlecell lymphoma); iii) linfoma di Burkitt (BL, Burkitt's lymphoma); focalizzando poi la maggior parte dei contenuti sul più frequente: il DLBCL.

\section{Alcune caratteristiche peculiari dei tre tipi di linfoma descritti}

\section{Linfoma diffuso a grandi cellule B}

Il linfoma diffuso a grandi cellule B (DLBCL) costituisce circa il 25-30\% dei linfomi non Hodgkin nella popolazione adulta nei paesi occidentali e il $37 \%$ dei linfomi a cellule $\mathrm{B}$, con una maggior incidenza nei paesi più sviluppati. Circa il $53 \%$ dei casi di DLBCL insorge dopo i 60 anni di età, e l'età mediana di insorgenza e compresa tra la sesta e la settima decade, ma può manifestarsi anche nei bambini e nei giovani adulti, con una lieve prevalenza nel sesso maschile. Nella maggior parte dei casi non è possibile trovare dei fattori predisponenti, tuttavia per lo sviluppo del DLBCL, sono riconosciuti alcuni fattori di rischio tra cui agenti virali, quali: virus dell'immunodeficienza acquisita (HIV), virus dell'epatite C (HCV), Epstein Barr Virus (EBV). Il linfoma a grandi cellule EBV correlato, considerato fino a pochi anni fa tipico dell'anziano (in realtà esiste anche nel giovane), è caratterizzato da un decorso clinico molto aggressivo. Altre condizioni sospette come agenti eziologici per lo sviluppo di DLBCL sono le patologie autoimmuni e un precedente trapianto di organo solido. Nella maggior parte dei casi si presenta come DLBCL de novo ma può derivare dalla progressione o dalla trasformazione di un linfoma non Hodgkin indolente.

\section{Linfoma mantellare}

Il linfoma mantellare (MCL) è un linfoma non Hodgkin aggressivo a cellule $\mathrm{B}$ mature con storicamente una prognosi negativa per sopravvivenze spesso poco prolungate. Ė molto meno frequente (7$10 \%$ dei linfomi a cellule B) rispetto al DLBCL. Recenti progressi nelle nostre conoscenze sulla biologia del MCL hanno portato a miglioramenti sostanziali nella prognosi dei pazienti e allo sviluppo di nuove targeted therapies. Mentre in passato veniva considerato un linfoma di grado intermedio, il
MCL ha una presentazione clinica e un decorso che spesso mimano o sono peggiori della sua controparte notoriamente aggressiva, il DLBCL. I pazienti spesso hanno linfoadenomegalie, splenomegalia, coinvolgimento midollare con leucemizzazione e infiltrazione dell' apparato gastrointestinale alla diagnosi. Il MCL è classicamente definito dall'iperespressione della ciclina D1 secondaria a traslcazione $\mathrm{t}(11 ; 14)$ che giustappone il gene CCDN1 che codifica per la ciclina D1 al gene per la catena pesante delle immunoglobuline. ${ }^{2}$ Altre rare traslocazioni possono portare a iperespressione della ciclina D2 e D3 con malattie a prognosi ancora peggiore. Oggi sappiamo che in realtà il MCL presenta varianti diverse con clinica e prognosi molto differenti. Un semplice marcatore immunoistochimico in grado di differenziare queste varianti, è il Ki 67 (indice di proliferazione). Oggi sappiamo che in caso di Ki 67 basso (inferiore al 30\%, ma spesso inferiore al 10\%) il MCL si comporterà come un Linfoma indolente a prognosi decisamente migliore. ${ }^{3}$ Tale forma di linfoma mantellare può essere sottoposto ad un monitoraggio come primo approccio terapeutico, proprio come e altre forme di linfoma indolente. ${ }^{4,5}$

\section{Linfoma di Burkitt}

In 1964, un nuovo herpes virus, il virus di Epstein-Barr virus (EBV), fu scoperto in colture di cellule tumorali derivate da biopsie di linfoma di Burkitt prelevate da un giovane paziente africano. Questo fu un momento cruciale che rinvigorì la ricerca sui virus in quanto possibili causa di neoplasie umane. Studi successivi dimostrarono che l'EBV era un potente agente trasformante per le cellule B e che tutti i casi di linfoma di Burkitt presentavano una tipica traslocazione cromosomica che portava ad attivazione costitutiva dell'oncogene c-Myc. Questi risultati sembravano postulare che, un semplice ed unico meccanismo oncogenetico, potesse porre il linfoma di Burkitt come paradigma per i tumori ad eziologia virale. In realtà la patogenesi di questa neoplasia è abbastanza complicata sia per quanto riguarda il contributo del virus che il coinvolgimento di oncogeni cellulari. L'alta incidenza di questo linfoma in Africa è limitata a quelle aree geografiche dove è endemico il Plasomodium falciparum. In queste aree l'EBV è presente nelle cellule tumorali di praticamente tutti i casi di linfoma di Burkitt. Al contrario, l'associazione con l'EBV è meno frequente nella forma sporadica di linfoma di Burkitt che compare nel resto del mondo. Questa osservazione dimostrava che una cooperazione tra EBV e malaria era responsabile dell'incremento dell'incidemza del linfoma di Burkitt endemico. In minore misura, anche la coinfezione con HIV incre- 
menta sia l'incidenza globale di Linfoma di Burkitt che la frequenza della linfoma di Burkitt EBV positivo. ${ }^{6-11}$ Infatti, Rochford et al. hanno ipotizzato che il linfoma di Burkitt endemico sia una malattia polimicrobica. Il linfoma di Burkitt si presenta caratteristicamente con interessamento mandibolare nella sua forma endemica africana, spesso pediatrica e con la presenza di masse a rapida crescita inglobanti o infiltranti i visceri addominali e pelvici. Nelle femmine in età post-puberale è abbastanza frequente un'infiltrazione delle mammelle. Comuni sono anche il coinvolgimento del sistema nervoso centrale (SNC) e l'interessamento midollare con leucemizzazione periferica (cosiddetto linfoma/leucemia a precursori linfoidi B tipo L3).

È comunque un linfoma raro nei paesi occidentali ( $1,2 \%$ dei linfomi dell'adulto) e l'età mediana alla diagnosi e di 35 anni. Data la rapida (a volte rapidissima) crescita delle masse neoplastiche una diagnosi tempestiva è fondamentale per intraprendere al più presto un trattamento e ottimizzare quindi la prognosi. Gli attuali trattamenti per il linfoma di Burkitt sono molto intensivi, per lo più mediati dai protocolli pediatrici e hanno tutti come obiettivo il somministrare una polichemioterapia a dose intensiva, con minimizzazione dei ritardi terapeutici al fine di mantenere elevati livelli sierici dei vari farmaci. Tali pazienti necessitano di precoce trasferimento in Centri di Riferimento Ematologici.

\section{Presentazione dei linfomi aggressivi}

\section{Clinica}

Il quadro clinico di presentazione dei linfomi aggressivi dipende dalla cinetica di crescita tumorale e dalle sedi interessate. Essi sono comunemente caratterizzati da rapida insorgenza, possibile associazione a sintomatologia sistemica (febbre, sudorazione notturna, calo ponderale) dovuti al rilascio di sostanze infiammatorie da parte delle cellule tumorali e da eventuali sintomi secondari a compressione/ostruzione di strutture nervose o vascolari. $\mathrm{Si}$ evince quindi che i sintomi e segni riferiti dal paziente sono parte fondamentale dell'iter diagnostico. Un'importante perdita di peso in pochi mesi, sudorazioni profuse soprattutto di notte o una febbre inspiegabile che compare prevalentemente alla sera, sono un campanello di allarme. Tuttavia bisogna sfatare un mito: la maggior parte dei pazienti con linfoma (anche aggressivo) non ha sintomi di questo tipo! Più spesso i pazienti giungono all'attenzione del medico perché osservano un linfonodo cervicale o a livello dell'ascella o dell'inguine che aumenta di volume, oppure perchè compaiono sintomi legati al fatto che linfoadenomegalie profonde coinvolgano (nella maggior parte dei casi per compressione più che per infiltrazione) strutture toraciche (provocando per esempio, tosse persistente o dispnea) o addominali (portando ad aumento di dimensioni dell'addome, stipsi, edemi agli arti inferiori ecc.). In caso di linfoadenomegalia superficiale, l'ecografia è spesso d'ausilio per porre il sospetto di patologia linfoproliferativa.

Della presentazione del linfoma mantellare e del Linfoma di Burkitt si è già accennato brevemente in precedenza.

Nel DLBCL, nel 70\% dei casi la localizzazione è nodale, ma nel 30\% dei casi, si presenta alla diagnosi con una localizzazione extranodale di malattia, dove le sedi piu colpite sono: lo stomaco o il tratto gastrointestinale, l'osso, la mammella, il testicolo, il sistema nervoso centrale (SNC) con localizzazione parenchimale o meningea, l'anello del Waldeyer, la tiroide, il fegato e il rene. L'infiltrazione a livello del midollo osseo non è frequente ed e presente in circa il 20\% (11-27\%) dei DLBCL alla diagnosi. Comunque il linfoma diffuso a grandi cellule B può coinvolgere teoricamente qualsiasi organo o tessuto, con sintomi di presentazione quindi a volte imprevedibili e fuorvianti e iter diagnostici anche dei più vari il cui risultato può sorprendere alla fine il clinico (che magari ipotizzava tutt'altro tipo di patologia). La prognosi è comunque diversa a seconda del sito interessato.

Un tipo di presentazione non frequente ma che, sin dall'esordio, pone in diagnosi differenziale una neoplasia linfoproliferativa con poche altre patologie, è la localizzazione a livello mediastinico. In questa condizione, sia perchè stiamo parlando di linfomi a rapida crescita, sia perchè solo la comparsa di sintomi porta all'evidenza di linfoadenomegalie per altro non palpabili e non visibili, la massa neoplastica può crescere tanto da arrivare a determinare, per ostruzione o compressione, la sindrome della vena cava (SVC), caratterizzata da edema del collo (edema a mantellina), turgore delle giugulari, presenza di reticoli venosi della parete toracica anteriore con sintomi da compressione delle vie aeree. Uno slargamento mediastinico di tale entità può essere visto anche da una semplice radiografia del torace e rappresenta un'urgenza clinica-diagnostica per qualunque medico. Se non ci si trova in condizione di avviare procedure diagnostiche invasive precocemente, si dovrà procedere al trasferimento urgente del paziente in un Centro di livello superiore. Si segnala che in caso di urgenza, lo steroide ad alto dosaggio può spesso permettere di migliorare il quadro clinico almeno transitoriamente (con risultati molto più marcati anche in caso di neoplasia solida). Il coinvolgimento del mediastino può essere associato ad altre 
localizzazioni nodali nell'ambito dei DLBCL, ma spesso si presenta in maniera isolata talora associato a localizzazioni extranodali (come fegato, rene, surrene e polmone) e rappresenta una variante anatomo-clinica distinta dal DLBCL secondo la classificazione WHO dei linfomi: il linfoma a grandi cellule B primitivo del mediastino che, pur essendo un linfoma B aggressivo, ha una prognosi generalmente favorevole e si presenta con un'incidenza maggiore nelle giovani donne.

\section{Esami di laboratorio}

Nei casi di malattia avanzata possiamo trovare incremento degli indici di flogosi (secondario al rilascio di citochine da parte delle cellule neoplastiche), anemia (da flogosi o da coinvolgimeno midollare), aumento dell'LDH o segni di sofferenza degli eventuali organi coinvolti dal linfoma, $m a$ nella maggior parte dei casi il quadro laboratoristico è nella norma. Da segnalare che in caso di linfocitosi è fondamentale l'effettuazione di un esame citofluorimetrico su sangue periferico che può essere di notevole e precoce ausilio diagnostico, specie nei casi di linfoma mantellare e di Burkitt leucemizzato. Raramente però, il solo riconoscimento della popolazione linfoide tipica nel sangue periferico è sufficiente a caratterizzare adeguatamente il linfoma, per cui un prelievo bioptico è quasi sempre necessario a corredare la diagnosi (per gli approfondimenti di cinetica, per esempio, e alcune caratterizzazioni che sono prettamente immunoistochimiche).

\section{Diagnosi}

La diagnosi di certezza si ottiene con l'esame istologico attraverso l'asportazione dell'intero linfonodo, oppure mediante biopsia del linfonodo stesso o dell'organo interessato. L'adeguatezza del campione istologico permette di eseguire esami specialistici sempre più approfonditi, indispensabili per ottenere una diagnosi completa.

È per questo motivo che non si consiglia l'agoaspirato del linfondo, per inadeguatezza del campione, che non è un campione istologico ma citologico e pertanto oltre a non permettere di fare una diagnosi per un alto numero di falsi negativi, nei casi positivi la diagnosi di linfoma non è comunque conclusiva perchè manca la caratterizzazione.

Diversamente invece, grazie alle nuove metodiche di associazione di indagini istologiche, citofluorimetriche e molecolari, l'agobiopsia tru-cut (o core-needle biopsy) è stata dimostrata, in numerose situazioni, affidabile e può quindi, se necessaria, permettere di evitare interventi invasivi nei casi in cui la massa neoplastica non sia superficiale. Si segnala inoltre che la rapidità con cui (a volte 24-48 ore), nella maggior parte dei Centri, la morfologia associata alla citofluorimetria e alla immunoistochimica fornisce informazioni almeno sull'adeguatezza del campione, sfata il mito di ipotetici ritardi legati ai tentativi meno invasivi di approccio diagnostico. Ovviamente è fondamentale la stretta cooperazione tra clinico, radiologo, anatomo patologo e citofluorimetrista.

\section{Alcuni cenni sulla caratterizzazione istologica e molecolare dei DLBCL}

Le cellule linfomatose del DLBCL possono essere di medie e grandi dimensioni e generalmente presentano un alto indice di proliferazione che viene identificato con l'anticorpo ki67, i cui valori sono sempre maggiori del $20 \%$ e possono anche superare il 90\% (nel linfoma di Burkitt tale indice raggiunge spesso il 100\%). In immunoistochimica tutti i markers per le cellule B sono positivi: CD20, CD22, Cd79a, PAX5. Numerosi studi hanno confrontato profili genetici diversi evidenziati in vari tipi di linfoma diffuso a grandi cellule, con l'utilizzo delle nuove tecniche di gene expression profiling (GEP), dimostrando l'esistenza di 2 diversi profili di espressione genica corrispondenti a cellule di diversa origine e con prognosi diversa. Data l'ancora scarsa diffusione anche nei grossi Centri, di tali metodiche di indagine molto costose, si è definito un algoritmo diagnostico, l'algoritmo di HANS basato su pochi marcatori definibili con semplice immunoistochimica, che distingua queste 2 diverse $\mathrm{COO}$ con prognosi diversa. Questi markers in immunoistochimica sono: BCL6, BCL2, CD10 e MUM1.

In questo modo si sono distinti due sottotipi di DLBCL, il DLBCL del centro germinativo (GCDLBCL), e il DLBCL post-centrogerminativo o a fenotipo attivato (Non-GC o ABC-DLBCL), quest'ultima categoria presenta una prognosi più sfavorevole.

\section{Linfomi a cellule $B$ ad alto grado}

Una nuova categoria è introdotta per designare i linfomi a cellule B ad alto grado con espressione di double o triple hit. Questa caratteristica viene identificata mediante metodica FISH e definisce una traslocazione tra MYC e BCL2 o MYC e BCL6:

- MYC sul cromosoma 8;

- BCL2 sul cromosoma 18;

- BCL6 sul cromosoma 3q27;

il double hit si dimostra in circa il 5\% dei DLBCL. 
Diversa è invece la caratteristica di double expresser valutata in immunoistochimica (con l'identificazione delle proteine c-Myc e Bcl2) che si dimostra invece nel 20\% dei DLBCL. Queste caratterizzazioni sono molto importanti in quanto definiscono entità a prognosi nettamente diversa: i linfomi double hit tendono ad avere la peggiore prognosi, i double expresser hanno una prognosi intermedia, mentre molto migliore è la prognosi dei DLBCL che non presentino nessuna di queste 2 caratteristiche. ${ }^{12,13}$

\section{Stadiazione clinica}

A tutt'oggi la classificazione in stadi si basa sulla revisione di Lugano del sistema di AnnArbor/Cotswolds che definisce quattro stadi di malattia (I-IV) in base al numero delle localizzazioni e alle sedi interessate dal linfoma. ${ }^{14}$ Sulla base di tale revisione il riferimento alla presenza di sintomi B (sudorazioni notturne, febbre, calo ponderale superiore al $10 \%$ negli ultimi sei mesi) è attualmente raccomandato solo per i LH. Viene inoltre stabilito in $13 \mathrm{~cm}$ il diametro massimo di normalità per la milza, e in presenza di malattia Bulky non è più richiesto l'utilizzo del suffisso X ma solo l'indicazione del diametro maggiore della lesione. ${ }^{12}$

Ulteriori novità introdotte con la classificazione di Lugano riguardano l'utilizzo delle PET per tutti i linfomi FDG avidi, e la semplificazione del processo di stadiazione per cui in determinati casi può essere omessa l'esecuzione della biopsia osteomidollare.

\section{Esami aggiuntivi}

Agli esami eseguiti per la stadiazione della malattia, sono associate valutazioni aggiuntive utili a definire gli indici prognostici e a fornire una migliore valutazione complessiva del paziente. Tali esami comprendono:

- esami di laboratorio: emocromo completo e chimica clinica inclusi LDH, VES, $\beta 2$ microglobulina, albumina, valutazione della funzionalità renale, epatica e tiroidea, vitamina $\mathrm{D}$;

- test di gravidanza per le donne in età fertile;

- sierodiagnosi per HBV, HCV e HIV;

- studio della funzionalità cardiaca con elettrocardiogramma e ecocardiogramma per la valutazione della frazione di eiezione;

- per i pazienti trattati con bleomicina è consigliabile eseguire prove di funzionalità respiratoria con spirometria.

Da quanto enunciato sopra si rende evidente come, in attesa di una conferma diagnostica, in presenza di un forte sospetto di linfoma, possano es- sere programmate al più presto le indagini strumentali considerate come obbligatorie in tutti i tipi di linfomi aggressivi (fondamentalmente TAC e TAC PET).

\section{Prognosi}

\section{Algoritmi prognostici per il DLBCL}

Negli ultimi 10 anni sono stati riportati notevoli miglioramenti nel controllo a lungo termine della malattia, con oltre il $50 \%$ dei pazienti in remissione a 5 anni dal trattamento. Parlando dei DLBCL, bisogna ricordare anche che i linfomi follicolari di grado 3 b sono trattati come un linfoma diffuso a grandi cellule. Diversa invece è la terapia del linfoma di Burkitt e del linfoma mantellare.

I DLBCL vengono suddivisi in gruppi prognostici in base all'Indice prognostico internazionale (IPI) ${ }^{11}$ e all'IPI aggiustato per età (age-adjusted IPI, aaIPI).$^{12}$ I fattori che contribuiscono al calcolo dell'IPI sono:

- età >60 anni;

- LDH sieriche >UNL;

- performance status $\geq 2$;

- Stadio AnnArbor III-IV;

- coinvolgimento $>1$ sede extranodale.

I fattori di rischio invece per il calcolo dell'aaIPI sono:

- LDH sierica >UNL;

- performance status $\geq 2$;

- Stadio AnnArbor III-IV.

Nel 2007 Sehn LH et al., ormai nell'era Rituximab (anticorpo monoclonale anti CD20) ha proposto l'indice R-IPI quale ulteriore evoluzione dell'indice IPI per i pazienti con DLBCL sottoposti a trattamento chemioimmunoterapico.

Fattori di rischio:

- età >60 anni;

- LDH aumentato;

- 2 o + localizzazioni;

- Stadio AnnArbor III o maggiore;

- ECOG performance status III o superiore.

Ad ogni fattore è attribuito 1 punto.

Nonostante i diversi modelli proposti siano utili a stimare i rischi connessi alla patologia, ad oggi trovano un limitato utilizzo come strumenti decisionali nella pratica clinica.

Dalle colonne PFs e OS si evidenzia comunque come il DLBCL, paradigma di linfoma aggressivo, sia in realtà una patologia potenzialmente guaribile nella maggior parte dei casi.

\section{Algoritmi prognostici per il linfoma mantellare}

Poiché l'applicazione di tali strumenti al MCL presentava serie limitazioni, è stato costruito recen- 
temente, grazie al supporto dell'European Mantle Cell Lymphoma Network, un indice prognostico specifico per il MCL, denominato MIPI (MantleCell-Lymphoma International Prognostic Index). Il MIPI si basa su quattro fattori prognostici indipendenti (età, ECOG performance status, LDH e numero di leucociti), facilmente disponibili nella quotidiana pratica clinica. Grazie all'utilizzo di questo nuovo strumento è possibile suddividere $\mathrm{i}$ pazienti in tre gruppi ben bilanciati caratterizzati da prognosi decisamente differenti in termini di sopravvivenza. ${ }^{15}$

Il MIPI è stato rivisitato da Hoster et al. ${ }^{15}$ con l'introduzione della variabile Ki67, ormai noto fattore prognostico molto importante nel MCL. Questo nuovo bMIPI (biological MIPI) definisce molto bene la popolazione di pazienti a bassissimo rischio e a prognosi decisamente favorevole.

\section{Terapia}

Non parlerò di terapia in quanto il paziente con linfoma aggressivo in genere viene affidato a Centri Ematologici e quindi tale aspetto, per altro molto complicato e in continua evoluzione, non coinvolge direttamente l'internista.

\section{Follow-up}

In questo ambito invece, alcune novità derivanti soprattutto dall'importante conferenza tenutasi a Lugano nel $2014,{ }^{12}$ sono meritevoli di attenzione anche per il medico di medicina interna che potrebbe trovarsi a valutare un paziente con diagnosi di linfoma non-Hodgkin aggressivo sottoposto a chemioterapia.

Innanzitutto, i dati disponibili a favore dell'utilizzo routinario della TC non sono conclusivi ma è comunque prassi diffusa sia nei centri nordamericani sia europei, eseguire esami radiologici periodici (TC e/o PET) nei programmi di follow-up. Differentemente, in uno studio del 2003, su 117 pazienti in remissione completa solo il 5,7\% dei ricaduti è stato individuato con una TC (eseguita a $3 \mathrm{e}$ 12 mesi dal termine della chemioterapia) in assenza di altri sintomi specifici, mentre nell' $86 \%$ dei casi la recidiva era riscontrata in seguito alla comparsa di segni e/o sintomi. ${ }^{16}$ In uno studio nel quale il follow-up dei pazienti comprendeva l'uso periodico della TC (ogni 6 mesi per i primi 2 anni) una diagnosi precoce di recidiva riscontrata mediante imaging non hanno mostrato un vantaggio nell'outcome dei pazienti. ${ }^{17}$ I dati di un recente studio retrospettivo multicentrico condotto su pazienti con NHL aggressivi e HL dimostrano, nei pazienti affetti da linfoma diffuso a grandi cellule B, che nel $41 \%$ dei casi la recidiva è riconosciuta per la comparsa di sintomi e per anomalie agli esami di laboratorio e solo nel $26 \%$ dei casi la TC aveva anticipato la diagnosi di recidiva con un modesto beneficio sulla sopravvivenza a scapito di un elevato numero di indagini radiologiche eseguite. ${ }^{18}$

Non vi è indicazione all'utilizzo della PET al di fuori di uno studio clinico controllato. ${ }^{19,20}$ Sulla scorta di questi dati, i pazienti con DLBCL in remissione completa dopo terapia di prima o anche seconda linea devono essere seguiti con: visita clinica + routine ematochimici, LDH ed esame clinico ogni 3 mesi per i primi 2 anni, poi ogni 6 mesi per i 3 anni successivi, poi annualmente. La TC può essere eseguita a 6,12 e 24 mesi dal termine del trattamento. $^{21}$

\section{HIV e linfoma non-Hodgkin}

L'incidenza di LNH associato all'infezione da HIV è aumentata sin dall'inizio dell'epidemia di HIV e, prima dell'introduzione dell'HAART, i LNH rappresentavano la seconda neoplasia più frequentemente associata all'HIV dopo il sarcoma di Kaposi. L'introduzione dell'HAART ha portato a una significativa diminuzione dell'incidenza del linfoma primitivo cerebrale, e recentemente anche dei LNH sistemici, a presentazioni cliniche che si avvicinano sempre più a quelle della popolazione generale, con una significativa riduzione dell'incidenza di sedi extranodali come le meningi ed il midollo osseo, e a un significativo miglioramento della sopravvivenza dei pazienti con LNH ed infezione da HIV. ${ }^{22,23}$ L'introduzione dell'HAART è coincisa con quella del rituximab per cui nel corso degli ultimi 10 anni diversi studi hanno testato la fattibilità e l'efficacia dell'associazione immunochemioterapica. Le conclusioni degli studi permettono di affermare che lo schema R-CHOP può essere considerato lo schema di riferimento in questi pazienti con Linfoma diffuso a grandi cellule B. Una certa cautela deve essere osservata nei pazienti con CD4 <50/dL per l'eventuale aumento del rischio infettivo. ${ }^{24-26}$ Il linfoma di Burkitt, che rappresenta circa un quarto dei LNH diagnosticati nei pazienti con infezione da HIV, fino a qualche anno fa era trattato con schemi simili a quelli per $i$ linfomi diffusi a grandi cellule. Diversi studi sembravano dimostrare che la prognosi dei pazienti con Burkitt rimanesse severa e i miglioramenti ottenuti con l'HAART non riguardassero questo sottotipo di linfoma. Questi risultati però riguardavano serie di pazienti trattati con schemi tipo R-CHOP, poco efficaci anche in pazienti non HIV positivi. Poiché parecchie serie hanno dimostrato la fattibilità e l'ef- 
ficacia di schemi chemioterapici aggressivi, anche supportati da trapianto autologo di cellule staminali, nei pazienti HIV+ con Burkitt, ${ }^{27,28}$ tali schemi (es. R-CODOX-M/IVAC, R-HyperCVAD) devono essere considerati lo standard anche in questi pazienti, che riescono ad ottenere risultati comparabili a quelli ottenuti in pazienti non HIV-positivi. ${ }^{29-31}$

\section{Bibliografia}

1. Luminari S, Cesaretti M, Rashid I, et al. Incidence, clinical characteristics and survival of malignant lymphomas: a population-based study from a cancer registry in northern Italy. Hematol Oncol 2007;25:189-97.

2. Salaverria I, Royo C, Carvajal-Cuenca A, et al. CCND2 rearrangements are the most frequent genetic events in cyclin D1 - mantle cell lymphoma. Blood 2013;121:1394-402.

3. Hoster E, Rosenwald A, Berger F, et al. Prognostic Value of Ki-67 Index, Cytology, and Growth Pattern in Mantle-Cell Lymphoma: Results From Randomized Trials of the European Mantle Cell Lymphoma Network. J ClinOncol 2016;34:1386-94.

4. Abrisqueta P, Scott DW, Slack GW, et al. Observation as the initial management strategy in patients with mantle cell lymphoma. Ann Oncol 2017;28:2489-95.

5. Martin P, Chadburn A, Christos P, et al. Outcome of deferred initial therapy in mantle-cell lymphoma. J Clin Oncol 2009;27:1209-13.

6. Mbulaiteye SM, Pullarkat ST, Nathwani BN, et al. Epstein-Barr virus patterns in US Burkitt lymphoma tumors from the SEER residual tissue repository during 1979-2009. APMIS 2014;122:5-15.

7. Magrath I. The pathogenesis of Burkitt's lymphoma. Adv Cancer Res 1990;55:133-270.

8. Dalldorf G. Lymphomas of African children with different forms or environmental influences. JAMA 1962;181:1026-8.

9. Ziegler JL, Beckstead JA, Volberding PA, et al. NonHodgkin's lymphoma in 90 homosexual men. Relation to generalized lymphadenopathy and the acquired immunodeficiency syndrome. N Engl J Med 1984;311:565-70.

10. Ziegler JL, Drew WL, Miner RC, et al. Outbreak of Burkitt's-like lymphoma in homosexual men. Lancet 1982;2:631-3.

11. Wiggill TM, Mantina H, Willem P, et al. Changing pattern of lymphoma subgroups at a tertiary academic complex in a high-prevalence HIV setting: a South African perspective. J Acquir Immune Defic Syndr 2011;56:460-6.

12. Cheson BD, Fisher RI, Barrington SF, et al. Recommendations for initial evaluation, staging, and response assessment of Hodgkin and non-Hodgkin lymphoma: the Lugano classification. J Clin Oncol 2014;32:3059-68,.

13. Johnson NA, et al. J Clin Oncol 2012;30:3452-9.

14. Linee Guida Linfomi, AIOM, edizione ottobre 2017.

15. Hoster et al. Blood 2008;111:558-565.

16. Guppy AE, Tebbutt NC, Norman A, et al. The role of surveillance CT scans in patients with diffuse large B-cell non-Hodgkin's lymphoma. Leuk Lymphoma 2003;44:123-5.

17. Liedtke M, Hamlin PA, Moskowitz CH, et al. Surveillance imaging during remission identifies a group of patients with more favorable aggressive NHL at time of relapse: a retrospective analysis of a uniformlytreated patient population. Ann Oncol 2006;17:909913.

18. El-Galaly TC, Mylam KJ, Bogsted M, et al. Role of routine imaging in detecting recurrent lymphoma: A review of 258 patients with relapsed aggressive nonHodgkin and Hodgkin lymphoma. Am J Hematol 2014;89:575-80.

19. Zinzani PL, Stefoni V, Tani M, et al. Role of [18F]fluorodeoxyglucose positron emission tomography scan in the follow-up of lymphoma. J Clin Oncol 2009;27:1781-7.

20. Avivi I, Zilberlicht A, Dann EJ, et al. Strikingly high false positivity of surveillance FDG-PET/CT scanning among patients with diffuse large cell lymphoma in the rituximab era. Am J Hematol 2013;88:400-5.

21. Tilly H, Vitolo U, Walewski J, et al. Diffuse large Bcell lymphoma (DLBCL): ESMO Clinical Practice Guidelines for diagnosis, treatment and follow-up. Ann Oncol 2012;23:vii78-82.

22. Engels EA, Biggar RJ, Hall HI, et al. Cancer risk in people infected with human immunodeficiency virus in the United States. Int J Cancer 2008;123:187-94.

23. Vaccher E, Spina M, Talamini R, et al. Improvement of systemic human immunodeficiency virus- related non-Hodgkin lymphoma outcome in the era of highly active antiretroviral therapy. Clin Infect Dis 2003;37:1556-64.

24. Spina M, Simonelli C, Talamini R, et al. Patients with HIV with Burkitt's lymphoma have a worse outcome than those with diffuse large-cell lymphoma also in the highly active antiretroviral therapy era [Internet]. J Clin Oncol 2005;23:8132-3-4.

25. Gabarre J, Gisselbrecht C, et al. Phase II trial of CHOP plus rituximab in patients with HIV-associated non-Hodgkin's lymphoma. J Clin Oncol 2006;24: 4123-8.

26. Ribera JM, Oriol A, Morgades M, et al. Safety and efficacy of cyclophosphamide, adriamycin, vincristine, prednisone and rituximab in patients with human immunodeficiency virus-associated diffuse large B-cell lymphoma: results of a phase II trial. Br J Haematol 2008;140:411-9.

27. Wang ES, Straus DJ, Teruya-Feldstein J, et al. Intensive chemotherapy with cyclophosphamide, doxorubicin, high-dose methotrexate/ifosfamide, etoposide, and high-dose cytarabine (CODOX-M/IVAC) for human immunodeficiency virus-associated Burkitt lymphoma [Internet]. Cancer 2003;98:1196-205.

28. Oriol A, Ribera JM, Bergua J, et al. High-dose chemotherapy and immunotherapy in adult Burkitt lymphoma: comparison of results in human immunodeficiency virus-infected and noninfected patients. Cancer 2008;113:117-25.

29. Re A, Cattaneo C, Michieli M, et al. High-dose therapy and autologous peripheral-blood stem-cell transplantation as salvage treatment for HIV-associated 
lymphoma in patients receiving highly active antiretroviral therapy. J Clin Oncol 2003;21:4423-7.

30. Balsalobre P, Diez-Martin JL, Re A, et al. Autologous stem-cell transplantation in patients with HIV-related lymphoma. J Clin Oncol 2009;27:2192-8.
31. Diez-Martin JL, Balsalobre P, Re A, et al. Comparable survival between HIV+ and HIV- non-Hodgkin and Hodgkin lymphoma patients undergoing autologous peripheral blood stem cell transplantation. Blood 2009;113:6011-4. 


\section{L'emofilia A acquisita}

Giovanni Andrea Berisso

SC Medicina Interna II, ASL 5 Spezzino, La Spezia, Italia

\section{Introduzione}

L'emofilia A acquisita è una coagulopatia rara, caratterizzata dall'insorgenza improvvisa di sanguinamenti, spontanei o dopo chirurgia o trauma, generalmente severi (87\% dei casi) e spesso fatali (8-22\%). ${ }^{1}$

La deplezione del fattore VIII e meno frequentemente del fattore IX è mediata da specifici autoanticorpi, diretti contro epitopi funzionali.

Ciò neutralizza il Fattore VII e/o accelera la sua clearance dal plasma.

L'incidenza dell'emofilia acquisita (EA) varia da 0.1 a 1 per milione di popolazione/anno, sebbene sia possibile che non tutti gli affetti vengano inclusi nelle casistiche pubblicate. ${ }^{1,2}$

L'età mediana alla presentazione è di 65 anni, e la sua frequenza aumenta con l'età dopo i 50 anni, con uguale distribuzione tra i 2 sessi. Fa eccezione il gruppo dei giovani, dove predominano le femmine dopo la gravidanza. ${ }^{3}$

L'emofilia A acquisita è comunemente associata con una variabilità di condizioni cliniche: malattie autoimmuni sistemiche (lupus eritematoso sistemico, artrite reumatoide, asma), tumori solidi, malattie linfoproliferative, ipersensibilità ai farmaci e gravidanza, ma nel $50 \%$ dei casi è idiopatica. ${ }^{4,5}$

La gravidanza è una condizione concomitante frequente, e in generale l'inibitore si sviluppa durante la prima gravidanza e non recidiva, sebbene la recidiva nelle gravidanze successive sia riportata in alcune casistiche. ${ }^{6,7}$

Dal 5 al 15\% di questi pazienti, hanno concomitanti neoplasie maligne; tre volte più frequenti nei

Corrispondente: Giovanni Andrea Berisso, SC Medicina Interna II, ASL 5 Spezzino, La Spezia, Italia.

E-mail: giovanni.berisso@as15.liguria.it

Articolo pubblicato secondo la Creative Commons Attribution NonCommercial 4.0 License (CC BY-NC 4.0).

(C) Copyright G.A. Berisso, 2019

Licensee PAGEPress, Italy

QUADERNI - Italian Journal of Medicine 2019; 7(1):23-28 maschi che nelle femmine, senza una precisa relazione con il tipo di neoplasia, sebbene la EA sia più comune nei tumori solidi piuttosto che nelle sindromi linfoproliferative.

La terapia tumore-specifica non è associata con la scomparsa dell'inibitore. ${ }^{8}$

Se la terapia è efficace, è comunque più verosimile la scomparsa di bassi titoli di inibitore a fronte di alti titoli.

La diagnosi di EA è suggerita dall'aspetto clinico e confermata dai test di laboratorio.

Comunemente, un sanguinamento severo o un diffuso spandimento emorragico si verificano spontaneamente o dopo un trauma minore o dopo una procedura invasiva (posizionamento di un catetere venoso centrale, chirurgia minore, iniezioni intramuscolari). ${ }^{8}$

Un registro europeo di questi casi è stato creato con lo scopo di raccogliere informazioni sulle caratteristiche cliniche, gli algoritmi diagnostici e le strategie terapeutiche nei diversi paesi europei per standardizzare il trattamento di questi pazienti.

Le sedi comuni di sanguinamento sono la cute (grandi ecchimosi), le mucose (epistassi, gengivorragia, metrorragia) e i muscoli; gli emartri sono rari.

Se il sanguinamento si verifica in sedi critiche, il problema della compressione si fa grave.

L'emorragia retroperitoneale è comune e, se si verifica, può essere fatale.

Un allungamento dell'aPTT non corretto dalla incubazione con plasma normale, in presenza di un normale tempo di protrombina, può essere il cardine della diagnosi laboratoristica. La presenza di un Lupus Anticoagulant (LA) o di eparina nel plasma devono essere escluse. La presenza di eparina è suggerita da un aPTT allungato con un normale tempo di reptilase.

La diagnosi è confermata dal dosaggio specifico del fattore e dal dosaggio dell'inibitore (Figura 1).

Il titolo dell'inibitore correla scarsamente con gli aspetti clinici, per cui è di minore utilità nel guidare la terapia piuttosto che nei pazienti con emofilia congenita portatori di inibitori. ${ }^{9}$

La mortalità è alta con la maggioranza di decessi entro le prime settimane dalla presentazione. L'elevato tasso di mortalità potrebbe anche correlare con errate procedure invasive (nel Registro Italiano Emofilia Acquisita [RIEA], 1/3 degli eventi mortali si verifica 
dopo un atto chirurgico) condotte per controllare l'emorragia, oppure ad un ritardo diagnostico, oppure ad una inadeguata terapia sostitutiva. ${ }^{10}$

\section{Manifestazioni cliniche}

La forma classica di emofilia (EC) esita in una tendenza congenita al sanguinamento associata a livelli ridotti di fattore VIII o IX, ed è ereditata con un meccanismo legato al sesso.

Per contro, 1'emofilia acquisita (EA) è un disordine acquisito della mezza età che si verifica in ambo i sessi. Il pattern di sanguinamento visto nella EA è completamente distinto da quello visto nella forma congenita.

Il versamento ematico intraarticolare (emartro), che caratterizza la severa emofilia congenita, è inusuale nella emofilia acquisita, dove le principali manifestazioni interessano la cute e i tessuti molli.

Gli aspetti più rimarchevoli sono i sanguinamenti cutanei profusi.

Ematomi retroperitoneali, sanguinamenti gastrointestinali ed urologici sono caratteristici. Il sanguina- mento intrafasciale ed intramuscolare può evolvere rapidamente in una sindrome compartimentale. Altre manifestazioni cliniche comprendono un sanguinamento uterino profuso del post-parto ed un sanguinamento eccessivo dopo traumi o terapie chirurgiche. ${ }^{10}$

\section{Immunopatogenesi}

Data la possibilità della presenza di anticorpi anti fattore VIII in situazioni cliniche diverse, è possibile pertanto distinguere: i) alloanticorpi, o isoanticorpi: sono gli anticorpi inibitori dell'attività procoagulante dei fattori della coagulazione in carenti congeniti; ii) autoanticorpi inibitori: sono anticorpi inibitori dell'attività procoagulante dei fattori della coagulazione che insorgono in soggetti non affetti da carenze congenite di fattori della coagulazione.

Gli alloanticorpi possono reagire con una gran varietà di determinanti antigenici; essi sono in genere policlonali, e quelli diretti contro il fattore VIII reagiscono prevalentemente con epitomi delle regioni omologhe A2 e C2 e raramente della catena leggera all'esterno della regione $\mathrm{C} 2$. Gli anticorpi diretti con-

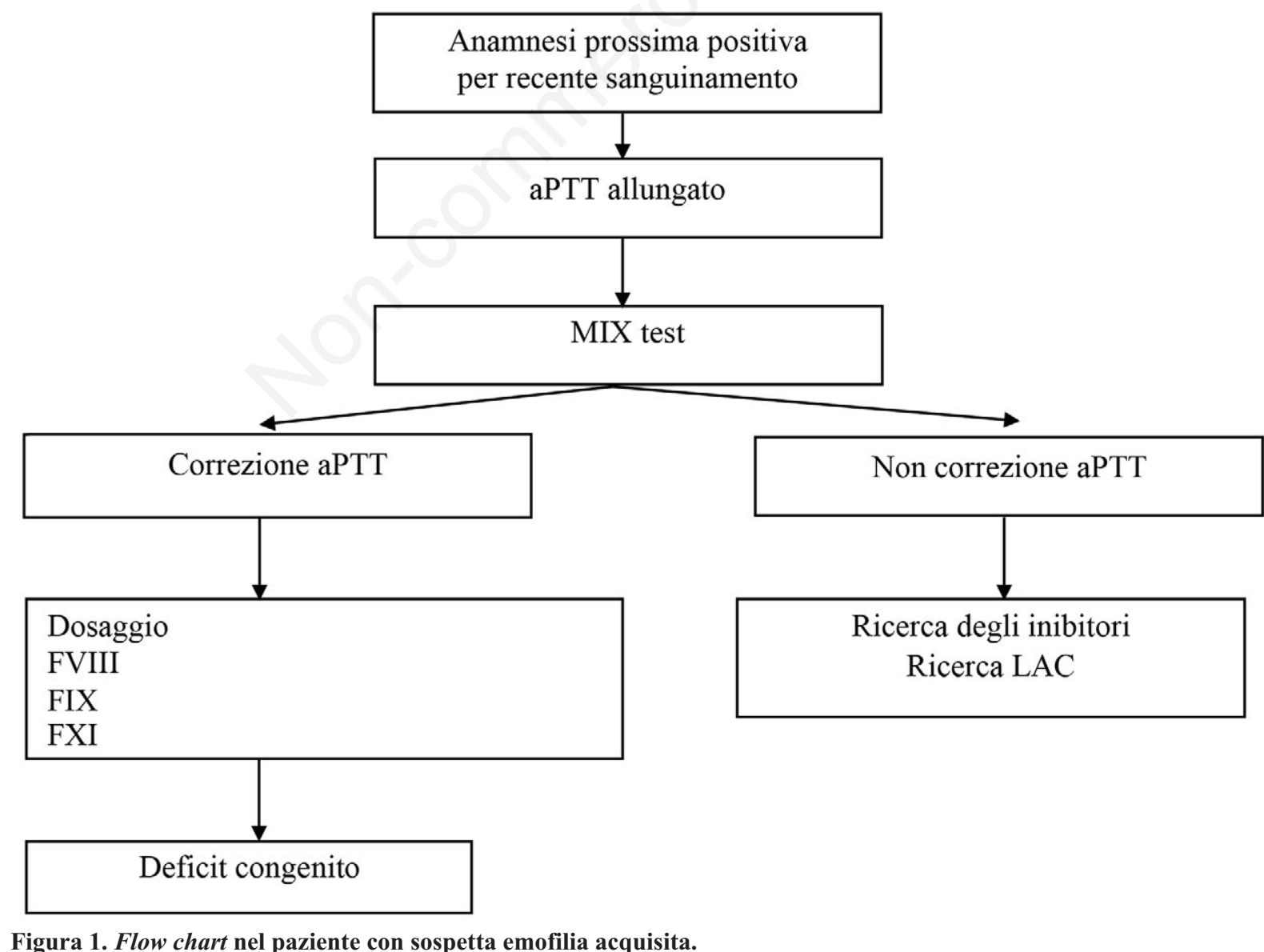

Figura 1. Flow chart nel paziente con sospetta emofilia acquisita. 
tro la regione $\mathrm{A} 2$ inibiscono la normale funzione del complesso di attivazione del fattore $\mathrm{X}$, mentre quelli diretti contro la regione $\mathrm{C} 2$ prevengono il legame del FVIII ai fosfolipidi ed al fattore di von Willebrand.

Gli alloanticorpi inibitori hanno tipicamente, anche se in modo non esclusivo, una cinetica di primo ordine o lineare. In pratica, inattivano il fattore progressivamente e proporzionalmente al loro titolo.

Gli autoanticorpi inibitori sono oligo- o poli-clonali, soprattutto $\mathrm{IgG}$, generalmente $\mathrm{IgG} 4$ con catene leggere Kappa o Lambda. L'attività procoagulante del Fattore VIII: C è neutralizzata dal legame dell'inibitore, il che è espresso da una ridotta attività coagulativa del Fattore VIII-CC.

Gli epitopi specifici verso cui sono diretti gli autoanticorpi della emofilia A acquisita sono diversi da quelli degli alloanticorpi che vengono sviluppati nei pazienti affetti da emofilia A in terapia sostitutiva.

Gli inibitori predominanti nella maggior parte dei campioni di plasma sono diretti contro i domini $\mathrm{C} 2 \mathrm{o}$ A2 (ma non contro entrambi) della molecola del fattore VIII, in contrasto con gli inibitori che si sviluppano nella emofilia congenita, dove questo pattern si mostra solo nel $15 \%$. Inoltre, gli inibitori anti A2 sono ritrovati nel plasma dell' $1 \%$ dei pazienti emofilici, ma solo nel 33\% dei pazienti con autoanticorpi.

È possibile che i meccanismi di inibizione che si verificano siano diversi.

Per esempio, questi autoanticorpi che si legano alla regione delle catene leggere inibiscono le interazioni fattore VIII-Fosfolipidi.

Altri possibili meccanismi considerati implicati nella patogenesi sono: i) un ridotto clivaggio indotto dalla trombina del fattore VIII; ii) un'aumentata clearance del fattore VIII dal torrente circolatorio; iii) un'alterata interazione con altri fattori emocoagulativi; iv) un'alterata interazione con il fattore von Willebrand.

Gli autoanticorpi, rispetto agli alloanticorpi, hanno usualmente una cinetica più complessa (di secondo ordine o esponenziale) con rapida attivazione iniziale, seguita da una fase più lenta o una fase di equilibrio, in cui l'attività del fattore può essere ancora misurata.

Più raramente possono avere una cinetica di primo ordine. $^{10}$

\section{Diagnosi di autoanticorpi inibitori}

Un inibitore anti fattore VIII acquisito (autoanticorpo) deve essere sospettato in presenza di emorragie ad inizio improvviso spesso gravi, che possono insorgere spontaneamente o dopo traumi minori o dopo procedure invasive (posizionamento di cateteri venosi centrali, indagini endoscopiche, prelievi arteriosi, iniezioni intramuscolari) o interventi chirurgici in pazienti con storia personale e familiare negativa per emorragie. $^{9}$
Il tempo di tromboplastina parziale attivato (aPTT) allungato, non corretto dal plasma normale (test di miscela) con un tempo di protrombina normale sono i cardini diagnostici di laboratorio.

L'aPTT della miscela del plasma del paziente con plasma normale deve essere eseguita prima e dopo l'incubazione a $37^{\circ}$ per 2 ore perché l'inattivazione del fattore VIII è correlata al tempo ed alla temperatura (questo metodo però potrebbe non evidenziare inibitori con cinetica complessa o lenti, tempo-dipendenti, dato il breve tempo di incubazione, oppure inibitori presenti a titolo molto basso, inferiore alla sensibilità del metodo).

Il dosaggio dell'inibitore con metodo Bethesda ne confermerà la presenza.

Deve essere esclusa la presenza di eparina e dell'inibitore di tipo lupico. La presenza dell'eparina è suggerita dall'allungamento del tempo di trombina con normale tempo di reptilase.

Valori di aPTT della miscela plasma paziente/plasma normale sovrapponibili al tempo 0 e dopo incubazione sono suggestivi di Lupus-anticoagulant. ${ }^{9}$

\section{Trattamento degli autoanticorpi inibitori}

La presenza di autoanticorpi contro i fattori della coagulazione è una situazione ad alto rischio emorragico e quindi necessita di un intervento immediato allo scopo di eradicare l'autoanticorpo. ${ }^{11}$

Presupposto per l'eradicazione dell'inibitore e per una corretta diagnosi del paziente è la ricerca di una patologia primitiva associata, la valutazione dell'assunzione acuta o cronica di farmaci, il riscontro di un parto recente (o di un'interruzione di gravidanza). Tuttavia è necessario ricordare che il $40-50 \%$ dei casi sono da causa sconosciuta.

Il trattamento si basa sulla terapia immunosoppressiva. ${ }^{11}$ Scopo della terapia immunosoppressiva è la neutralizzazione degli autoanticorpi e l'inibizione o l'eliminazione del clone cellulare responsabile della loro sintesi.

I farmaci usati sono il prednisone, la ciclofosfamide, l'azatioprina, la vincrisitina, la ciclosporina A, le immunoglobuline ad alte dosi somministrate in monoterapia o in diverse combinazioni. ${ }^{11,12}$ Non sono presenti studi prospettici controllati per confrontare l'efficacia delle diverse modalità terapeutiche anche a causa delle possibili remissioni spontanee (casi pediatrici o associati alla gravidanza o a farmaci). La plasmaferesi e l'immunoadsorbimento su proteina A sono state utilizzate in situazioni cliniche particolari come ad esempio in chirurgia. ${ }^{13}$

Fattori predittivi per la risposta sono un basso livello di inibitore e un breve intervallo di tempo tra comparsa di inibitore ed inizio di terapia immunosoppressiva. Nel $30 \%$ dei casi tuttavia l'autoanticorpo può 
scomparire spontaneamente, evento non prevedibile, più frequente dopo parto o assunzione di farmaci. Differenti strategie possono essere impiegate per i differenti sottogruppi di pazienti. ${ }^{10-14}$

Un approccio watch \& wait può essere indicato nei bambini e nei casi associati alla gravidanza ed alla assunzione di farmaci. Una terapia combinata è indicata nei casi idiopatici od associati a malattie autoimmuni. Tuttavia, per il rischio emorragico legato all'anticorpo, il trattamento si impone in presenza di una sintomatologia emorragica e quando l'inibitore persiste nel tempo, anche se la sintomatologia non è rilevante.

Vari studi prospettici, uno dei quali randomizzato, hanno mostrato che la terapia steroidea rappresenta il presidio di prima scelta. ${ }^{12}$ È possibile infatti ottenere una risposta positiva in un terzo dei casi entro le prime tre settimane di trattamento, con possibilità di incrementare la risposta ad oltre il $70 \%$ protraendo la terapia stessa. Le ricadute dopo la sospensione del prednisone sono possibili. Il dosaggio utilizzato è 1-2 $\mathrm{mg} / \mathrm{kg} /$ die per almeno tre settimane, modulando successivamente la dose in base alla risposta terapeutica.

La Ciclofosfamide è stata valutata in studi randomizzati e non, associata al prednisone, mostrando un'elevata percentuale di remissioni complete (superiori al $50-70 \%$ ) e continue, anche in pazienti inizialmente refrattari al cortisone. Potrebbe costituire il trattamento di prima scelta, associata ai cortisonici, in casi selezionati, oppure di seconda scelta, dopo una mancata risposta iniziale ai soli cortisonici. Il dosaggio iniziale è $2 \mathrm{mg} / \mathrm{kg} /$ die per os per 3-6 settimane o fino a remissione completa, modulando le dosi in base alla tolleranza ematologica.

Le immunoglobuline ad alte dosi (HDIg) possono ridurre il titolo o determinare la scomparsa dell'inibitore nel $12-30 \%$ dei casi. Però questa terapia, ad alto costo e non esente dai rischi di insufficienza renale acuta, non dovrebbe essere considerata di prima scelta, ma piuttosto di seconda, dopo un iniziale fallimento dei corticosteroidi e/o della ciclofosfamide e prima di iniziare una immunosoppressione più aggressiva. ${ }^{15}$ Una risposta positiva è stata osservata entro 24-48 h, talora più tardivamente dopo settimane $\mathrm{o}$ anche mesi dalla sospensione delle HDIg, alla dose di 400 $\mathrm{mg} / \mathrm{kg} /$ die per 4 giorni o di $1 \mathrm{~g} /$ die per 2 giorni.

Risultati promettenti sono stati ottenuti anche con Ciclosporina, 2-Clorodesossiadenosina e interferone alfa. Sempre maggiori evidenze si stanno ottenendo sull'efficacia degli anticorpi monoclonali anti CD 20 (rituximab) in particolare in pazienti con titoli relativamente bassi, resistenti ad altri trattamenti, con una modesta tossicità, tale che il loro uso è stato suggerito in pazienti gravi, che non rispondono alla terapia standard o nei quali la terapia citotossica non è indicata. ${ }^{15}$

Ciononostante, molti aspetti di questo trattamento restano da accertare quali la dose ottimale, il mecca- nismo d'azione e gli effetti collaterali a lungo termine.

L'immunotolleranza è stata raramente impiegata nella emofilia A acquisita. La sua efficacia e sicurezza è dimostrata nel protocollo Budapest: FVIII umano 30 $\mathrm{UI} / \mathrm{kg} /$ die per la prima settimana; $20 \mathrm{UI} / \mathrm{Kg} /$ die la seconda e $15 \mathrm{UI} / \mathrm{kg} / \mathrm{die}$ per la terza combinato con $\mathrm{Ci}$ clofosfamide $200 \mathrm{mg}$ /die ev (dose totale 2-3 g) e metilprednisolone ev $(100 \mathrm{mg} /$ die la prima settimana e graduale diminuzione nelle successive due settimane). Una remissione completa e stabile è stata riportata in più del $90 \%$ dei pazienti. Risultati simili sono stati riportati dal gruppo di Heidelberg con il protocollo Malmo modificato (immunoadsorbimento, alte dosi di FVIII, Ciclofosfamide e steroidi). ${ }^{10}$

\section{Trattamento e prevenzione delle emorragie}

I principali criteri di scelta della terapia antiemorragica sono: i) la gravità del difetto di fattore della coagulazione; ii) le caratteristiche dell'inibitore; iii) sede ed entità dell'emorragia.

Infatti, il trattamento del paziente con emofilia da inibitori acquisiti dei fattori della coagulazione cosisterebbe nell'ottenere e mantenere livelli efficaci emostaticamente del fattore carente, obiettivo di cruciale importanza in presenza di emorragie di particolare gravità, ma spesso irraggiungibile per l'attività inibitoria dell'anticorpo.

La presenza dell'anticorpo inibitore deve quindi essere saturata inizialmente da una dose neutralizzante, cui andrebbe aggiunta una dose incrementante seguita da dosi di mantenimento ripetute ad intervalli più $o$ meno brevi, oppure da una infusione continua, al fine di raggiungere e mantenere i livelli ematici prescelti.

Sulla base dell'esperienza italiana, la scelta della dose neutralizzante si basa sul calcolo di quanto fattore infuso è inattivato dall' anticorpo, secondo la formula: titolo dell'inibitore in $\mathrm{BU}$ x $40 \mathrm{x} \mathrm{kg}$ di peso corporeo.

La dose incrementante è rappresentata dalla dose necessaria per raggiungere livelli circolanti di fattore efficaci per il trattamento dell'episodio emorragico. Questo normalmente oscilla tra 20 e $50 \mathrm{UI} / \mathrm{kg}$ peso in rapporto alla gravità della emorragia.

A questa seguiranno dosi di mantenimento costituite dalla stessa dose incrementante, ripetuta ogni 6$8-12$ ore, aggiustata per mantenere livelli minimi emostatici. ${ }^{16}$

Nei pazienti con autoanticorpi anti fattore VIII con fattore VIII dosabile si può impiegare la DDAVP (desmopressina) per elevare a livelli emostatici il FVIII senza induzione di una risposta; da ricordare il rischio di tachifilassi recettoriale (scomparsa della risposta alla desmopressina dopo infusione di più dosi) e la ritenzione idrica. ${ }^{16}$

Quando non sia possibile o non sia indicato il trat- 
tamento sostitutivo con il fattore carente a dosi neutralizzanti, è necessario ricorrere ad agenti che saltano il difetto acquisito di FVIII attivando la coagulazione. I più conosciuti e studiati agenti bypassanti sono il Fattore VIII ricombinante (NovoSeven) e il complesso protrombinico attivato (APC) (FEIBA).

Non ci sono studi comparativi che possano indicare la maggiore efficacia di uno dei due prodotti rispetto all'altro o dimostrarne l'equivalenza.

L'utilizzo di agenti bypassanti è indicato nei pazienti con elevati livelli di inibitori acquisiti per qualsiasi gravità di emorragia. ${ }^{17,18}$

L'associazione di agenti antifibrinolitici è sconsigliata in concomitanza dell'uso di concentrati dei fattori del complesso protrombinico attivato, per il rischio di eventi tromboembolici. Può essere utilizzata con successo in associazione al trattamento con FVIII attivato ricombinante. ${ }^{18}$

In condizioni cliniche di particolare gravità o in caso di insuccesso degli agenti bypassanti, l'immunoadsorbimento extracorporeo dell'inibitore alla proteina A stafilococcica o a resine è in grado di ridurre il titolo dell'inibitore a livelli $(5-10 \mathrm{BU} / \mathrm{mL})$ compatibili alla sua neutralizzazione con il FVIII, seppure temporaneamente, in associazione o meno con immunosoppressori (ciclofosfamide) e/o immunoglobuline endovena ad alto dosaggio.

L'elemento limitante è rappresentato dalla necessità di accessi vascolari (almeno 2) con alta portata, non sempre disponibili e la necessità spesso di ripetere l'immunoadsorbimento per più giorni consecutivi.

Il FVII attivato ricombinante, prodotto con tecniche di ingegneria genetica e privo del rischio di infezioni trasmissibili con il sangue, alle dosi di 90-120 $\mathrm{mg} / \mathrm{kg}$ ogni 4-6 h ha dimostrato in diversi studi la sua efficacia nel 90-95\% degli episodi emorragici moderati o lievi, con ripresa del sanguinamento nel 2-4\% nelle successive $72 \mathrm{~h}$. L'efficacia è maggiore quando il trattamento è iniziato a $72 \mathrm{~h}$ dall'emorragia.

Il FVIII attivato ricombinante ha dimostrato la sua efficacia anche nel trattamento di episodi emorragici gravi: $62 \%$ negli ematomi muscolari, $76 \%$ nelle emorragie articolari, $80 \%$ nelle emorragie gastroenteriche, $88 \%$ nelle emorragie del sistema nervoso centrale e il $75 \%$ delle emorragie retroperitoneali.

La sicurezza del FVII attivato ricombinante è elevata. Gli eventi avversi più gravi sono quelli tromboembolici. Sono stati riportati complessivamente 116 eventi avversi gravi su oltre 140.000 infusioni calcolate con un tasso dello $0,08 \%$ per dose. Gli eventi avversi più frequentemente riportati sono tromboflebiti, infarto del miocardio seguiti da coagulazione intravascolare disseminata ed eventi cerebrovascolari.

I concentrati del complesso protrombinico attivato (APCC), derivati dal plasma umano e sottoposti ad in attivazione con la tecnica del calore umido (vapore) hanno dimostrato maggiore efficacia nel trattamento di episodi emorragici moderati e lievi rispetto agli altri fattori non attivati: $52 \%$ degli episodi erano risolti con singola infusione; $64-91 \%$ con infusioni fino a 3 o più, a dosaggi di $50 \mathrm{UI} / \mathrm{Kg}$ o superiori.

Gli agenti antifibrinolitici mostrano una scarsa efficacia nel trattamento degli episodi emorragici quando usati da soli, con l'unica eccezione delle emorragie della bocca. In questi casi, l'utilizzo di acido tranexamico alla dose di $1 \mathrm{~g}$ per os si sono rivelati altamente efficaci.

Gli agenti antifibrinolitici sono controindicati in caso di ematuria, per il rischio di formazione di grossi coaguli a livello ureterale o vescicole, o di una coagulazione intratubulare. Controverso è il loro uso nelle emorragie sub aracnoidee. ${ }^{16-18}$

\section{Bibliografia}

1. Green D, et al. Survey of 215 patients with inhibitors to fator VII. Thromb. Haemost. 1981;45:200-3.

2. Morrison AE, et al. Acquired Haemophilia and its treatment. Haematol 1995;89:213-6.

3. Lottenberg R, et al. Acquired Haemophilia A; Natural History study of 16 patients with factor VIII Inhibitors receiving little or no therapy. Arch. Int. Med 1987;147: 1077-81.

4. Baudo F, et al. Acquired VIII factor and fator IX inhibitors: survey of Italian Haemophlia Centers (AICE). Haematologica 2003; 88 Suppl. 12;93-9.

5. Ludlam CA, et al. Treatment of acquired haemophilia. Semin. Haematol.1994;41 Suppl 4;16-9.

6. Postpartum Factor VIII inhibitors. A review of the literature with special reference to the value of steroid and immunosuppressive therapy. Thromb. Haemost 1995; 73:1-5.

7. Baudo F, et al. Acquired Factor VIII Inhibitors in pregnancy. Data from the Italian haemophilia register relevant to clinical practice. BR. J. Obst. Gynaecol. 2003; 110:1-4.

8. Sallah $\mathrm{S}$, et al. Inhibitors against factor VII in patients with cancer. Cancer 2001;91:1067-74.

9. Vermylen J, et al. How do some haemophiliac develop in hibitors? Haemophilia 1998;4(4):538-42.

10. Zakarija A, et al. Acquired Haemopilia: diagnosis and management. Curr Haematol. Rep. 2002;1(1):27-33.

11. Lian EC, et al. Combination Immunosoppressive therapy after FVIII infusion for FVIII inhibitors. Ann. Int. Med 1989;95:575.

12. Shaffer LG, et al. Successful treatment of acquired haemophlia A with oral immunosuppressive therapy; Ann. Int. Med. 1997;127(3):206-9.

13. Delgado J, et al. Acquired haemophilia: a single-center survey with emphasis on immunotherapy and treatmentrelated side-effects. Eur. J. Haematol. 2002;69(3).

14. Petrovic M, et al. Cyclosporine treatment of acquired haemophilia due to factor VIII antibodies. 200;85(8) 895-6.

15. Wiestner A, et al. Rituximab in the treatment of acquired factor VIII inhibitors. Blood 2002;100(9): 3246-8. 
16. Kulkarni R, et al. Successful treatment of high titer inhibitors in mild haemophlia A with avoidance of factor VIII and Immunosoppressive therapy. Am. J. Haematol. 2001;68(3):184-8.

17. Hind D, et al. Recombinant Factor VII concentrate versus plasma derived concentrates for the treatment of acute bleeding episodes in people with haemophilia A and inhibitors. Cochrane database syst.rev 2004(2):CD 004449 .

18. Lusher JM. Recombinant factor VII in treatment of internal bleeding in patients with factor VIIII and IX inhibitors. Haemostasis 1996;26 (suppl.1):124-130. 


\title{
La gestione delle complicanze acute del paziente con mieloma multiplo
}

\author{
Riccardo Goretti \\ SC Medicina Interna, Ospedale Santa Corona, ASL 2 Savonese, Savona, Italia
}

\section{Introduzione}

Il mieloma multiplo $(\mathrm{MM})$ è una neoplasia caratterizzata dalla patologica proliferazione clonale di linfociti B e plasmacellule nel midollo osseo con conseguente abnorme produzione di immunoglobuline (Ig) o frazioni di Ig monoclonali, danno renale, aumento della viscosità plasmatica, alterazione dell'emopoiesi, attivazione degli osteoclasti con distruzione del tessuto osseo e rilascio di calcio, riduzione della normale funzione immunitaria e aumentata predisposizione alle infezioni.

Rappresenta poco più dell' $1 \%$ delle nuove diagnosi di cancro e circa il $17 \%$ di tutte le neoplasie ematologiche con un trend in incremento. ${ }^{1}$

È una malattia dell'anziano: l'età media alla diagnosi è di 70 anni, meno del $5 \%$ dei casi viene diagnosticato prima dei 50 anni.

Le manifestazioni del mieloma sintomatico sono sintetizzate nell'acronimo CRAB: i) $\mathrm{C}=$ calcemia: calcio $>1 \mathrm{mg} / \mathrm{dL}$ del valore normale oppure $>11 \mathrm{mg}$; ii) $\mathrm{R}=$ rene: clearance della creatinina $<40 \mathrm{~mL}$ o creatinina $>2 \mathrm{mg}$; iii) $\mathrm{A}=$ anemia: $\mathrm{Hb}<2 \mathrm{~g} / \mathrm{dL}$ del valore normale $\mathrm{o}<10 \mathrm{~g} / \mathrm{dL}$; iv) $\mathrm{B}=\mathrm{osso}$ (bone): 1 o più lesioni osteolitiche rilevate con Rx scheletro, TC o TCPET.

La malattia conclamata è sempre virtualmente preceduta da una fase asintomatica, clinicamente indolente. ${ }^{2}$ L'evento oncogeno sembra colpire il linfocita B a livello del centro germinativo probabilmente durante il processo di switch isotipico di classe o di mutazione ipersomatica. La progressione neoplastica

Corrispondente: Riccardo Goretti, SC Medicina Interna, Ospedale Santa Corona, ASL 2 Savonese, Savona, Italia. E-mail: r.goretti@asl2.liguria.it

Articolo pubblicato secondo la Creative Commons Attribution NonCommercial 4.0 License (CC BY-NC 4.0).

(C) Copyright R. Goretti, 2019

Licensee PAGEPress, Italy

QUADERNI - Italian Journal of Medicine 2019; 7(1):29-32 viene successivamente favorita sia dall'acquisizione di ulteriori alterazioni genetico-molecolari sia dal contatto con il microambiente midollare. ${ }^{3}$

La proliferazione neoplastica e la produzione di citochine possono compromettere fin dal momento della diagnosi diversi organi con modalità differenti per gravità e velocità di progressione. ${ }^{4}$

\section{Manifestazioni cliniche}

Le più comuni manifestazioni clinico laboratoristiche del mieloma sono rappresentate, in ordine di frequenza e severità da: i) malattia ossea con o senza ipercalcemia; ii) insufficienza renale; iii) anemia; iv) immunodepressione con incremento della morbilità infettiva; v) sindrome da iperviscosità.

\section{La malattia ossea}

La malattia ossea è la maggior causa di morbilità, invalidità e la seconda causa di mortalità dopo le infezioni dei pazienti affetti da MM. Può comprendere osteoporosi, lesioni osteolitiche, fratture patologiche anche con compromissione neurologica (compressione del midollo spinale) e ipercalcemia.

Sia osteoporosi che lesioni litiche possono interessare ogni segmento scheletrico e possono insorgere in ogni fase della malattia.

Sono causa del dolore osseo, il sintomo più frequente e spesso più invalidante del MM.

Interessa il $75 \%$ dei pazienti, il $35 \%$ già alla diagnosi ed è maggiormente frequente nei pazienti in recidiva.

L'IMWG ${ }^{5}$ raccomanda che nel sospetto di mieloma tutti i pazienti vengano sottoposti ad almeno una delle seguenti metodiche per la ricerca della malattia ossea: i) TAC total body a basso dosaggio; ii) TC PET; iii) RNM total body o della colonna intera.

La dimostrazione di una lesione focale con una di queste metodiche soddisfa la definizione di malattia ossea.

Una diffusa captazione alla PET non è sufficiente per porre diagnosi di malattia ossea nel MM. 


\section{Trattamento del dolore nella malattia ossea}

Il trattamento del dolore può, in occasione di manifestazioni particolarmente intense, rappresentare un'emergenza perché non differibile.

Bisogna identificare tempestivamente causa, intensità, durata, tipo e sede del dolore, fattori scatenanti, impatto sulla autonomia e sulla vita sociale.

Si avvale di:

- Trattamento farmacologico, modulato sull'intensità misurata con scala VAS: i) VAS 0-3 paracetamolo e adiuvanti; ii) VAS 4-6 codeina+ paracetamolo, ossicodone+paracetamolo, tramadolo, e adiuvanti; iii) VAS 7-10 fentanil (td), buprenorfina, ossicodone, morfina, idromorfone, metadone e adiuvanti; iv) adiuvanti: antidepressivi anticonvulsivanti, FANS, corticosteroidi.

Raccomandati l'utilizzo di farmaci a lunga emivita con farmaci a rapida azione per il dolore parossistico, es. fentanil td e fentanil sublinguale, e la prevenzione della stipsi.

- Contemporaneamente al trattamento antalgico, la cura del dolore si giova dell'associazione con: i) trattamenti radioterapici; ii) uso dei presidi ortopedici; iii) vertebroplastica; iv) trattamento chirurgico delle fratture; v) trattamento immuno chemioterapico del mieloma.

\section{Trattamento dell'osteoporosi}

La terapia con bifosfonati deve essere somministrata salvo controindicazioni, a tutti i pazienti che intraprendono il trattamento di prima linea indipendentemente dalla presenza di osteolisi e va ripresa in caso di recidiva. ${ }^{6}$

Il trattamento deve essere continuativo ogni 3-4 settimane per almeno 2 anni dall'esordio e con durata personalizzata in caso di recidiva.

I bifosfonati utilizzati e raccomandati dalle linee guida sono l'acido zoledronico ed il pamridonato, con preferenza per il primo, visti gli effetti favorevoli sulla lisi delle cellule neoplastiche e sulla sopravvivenza dimostrati in alcuni lavori. ${ }^{7}$

\section{Trattamento delle fratture}

Nel caso di fratture patologiche è necessario eseguire interventi chirurgici di stabilizzazione delle ossa lunghe e delle vertebre.

\section{Trattamento della compressione midollare}

L'insorgenza di paraplegia, disestesia anestesia o perdita del controllo degli sfinteri è un'emergenza che impone la ricerca di compressione midollare con l'esecuzione TC e/o RMN della colonna urgenti in modo da poter intervenire immediatamente con terapia antiedemigena (Desametasone 12-24 mg ev al dì frazio- nati) e, nell'arco di 12/24 ore, con interventi chirurgici di decompressione (laminectomia e/o stabilizzazione vertebrale). Un ritardo nella decompressione può danneggiare in modo irreversibile il midollo spinale e comprometterne il completo recupero funzionale.

L'intervento chirurgico nella maggior parte dei casi non è in grado di asportare tutto il tessuto patologico intracanalare per cui all'intervento seguirà trattamento radioterapico sui segmenti vertebrali coinvolti.

\section{Trattamento dell'ipercalcemia}

Meno frequente della malattia ossea interessa il 30\% dei casi nel corso dell'intera malattia, con predominanza nelle fasi avanzate. Il calcio extracellulare aumenta per la lisi ossea e la concomitante ridotta clereance del calcio dovuta al progressivo danno tubulare.

Il livello di urgenza ed il tipo di trattamento sono definiti dall'elevato livello del calcio e dalla presenza di sintomi, in genere prevalenti in modo sincrono: i) ipercalcemia lieve $(<12)$ asintomatica. Trattamento: bifosfonati; ii) ipercalcemia moderata (tra 12 e 14 e associata ad astenia, poliuria, nefrocalcinosi). Trattamento: idratazione spinta, diuretici appena corretta la disidratazione, cortisonici a dosaggio medio/elevato, bifosfonati (acido zoledronico maggiormente efficace); iii) ipercalcemia grave (>14 con sintomi neurologici, gastroenterici e cardiaci). Trattamento: monitoraggio parametri, trattamento intensivo e immediato con gli stessi farmaci.

\section{La malattia renale}

È presente all'esordio nel $15-20 \%$ dei casi, coinvolge sino al $40 \%$ dei pazienti nell'arco di tutto il periodo di malattia, almeno un paziente su 50 deve ricorrere al trattamento dialitico.

Il danno renale dipendente dal MM può essere sia tubulare che glomerulare, dovuto alla filtrazione e al riassorbimento delle catene leggere piuttosto che al deposito di sostanza amiloide.

Presentazione:

- Insufficienza renale acuta: rappresenta una delle complicanze più drammatiche del mieloma ed è provocata dall'ostruzione dei tubuli da parte di cilindri contenenti catene leggere (in genere favorita da situazioni concomitanti quali dalla disidratazione, ipercalcemia, danno iatrogeno). ${ }^{8}$

- Insufficienza renale cronica: si osserva nel 15\% dei casi di mieloma al momento della diagnosi; nel $15-20 \%$ di questi casi è severa, con livelli di creatinina sierica maggiori di $2 \mathrm{mg} / \mathrm{dL}$. Spesso coesistono patologie renali indipendenti dal $\mathrm{MM}$ (nefroangiosclerosi, nefropatia diabetica ecc.) che aggravano la compromissione funzionale.

Nei pazienti affetti da mieloma, che hanno solita- 
mente masse muscolari ridotte per via dell'elevato catabolismo, i livelli di creatinina possono non essere rappresentativi del grado di compromissione renale ed è preferibile misurare la velocità di filtrazione glomerulare stimata attraverso la formula di Cockcroft e Gault e secondo MDRD.

Può essere provocata da tutti i meccanismi patologici sopra descritti ed il decorso, così come la prognosi, è fortemente influenzato dall'andamento della malattia di base e dal trattamento.

- Sindrome nefrosica: si sviluppa meno frequentemente, la proteinuria può raggiungere valori elevati, nell'ordine di 10 grammi nelle 24 ore. La sindrome nefrosica del mieloma presenta la caratteristica insolita di essere associata a iperprotidemia, contrariamente alle sindromi nefrosiche di altra causa dove risulta la presenza di ipoprotidemia Anche la presenza di edemi, da ridotta pressione oncotica rilevata a seguito dell'ipoprotidemia, spesso è ridotta.

La possibilità di ottenere una remissione anche parziale del danno renale è aumentata negli ultimi anni, con l'utilizzo dei nuovi farmaci, sino ad arrivare sino al 40-50 dei casi. È ovviamente dipendente dalla gravità dell'insufficienza renale, dalla risposta alle cure e dalla possibilità di aggredire il mieloma in tempi brevi, dalle comorbilità e dal perfomance status del paziente.

\section{Trattamento dell'insufficienza renale acuta}

- Idratazione parenterale con monitoraggio diuresi, parametri cardiocircolatori e di laboratorio;

- associazione con diuretico dell'ansa in boli o infusione continua;

- terapia steroidea a dosaggio intermedio/alto;

- se concomitante alla presenza di malattia attiva, iniziare appena possibile la terapia di salvataggio basata su Desametasone ad alte dosi e Bortezomib più o meno Ciclofosfamide;

- allertare l'emodialisi e posizionare CVC a doppia in caso di instabilità emodinamica e/o iniziale refrattarietà al trattamento medico;

- procedere con emodialisi in caso di gravi alterazioni laboratoristiche, emodinamiche o persistente oligoanuria.

\section{L'anemia}

La proliferazione delle plasmacellule a livello midollare ne compromette la normale attività emopoietica, portando alla riduzione della produzione di globuli rossi e, di conseguenza, a una progressiva anemizzazione. L'astenia è l'espressione più significativa dello stato anemico dei pazienti.

I meccanismi patogenetici che concorrono all'in- staurarsi dello stato anemico sono molteplici: infiltrazione midollare, inibizione dell'eritropoiesi da citochine prodotte dalle plasmacellule neoplastiche, emodiluizione, insufficienza renale, carenza marziale e di cofattori vitaminici.

\section{Trattamento dell'anemia}

- Intraprendere appena possibile il trattamento del mieloma.

- Integrazione marziale e vitaminica.

- Eritropoietina $30.000 \mathrm{U}$ alla settimana.

- Emotrasfusioni.

\section{La sindrome da iperviscosità}

Si può osservare nel 2-3\% dei pazienti.

Si manifesta con astenia, anoressia, vertigini, alterazione del visus, sintomi neurologici (rallentamento, confusione, convulsioni).

L'associazione di elevati livelli di paraproteina con la comparsa di uno o più sintomi pone il sospetto diagnostico.

La conferma si ha ricercando le caratteristiche alterazioni del fondo oculare.

\section{Trattamento della sindrome da iperviscosità}

Emodiluizione, se possibile, in attesa di intraprendere il trattamento specifico del mieloma.

Solo in casi di particolare gravità (alterazioni neurologiche persistenti e rischio di lisi tumorale) si ricorre ad una o più sedute di plasmaferesi prima dell'inizio del trattamento di induzione.

\section{Le infezioni ricorrenti}

L'espansione del clone neoplastico si accompagna alla riduzione delle immunoglobuline normali e i pazienti presentano una significativa immunosoppressione.

Le infezioni sono la prima causa di morte nel mieloma multiplo.

La maggiore suscettibilità alle infezioni è determinata dalle interazioni tra meccanismi patogenetici del $\mathrm{MM}$, dai deficit funzionali correlati all'età e alle comorbilità associati agli effetti della terapia antitumorale. ${ }^{9}$

Complicazioni che incrementano il rischio di infezione: i) insufficienza renale (cast nephropathy, nefropatia da depositi, ipercalcemia, farmaci); ii) insufficienza respiratoria (fratture vertebrali, farmaci, allettamento); iii) depositi amiloide multiorgano; iv) mucosite (terapia, graft); v) iperglicemia.

La stratificazione dei pazienti per rischio infettivo, oltre a valutare le caratteristiche del paziente (età, condizioni generali, capacità funzionali, comorbilità, vita di relazione), della malattia (stadio, loca- 
lizzazioni, complicazioni) dei farmaci usati o da usare, deve considerare la fase della malattia: esordio, induzione, remissione mantenimento, ricaduta, resistenza. ${ }^{10} \mathrm{Il}$ tipo di infezione può essere sostenuto da patogeni differenti con impatto sulla prognosi, sui trattamenti e profilassi.

\section{Profilassi delle infezioni}

Basata su periodo di malattia, tipo di terapia, storia del paziente. Sicuramente validate: i) anti oneumocisti C: cotrimossazolo per pazienti a lungo esposti a farmaci immunodepressivi; ii) anti HSV e VZV: Acyclovir, Talavir se infezioni ricorrenti, $\mathrm{CD} 4<50$, terapia con Bortezomib; ${ }^{11}$ iii) profilassi per CMV e Aspergillus solo in base a monitoraggio dell'antigenemia in pazienti pesantemente trattati; iv) vaccinazioni: anti influenzale: raccomandata da più linee guida, lavori dimostrano $20 \%$ pazienti immunizzati, riduzione infezioni, ricoveri e mortalità. ${ }^{12}$ Raccomandata anche ai familiari dei riceventi allotrapianto; anti pneumococcico e anti Haemophilus I. È raccomandato nei riceventi auto e allotrapianto di midollo. ${ }^{13}$

\section{Trattamento delle infezioni}

\section{Basso rischio:}

i) piperacillina/tazobactam;

ii) efepime o ceftazidime;

iii) ceftriaxone;

iv) levofloxacina (OS);

v) ciprofloxacina + amoxicillina/ac. clavulanico (OS). Alto rischio:

i) cefepime o ceftazidime \pm amikacina;

ii) carbapenemico; iii) ceftriaxone + amikacina.

Se correlabile a catetere venoso centrale: associare vancomicina.

Se sintomatologia addominale: associare metronidazolo.

Se persistenza febbre dopo 48-72 ore e colture negative o TC compatibile: terapia antifungina empirica.

\section{Bibliografia}

1. Siegel R, Miller KD, Jemal A. Cancer statistics. Cancer J Clin 2016;66:7-30.

2. Kyle RA, Therneau TM, Rajkumar SV, et al. Prevalence of monoclonal gammopaty of undetermined significance. N Engl J Med 2006;354:1362-9.

3. Bianchi G, Munshi NC. Pathogenesis beyond de cancer clone in a multiple myeloma. Blood 2015;125:3049-58.

4. Kyle RA, Gertz MA, Witzig TE, et al. Review of 1027 patients with newly diagnosed MM. Mayo Clinic Proc 2003;78:21-33.

5. Rajkumar SV, Dimopoulos MA, Palumbo A, et al. IMWG updated criteria for the diagnosis of multiple myeloma. Lancet Oncol 2014;15:538-48.

6. Terpos E. International Myeloma Working Group recommendation for the treatment of multiple myeloma-related disease. J Clin Oncol 2013;31:2347-57.

7. Morgan GJ, Davies FE, Gregory WM, et al. Survival outcomes with bisphosphonate and thalidomide treatment. Clin Canc Res 2013;19:6030-8.

8. Leung N, Behrens J. Current approach to diagnosis and management of acute renal failure in myeloma patients. Adv Chronic Kidney Dis 2012;19:297-302.

9. Blimark C, Holmberg E, Mellqvist UH, et al. Multiple myeloma and infections: a population-based study based on 9610 multiple myeloma patients. Haematologica 2015;100:107-13.

10. Augustson BM, Begum G, Dunn JA, et al. Early mortality after diagnosis of multiple myeloma: analysis of patients entered onto the United kingdom Medical Research Council trials between 1980 and 2002-Medical Research Council Adult Leukaemia Working Party. J Clin Oncol 2005;23:9219-26.

11. Chanan-Khan A, Sonneveld P, Schuster MW, et al. Analysis of herpes zoster events among Bortezomibtreated patients in the phase III APEX study. J Clin Oncol 2008;26:4784-90.

12. Robertson JD, Nagesh K, Jowitt SN, et al. Immunogenicity of vaccination against influenza, Streptococcus pneumoniae and Haemophilus influenzae type B in patients with multiple myeloma. Br J Cancer 2000;82: 1261-5.

13. Musto P, Carotenuto M. Vaccination against influenza in multiple myeloma. Br J Haematol 1997;97:505-6. 


\title{
Le complicanze trombo-emboliche nel paziente ematologico
}

\author{
Serena Panarello, Chiara Fioravanti, Francesca Raggi, Giancarlo Antonucci \\ SC Medicina Interna, EO Ospedale Galliera, Genova, Italia
}

\section{Introduzione}

Il tromboembolismo venoso (TEV) complica frequentemente le malattie ematologiche, neoplastiche e non, e ha un significativo impatto su morbidità e mortalità in tali patologie. Nei reparti di medicina, inoltre, spesso è la presenza di un evento trombotico acuto a condurre alla diagnosi di una malattia ematologica sottostante.

Nei pazienti oncoematologici emerge dalla letteratura un'incidenza di eventi trombotici equiparabile a quella osservata nei tumori solidi ad alto rischio trombotico. ${ }^{1}$

Oltre ai tradizionali fattori di rischio trombotico, rivestono un ruolo significativo la chemioterapia, la terapia ormonale e immunomodulante, l'uso di fattori di crescita e di steroidi ad alte dosi e infine l'impiego di cateteri venosi centrali (CVC). I tumori ematologici inoltre hanno un profilo di rischio ampiamente variabile per via della loro estrema eterogeneità clinica.

Tra le malattie ematologiche le sindromi mieloproliferative rappresentano un capitolo a se stante per il rischio di trombosi arteriose e venose, spesso in sedi atipiche, che ne condizionano la prognosi.

Infine, l'emoglobinuria parossistica notturna (EPN) rappresenta in assoluto la condizione trombofilica acquisita più severa in medicina.

Tale rassegna si propone pertanto di trattare alcuni quadri ematologici di frequente riscontro nei reparti di medicina interna, in cui la profilassi, il riconoscimento precoce e la terapia dell'evento trombotico hanno un impatto rilevante sulla gestione clinica complessiva del paziente.

Corrispondente: Serena Panarello, SC Medicina Interna, EO Ospedale Galliera, Genova, Italia.

E-mail: serena.panarello@galliera.it

Articolo pubblicato secondo la Creative Commons Attribution NonCommercial 4.0 License (CC BY-NC 4.0).

CC Copyright S. Panarello et al., 2019

Licensee PAGEPress, Italy

QUADERNI - Italian Journal of Medicine 2019; 7(1):33-39

\section{Linfomi e leucemie}

Una recente metanalisi che ha incluso oltre 18.000 pazienti con linfoma riporta una incidenza globale di trombosi del 6,4\% (5,3\% venosa e 1,1\% arteriosa). Le complicanze trombotiche sono risultate significativamente superiori nei linfomi non Hodgkin rispetto al linfoma di Hodgkin e nei linfomi ad alto grado rispetto ai linfomi a basso grado di malignità. L'incidenza di TEV è risultata inoltre correlata allo stadio di malattia. ${ }^{2}$ Tra i linfomi la più alta incidenza di eventi trombotici riportata in letteratura è stata osservata nel linfoma primitivo del SNC (fino al $60 \%$ dei casi) ${ }^{3} \mathrm{e}$ nel linfoma primitivo mediastinico a cellule B. ${ }^{4}$

I linfomi indolenti sembrano invece associarsi ad un rischio tromboembolico piuttosto basso, simile a quello della popolazione generale. ${ }^{5}$

I pazienti con leucemia acuta possono presentare un ampio spettro di anomalie coagulative e manifestazioni cliniche di gravità variabile, da trombosi arteriose o venose distrettuali a quadri emorragici fatali come quelli in corso di coagulazione intravascolare disseminata.

L'incidenza di queste complicanze varia in rapporto al tipo di leucemia e alla fase di trattamento (se di induzione o consolidamento). In letteratura l'incidenza di TEV nelle leucemie acute varia dal 1,7 al $9,6 \%$ alla diagnosi, e dal 1,7 al $12 \%$ in corso di terapia di induzione. ${ }^{3}$

In uno studio su una coorte di circa 8000 pazienti con leucemia mieloide acuta (LMA) e leucemia linfoblastica acuta (LLA), la maggior parte degli eventi si è verificata nel primo mese di terapia e l'età avanzata, la presenza di comorbidità e di CVC rappresentavano i principali fattori predittivi di eventi trombotici entro un anno.

In taluni casi il trattamento antiblastico è uno dei principali fattori di rischio per lo sviluppo di trombosi. Questo è il caso della chemioterapia con L-asparaginasi nella LLA, molto spesso associata a trombosi del SNC. ${ }^{6}$ A causa di questa stretta associazione alcuni gruppi di studio raccomandano un trattamento anticoagulante profilattico in tutti i pazienti con LLA in corso di terapia con L-asparaginasi. ${ }^{7}$ Anche il trattamento con inibitori delle tirosino-kinasi (TK) di nuova generazione nella leucemia mieloide cronica (LMC) è stato associato a 
eventi trombotici, soprattutto arteriosi (ponatinib associato a rischio 6 volte maggiore di imatinib). ${ }^{4}$

Al contrario, l'avvento della terapia con acido tutto-trans retinoico (ATRA) nella leucemia promielocitica ha rivoluzionato l'outcome di questa neoplasia, contrastandone efficacemente la severa coagulopatia trombo-emorragica; ancor oggi tuttavia, le emorragie fatali rappresentano la principale causa di mortalità in fase di induzione (incidenza 2,4-6,5\%). ${ }^{1}$

Anche in corso di leucemia promielocitica l'incidenza delle complicanze trombotiche è significativa e varia in letteratura dal 5,1 al $16 \%{ }^{1}$

Infine, disponiamo di dati limitati nella leucemia linfatica cronica; un recente studio retrospettivo su 346 pazienti ha dimostrato un'incidenza di TEV dell' $11 \%$ in un follow up mediano di 6 anni, correlato alla presenza di fattori prognostici negativi (stadio Rai avanzato, profilo citogenetico sfavorevole, stato non mutato dei geni $\operatorname{IgVH}){ }^{8}$

Attualmente non disponiamo di solide evidenze circa la gestione ottimale delle complicanze trombotiche nelle neoplasie ematologiche poiché i pazienti oncoematologici sono scarsamente rappresentati nei grandi trial. La gestione di questi pazienti è inoltre complessa per la coesistenza in varia misura di fattori di rischio trombotico ed emorragico, e deve essere pertanto individualizzata.

Nei pazienti affetti da leucemia e linfoma, il trattamento delle complicanze trombotiche segue in generale le indicazioni che provengono dalle linee guida sul TEV nei pazienti oncologici e si basa sull'utilizzo, principalmente, di eparina a basso peso molecolare (EBPM) e fondaparinux. I dati circa l'uso dei DOAC in questo contesto sono scarsi e insufficienti a raccomandarne l'impiego.

Un problema frequente nei pazienti oncoematologici è la presenza di piastrinopenia, che può essere secondaria a infiltrazione midollare, terapia antiblastica, coagulopatia da consumo o autoimmunità.

Nei grandi trial che hanno valutato il trattamento del TEV, la piastrinopenia è considerata un criterio di esclusione, e abbiamo pertanto scarse informazioni circa i reali rischi di sanguinamento e la progressione del trombo nei pazienti piastrinopenici.

La piastrinopenia di per sé non sembra tuttavia proteggere nei confronti degli eventi trombotici.
Recentemente uno studio multicentrico su 1461 pazienti con leucemia acuta ha dimostrato una significativa incidenza di TEV non CVC correlato anche in pazienti severamente piastrinopenici $(<30.000)$; in questi pazienti è stata somministrata in sicurezza EBPM a dosi piene per il primo mese e a dosi ridotte per $i$ tre mesi successivi. ${ }^{6}$

In oncoematologia valgono le raccomandazioni NCCN di aggiustamento della posologia di enoxaparina in presenza di piastrinopenia (Tabella 1).

Le trasfusioni piastriniche, quando è possibile, possono essere una misura adeguata a mantenere la conta piastrinica al di sopra della soglia che consenta la terapia eparinica. ${ }^{4}$

Nei pazienti ad elevato rischio di sanguinamento che non possono essere trasfusi e con trombosi venosa acuta può essere considerato il posizionamento di un filtro cavale.

Per quanto riguarda la profilassi trombotica, non esistono specifiche raccomandazioni e i modelli di stratificazione del rischio trombotico normalmente utilizzati nella pratica clinica, derivati da studi condotti su pazienti affetti per lo più da tumori solidi (come lo score di Khorana), sono soltanto in parte applicabili ai pazienti ematologici e sembrano poco affidabili.

A tal proposito è stato recentemente sviluppato il ThroLy risk model, uno score di rischio più specifico per il linfoma, in cui i fattori considerati sono: precedente evento TE arterioso o venoso, coinvolgimento mediastinico, BMI $>30 \mathrm{Kg} / \mathrm{m}^{2}$, ridotta mobilità (ECOG 2-4), malattia extranodale, neutropenia $<1$ $\mathrm{x} 10^{9} / 1 \mathrm{ed} \mathrm{Hb}<10 \mathrm{~g} / \mathrm{dL}$. In base a questo score i pazienti sono considerati a rischio di TEV in presenza di score $>1$ (potere predittivo negativo del 98,5\%) e a rischio elevato in presenza di score $>3$ (nei pazienti con score $>4$ il potere predittivo positivo di TEV è risultato $\operatorname{del} 65,2 \%)^{2}$

Questo score di rischio necessita tuttavia di validazione esterna in ampie popolazioni di pazienti.

In attesa di maggiori evidenze provenienti da studi randomizzati, le principali società scientifiche al momento raccomandano di estendere la tromboprofilassi in tutti i pazienti con neoplasie ematologiche ospedalizzati in presenza di ipomobilità o di un evento medico acuto. ${ }^{9-13}$

Per quanto riguarda invece il paziente ambulato-

Tabella 1. Aggiustamento della dose di enoxaparina in corso di trombocitopenia. (Modificato da NCCN Guidelines Version 1.2018). ${ }^{11}$

\begin{tabular}{lll}
\hline Conta piastrinica & Aggiustamento dosaggio di enoxaparina suggerito & Alternativa \\
\hline$>50.000$ & Dose piena: $1 \mathrm{mg} / \mathrm{kg} 2$ volte die & $1,5 \mathrm{mg} / \mathrm{kg} \mathrm{die}$ \\
\hline $25.000-50.000$ & Metà dose: $0,5 \mathrm{mg} / \mathrm{kg} 2$ volte die & - \\
\hline$<25.000$ & Sospensione temporanea & \\
\hline
\end{tabular}


riale, $i$ casi in cui ad oggi è sicuramente raccomandata la profilassi sono rappresentati da un Khorana score $\geq 3$ e i pazienti in terapia con talidomide o lenalidomide.

Le linee guida dell'International Consensus Working Group, pubblicate nel 2013 includono anche i pazienti con leucemia linfoblastica acuta in terapia con L-asparaginasi.?

Nonostante le numerose evidenze circa l'elevato rischio di TEV associato alla presenza dei cateteri venosi centrali, attualmente la tromboprofilassi non è routinariamente raccomandata.

\section{Mieloma}

I pazienti con mieloma multiplo (MM) presentano un elevato rischio di trombosi sia venosa che arteriosa che condiziona fortemente la mortalità. ${ }^{12}$

Le cause dello sviluppo di trombosi in questi pazienti sono il risultato dell'interazione di comorbidità, fattori legati alla neoplasia e chemioterapia. È descritto infatti nel MM lo sviluppo di anormalità protrombotiche come il riscontro di elevati valori di fattore VIII, di von Willebrand, di citochine infiammatorie, l'acquisizione di resistenza alla proteina $\mathrm{C}$ attivata e l'ipofibrinolisi.

Il rischio di TEV risulta aumentato anche nelle persone affette da M-GUS che non ricevono chemioterapia, fino a due a tre volte rispetto a persone sane.

Tuttavia il rischio aumenta notevolmente durante l'assunzione di terapia immunomodulatrice associata a desametasone. Il tromboembolismo venoso tende a svilupparsi dai primi tre cicli sino al sesto ciclo di induzione e più frequentemente entro il primo anno dalla diagnosi o durante ricaduta di malattia.

La somministrazione di un singolo farmaco, come talidomide o lenalidomide, porta ad un rischio di sviluppo di trombosi del 2-4\%. ${ }^{12}$ L'esatto meccanismo con cui la talidomide contribuisce allo sviluppo di trombosi non è del tutto chiaro; sono ipotizzati effetti sulla trombomodulina (riduzione transitoria dell'effetto anticoagulante) o un possibile aumento dell'espressione endoteliale del protease activated receptor-1 (PAR-1) che potrebbe favorire il legame della trombina con le cellule endoteliali.

L'incidenza di TEV aumenta in maniera significativa quando la talidomide è associata a desametasone arrivando a un rischio del $12-26 \%$ o sono utilizzati schemi chemioterapici multifarmacologici (16-34\%). ${ }^{12}$

Anche per quanto riguarda la lenalidomide il rischio di sviluppare TEV aumenta fino al $26 \%$ se sono associate alte dosi di desametasone, così come l'uso di melphalan con prednisone aumenta il rischio di TEV dell' $11 \%$, che peggiora ulteriormente con l'associazione di talidomide. ${ }^{12}$

Al contrario il Bortezomid, inibitore del proteosoma studiato in associazione a talidomide, sembra prevenirne gli effetti pro trombotici, con meccanismi di protezione poco chiari, ma non dovrebbe escludere i pazienti a rischio TEV dalla tromboprofilassi. ${ }^{12}$

In pazienti selezionati ed in assenza di controindicazioni, la profilassi anti-trombotica va iniziata al momento della diagnosi e continuata sino a che i fattori rischio per TEV intrinsechi al MM e la chemioterapia sono terminati.

L'International Myeloma Working Group propone di utilizzare una strategia di valutazione per la tromboprofilassi basata su una stratificazione del rischio individuale dei pazienti di sviluppare TEV e di utilizzare una terapia legata ai fattori di rischio.

Esistono diversi studi in corso di chemioterapia in cui vengono valutati singolarmente l'acidoacetilsalicilico (ASA) a basso dosaggio ( $81 \mathrm{mg} /$ die), l'uso profilattico di eparina a basso peso molecolare e l'uso di basse dosi di warfarin $(1 \mathrm{mg} / \mathrm{die})$ ma non abbiamo studi di confronto diretto. ${ }^{12}$

L'efficacia preventiva dall'ASA nel MM potrebbe trovare ragione in una possibile attivazione piastrinica ed endoteliale da parte della chemioterapia.

Circa il 5-7\% dei pazienti tuttavia sviluppa trombosi nonostante la tromboprofilassi. ${ }^{12}$

Anche nei pazienti con MM il rischio emorragico è aumentato (comorbidità, piastrinopenia secondaria, emostasi alterata dalle paraproteine); tuttavia il rischio di sanguinamenti maggiori durante terapia antitrombotica a dose profilattica rimane basso $(<0,5 \%) .^{12}$

Infine i pazienti ad elevato rischio di TEV come quelli con pregressa trombosi o compressione del midollo spinale secondaria a MM dovrebbero poter essere trattati con dosi terapeutiche di anticoagulanti.

\section{Malattie mieloproliferative $\mathbf{P h}$-negative}

Il rischio di tromboembolismo nelle MPNs, ha un rilevante impatto sulla sopravvivenza, tale da rendere il trattamento, il principale obiettivo terapeutico.

Un recente studio condotto su 9429 pazienti ha permesso di evidenziare alcuni aspetti: ${ }^{14}$ i) il maggior rischio trombotico si osserva nei primi tre mesi dalla diagnosi (3 volte per le trombosi arteriose e fino a 10 volte per le trombosi venose) e decresce significativamente nel corso del follow up per effetto della terapia citoriduttiva e profilattica antitrombotica, rimanendo comunque più elevato rispetto alla popolazione generale; ii) non ci sono significative differenze tra le tre sindromi mieloproliferative in termini di incidenza; iii) i consueti fattori di rischio (in particolare l'età > di 60 anni e un precedente evento) sono associati ad un rischio trombotico di 7 volte maggiore, tuttavia sono presenti altri fattori di rischio indipendenti, legati sia alla patologia (ematocrito, conta dei bianchi, tipo di mutazione MPNs correlata), che al paziente stesso (trombofilia, fattori di rischio cardiovascolare) che 
rendono la stratificazione in questi pazienti più complessa rispetto alla popolazione generale; iv) la mutazione del JAK2 è associata ad un elevato rischio trombotico, mentre la presenza della mutazione CALR si associa ad un rischio trombotico più basso fra i pazienti con MPNs. Le cellule con mutazione JAK2 infatti presentano in vitro aumentata mobilità, iperaggregabilità e adesività all'endotelio, che potrebbe manifestarsi in vivo in particolare nelle zone a rallentata velocità di flusso.

Nei pazienti con MPNs la mutazione JAK2 si associa ad un incremento del rischio di trombosi in sedi atipiche, in particolare del circolo venoso splancnico (SVT) (trombosi venosa splancnica, portale e sindrome di Budd Chiari) tanto da raccomandare in questi pazienti, anche in assenza di MPNs conclamata, lo screening per il JAK $2{ }^{15,16}$ In soggetti positivi per la mutazione del JAK2 e al di sotto dei 40 anni, la prevalenza di trombosi è risultata molto elevata (venose $47 \%$, arteriose $37 \%$ ) e in particolare le trombosi venose del circolo splancnico hanno raggiunto il $79 \%$ degli eventi tromboembolici. ${ }^{15}$

L'SVT rappresenta una importante quota degli eventi tromboembolici nei pazienti con MPNs con una prevalenza del 5-10\% nei pazienti con PV e nel 9-13\% dei pazienti con ET. ${ }^{15,16}$

I pazienti con SVT, inoltre, risultano essere più frequentemente giovani donne con una risposta al trattamento anticoagulante minore, più recidive e più eventi emorragici associati. ${ }^{16}$

Per questo motivo le sindromi mieloproliferative sono considerate dalle linee guida ACCP fattore di ri- schio persistente di TEV e nei pazienti a basso rischio emorragico è consigliato il trattamento anticoagulante a lungo termine. ${ }^{17}$

Da quanto sopra esposto è evidente come una stratificazione del rischio trombotico arterioso cardiovascolare e venoso sia fondamentale per la gestione di questi pazienti.

Nella trombocitemia essenziale (TE) è noto infatti che l'aspettativa di vita non è significativamente compromessa dalla patologia in se ma il $10-20 \%$ dei pazienti sviluppa una complicanza trombotica arteriosa o venosa che ne condiziona morbilità e mortalità. Per tale motivo, ad oggi, il trattamento della TE è indicato per la prevenzione delle complicanze trombotiche. ${ }^{13}$

Per questi pazienti è stato creato e validato uno score prognostico (IPSET-thrombosis), consigliato dalle linee guida NCCN, che identifica quattro categorie di rischio (incidenza annuale da $0,44 \%$ a 3,56\%) ) $^{13-18}$ (Figura 1).

Lo score IPSET-thrombosis migliora l'approccio preventivo-terapeutico nei pazienti con $\mathrm{TE},{ }^{13-18}$ proponendo l'aspirina, per la riduzione di eventi arteriosi, in mono o bi-somministrazione (miglior soppressione della sintesi del trombossano-A2 in pazienti con elevato turnover piastrinico ${ }^{13}$ ), la terapia anticoagulante per la prevenzione delle recidive di TEV e l'associazione della terapia citoriduttiva con idrossiurea (goal terapeutico piastrine $<600.000 / \mathrm{dL}$ ) con lo scopo dimostrato di ridurre il rischio di trombosi dal $24 \%$ al 3,6\%. ${ }^{18}$

Anche nella Policitemia vera (PV), che pure ha una sopravvivenza media di circa 14 anni dalla diagnosi, la morbilità e la mortalità sono condizionate dagli eventi trombotici che, nello studio ECLAP,
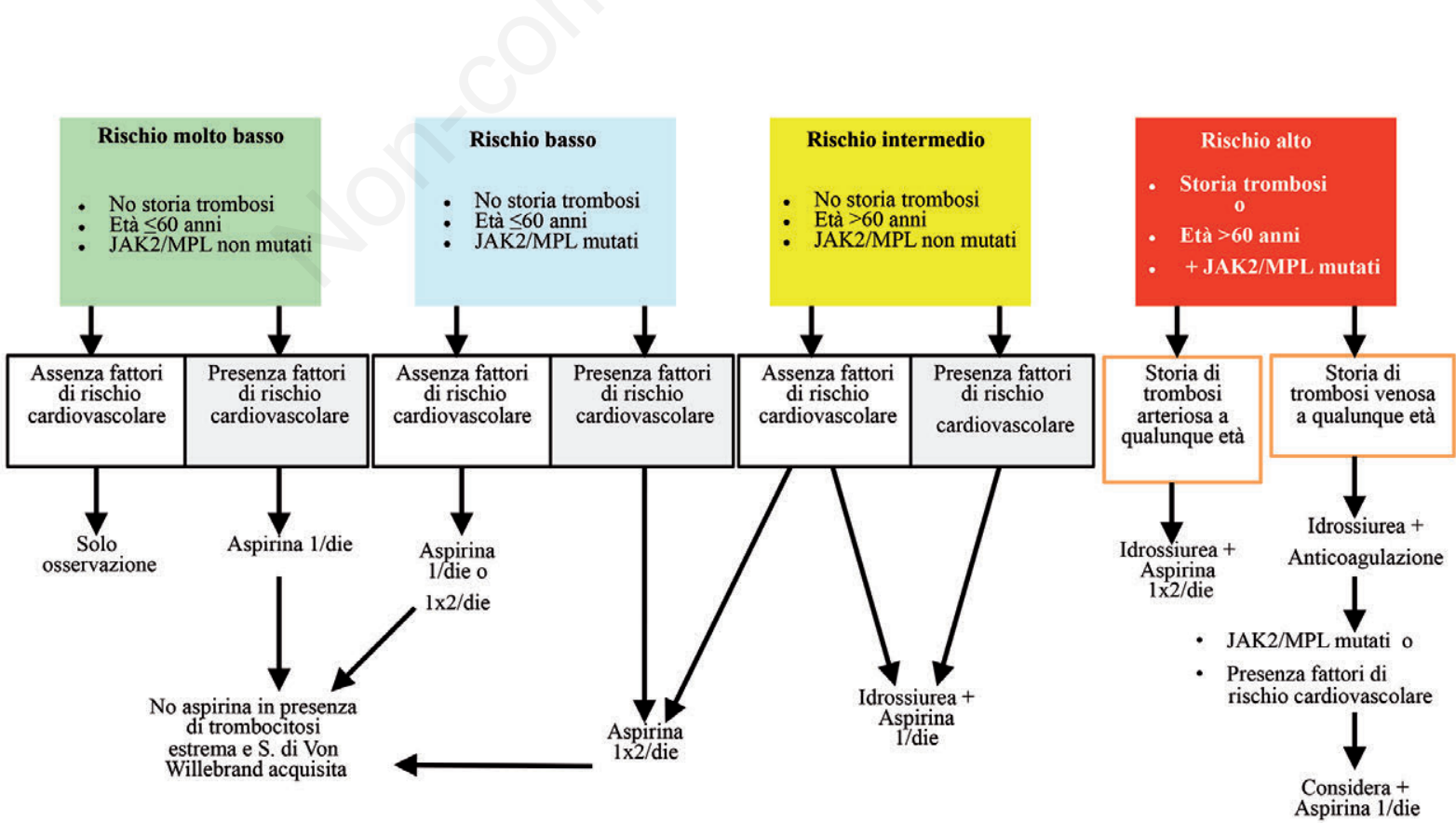

Figura 1. Score prognostico IPSET-thrombosis per la trombocitemia essenziale. (Modificato da Essential Thrombocythemia treatment algorithm 2018). 
hanno un incidenza del 3,8\%/anno. ${ }^{13}$ Anche in questa patologia si è ritenuto necessario stratificare il rischio di trombosi per definire il corretto trattamento identificando due classi di rischio (alto e basso) e diverse soluzioni preventivo-terapeutiche (Figura 2).$^{13}$

Le linee guida più recenti pongono l'attenzione sulla correzione dei fattori di rischio cardiovascolari quali ipertensione (frequente in questi pazienti e verosimilmente associata all'incremento dell'ematocrito) e indicano l'utilità di un trattamento citoriduttivo nei pazienti a basso rischio ma con fattori di rischio CV associati. ${ }^{13}$

Fattori di rischio indipendenti di trombosi nei pazienti con PV sono inoltre rappresentati dalla mutazione del JAK2 e dalla leucocitosi. In particolare una conta leucocitaria superiore a $15.000 / \mathrm{dL}$ è associata ad un aumento significativo del rischio trombotico, legato all'attivazione dell'endotelio e della cascata coagulativa. ${ }^{13}$

Contrariamente alla PV e alla TE, la Mielofibrosi primitiva $(P M F)$ è caratterizzata da un decorso più rapido, una più frequente trasformazione leucemica $\mathrm{e}$ una minor aspettativa di vita, con una mediana di sopravvivenza dalla diagnosi di circa 5 anni. ${ }^{19}$

Diversi studi hanno dimostrato che la frequenza di eventi trombotici nei pazienti affetti da PMF è sovrapponibile a quella dei pazienti con TE con gli stessi fattori favorenti (età $>60$ anni, JAK2 mutato); è stata inoltre evidenziata una probabile associazione con la presenza di leucocitosi, mentre l'impatto dei fattori di rischio cardiovascolari sul rischio trombotico di questi pazienti non è definito. ${ }^{19}$
Il trattamento dovrebbe essere più che mai individualizzato per l'alto rischio emorragico che li caratterizza (piastrinopenia, anomalie funzionali delle piastrine e Sindrome di von Willebrand acquisita). Anche il ruolo della terapia citoriduttiva con idrossiurea non sembra ridurre significativamente il rischio trombotico come accade nella altre MPNs. ${ }^{19}$ Tuttavia il trattamento con aspirina a base dosi e idrossiurea è consigliato in pazienti con un elevato profilo di rischio (età > di 60 anni, storia pregressa di trombosi). ${ }^{19}$

Una trattazione a parte merita la PMF prefibrotica che per caratteristiche cliniche è sovrapponibile alla ET e presenta un profilo di rischio tromboembolico analogo. Va pertanto correttamente identificata e distinta dalla PMF per un corretto approccio terapeutico. ${ }^{19}$

\section{Emoglobinuria parossistica notturna}

L'emoglobinuria parossistica notturna (EPN) non è soltanto la patologia ematologica a più alto rischio trombotico, ma rappresenta in assoluto la condizione trombofilica acquisita più severa in medicina.

Sicuramente lo stato emolitico cronico intravascolare rappresenta il principale substrato patogenetico ma l'insorgenza di complicanze trombotiche anche in pazienti con piccoli cloni EPN e minima evidenza di emolisi suggerisce il ruolo di altri meccanismi indipendenti quali l'iperattivazione piastrinica, alterazioni del sistema fibrinolitico ed effetti proinfiammatori di C5a. ${ }^{20}$

Prima dell'introduzione della terapia con eculizumab (anticorpo monoclonale umanizzato inibitore
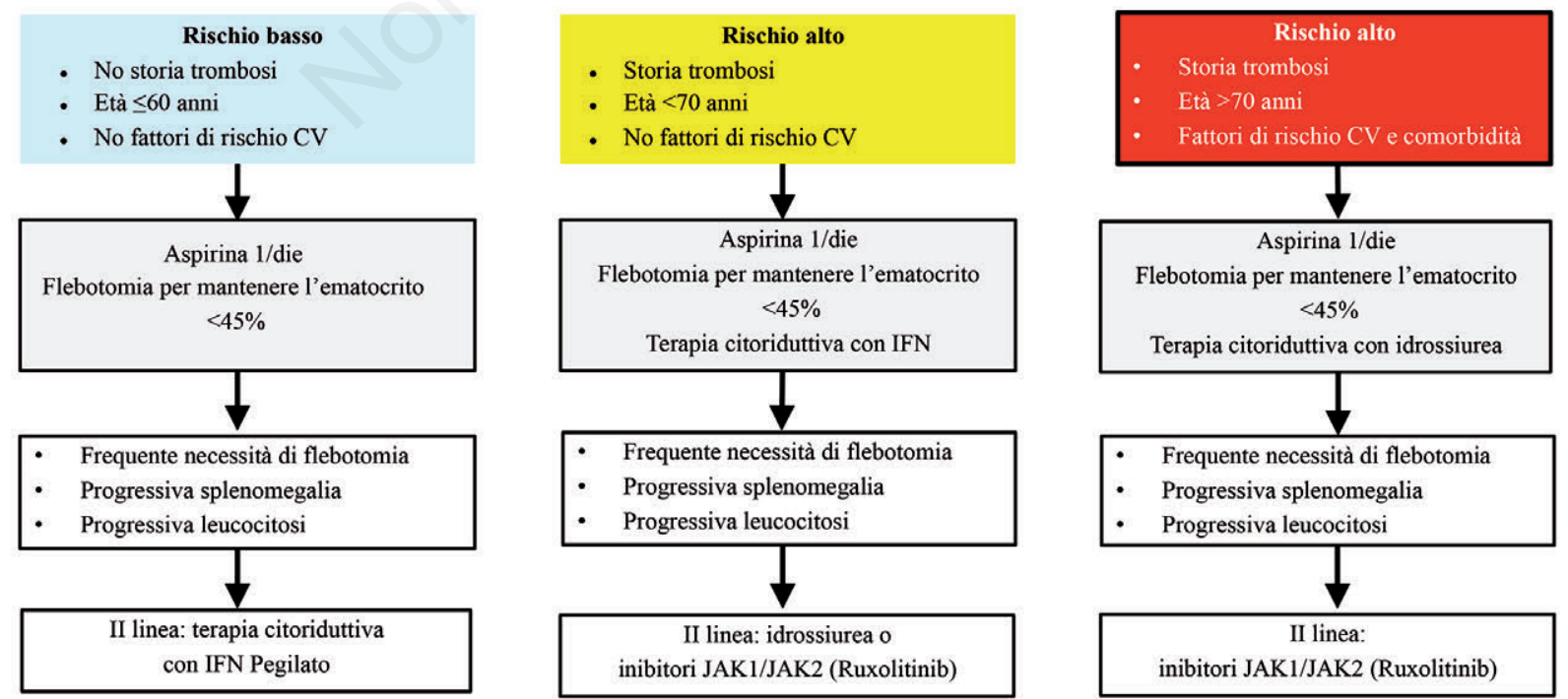

Figura 2. Score prognostico per la policitemia vera. (Modificato da NCCN Guidelines Insights Myeloproliferative Neoplasm, Version 2.2018). ${ }^{13}$ 
della frazione C5 del complemento) fino oltre il $40 \%$ dei pazienti con EPN andava incontro a un evento tromboembolico nel corso della malattia e questa complicanza si associava a una sopravvivenza significativamente ridotta, con un rischio relativo di decesso incrementato fino a 15 volte; nei pazienti che presentavano trombosi all'esordio della malattia il tasso di sopravvivenza a 4 anni era solo il $40 \%{ }^{20}$

Esiste una forte correlazione tra l'espansione del clone granulocitario EPN, l'entità dell'emolisi e il rischio trombotico; anche piccoli cloni EPN si associano tuttavia ad un rischio trombotico estremamente elevato se confrontato al rischio della popolazione generale.

L'età media di esordio delle trombosi associate ad EPN è notevolmente più bassa rispetto a quanto osservato nella popolazione generale (46 anni vs 73 anni). ${ }^{21}$ Le trombosi associate ad EPN sono per lo più venose $(85 \%)$ ma non infrequenti sono le trombosi arteriose, soprattutto cerebrali e coronariche. ${ }^{20}$

Particolarmente frequenti sono le trombosi in gravidanza e puerperio, associate - in era pre-eculizumab - ad una mortalità materna del $20 \%$ e fetale del $4 \%{ }^{21}$

Le trombosi possono interessare soprattutto sedi inusuali e nel $20 \%$ dei casi si osserva il coinvolgimento simultaneo di più siti e conseguente aumento della mortalità associata.

Particolarmente frequenti e pericolose sono la sindrome di Budd Chiari (descritta in più del $40 \%$ dei casi $^{21}$ ) e la trombosi del seno sagittale superiore, fatale in $1 / 3$ dei casi. ${ }^{20}$

Le trombosi cerebrali osservate in corso di EPN sono risultate frequentemente associate alla terapia estroprogestinica, alla gravidanza e al puerperio.

L'interessamento dei vasi del derma è caratteristico e può determinare quadri di gravità estremamente variabile fino a forme di porpora fulminante.

La prevalenza di trombosi nei pazienti con EPN è inoltre probabilmente sottostimata, in quanto sono stati descritti con elevata frequenza eventi tromboembolici polmonari e miocardici subclinici. ${ }^{20}$

Nei pazienti con trombosi non altrimenti spiegata, soprattutto se di giovane età, con trombosi in sede inusuale, evidenza di emolisi o di citopenia uni- o multilineare è sicuramente indicato lo screening per EPN. Tutti i pazienti con sindrome di Budd Chiari dovrebbero essere indagati per EPN.

Riconoscere precocemente l'EPN in un paziente con trombosi è cruciale per la gestione terapeutica. Grazie al trattamento immediato con eculizumab è possibile bloccare la cascata complemento-mediata che conduce all'emolisi intravascolare e prevenire tutti gli effetti proinfiammatori e protrombotici ad essa correlata. Questo modifica la storia naturale della malattia in modo sostanziale mentre la sola terapia anticoagulante si è dimostrata di parziale efficacia.

Non esistono attualmente indicazioni standardiz- zate all'avvio della terapia con eculizumab. Il trattamento è generalmente iniziato nei pazienti fortemente sintomatici, con emolisi significativa, segni di danno d'organo e trombosi. ${ }^{22}$ L'evento trombotico rappresenta tuttavia un'indicazione assoluta all'avvio immediato della terapia con eculizumab.

I dati circa l'uso di eculizumab, sebbene osservazionali, suggeriscono un buon profilo di sicurezza in gravidanza e puerperio e l'impiego di eculizumab in questi contesti ha notevolmente ridotto l'incidenza delle complicanze tromboemboliche. ${ }^{23}$

Analogamente a quanto indicato negli altri contesti clinici, la gestione della trombosi acuta prevede comunque l'impiego della terapia anticoagulante con eparina seguita da warfarin, ed eventualmente della terapia trombolitica. Non vi sono evidenze sufficienti circa il ruolo dei DOAC nel trattamento della trombosi associata ad EPN.

Nei pazienti in terapia con eculizumab dopo un primo evento trombotico è suggerita attualmente la prosecuzione della terapia anticoagulante a lungo termine, in quanto non esistono evidenze sufficienti a raccomandarne la sospensione. ${ }^{21} \mathrm{Al}$ contrario l'impiego della terapia anticoagulante in prevenzione primaria è controverso data la modesta efficacia dimostrata e gli elevati tassi di sanguinamento osservati, soprattutto in presenza di piastrinopenia ${ }^{24}$ nei pazienti già in terapia con eculizumab non viene generalmente suggerita. ${ }^{22}$

Per quanto riguarda invece i pazienti non candidati a terapia con eculizumab, la terapia anticoagulante in profilassi primaria generalmente è suggerita solo in contesti clinici peculiari quali la gravidanza e il puerperio. Non disponiamo al momento di evidenze sufficienti a fornire raccomandazioni circa il dosaggio anticoagulante più adeguato in questi particolari contesti; in alcune casistiche le pazienti sono state trattate con dosaggi terapeutici e in altre sono stati utilizzati dosaggi profilattici sulla base del profilo di rischio individuale. ${ }^{22}$

Nei pazienti con EPN è sicuramente necessaria una più precisa stratificazione del rischio trombotico a fini di individuare i sottogruppi di pazienti che possono maggiormente beneficiare di una profilassi, ma attualmente non vi sono dati sufficienti a fornire precise raccomandazioni.

$\mathrm{Al}$ momento inoltre non esistono evidenze circa il ruolo della terapia antiaggregante nella profilassi della trombosi associata ad EPN. ${ }^{21}$

\section{Bibliografia}

1. Falanga A, Marchetti M, Russo L. Venous thromboembolism in hematologic malignancies. Curr Opin Oncol 2012;24:702-710.

2. Antic D, Milic N, Nikolovski S, et al. Development and 
validation of multivariable predictive model for thromboembolic events in lymphoma patients. Am J Hematol 2016;91:1014-1019.

3. Falanga A, Marchetti M. Venous thromboembolism in hematologic malignancies. J Clin Oncol 2009;27:48484857.

4. Kekre N, Connors JM. Venous thromboembolism incidence in hematologic malignancies. Blood Rev 2018 Jun 21.

5. Gade IL, Brækkan S, Næss IA, et al. Epidemiology of venous thromboembolism in hematological cancers: The Scandinavian Thrombosis and Cancer (STAC) cohort. Thromb Res 2017;158:157-160.

6. Annibali O, Napolitano M, Avvisati G, Siragusa S. Incidence of venous thromboembolism and use of anticoagulation in hematologic malignancies: critical review of the literature. Crit Rev Oncol 2018;124:41-50.

7. Farge D, Debordeau P, Beckers M, et al. International clinical prctice guidelines for the treatment and prophylaxis of venous thromboembolism in patients with cancer. J Thromb Haemost 2013;11:56-70.

8. Whittle AM, Allsup Dj, Bailey JR. Chronic lymphocytic leukaemia is a risk factor for venous thromboembolism. Leuk Res 2011;35:419-421.

9. Lyman GH, Khorana AA, Kuderer NM, et al. Venous thromboembolism prophylaxis and treatment in patients with cancer: American Society of Clinical Oncology clinical practice guideline update. J Clin Oncol 2013; 31:2189-2204.

10. Lyman GH, Bohlke K, Khorana AA, et al. Venous Thromboembolism prophylaxis and treatment in patients with cancer: American Society of Clinical Oncology clinical practice guideline update 2014. J Clin Oncol 2015;33:654-656.

11. Streiff MB, Holmstrom B, Ashrani A, et al. Cancer-associated venous thromboembolic disease. NCCN clinical practice guidelines in oncology; National Comprehensive Cancer Network, 2018.

12. Cesarman-Maus G, Braggio E, Fonseca R. Hematology, 2012 Apr; 17(01): S177-S180.
13. Mesa RA, Jamieson C, Bhatia R, et al. NCCN Guidelines Insights Myeloproliferative Neoplasm, Version 2.2018. J Nat Compr Canc Netw. 2017;15(10):1193-1207.

14. Hultcrantz M, Bjorkholm M, Dickman PW, et al. Risk for Arterial and Venous Thrombosis in Patients With Myeloproliferative Neoplasms. Ann Intern Med. 2018;168(5):317-325.

15. Lussana F, Carobbio A, Randi ML, et al. A lower intensity of treatment may underlie the increased risk of thrombosis in young patients with masked polycythaemia vera. Br J Haematol. 2014;167(4):541-546.

16. De Stefano V, Vannucchi AM, Ruggeri M, et al. Splanchnic vein thrombosis in myeloproliferative neoplasms: risk factors for recurrences in a cohort of 181 patients. Blood Cancer J. 2016;6(11):e493.

17. Kearon C, Akl EA, Omelas J, et al. Antithrombotic therapy for VTE disease chest guidelines and expert panle report. Chest. 2016;149(2):315-352.

18. Tefferi A, Vannucchi AM, Barbui T. Essential Thrombocythemia treatment algorithm 2018. Blood Cancer J. 2018;8(1):2.

19. Devendra KC, Falchi L, Verstovsek S. The underappreciated risk of thrombosis and bleeding in patients with myelofibrosis: A review. Ann Hematol. 2017;96(10): 1595-1604.

20. Hill A, Kelly RJ, Hillmen P. Thrombosis in paroxysmal nocturnal hemoglobinuria. Blood 2013;121:4985-4996.

21. Devalet B, Muller F, Chatelain B, et al. Pathophysiology, diagnosis, and treatment of paroxysmal nocturnal hemoglobinuria: a review. Eur JHaematol 2015;95:190-198.

22. Robert A. Brodsky How I treat paroxysmal nocturnal hemoglobinuria Blood 2009;113:6522-6527.

23. Kelly R, Hochsmann B, Szer J, Kulasekararaj A, De Guibert S, Roth A, et al. (2015) Eculizumab in pregnant patients with paroxysmal nocturnal hemoglobinuria. $\mathrm{N}$ Engl J Med 373:1032-1039.

24. Weitz IC. Thrombosis in patients with paroxysmal nocturnal hemoglobinuria. Semin Thromb Hemost 2011; 37:315-321. 


\title{
Come affrontare il paziente con leucocitosi e linfocitosi
}

\author{
Claudia Venturino, Rodolfo Tassara \\ SC Medicina 1 ed Ematologia, Ospedale San Paolo, Savona, Italia
}

\section{Leucocitosi con linfocitosi}

Cause di linfocitosi:

- Infezioni virali: sono le patologie infettive più frequenti in assoluto e sono causa di alterazioni della formula leucocitaria, con aumento soprattutto dei linfociti (Tabella 1). Si distinguono in: i) infezioni acute: Epstein Barr virus (mononucleosi), influenzavirus, rinhovirus, adenovirus, cytomegalovirus, virus della parotite e della rosolia; ii) infezioni croniche: virus epatite $\mathrm{B}(\mathrm{HBV})$, virus epatite $\mathrm{C}(\mathrm{HCV})$, herpes virus (labiale o genitale), HIV.

- Infezioni batteriche: responsabili principalmente di leucocitosi neutrofila ma possono essere anche causa di linfocitosi, soprattutto le infezioni da germi atipici (ad esempio le infezioni respiratorie da Chlamydia pneumoniae o da Mycoplasma pneumoniae) oppure la Brucellosi e la pertosse.

- Infezioni da micobatteri: la TBC (tubercolosi) è una non trascurabile causa di rialzo dei linfociti.

- Infezioni da miceti: raramente possono determinare aumento dei linfociti circolanti.

- Infezioni da parassiti: ad esempio la Toxoplasmosi o le infezioni intestinali da Tenia solium o da Toxocara (nematodi), causano un aumento della conta degli eosinofili e, a volte, dei linfociti.

- Eparina: sia per via endovenosa che sottocute può indurre leucocitosi, principalmente con linfocitosi, più raramente leucocitosi neutrofila.

- Farmaci antiepilettici: farmaci come la carbamazepina, il fenobarbital e la fenitoina possono scatenare una grave reazione di ipersensibilità: reazione da farmaco con eosinofilia e sintomi si-

Corrispondente: Claudia Venturino, SC Medicina 1 ed Ematologia, Ospedale S. Paolo, Savona, Italia. Tel.: +39.019.8404551

E-mail: c.venturino@asl2.liguria.it

Articolo pubblicato secondo la Creative Commons Attribution NonCommercial 4.0 License (CC BY-NC 4.0).

C Copyright C. Venturino e R. Tassara, 2019

Licensee PAGEPress, Italy

QUADERNI - Italian Journal of Medicine 2019; 7(1):40-45 stemici (drug reaction with eosynophilia and systemic symptoms, DRESS), associata a leucocitosi con marcato aumento di eosinofili e neutrofili. Alcuni pazienti sviluppano aumento selettivo dei linfociti, altri leucopenia.

- Minociclina: tetraciclina, comunemente usato per l'acne può dare linfocitosi.

- Malattie autoimmuni: possono causare infiammazione sistemica e associarsi a leucocitosi con linfocitosi: i) artrite reumatoide; ii) tireopatie autoimmuni (ad esempio il Morbo di Basedow, tiroidite di Hashimoto); iii) lupus eritematoso sistemico.

- Vasculiti: le più frequenti sono la granulomatosi di Wegener, l'arterite di Takayasu, la sindrome di Churg-Strauss, l'arterite temporale (arterite a cellule giganti o arterite di Horton), la malattia di Kawasaki, la porpora di Scholein-Henoch e la vasculite crioglobulinemica.

- Malattie infiammatorie croniche intestinali: inflammatory bowel disease (IBD), sono fondamentalmente il morbo di Crohn e la rettocolite ulcerosa, comportano un'infiammazione e un danno cronico all'apparato gastrointestinale, hanno andamento cronico o ricorrente e si presentano con periodi di latenza alternati a fasi di riacutizzazione, spesso associate a lieve leucocitosi con aumento di neutrofili e/o di linfociti.

- Stress: in presenza di situazioni stressanti, il rilascio endogeno di corticosteroidi ed epinefrina è causa di leucocitosi, talvolta con linfocitosi

- Splenectomia: l'assenza di milza, congenita o secondaria a rimozione chirurgica (splenectomia):

- Traumi: si accompagnano a leucocitosi con lo stesso meccanismo dello stress.

- Dolore severo: come per i traumi e le situazioni di stress psicofisico, spesso il dolore è caratterizzato dal riscontro di leucocitosi e talvolta di linfocitosi.

Il medico internista in caso di riscontro di leucocitosi con linfocitosi dunque dovrà raccogliere tutte le informazioni del paziente mediante: i) anamnesi accurata: indagare in merito a patologie reumatiche, autoimmuni, tireopatie, morbo celiaco, asplenia/splenectomia, epatopatie, terapia farmacologica, ecc.; ii) quadro clinico: sintomi quali febbre/febbricola, re- 
centi infezioni, ecc.; iii) esame obiettivo: presenza di adenomegalie, epatosplenomegalia; iv) esami di laboratorio: PCR, VES, TSH, test di autoimmunità, esami sierologici, ecc.; v) esami strumentali: ecografia, TC.

Escluse cause di linfocitosi reattiva, quando la linfocitosi è confermata e significativa $(\mathrm{L}>5000 / \mathrm{mcL}$ ) e/o quando il quadro clinico è fortemente suggestivo per malattia ematologica (linfoadenomegalie, epatosplenomegalia, sintomi specifici), il medico internista dovrà orientarsi verso malattie linfoproliferative e quindi programmare uno studio dell'immunofenotipo su sangue periferico.

L'immunofenotipo potrà mettere in evidenza la presenza di una malattia ematologica (la patologia di maggiore frequenza è la leucemia linfatica cronica (LLC) ma esistono anche linfomi leucemizzati, leucemie acute). Talvolta invece la linfocitosi potrà essere etichettata come MBL.

\section{Linfocitosi B monoclonale}

Condizione clinica asintomatica, benigna, caratterizzata dalla presenza di popolazioni B linfocitarie clonali di piccola entità, rilevabili a livello del sangue periferico di soggetti altrimenti sani. Questa condizione racchiude tutti quei casi che, stante la presenza di popolazioni B cellulari anomale nel sangue periferico, non soddisfano i criteri per la diagnosi di una malattia linfoproliferativa. La recente definizione di linfocitosi $\mathrm{B}$ monoclonale (MBL) come entità diagnostica a sé assolve lo scopo di fornire criteri classificativi uniformi, necessari per l'attuazione di studi epidemiologici e biologici mirati, e costituisce un punto di partenza per indagarne l'evoluzione clinica ed il rischio di progressione, soprattutto in considerazione del fatto che soggetti portatori di questa condizione vengono identificati incidentalmente nel corso di indagini effettuate per problematiche mediche non correlate con sempre maggiore frequenza (dunque è una condizione di fronte alla quale può trovarsi anche il medico internista).

Dal punto di vista dell'entità del clone e del contesto in cui vengono individuate, le MBL possono essere suddivise in: ${ }^{1}$ i) population-screening $M B L$ : rilevate in individui altrimenti sani, in assenza di linfocitosi. Il numero di linfociti B è compreso nei limiti di norma ed una quota di cellule clonali estremamente bassa, hanno un rischio di evoluzione in LLC sovrapponibile a quello della popolazione generale. Non viene consigliato alcun tipo di follow-up in questi casi, se non nell'ambito di studi di ricerca; ii) clinical MBL: riscontrate nel corso di approfondimenti eseguiti nell'ambito di una linfocitosi, si caratterizza per il riscontro di una popolazione B-cellulare clonale in presenza di una linfocitosi clinicamente rilevabile, ma con una quota di linfociti $\mathrm{B}<5000 / \mu \mathrm{L}$.

La MBL rappresenta una condizione di grande interesse per la comprensione dei meccanismi alla base della comparsa e dell'evoluzione della LLC. I controlli periodici sono mirati ad accertare la stabilità della linfocitosi e cogliere eventuali, rari incrementi significativi della stessa.

Anche la rara evenienza di trasformazione da MBL in LLC, configura una situazione clinica asintomatica per la quale non è richiesto, in genere, alcun trattamento per molti anni ${ }^{2}$ (Tabella 2 ).

Tabella 1. Leucociti: valori normali e leucocitosi.

\begin{tabular}{ll}
\hline Valore normale leucociti: & $4000-10.000 / \mathrm{mcL}$ \\
\hline Leucocitosi neutrofilia: & $\mathrm{N}>6000 / \mathrm{mcL}$ \\
\hline Linfocitosi: & $\mathrm{L}>3600 / \mathrm{mcL}$ \\
\hline Monocitosi: & $\mathrm{M}>1000 / \mathrm{mcL}$ \\
\hline Leucocitosi eosinofilia: & Eo $>700 / \mathrm{mcL}$ \\
\hline Leucocitosi basofila: & $\mathrm{Ba}>50 / \mathrm{mcL}$ \\
\hline
\end{tabular}

Tabella 2. Classificazione delle MBL.

MBL LLC-simile Il 75\% dei casi. I cloni B cellulari hanno lo stesso fenotipo delle cellule della leucemia linfatica cronica. La MBL LLCsimile (la più studiata tra le MBL) è almeno 100 volte più frequente rispetto alla LLC, è evidente che la sua progressione in una malattia clinicamente significativa si verifica in una percentuale minoritaria di casi e secondo meccanismi tuttora non chiari. ${ }^{2}$ Il rischio di progressione della MBL LLC-simile in forme clinicamente conclamate è pari all'1-2\%, l'atteggiamento corretto è quello di rassicurare il paziente sulla bassa probabilità di manifestare una LLC sintomatica, istruendolo a riconoscere eventuali manifestazioni sistemiche correlate alla malattia di base (febbre, calo ponderale, abbondanti sudorazioni notturne, astenia estrema). Poiché non esiste un periodo al di là del quale il rischio di progressione del singolo è inesistente, i soggetti con diagnosi di MBL LLC-simile associata a linfocitosi clinicamente significativa vengono sottoposti a monitoraggio clinico regolare (generalmente rappresentato da una visita ematologica con esami ematochimici a cadenza annuale) a tempo indeterminato

MBL LLC-atipica In questi pazienti è compito dell'ematologo escludere il linfoma mantellare

MBL Non-LLC Hanno immunofenotipo simile a quello dei linfomi non Hodgkin (in particolare tipo cellule B della zona marginale) Vanno monitorati in ambito specialistico 


\section{Leucemia linfatica cronica}

Caratterizzata dall'accumulo di linfociti B a livello di sangue periferico, midollo osseo, linfonodi, milza, spesso si presenta con una leucocitosi con linfocitosi. La LLC prende origine da una ricca serie di eventi biologici e genetici primari e secondari: l'interazione con gli antigeni, lo stato di attivazione cellulare che ne segue, le interazioni con il microambiente. Talora preceduta da una condizione predisponente, la linfocitosi B-monoclonale (monoclonal $B$-cell lymphocytosis, MBL). L'approccio al paziente con LLC prevede lo studio di marcatori prognostici, molto utili per l'adeguata programmazione di terapie sempre più efficaci.

Definizione ed epidemiologia: è la più diffusa tra le leucemie (circa il 33\% dei casi totali). Nella maggior parte dei casi sono gli anziani ad ammalarsi, età media alla diagnosi: 70 anni, solo il $15 \%$ dei pazienti ha meno di 60 anni alla diagnosi. Più frequente nei maschi che nelle femmine $(1,5-2,0 / 1)$, incidenza nei paesi occidentali, riferita a 100.000 abitanti, pari a 26 casi/anno, l'incidenza aumenta da 1 caso/anno/ 100.000 abitanti nella fascia $40-50$ anni a 20 casi nella fascia 70-80 anni.

Diagnosi: nella maggior parte dei casi in occasione di esami del sangue routinari in pazienti asintomatici, in una minoranza di casi già alla diagnosi è presente un quadro clinico conclamato con adenopatie e/o splenomegalia, segni di insufficienza midollare, sintomi sistemici e, raramente, localizzazioni extranodali. Il medico internista deve dunque effettuare un'accurata diagnosi differenziale con le altre cause di linfocitosi.

La diagnostica della LLC prevede: i) valutazione dell'esame emocromocitometrico; ii) analisi citofluorimetrica per la determinazione dell'immunofenotipo; iii) analisi morfologica dello striscio di sangue periferico. La morfologia tipica mostra piccoli linfociti a cromatina addensata e le ombre di Gumprecht, che rappresentano linfociti rotti durante la preparazione dello striscio a causa di una loro intrinseca fragilità, determinata dalla riduzione della proteina del citoscheletro vimentina. ${ }^{3}$

Per la definizione diagnostica della LLC, secondo le linea guida del 2008 dell'International Workshop on Chronic Lymphocytic Leukemia, devono essere soddisfatti due criteri: ${ }^{4}$ i) conta B-linfocitaria assoluta nel sangue periferico di $\geq 5000 / \mathrm{mL}$, con una morfologia di piccoli linfociti maturi; ii) dimostrazione della clonalità dei linfociti $\mathrm{B}$ circolanti mediante citoflorimetria del sangue periferico.

L'analisi immunofenotipica, consente di porre diagnosi di LLC in presenza di una espansione di elementi CD19+, CD5+, CD23+, con CD22 e/o CD79b debolmente positivo e debole espressione delle immu- noglobuline di superficie (sIg) associata a restrizione delle catene leggere e negatività per FMC7. Forme aventi solo linfoadenopatie con biopsia positiva per LLC, ma con una conta periferica assoluta B linfocitaria minore di $5000 / \mu \mathrm{L}$, sono classificate come linfoma a piccoli linfociti (small lymphocytic lymphoma, SLL). Quindi, lo SLL si distingue dalla LLC solo per l'assenza di linfocitosi, avendo però le identiche caratteristiche patologiche e immunofenotipiche della LLC. Le due forme sono considerate due manifestazioni della stessa patologia.

\section{Anomalie citogenetiche, le alterazioni più frequenti}

La tecnica FISH ha permesso l'individuazione di aberrazioni cromosomiche in circa $1{ }^{\prime} 80 \%$ dei pazienti con LLC. Ogni paziente viene oggi incluso in uno specifico gruppo in base a una classificazione citogenetica gerarchica che attribuisce importanza decrescente alle seguenti lesioni: $17 \mathrm{p}->11 \mathrm{q}->+12>$ 13q-. i) perdita di una porzione del cromosoma 13 (del13q14), presente nel 55\% dei pazienti, associata, in assenza di altre anomalie cromosomiche, a decorso favorevole; ii) perdita di una porzione del cromosoma 11 (del11q23); iii) acquisizione di una terza copia del cromosoma 12 (trisomia 12); iv) perdita di una porzione del cromosoma 17 (del17p13), associata a sviluppo di resistenza al trattamento, decorso clinico sfavorevole; v) mutazioni nel gene TP53, hanno effetti simili a quelli della perdita del cromosoma 17. Questa condizione ha come ripercussione la perdita del controllo del ciclo cellulare, a causa del ruolo di sorveglianza che p53 svolge sul processo di replicazione del DNA. Le anomalie della via di TP53 sono alla base della resistenza all'apoptosi e dell'instabilità genetica, per cui i pazienti portatori di del17p13 hanno spesso anomalie cromosomiche complesse e molteplici lesioni genetiche. ${ }^{5}$ Questo ha avuto notevoli ripercussioni sulla scelta terapeutica già alla prima linea di trattamento: la presenza di mutazioni di TP53/dell7p13 suggerisce di evitare trattamenti chemio-immunoterapici e di prediligere trattamenti che sfruttino un meccanismo citotossico p53-indipendente. ${ }^{6}$ L'impiego dei nuovi inbitori del pathway del BCR e degli anti-BCL2 hanno apportato un significativo incremento delle risposte al trattamento nei pazienti portatori delle mutazioni di TP53/del17p13 mitigando l'impatto su PFS ed OS di queste aberrazioni.?

\section{Clinica}

\section{Manifestazioni principali}

Circa il $70 \%$ dei pazienti viene diagnosticato in seguito ad esami ematici routinari che dimostrano linfocitosi asintomatica, con obiettività negativa o con adenopatie diffuse a poche sedi, talvolta può essere 
presente già alla diagnosi ipogammaglobulinemia. Negli stadi intermedi compaiono, nelle principali sedi superficiali, adenopatie non dolenti, di consistenza parenchimatosa, non dura, associate o meno a epatosplenomegalia. Negli stadi avanzati possono comparire anemia o piastrinopenia secondarie a infiltrazione midollare.

\section{Quadro evolutivo}

Il primo criterio utile a definire il decorso della malattia è lo stadio clinico (il sistema di Rai e il sistema di Binet si basano sulle caratteristiche cliniche del paziente e sui valori dell'emocromo).

Lo stadio clinico può essere iniziale, intermedio o avanzato: nella maggior parte dei pazienti (80\%) la malattia viene diagnosticata nello stadio iniziale. I vari stadi della malattia comportano un andamento clinico differente; lo stadio determina anche la scelta se iniziare o meno il trattamento. Decorso clinico e sopravvivenza sono variabili: alcuni soggetti rimangono asintomatici con malattia stabile e non richiedono trattamento per anni, altri presentano andamento clinico aggressivo, rapida progressione della malattia, a volte difficilmente controllabile dalla terapia. La gestione clinica è molto migliorata negli ultimi anni, grazie a marcatori prognostici, a nuovi agenti terapeutici e al miglioramento delle terapie di supporto, tuttavia, negli stadi clinici più avanzati sono presenti manifestazioni sistemiche correlate all'anemia e alla trombocitopenia e al coinvolgimento di organi e apparati (fegato, milza, reni e midollo osseo), linfoadenomegalie superficiali e splenomegalia sono presenti nel $90 \%$ dei casi, epatomegalia nel $50 \%$ dei casi. Spesso la causa del decesso è una malattia intercorrente, poiché i pazienti sono solitamente soggetti anziani. ${ }^{8}$

Le complicanze infettive sono tra le principali cause di morbidità e mortalità nei pazienti con LLC ${ }^{9}$ non devono essere mai sottovalutate nel paziente con LLC, soprattutto se anziano e se già chemiotrattato. Il paziente affetto da LLC ricoverato per una complicanza infettiva in un reparto di medicina interna (oppure un paziente ricoverato per altro motivo ma che sviluppa una complicanza infettiva) deve essere prontamente studiato mediante esami colturali e strumentali e se necessario deve essere sottoposto a valutazione specialistica infettivologica ed ematologica. La patogenesi dell'aumentato rischio infettivo è correlata a fattori legati alla malattia, a fattori legati all'ospite e alle terapie specifiche effettuate. Nella LLC è presente una disregolazione immunitaria (descritte alterazioni dell'immunità cellulo-mediata in particolare delle cellule $\mathrm{T},{ }^{10}$ alterazioni della funzione del complemento ${ }^{11}$ e della via immunitaria umorale, con frequente ipogammaglobulinemia. ${ }^{12}$ Soprattutto negli stadi avanzati, i pazienti sono soggetti ad infe- zioni recidivanti sia per la neutropenia conseguente alla infiltrazione midollare, sia come conseguenza delle terapie. ${ }^{13}$ Gli agenti alchilanti e gli analoghi delle purine si associano prevalentemente ad infezioni batteriche da Streptococcus pneumoniae, Staphylococcus ed Haemophilus influenzae; complicanza infettiva frequente è l'Herpes zoster. ${ }^{9}$ Anche gli anticorpi monoclonali quali rituximab, ofatumumab e obinutuzumab si associano ad un aumentato rischio infettivo. Considerare inoltre le infezioni opportunistiche da Legionella pneumoniae, Pneumocystis carinii e Listeria monocytogenes, la polmonite da Citomegalovirus (CMV), le infezioni fungine da Candida e Aspergillo,${ }^{14}$ le infezioni opportunistiche e le riattivazioni di HBV soprattutto in pazienti in trattamento con ibrutinib. ${ }^{15}$ Idelalisib in associazioni terapeutiche o in popolazioni di pazienti non precedentemente autorizzate è associato ad un aumento degli eventi avversi gravi e dei decessi per cause infettive, principalmente da $P$. carinii e CMV. ${ }^{15}$

\section{Le seconde neoplasie}

I pazienti affetti da LLC hanno un rischio aumentato rispetto alla popolazione generale di sviluppare neoplasie secondarie (ematologiche e non-ematologiche), che ne rappresentano una delle principali cause di morte. L'incidenza di seconde neoplasie nella LLC è di 1,2-2,2 volte maggiore di quella attesa in una popolazione di pari età. ${ }^{16}$ Anche la linfocitosi B monoclonale è associata ad aumentato rischio di neoplasie secondarie non ematologiche. ${ }^{17}$

Le forme più frequenti sono le neoplasie cutanee, i tumori prostatici, mammari, gastrointestinali e polmonari. ${ }^{18}$ I meccanismi patogenetici non sono ancora del tutto chiari, ruolo importante è probabilmente svolto dallo stato di immunosoppressione tipico della LLC, in particolare riguardo alla disfunzione T-cellulare. ${ }^{19}$ L'utilizzo di terapie di combinazione contenenti fludarabina correla invece con una maggiore incidenza di leucemia acute mieloide (LAM) e mielodisplasie (SMD) secondarie. Le neoplasie secondarie a LLC hanno decorso più aggressivo $\mathrm{e}$ sopravvivenza inferiore rispetto alle forme non associate a LLC, in particolare nelle neoplasie mammarie, prostatiche, cutanee e del colon-retto. ${ }^{20} \mathrm{La}$ causa della differente prognosi è probabilmente legata alla minor efficacia del sistema immunitario che favorisce così invasione locale e le metastasi. Sembrano svolgere un ruolo importante anche le precedenti terapie per la LLC. È possibile, infatti, che la deplezione $\mathrm{T}$ cellulare indotta dalla fludarabina sia responsabile del diverso comportamento biologico delle cellule neoplastiche.

Dunque il medico internista deve sempre considerare la possibilità della presenza di una seconda neoplasia in un paziente con una LLC in anamnesi. 


\section{La trasformazione istologica}

La sindrome di Richter rappresenta lo sviluppo di un linfoma aggressivo in un paziente affetto da LLC. Condizione relativamente rara, che può verificarsi nel $5-10 \%$ dei pazienti affetti da LLC. ${ }^{21}$ La forma più frequente (90-95\% dei casi) è la SR variante diffuse large B-cell lymphoma (DLBCL). Più raramente (5$10 \%$ dei casi) è possibile lo sviluppo di un Hodgkin lymphoma (HL). ${ }^{22}$ Si parla in questo caso di SR variante Hodgkin. ${ }^{23}$ È caratterizzata da rapido deterioramento clinico, sintomi sistemici, aumento asimmetrico dei linfonodi, splenomegalia ed epatomegalia, versamenti nelle cavità sierose e cachessia. La diagnosi, sospettata clinicamente, laboratoristicamente e radiologicamente, necessita della conferma istologica su biopsia di un linfonodo ingrandito. ${ }^{24}$ L'accumulo di molteplici lesioni genetiche suggerisce che nella SR vi sia una instabilità genomica che predispone le cellule neoplastiche alla trasformazione. ${ }^{25}$ Non esiste consenso sul miglior approccio terapeutico, le risposte alle terapie standard sono limitate, la sopravvivenza mediana è 8-12 mesi La trasformazione in leucemia a prolinfociti è evenienza poco frequente caratterizzata da comparsa nel sangue periferico e nel midollo osseo di cellule linfoidi con caratteristiche morfologiche sovrappponibili a quelle della leucemia prolinfocitica, rapido decadimento fisico, refrattarietà ai trattamenti chemioterapici, splenomegalia, prognosi infausta. ${ }^{8}$

\section{Terapia della leucemia linfatica cronica}

In genere, la LLC in fase iniziale è asintomatica: in questi casi il paziente non necessita di alcuna terapia e deve solo sottoporsi a controlli periodici programmati dallo specialista ematologo.

Tuttavia, se la malattia causa sintomi sistemici, riduzione dei globuli rossi (anemia) o delle piastrine (piastrinopenia), o eccessivo ingrossamento di milza o dei linfonodi, è necessario iniziare il trattamento. In alcuni casi, se le cellule leucemiche si moltiplicano molto rapidamente (aumentando del 200\% in 6 mesi o del $50 \%$ in 2 mesi), la terapia può essere iniziata anche prima che si sviluppino dei sintomi. La terapia più utilizzata nella leucemia linfatica cronica consiste nella combinazione di due diversi trattamenti: la chemioterapia e la terapia con anticorpi monoclonali (chemioimmunoterapia). Nella pratica clinica si possono inoltre presentare frequentemente condizioni nelle quali la terapia di induzione prescelta o il numero totale di cicli da somministrare può essere il frutto di un'attenta valutazione delle condizioni generali del paziente, del grado di aggressività della malattia e della tolleranza al trattamento. Il trapianto di cellule staminali da donatore invece è indicato solo in un numero limitato di pazienti, defi- niti in base all'età e alle caratteristiche della malattia: ad esempio per i pazienti con delezione $17 \mathrm{p}$ o mutazioni di TP53 e per i pazienti giovani e in buone condizioni che non abbiano risposto o che siano progrediti dopo terapia di prima linea con inibitori del BCR signaling o con venetoclax.

Il processo decisionale deve tener presente tutti i seguenti aspetti: i) quando iniziare il trattamento. Esiste evidenza, ${ }^{26}$ che il trattamento precoce degli stadi iniziali o intermedi nei pazienti con malattia stabile e asintomatica non prolunga la sopravvivenza rispetto ad una vigile attesa seguita dalla terapia somministrata al momento dell'evoluzione clinica. Vi è pertanto attualmente unanime consenso sul concetto di non trattare i pazienti asintomatici, in stadio iniziale o intermedio che non presentano adenopatie massive, indipendentemente dalla presenza alla diagnosi di uno o più fattori di rischio biologico; ii) l'età e le condizioni cliniche generali del paziente (specie se pretrattato o con comorbidità); iii) le caratteristiche cliniche della malattia. Il paziente può richiedere trattamento per l'espansione di malattia a livello emato-midollare, per progressivo coinvolgimento linfonodale, oppure per le manifestazioni autoimmuni: le più frequenti sono l'anemia emolitica autoimmune (AEA) e la piastrinopenia autoimmune. L'approccio terapeutico iniziale dell'AEA, che può presentarsi alla diagnosi o durante il decorso della malattia e nei pazienti pretrattati è il cortisone; iv) alcune caratteristiche biologiche tra queste, le più importanti sono la perdita di una parte del cromosoma 17 e la presenza di mutazioni nel gene TP53, che favoriscono la resistenza alla chemioterapia. Al momento del trattamento di prima linea o alla ricaduta, la determinazione della delezione $17 \mathrm{p}$ e delle mutazioni di TP53 sono oggi assolutamente necessarie per programmare per alcuni pazienti una terapia incentrata su inibitori del signaling intracellulare (nella pratica clinica ibrutinib, idelalisib e venetoclax).

Il medico internista che si prende cura di un paziente che sta assumendo questo tipo di terapia deve tenere conto del fatto che tra le tossicità specifiche di questi farmaci occorre considerare con attenzione: i) la fibrillazione atriale e l'ipertensione arteriosa, oltre ai sanguinamenti e la diarrea, quasi sempre di grado lieve, per ibrutinib; ${ }^{27}$ ii) fenomeni su base infiammatoria e/o disimmune per idelalisib, quali diarrea e/o colite anche ad insorgenza tardiva, polmonite interstiziale anche di grado severo, infezioni polmonari da Pneumocystis jirovecii e/o da Cytomegalovirus e aumento delle transaminasi ${ }^{28}$ (in questi pazienti la terapia di profilassi con cotrimoxazolo e trimetoprim è obbligatoria, al pari del monitoraggio della viremia da Cytomegalovirus); iii) la sindrome da lisi tumorale con venetoclax, che richiede misure preventive e attento monitoraggio. 


\section{Bibliografia}

1. Shanafelt TD, Ghia P, Lanasa MC, et al. Monoclonal Bcell lymphocytosis (MBL): biology, natural history and clinical management. Leukemia 2010;24:512-20.

2. Caligaris-Cappio F, Ghia P. Novel insights in chronic lymphocytic leukemia: are we getting closer to under standing the pathogenesis of the disease? J Clin Oncol 2008;26:4497-503.

3. Nowakowski GS, Maurer MJ, Habermann TM, et al. Percentage of smudge cells on routine blood smear predicts survival in chronic lymphocytic leukemia. J Clin Oncol 2010;28:412-7.

4. Hallek M, Cheson BD, Catovsky D, et al. Guidelines for the diagnosis and treatment of chronic lymphocytic leukemia: a report from the International Workshop on Chronic Lymphocytic Leukemia updating the National Cancer Institute-Working Group 1996 guidelines. Blood 2008;111:5446-56.

5. Herling CD, Klaumünzer M, Rocha CK, et al. Complex karyotypes and KRAS and POT1 mutations impact outcome in CLL after chlorambucil-based chemotherapy or chemoimmunotherapy. Blood 2016;128:395-404.

6. Cramer P, Langerbeins P, Eichhorst B, Hallek M. Advances in first-line treatment of chronic lymphocytic leukemia: current recommendations on management and first-line treatment by the German CLL Study Group (GCLLSG). Eur J Haematol 2016;96:9-18.

7. Roberts AW, Davids MS, Pagel JM, et al. Targeting BCL2 with Venetoclax in Relapsed Chronic Lymphocytic Leukemia. N Engl J Med 2016;374:311-22.

8. Castoldi G, Liso V. Malattie del sangue e degli organi ematopoietici. 6 ed. Milano: McGraw Hill; 2013. pp 402-418.

9. Kjellander C, Björkholm M, Källman O, et al. Bloodstream infections in patients with chronic lymphocytic leukemia: a longitudinal single-center study. Ann Hematol 2016;95:871-9.

10. Maharaj K, Sahakian E, Pinilla-Ibarz J. Emerging role of BCR signaling inhibitors in immunomodulation of chronic lymphocytic leukemia. Blood Adv 2017;1:1867-75.

11. Randhawa JK, Ferrajoli A. A review of supportive care and recommended preventive approaches for patients with chronic lymphocytic leukemia. Exp Rev Hematol 2016;9:235-44.

12. Freeman JA, Crassini KR, Best OG, et al. Immunoglobulin $\mathrm{G}$ subclass deficiency and infection risk in 150 patients with chronic lymphocytic leukemia. Leuk Lymph 2013;54:99-104.

13. Castoldi G, Liso V. Malattie del sangue e degli organi ematopoietici. 6 ed. Milano: McGraw Hill; 2013. pp 402-418.

14. Montserrat E, Campo E. Small lymphocytic lymphoma/chronic lymphocytic leukemia. In: Canellos GP, Lister TA, Young BD, eds. The Lymphomas. 2nd ed. Philadelphia, PA: Saunders Elsevier; 2006. pp. 406-414.
15. de Weerdt I, Koopmans SM, Kater AP, Gelder M. Incidence and management of toxicity associated with ibrutinib and idelalisib: a practical approach. Haematologica 2017 [epub ahead of print].

16. Tsimberidou AM, Wen S, McLaughlin P, et al. Other malignancies in chronic lymphocytic leukemia/small lymphocytic lymphoma. J Clin Oncol 2009;27:904-10.

17. Solomon BM, Rabe KG, Moreira J, et al. Risk of cancer in patients with clinical monoclonal b-cell lymphocytosis (MBL): a cohort study of newly diagnosed patients compared to controls. ASH Annu Meeting Abstr 2012;120:2893.

18. Travis LB, Curtis RE, Hankey BF, Fraumeni JF Jr. Second cancers in patients with chronic lymphocytic leukemia. J Natl Cancer Inst 1992;84:1422-7.

19. Greene MH, Hoover RN, Fraumeni JF Jr. Subsequent cancer in patients with chronic lymphocytic leukemia a possible immunologic mechanism. J Natl Cancer Inst 1978;61:337-34.

20. Solomon BM, Rabe KG, Slager SL, et al. Overall and cancer-specific survival of patients with breast, colon, kidney, and lung cancers with and without chronic lymphocytic leukemia: a SEER population-based study. J Clin Oncol 2013;31:930-7.

21. Rossi D, Cerri M, Capello D, et al. Biological and clinical risk factors of chronic lymphocytic leukaemia transformation to Richter syndrome. $\mathrm{Br} \mathrm{J}$ Haematol 2008;142:202-15.

22. Tsimberidou AM, O'Brien S, Kantarjian HM, et al. Hodgkin transformation of chronic lymphocytic leukemia: the M.D. Anderson Cancer Center experience. Cancer 2006;107:1294-302.

23. Tadmor T, Shvidel L, Bairey O, et al. Richter's trnasformation to diffuse large B-cell lymphoma: a retrospective study reporting clinical data, outcome, and the benefit of adding rituximab to chemotherapy, from the Israeli CLL Study Group. Am J Hematol 2014;89:218-22.

24. Rossi D, Gaidano G. Richter syndrome: molecular insights and clinical perspectives. Hematol Oncol 2009;27:1-10.

25. Fuilop Z, Csernus B, Tímár B, et al. Microsatellite instability and hMLH1 promoter hypermethylation in Richter's transformation of chronic lymphocytic leukemia. Leukemia 2003;17:411-5.

26. CLL Trialists' Collaborative Group. Chemotherapeutic options in chronic lymphocytic leukemia: a meta-analysis of the randomized trials. J Natl Cancer Inst 1999;91:861-8.

27. Byrd JC, Furman RR, Coutre SE, et al. Three-year follow-up of treatment-naïve and previously treated patients with CLL and SLL receiving single-agent ibrutinib. Blood 2015;125:2497-506.

28. Louie CY, DiMaio MA, Matsukuma KE, et al. Idelalisib-associated enterocolitis: clinicopathologic features and distinction from other enterocolitides. Am J Surg Pathol 2015;39:1653-60. 


\title{
Come affrontare il paziente con adenomegalia
}

\author{
Paola Gnerre, ${ }^{1}$ Nathan Artom, ${ }^{2}$ Elisa Schiavetta, ${ }^{3}$ Lionello Parodi ${ }^{1}$ \\ ${ }^{1}$ Medicina 2 e Cure Intermedie, Ospedale San Paolo, Savona; ${ }^{2}$ Medicina 1 e Ematooncologia, Ospedale San Paolo, Savona; \\ ${ }^{3}$ Facoltà di Medicina e Chirurgia, Università degli Studi di Siena, Siena, Italia
}

\section{Introduzione}

I linfonodi insieme a milza, tonsille, adenoidi e placche di Peyer costituiscono il tessuto linfoide deputato alla rimozione degli antigeni dai fluidi extracellulari. Il corpo umano contiene circa 600 linfonodi. I linfonodi in condizioni normali non sono palpabili, possono essere superficiali e profondi, hanno una forma a fagiolo con dimensione variabile tra 1-25 mm. Per linfoadenopatie (LP) si definisce un'alterazione delle dimensioni e delle caratteristiche dei linfonodi. Le linfoadenopatie possono essere isolate o generalizzate. Le linfoadenopatie localizzate si verificano tipicamente nel territorio di drenaggio linfonodale di una neoplasia o di una patologia infiammatoria/infettiva. Una linfoadenopatia generalizzata generalmente si associa a sintomi sistemici e fa propendere maggiormente verso una patologia maligna. ${ }^{1}$

Le linfoadenomegalie sono da sempre un dilemma per il medico soprattutto per la possibile associazione con patologie neoplastiche. Nella pratica clinica, comunque, meno dell' $1 \%$ dei pazienti con linfoadenomegalie ha una patologia neoplastica maligna. Studi in cure primarie, riportano una prevalenza di neoplasia in presenza di linfoadenomegalie di circa lo $0,4 \%$ nei pazienti con età $<40$ anni e di circa il $4 \%$ in quelli con età $>40$ anni. L'incidenza di neoplasia incrementa del $17 \%$ in centri di riferimento e del $40-60 \%$ nei pazienti con alto sospetto clinico. Numerosi studi dimostrano come le principali manifestazioni di malattie comuni benigne sono rappresentate proprio da alterazioni aspecifiche reattive a carico dei linfonodi. Tra le prin-

Corrispondente: Paola Gnerre, Medicina 2 e Cure Intermedie, Ospedale San Paolo, Savona, Italia.

Tel.: +39.019.8404358 - Fax: +39.019.8404583.

E-mail:pgnerre@yahoo.it

Articolo pubblicato secondo la Creative Commons Attribution NonCommercial 4.0 License (CC BY-NC 4.0).

CCopyright P. Gnerre et al., 2019

Licensee PAGEPress, Italy

QUADERNI - Italian Journal of Medicine 2019; 7(1):46-51 cipali cause di LP nell'adulto si annoverano infatti le malattie infettive ( $75 \%$ delle cause) seguite da malattie autoimmuni (15\%) ed emato-oncologiche (circa 10\% dei casi). Pertanto in molti casi la linfoadenomegalia è una diretta conseguenza di una patologia infettiva $\mathrm{e}$ non necessita di ulteriori indagini diagnostiche. Anche la sede riveste un importante ruolo prognostico. Una LP sovraclaveare è altresì ad alto rischio di malignità con un rischio pari al $90 \%$ nei pazienti con età $>40$ anni e del $25 \%$ in quelli con età $<40$ anni. Comunque la stabilità delle LP per almeno un anno riduce la probabilità che le linfoadenomegalie siano diretta espressione di una patologia neoplastica maligna. ${ }^{2}$

L'approccio al paziente con linfoadenopatia pertanto può essere complesso e deve comunque includere in primis un'attenta storia anamnestica e un dettagliato esame obiettivo che da soli possono già indirizzare il clinico nel successivo work-up diagnostico laboratoristico e strumentale.

\section{Linfoadenopatie localizzate}

Le stazioni linfonodali cervicali sono interessate più frequentemente rispetto alle altre. Le linfoadenopatie cervicali sono però segno di differenti patologie e quindi richiedono un approccio più esteso. In Tabella 1 sono mostrate le differenti possibili diagnosi in relazione alla sede della linfoadenopatia. ${ }^{1}$

\section{Linfoadenopatie generalizzate}

Si parla di linfoadenopatia generalizzata quando interessa più di tre stazioni linfonodali. La presenza di linfoadenopatia generalizzata è sempre espressione di una malattia sottostante. In Tabella 2 sono mostrate le principali cause di linfoadenopatia generalizzata. ${ }^{1}$

\section{Storia anamnestica}

Nella valutazione anamnestica rientrano l'età del paziente (nel paziente più anziano e più alta la probabilità di una genesi maligna), eventuali viaggi effettuati e farmaci assunti (Tabella 3), storia di comportamenti a ri- 
schio (abitudini sessuali con multipli partner sessuali, assunzione di droghe per via endovenosa) e di pregresse infezioni o neoplasie e la durata dei sintomi. Una lunga storia di sintomi ad esempio può suggerire un'infezione cronica come la tubercolosi o una malattia neoplastica indolente come un linfoma follicolare. Nelle aree tropicali la tubercolosi è la principale causa di LP sia negli adulti che nei bambini. La presenza di dolore correla generalmente con la presenza di una patologia infettiva ma il dolore potrebbe anche essere indotto da un evento emorragico nella zona necrotica di un linfonodo neoplastico. La triade caratterizzata da febbre elevata, faringite, linfonodi dolenti con associata splenomegalia (>50\%) è altamente suggestivo per mononucleosi infettiva da virus di Epstein Barr (EBV). La mononucleosi infettiva può interessare tutte l'età se pur è più frequente negli adolescenti. Un'infezione da CMV, toxoplasma, HIV e virus erpetici possono comunque determinare una sintomatologia simile a quella della mononucleosi infettiva. Circa il 90\% degli adulti nel mondo sono sieropositivi per CMV sebbene soltanto il $25-30 \%$ di essi sviluppa la malattia. La presenza di sintomi da compressione meccanica come disfagia, tosse, disfonia, emottisi o una sintomatologia sistemica come il calo ponderale, l'anoressia, l'astenia e la febbre possono orientare verso una possibile genesi neoplastica. L'esposizione al tabacco, all'alcool, a radiazioni ultraviolette può incrementare il sospetto clinico di carcinoma metastatico. La presenza di linfoadenomegalia con associata artromialgie, dolori muscolari, inusuali rash cutanei e anemia può

Tabella 1. Aree di drenaggio linfonodale e cause di linfoadenopatia localizzata. ${ }^{2}$

\begin{tabular}{lll}
\hline Linfonodo & Area di drenaggio & Cause di ingrandimento \\
\hline Cervicale & Regione del collo e del cuoio capelluto & Infezioni virali: infezioni del tratto respiratorio alto, mononucleosi, herpes
\end{tabular}
virus, virus coxsackie, CMV virus, HIV.

Infezioni batteriche: stafilococco aureus, streptococco pyogenes, TBC, ascesso dentale, malattia da graffio di gatto.

Neoplasie: della testa e del collo, della tiroide, linfoma di Hodgkin e non Hodgkin.

\begin{tabular}{|c|c|c|}
\hline Sovraclaveare & $\begin{array}{l}\text { Mammella } \\
\text { Mediastino parte di destra } \\
\text { Addome parte di sinistra }\end{array}$ & $\begin{array}{l}\text { Infezioni: TBC e infezioni fungine. } \\
\text { Neoplasie: linfoma di Hodgkin. } \\
\text { Linfoma non Hodgkin, carcinoma della mammella, carcinoma bronchiale, } \\
\text { neoplasia della tiroide, neoplasie toraciche e addominali. }\end{array}$ \\
\hline Epitrocleare & Arto superiore dell'arto, avambraccio e mano & $\begin{array}{l}\text { Malattie granulomatosi: sarcoidosi. } \\
\text { Neoplasie: linfoma. } \\
\text { Infezioni: mononucleosi infettiva, infezioni localizzate nelle estremità } \\
\text { superiori, sifilide secondaria, HIV. }\end{array}$ \\
\hline Mediastinici & Mediastino & $\begin{array}{l}\text { Malattie granulomatosi: sarcoidosi, istoplasmosi. } \\
\text { Miscellanee: silicosi. } \\
\text { Infezioni: tubercolosi. } \\
\text { Neoplasie: linfoma e altre neoplasie toraciche e addominali. }\end{array}$ \\
\hline Ascellare & Estremità superiori, petto e torace & $\begin{array}{l}\text { Infezioni: infezioni cutanee dastreptococco e stafilococco, malattia da graffio } \\
\text { di gatto. } \\
\text { Malattie granulomatosi: sarcoidosi. } \\
\text { Neoplasie: carcinoma della mammella, melanoma metastatico, linfoma, } \\
\text { leucemia, linfoadenopatia reattiva benigna. }\end{array}$ \\
\hline Addominale & Spazio mesenterico o retroperitoneale & Tubercolosi, linfoma, neoplasia gastrica, ecc. \\
\hline Inguinali & Pelvi e arti inferiori & $\begin{array}{l}\text { Infezioni: infezioni sessualmente trasmesse, cellulite. } \\
\text { Neoplasie: linfoma, carcinoma squamocellulare del pene e della vulva, } \\
\text { melanoma metastatico. }\end{array}$ \\
\hline
\end{tabular}

Tabella 2. Cause di linfoadenopatia generalizzata. ${ }^{1}$

\begin{tabular}{ll}
\hline Infezioni & Mononucleosi, HIV, tubercolosi miliare, febbre tifoide, sifilide \\
\hline Neoplasie & Linfoma, leucemia acuta \\
\hline Disordini autoimmuni & LES, artrite reumatoide, sindrome di Sjogren \\
\hline Reazioni da farmaci & Fenitoina, allopurinolo, atenololo \\
\hline Malattia da deposito di lipidi & $\begin{array}{l}\text { Malattia di Gusher } \\
\text { Malattia di Neiman-Peak }\end{array}$ \\
\hline
\end{tabular}


indirizzare verso la diagnosi di malattia autoimmune come l'artrite reumatoide, il LES e la dermatomiosite. Comunque se è diagnosticata una dermatomiosite va sempre esclusa una sottostante patologia neoplastica. La presenza di sintomi B (febbre, sudorazioni notturne e una perdita di peso inspiegabile più del $10 \%$ in 6 mesi) associata a LP è altamente suggestiva per malattie linfoproliferative. La presenza di prurito generalizzato associato a LP è presente nel $30 \%$ dei pazienti con linfoma di Hodgkin e nel $10 \%$ dei pazienti con linfoma non Hodgkin. Il 75\% di tutte le linfoadenomegalia sono localizzate e in più del $50 \%$ interessano le stazioni linfonodali di testa e del collo. Generalmente sono diretta conseguenza di specifiche patologie nella regione del drenaggio linfatico e quindi possono essere diagnosticate senza ulteriori accertamenti. Nel $25 \%$ dei casi le LP sono generalizzate e spesso sono il segno di una sottostante malattia sistemica. ${ }^{1}$

\section{Esame obiettivo}

In presenza di una linfoadenopatia tutte le stazioni linfonodali palpabili dovrebbero essere valutate facendo particolare attenzione alle caratteristiche, alle dimensioni, alla consistenza e la mobilità dei linfonodi rispetto ai piani sottostanti. Importante valutare la presenza di organomegalia in particolare di splenomegalia e di segni e sintomi di malattia sistemica. L'organomegalia soprattutto la splenomegalia è frequentemente associata a patologie infettive come la mononucleosi ma può essere presente anche nel linfoma di Hodgkin e non Hodgkin e nella sarcoidosi. Il quadro obiettivo cutaneo associato è importante: la presenza ad esempio di una striatura linfangitica rossa suggestiva per linfangite può maggiormente orientare verso una patologia infettiva localizzata. In merito alle dimensioni i linfonodi normalmente sono $<1 \mathrm{~cm}$ di diametro. Linfoadenomegalie palpabili in sede sovraclaveare, linfoadenopatie iliache, poplitee ed epitrocleari maggiori di $0,5 \mathrm{~cm}$ sono da considerare sempre patologiche. Si parla di linfonodi inguinali patologici invece quando questi hanno dimensioni $>1,5 \mathrm{~cm}$. Linfonodi in altre aree sono da considerare anomali se il loro diametro eccede il centimetro. Nel bambino (età 2-10 anni) i linfonodi sono da considerare patologici solo quando hanno dimensioni superiori a $2 \mathrm{~cm}$. Per quanto riguarda la consistenza, linfonodi di consistenza soffice sono comunemente presenti nelle leucemie acute mentre nelle leucemie e nei linfomi cronici sono presenti prevalentemente linfonodi di consistenza teso-elastica o gommosa. Linfonodi duri sono tipici di neoplasie maligne e patologie croniche ad evoluzione fibrotica. Altro elemento da valutare obiettivamente è la mobilità rispetto ai piani sottostanti. In presenza di infezioni e connettiviti i linfonodi risultano generalmente mobili rispetto ai piani sottostanti. Linfonodi fissi alla cute o ai tessuti circostanti sono spesso di natura maligna. Infine la cute deve essere esaminata attentamente per escludere lesioni inusuali per neoplasia come il melanoma. ${ }^{1}$

\section{Work-up diagnostico}

Nella Tabella 4 è presentato il work-up diagnostico nel paziente con LP localizzata e generalizzata. Il primo step include un'attenta valutazione anamnestica e obiettiva. ${ }^{1}$ Test laboratoristici come l'emocromo, gli indici

Tabella 3. Farmaci che possono causare linfoadenopatie. ${ }^{2}$

\begin{tabular}{l}
\hline Idralazina \\
\hline Fenitoina \\
\hline Primidone \\
\hline Allopurinolo \\
\hline Atenololo \\
Carbamazepina \\
Cefalosporine
\end{tabular}

Chinidina

Sulfamidici

Tabella 4. Principali caratteristiche che possono orientare verso linfoadenomegalie infettive infiammatorie o neoplastiche. ${ }^{3}$

\begin{tabular}{ll}
\hline Malattia infettiva-infiammatoria & Malattia neoplastica \\
\hline Dimensioni $<2 \mathrm{~cm}$ & Dimensioni $>2 \mathrm{~cm}$ \\
\hline Consistenza elastica & Consistenza lignea \\
\hline Senza tendenza alla coesione & Tendenza alla conglomerazione \\
\hline Non adesa ai piani superficiali né profondi & Adesa ai piani superficiali e profondi \\
\hline Dolente & Non dolenti \\
\hline Dolorabile & Non dolorabili \\
\hline
\end{tabular}

Con carattere suppurativo 
di flogosi, l'elettroforesi delle proteine, la sierologia per HIV, per EBV, gli anticorpi IgM anti CMV o la PCR per CMV, la sierologia per Toxoplasma e Bartonella sono indicati nella maggior parte dei pazienti con linfoadenopatia. ${ }^{4}$ Il riscontro di linfocitosi con la presenza di almeno il 10\% di linfociti atipici e la positività della sierologia per virus di Epstein Barr orienta fin da subito verso la diagnosi di mononucleosi infettiva. ${ }^{5} \mathrm{La}$ presenza di linfonodi atipici in assenza di una clinica suggestiva e una sierologia negativa per EBV può orientare verso una leucemia acuta che impone ulteriori accertamenti come l'esecuzione della biopsia osteomidollare. Test specifici come il test alla tubercolina, lo studio dell'autoimmunità sistemica (ANA, Ab antiDsDNA, gli anticorpi anti-citrullina, il dosaggio del complemento) e i test per la sifilide vanno riservati a situazioni suggestive per quelle diagnosi. La valutazione linfonodale attraverso le imaging permette un più completo inquadramento dei linfonodi rispetto alla sola valutazione obiettiva. ${ }^{6}$ In caso di LA periferica l'ecografia consente la valutazione del numero, delle dimensioni, dei margini e della struttura dei linfonodi, in caso di linfoadenomegalia pronfonda, mentre la TAC e la RMN permettono la valutazione dei linfonodi profondi oltre ad un'eventuale stadiazione di malattia. L'uso del colordoppler all'indagine ecografica permette di valutare il pattern vascolare, il tipo di vascolarizzazione e il grado di resistenza vascolare. Permette inoltre di distinguere tra una linfoadenomegalia attiva da una non attiva. ${ }^{1} \mathrm{Un}$ linfonodo reattivo normale è generalmente ovalare con l'ilo ben rappresentato mentre un linfonodo metastatico e linfomatoso si caratterizza per una lesione rotonda. Numerosi studi hanno mostrato come un rapporto tra asse lungo e corto inferiore a 2 è indicativo di lesione metastatica. I linfonodi metastatici sono generalmente ipoecogeni rispetto al parenchima circostante mentre i linfonodi reattivi tendono ad avere una vascolarizzazione ilare prominente rispetto alla vascolarizzazione periferica dovuto all'incremento del flusso. I linfonodi metastatici spesso hanno un pattern periferico perfusionale e anormale struttura ilare. La valutazione ecografica permette inoltre la valutazione della presenza di micro calcificazioni che sono presenti nel $50-70 \%$ dei casi ad esempio di carcinoma papillare tiroideo e nei linfonodi carcinomatosi ascellari da neoplasia della mammella. Multipli linfonodi tendenti alla fusione e con un forte eco interno (dovuto alla presenza di calcificazioni) sono caratteristiche tipiche invece di linfadenite tubercolare.

I pazienti con linfoadenomegalie ma senza sintomi e segni suggestivi per patologie neoplastiche potrebbero essere ragionevolmente sottoposti ad un follow up di 34 settimane con un atteggiamento wait and watch. ${ }^{4}$ Una successiva conferma diagnostica infatti come ad esempio in caso di tubercolosi o linfoma indolente non avrebbe comunque esiti negativi sugli outcome succes- sivi. In caso di persistenza della linfoadenomegalia anche dopo 3-4 settimane di follow-up o nel caso di linfonodi fin dall'esordio ad alto sospetto di malignità è indicata la biopsia linfonodale. Il citologico mediante ago aspirato sottile (FNAC) è una procedura semplice, sicura e accurata, nella diagnosi di iperplasia reattiva, infezioni granulomatose, linfoadenopatie, linfoma e localizzazioni metastatiche. L'accuratezza diagnostica del FNAC nella localizzazione linfonodale metastatica da carcinoma è pari al 82-96\%. Le principali limitazioni di una FNAC sono l'inadeguatezza del campione, l'alto rischio di falsi negativi in patologie neoplastiche come la malattia di Hodking e l'inadeguata classificazione per il linfoma non Hodgkin. Una biopsia core need non con ago sottile è un ulteriore metodo di diagnosi che permette un maggior quantitativo di campione rispetto alla FNAC. Una biopsia core need eco-guidata nel linfoma ha un'accuratezza pari al 76-100\%. Pertanto l'esame citologico mediante FNAC eco guidata risulta ad oggi il principale metodo diagnostico per infiltrazione linfonodale neoplastica carcinomatosa mentre nel linfoma il primo approccio potrebbe essere rappresentato dalla biopsia core need se pur la biopsia escissionale è tutt'ora considerato il gold standard. La biopsia escissionale va sempre eseguita sul linfonodo di dimensioni maggiori o con le caratteristiche più suggestive. In caso di multiple linfoadenopatie in ordine di preferenza va scelta in primis la sede sovraclaveare, seguita dalla sede cervicale, mediastinica, ascellare e inguinale. Studi di imaging come la TAC o la Risonanza Magnetica hanno un ruolo nelle linfoadenopatie perché ne permettono di valutare l'estensione oltre a identificare altre lesioni associate e ad eseguire una stadiazione in caso di patologia neoplastica. Un'età $>40$ anni, il coinvolgimento di multipli siti linfonodali, linfoadenomegalie sopraclaveari, un dimatro linfonodale $>2 \mathrm{~cm}$, noduli fissi o duri rispetto ai piani sottostanti, mancanza di elasticità, consistenza solida o dura, anomalo RX torace deve indurre il clinico ad eseguire il più rapidamente possibile un'indagine citologica o istologica (Figura 1). Non c'è invece nessuna evidenza alla somministrazione di terapia antibiotica empirica per poter identificare una linfoadenopatie batterica rispetto ad altre possibili cause. ${ }^{4}$

\section{Trattamento}

Il trattamento delle LP dipende dalla causa identificata nel corso del work-up diagnostico ed è quindi conseguente alla diagnosi. Il trattamento antitubercolare può essere avviato anche in assenza di una diagnosi certa in caso di alto sospetto clinico. La terapia corticosteroidea o immunosoppressiva può essere avviata in caso di patologie autoimmuni come il LES o la sarcoidosi. Il trattamento chemioterapico, la radioterapia e la chirurgia possono essere indicate in caso di patologia neoplastica maligna. ${ }^{7}$ 


\section{Conclusioni}

Un approccio sistematico alle linfoadenopatie è necessario per le varie condizioni che possono causarle. È quindi importante effettuare un'attenta anamnesi, un accurato esame obiettivo ed eseguire indagini laboratoristiche e strumentali che possono poi orientare ad effettuare ulteriori accertamenti come la biopsia citologica o tissutale. È importante valutare attentamente la sede della biopsia per evitare falsi negativi.

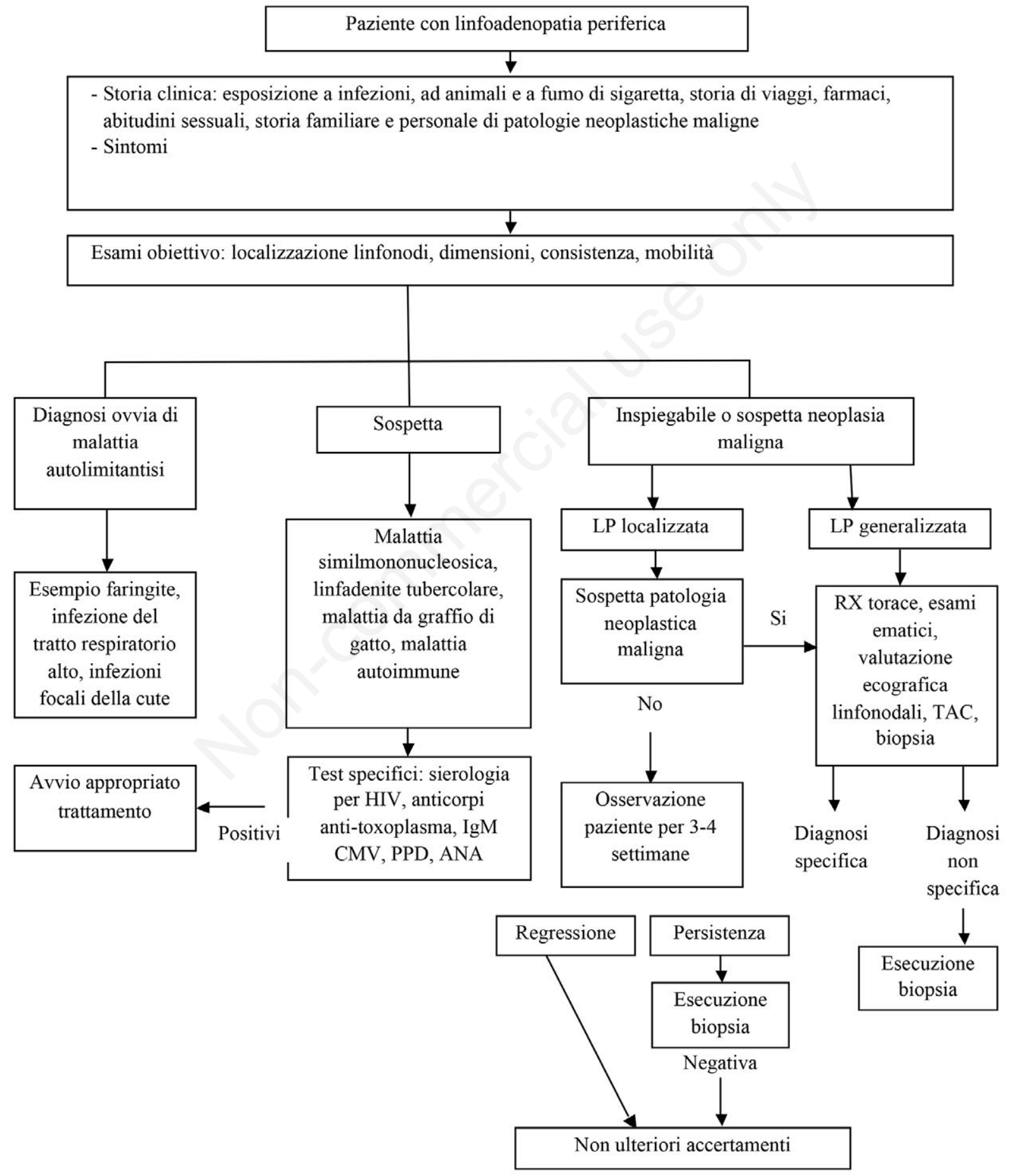

Figura 1. Approccio al paziente con linfoadenomegalie. 


\section{Bibliografia}

1. Rathod N. Practical Approach to Lymphadenopathy. Capitolo 59.

2. Mohseni S, Shojaiefard A, Khorgami Z. Peripheral Lymphadenopathy: Approach and Diagnostic Tools. Iran J Med Sci Supplement March 2014; Vol 39 No 2.

3. Slap GB, Brooks JS, Schwartz JS. When to perform biopsies of enlarged peripheral lymph nodes in young patients. JAMA. 1984;252:1321-6.

4. Bazemore AW, Smucker DR. Lymphadenopathy and malignancy. Am Fam Physician. 2002.

5. Luzuriaga K, Sullivan JL. Infectious Mononucleosis. N Engl J Med. 2010;362:1993-2000.

6. Leung AK, Davies HD. Cervical lymphadenitis: etiology, diagnosis and management. Curr Infect Dis Rep. 2009;11:183-9.

7. Kunitz G. An approach to peripheral lymphadenopathy in adult patients. West J Med. 1985;143:393-6. 


\title{
Come affrontare il paziente con splenomegalia
}

\author{
Paola Gnerre, ${ }^{1}$ Nathan Artom, ${ }^{2}$ Elisa Schiavetta, ${ }^{3}$ Lionello Parodi ${ }^{1}$ \\ ${ }^{1}$ Medicina 2 e Cure Intermedie, Ospedale San Paolo, Savona; ${ }^{2}$ Medicina 1 e Ematooncologia, Ospedale San Paolo, Savona; \\ ${ }^{3}$ Facoltà di Medicina e Chirurgia, Università degli Studi di Siena, Siena, Italia
}

\section{Introduzione}

La milza è un organo con funzioni sia di immunosorveglianza che di ematopoiesi. Pesa circa 150 grammi e ha un diametro cranio-caudale di circa 11 $\mathrm{cm}$. Si definisce splenomegalia un aumento di dimensioni e peso della milza. Si parla di splenomegalia moderata quando la milza ha un peso di circa 400-500 gr e una lunghezza tra $11-20 \mathrm{~cm}$ di splenomegalia massiva quando la milza pesa circa 1000 grammi e ha una lunghezza $\geq 20 \mathrm{~cm}$. L'ipersplenismo è una complicanza della splenomegalia e non è una diagnosi. In passato in mancanza di indagini strumentali la splenomegalia era solo un reperto obiettivo oggi le indagini diagnostiche ci permettono di valutare e confermare anche una lieve splenomegalia. Normalmente la milza non è palpabile ma una milza palpabile non sempre è patologica così come una milza iperplasica non sempre è palpabile. ${ }^{1}$ I pazienti enfisematosi con margini costali ampiamenti distanziati possono avere infatti una milza palpabile se pur di normali dimensioni. Le principali funzioni della milza sono la rimozione dal circolo ematico di microorganismi e determinati antigeni, la sintesi di immunoglobuline, properdina (un componente essenziale della via alternativa di attivazione del complemento) e di tuftsina (un immunostimolatore), la rimozione dal circolo di eritrociti anomali e in alcune malattie della funzione di ematopoiesi. Molti dei meccanismi alla base della splenomegalia sono in realtà la diretta conseguenza di un incremento patologico della normale funzione splenica. Una dettagliata storia clinica, un accurato esame

Corrispondente: Paola Gnerre, Medicina 2 e Cure Intermedie, Ospedale San Paolo, Savona, Italia.

Tel.: +39.019.8404358 - Fax: +39.019.8404583.

E-mail:pgnerre@yahoo.it

Articolo pubblicato secondo la Creative Commons Attribution NonCommercial 4.0 License (CC BY-NC 4.0).

(C) Copyright P. Gnerre et al., 2019

Licensee PAGEPress, Italy

QUADERNI - Italian Journal of Medicine 2019; 7(1):52-55 obiettivo e alcuni indagini diagnostiche sono gli strumenti che nella maggior parte dei casi consentono di porre una diagnosi. Una minima splenomegalia in assenza di evidenza di malattia sistemica potrebbe anche essere sottoposta ad un attento e regolare follow up. ${ }^{1}$

\section{Epidemiologia}

Uno studio americano riporta un'incidenza pari al $2 \%$ di milze palpabili nella popolazione generale un altro di circa il $5 \%$. Negli adulti non è segnalata una predominanza in relazione all'etnia o al sesso. La mortalità della splenomegalia è correlata alla patologia causale e alle eventuali conseguenze di una splenectomia. ${ }^{1}$

\section{Eziologia}

Le principali cause di splenomegalia includono malattie epatiche (cirrosi, epatiti), infezioni acute o croniche (endocarditi batteriche, mononucleosi, HIV, malaria, tubercolosi, istiocitosi), neoplasie ematologiche maligne (linfoma, leucemia, disordini mieloproliferativi), patologie congestizie (trombosi della vena splenica, ipertensione portale, scompenso cardiaco), malattie infiammatorie (sarcoidosi, LES, artrite reumatoide), sequestro splenico (anemia a cellule falciformi, anemia emolitica, talassemia) e altre malattie come le localizzazioni metastatiche, gli ascessi, i traumi, gli emagiomi, le ciste, la malattia di Gaucher, la malattia di Niemann Pick e le rare reazioni a farmaci. Il meccanismo fisiopatologico che induce splenomegalia varia sulla base dell'eziologia causale e pertanto può essere congestizio, infilitrativo, immune e neoplastico. Ad esempio nelle patologie acute infettive la milza incrementa il numero di cellule del sistema reticolo-endoteliale per aumentare la sua attività di rimozione degli antigeni e di produzione di anticorpi. L'aumento della funzione immune induce pertanto iperplasia splenica. Nei casi di malattia epatica e di malattie che inducono congestione venosa si verifica splenomegalia per congestione della milza stessa. L'emopoiesi extramidollare che si verifica nei disordini mieloproliferativi determina splenomegalia per infiltrazione. La crisi da sequestro acuto splenico 
è una malattia con elevata mortalità comune in età pediatrica nei pazienti con anemia a cellule falciforme omozigote e beta-talassemia. Più del $30 \%$ di questi bambini può svilupparla con una mortalità superiore al $15 \% .{ }^{2}$ In Tabella 1 sono presentati i vari meccanismi fisiopatologici con relative patologie che possono essere responsabili di splenomegalia.

La splenomegalia tradizionalmente è classificata in lieve, moderate e severa. In Tabella 2 sono presen- tate le possibili cause di splenomegalia massiva e lieve-moderata.

\section{Segni e sintomi del paziente con splenomegalia}

La sintomatologia correlata alla splenomegalia è generalmente lieve e correla con un vago senso di peso a livello addominale. Una splenomegalia massiva si

Tabella 1. Cause di splenomegalia in relazione al meccanismo eziologico.

Splenomegalia infiammatoria Un incremento acuto della milza dovuto a patologie infettive o a processi infiammatori si verifica per un incremento dell'attività di difesa dell'organo. L'incrementata attività di rimozione dal circolo di antigeni induce un incremento del numero delle cellule del sistema reticolo-endoteliale oltre a stimolare la produzione di anticorpi determinando iperplasia linfoide. Questo si verifica in condizioni come il Lupus, la sindrome di Felty e infezioni virali come la mononucleosi infettiva da virus di Epstain Barr.

Splenomegalia iperplastica La rimozione di globuli rossi anomali dal circolo è generalmente causa di splenomegalia iperplastica. In alcuni casi l'ematopoiesi extramidollare come nelle sindromi mieloproliferative induce iperplasia.

Splenomegalia congestizia La cirrosi con ipertensione portale, la trombosi della vena splenica o lo scompenso cardiaco inducono incremento della pressione venosa centrale con conseguente splenomegalia. Nei pazienti in trattamento chemioterapico con oxaliplatino l'ostruzione dei sinusoidi epatici può indurre splenomegalia.

Splenomegalia infiltrativa La splenomegalia è conseguente all'accumulo di macrofagi contenenti materiali non digeribile (esempio nella sarcoidosi, nell'amiloidosi, nella malattia di Gaucher, nelle localizzazioni metastiche).

Splenomegalia infettiva La splenomegalia è un filtro di patogeni ematici soprattutto di quelli endocapsulati che possono portare alla formazioni di ascessi. Le dimensioni della milza possono quindi incrementare in seguito ad incremento delle formazioni ascessuali.

Splenomegalia da sequestro La crisi da sequestro splenico acuto è la principale causa di mortalità nei bambini con anemia a cellule falciforme e altre anemie emolitiche ereditarie.

Tabella 2. Cause di splenomegalia massiva, lieve e moderata.

\begin{tabular}{ll}
\hline Cause di splenomegalia massiva & Cause di splenomegalia lieve e moderata \\
\hline Leishmaniosi & Sepsi batterica \\
\hline Malaria & Endocardite infettiva \\
\hline Malattia mieloproliferativa & Anemia a cellule falciforme \\
\hline Ipertensione portale/ostruzione venosa portale & Ascesso splenico \\
\hline Schistosomiasi & Malattie infettive acute (tifo, malattia, malattie tropicali) \\
\hline Malattia di Niemann-Pick & Infezioni virali acute (mononucleosi infettiva) \\
\hline Mucopolisaccaridosi & LES \\
\hline Linfoma & Tubercolosi \\
\hline Malattia di Gaucher & Linfadenopatia angioimmunoblastica \\
\hline Sferocitosi ereditaria & Malattia di Banti \\
\hline Talassemia major & Scompenso cardiaco congestizio \\
\hline Istocitosi & Reazione a farmaci con malattia da siero \\
\hline & Iperlipidemia \\
\hline & Splenomegalia idiopatica \\
\hline & Anemia emolitica immune \\
\hline Disordini trombocitopenici immuni \\
\hline Disordini leucocitari \\
\hline Ovalocitosi \\
\hline Ostruzione della vena splenica \\
\hline Infezione da HIV \\
\hline Tripanosomiasi \\
\hline
\end{tabular}


accompagna a precoce senso di sazietà dovuto all'ingombro a livello addominale. Generalmente ulteriori sintomi e segni sono conseguenti della patologia causale e potrebbero essere: febbre in caso di patologia infettiva, pallore, dispnea ecchimosi e/o petecchie in caso di processo emolitico, sintomi e segni di congestione correlati a patologa epatica, perdita di peso e sintomi sistemici in caso di malattia neoplastica e sintomi di pancreatite in caso di trombosi della vena splenica. Le dimensioni della milza non sempre correlano al suo stato funzionale per cui una milza palpabile non sempre è patologica. La valutazione obiettiva deve includere la palpazione del paziente in decubito supino e sul fianco di destra con le ginocchia tirate su e hips flessi. La milza si muove con gli atti respiratori per cui la milza è palpabile al termine dell'inspirazione. Segni associati a splenomegalia che possono indirizzare verso la diagnosi causale includono segni di cirrosi (ittero, teleangectasie, ginecomastia, ascite, caput medusae), soffi cardiaci (in caso di endocardite), ittero, ittero sclerale in corso di sferocitosi o cirrosi e petecchie correlate a trombocitemia. ${ }^{2}$

\section{Work-up diagnostico}

Mentre alcune cause di splenomegalia sono usualmente ovvie dovute a malattie concomitanti (endocardite, malaria, infezioni) la diagnosi eziologica di splenomegalia deve includere un'attenta storia anamnestica inclusa storia di malattie epatiche, di anemia ereditaria o disordini infilitrative. La presenza di sintomi B e sintomi sistemici deve indirizzare verso una neoplasia midollare o un disordine mieloproliferativo. Le indagini di laboratorio comprendono l'emocromo con conta leucocitaria, piastrinica e con lo striscio periferico, test di funzionalità epatica, test per epatite $\mathrm{C}$ e B, LDH, VES e l'assetto coagulativo. L'anemia è conseguenza del sequestro splenico e dell'emodiluizione così come la leucopenia e in particolare la neutropenia e la piastrinopenia. Nell'ipersplenismo la conta piastrinica è generalmente tra 50.000$150.000 / \mathrm{mL}^{1}$

In caso di VES elevata la diagnosi differenziale deve includere patologie infettive, la leucemia acuta, la sarcoidosi e altri disordini infiammatori. In caso di VES normale la diagnosi differenziale include disordini mieloproliferativi, anemia emolitica ereditaria e disordini infilitrativi. L'associazione di anemia e alterazioni allo striscio periferico suggestive per sferocitosi, cellule falciformi o ellisocitosi indirizza verso una splenomegalia dovuta a questi disordini. Alterazioni dei parametri coagulativi possono indirizzare verso una malattia epatica associata. La presenza di febbre può indicare infezioni virali quali la mononucleosi da virus di Epstein-Barr, infezioni fungine o batteriche acuta, leucemia acuta o linfoma.

Il riscontro obiettivo di splenomegalia deve essere confermato e quantificato mediante studi di imaging. L'indagine ecografica è non-invasiva, altamente sensibile e specifica per la valutazione delle dimensioni della milza. Negli studi di imaging un diametro cranio-caudale di $11-13 \mathrm{~cm}$ è frequentemente usato come limite massimo per una milza ritenuta di dimensioni normali. Con il termine di ipersplenismo si indicano alcune conseguenze causate dalla splenomegalia. La

Tabella 3. Approccio diagnostico al paziente con splenomegalia. ${ }^{1}$

\begin{tabular}{|c|c|c|}
\hline $\begin{array}{l}\text { Il paziente ha una malattia nota che può } \\
\text { causare splenomegalia? }\end{array}$ & $\begin{array}{l}\text { Patologie infettive: malaria, mononucleosi } \\
\text { infettiva, ecc. } \\
\text { Patologie ematologiche: anemia emolitica, } \\
\text { emoglobinopatie, neoplasie, malattie } \\
\text { mieloproliferative. } \\
\text { Patologie epatiche: ipertensione portale, } \\
\text { trombosi della vena porta o della vena splenica. }\end{array}$ & $\begin{array}{l}\text { Trattare la patologia causale e monitorare } \\
\text { la risoluzione della splenomegalia. }\end{array}$ \\
\hline Ricerca per una malattia occulta & $\begin{array}{l}\text { Infezioni: esempio endocardite infettiva. } \\
\text { Malattie ematologiche: sferocitosi ereditaria, } \\
\text { policitemia vera. } \\
\text { Malattie epatiche: cirrosi criptogenetica. } \\
\text { Malattie autoimmuni: LES. } \\
\text { Malattie da deposito: malattia di Gaucher } \\
\text { Miscellanee: sarcoidosi, amiloidosi, } \\
\text { splenomegalia tropicale, cisti spleniche. }\end{array}$ & $\begin{array}{l}\text { Se trovare la patologia causale avviare } \\
\text { trattamento appropriato. }\end{array}$ \\
\hline Splenectomia diagnostica se & $\begin{array}{l}\text { Sono presenti sintomi sistemici o sintomi } \\
\text { che suggeriscono una patologia maligna. } \\
\text { Alterazioni focali della milza alle indagini } \\
\text { strumentali. } \\
\text { Non disponibili altri siti per la biopsia. }\end{array}$ & \\
\hline $\begin{array}{l}\text { Stretto monitoraggio della milza fino a quando } \\
\text { la splenomegalia non si risolve oppure }\end{array}$ & $\begin{array}{l}\text { Non vi è evidenza di malattia sistemica. } \\
\text { La milza è solo lievemente aumentata. }\end{array}$ & \\
\hline
\end{tabular}


Tabella 4. Indagini laboratoristiche-strumentali nel paziente con splenomegalia n.d.d prima della splenectomia. ${ }^{3}$

\begin{tabular}{ll}
\hline Indagini radiologiche & RX toraceTC-RMN torace-addome \\
\hline Procedure & Biopsia epatica (se clinicamente indicata) \\
& Biospia e aspirato midollare \\
& Biopsia linfonodale se linfonodi palpabili \\
& Lavaggio bronco-alveolare \\
& Endoscopia del tratto GI superiore \\
\hline Indagini ematiche & Fattore reumatoide \\
& ANA \\
& Test di Coombs \\
& Emocolture \\
& Sierologia per HIV, epatite e altre infezioni \\
\hline
\end{tabular}

TC addome è la principale indagine pre-operatoria per valutare il volume splenico e per escludere la presenza di linfonodi all'ilo splenico, per valutare l'eventuale presenza di milza accessorie e/o ascessi splenici. ${ }^{4}$

La storia anamnestica, la valutazione obiettiva, le indagini di laboratorio, le indagini ecografiche e la TC permettono di porre una diagnosi di splenomegalia nel $90 \%$ dei casi. Occasionalmente può essere necessario effettuare una valutazione istologica mediante splenectomia o biopsia splenica. ${ }^{5}$
La splenectomia in determinati individui può essere utile per determinare l'eziologia della splenomegalia ma l'esecuzione della splenectomia deve essere attentamente valutata nei rischi e nei benefici. La biopsia splenica deve eseere eseguita in centri specializzati per l'alto rischio di sanguinamento. ${ }^{5}$ Nelle Tabelle 3 e 4 sono presentati l'approccio clinico-diagnostico e strumentale del paziente con splenomegalia e conseguente atteggiamento terapeutico.

\section{Bibliografia}

1. Mahapatra M, Mishra P, Kumar R. Chapter 77. Clinical approach to isolated splenomegaly.

2. Cronin CC, Brady MP, Murphy C, et al. Splenectomy in patients with undiagnosed splenomegaly. Postgrad Med J 1994;70:288-91.

3. Pottakkat B, Kashyap R, Kumar A, et al. Redefining the role of splenectomy in patients with idiopathic splenomegaly. ANZ J Surg 2006;76(8):679-82.

4. Chapman J, Bhimji S. Splenomegaly. 2017 Jun. [Medline]. [Full Text].

5. O'Reilly RA. Splenomegaly in 2,505 patients at a large university medical center from 1913 to 1995.1963 to 1995: 449 patients. West J Med. 1998 Aug. 169 (2):88-97. 


\title{
Come affrontare il paziente con leucopenia
}

\author{
Giordana Pastori, Rodolfo Tassara \\ SC Medicina 1 ed Ematologia, Ospedale San Paolo, Savona, Italia
}

\section{Introduzione}

La normale conta leucocitaria è compresa tra $\mathrm{i}$ 4000 e i 10.000 globuli bianchi, suddivisi in neutrofili (38-74\%), linfociti (19-45\%), monociti (2-10\%), eosinofili e basofili rispettivamente $0,5-6 \%$ e $0-2 \%$.

Le popolazioni leucocitarie hanno ruoli differenti: i) neutrofili: la funzione principale è liberare l'organismo da agenti infettivi (prevalentemente batteri) o altro materiale estraneo o dannoso (es. prodotti di necrosi cellulare); ii) linfociti: preposti alla difesa dell'organismo contro strutture antigeniche estranee, agiscono attraverso diversi meccanismi (produzione di immunoglobuline, promozione dell'attività di altre popolazioni leucocitarie, lisi di cellule infettate-neoplastiche-allogeniche...); iii) monociti: implicati nella fagocitosi, nel killing cellulare, nella processazione e presentazione dell'antigene ai linfociti e nella regolazione dell'emopoiesi; iv) eosinofili: coinvolti in reazioni immunitarie evocate da proteine estranee e da complessi antigene-anticorpo, difesa dell'organismo da alcuni tipi di parassiti; v) basofili: granulazioni contenenti istamina, implicati in reazioni allergiche.

Si definisce leucopenia, una conta leucocitaria inferiore ai 4000 globuli bianchi $/ \mathrm{mm}^{3}$.

La leucopenia può essere isolata $\mathrm{o}$ associata a piastrinopenia e anemia (pancitopenia).

Nonostante sia impreciso utilizzare leucopenia e neutropenia come termini interscambiabili, la maggior percentuale di pazienti che presentano leucopenia sono neutropenici (Tabella 1), essendo i neutrofili la popolazione maggiormente rappresentata all'interno

Corrispondente: Giordana Pastori, SC Medicina 1 ed Ematologia, Ospedale San Paolo, Savona, Italia.

E-mail: g.pastori@asl2.liguria.it

Articolo pubblicato secondo la Creative Commons Attribution NonCommercial 4.0 License (CC BY-NC 4.0).

CC Copyright G. Pastori e R. Tassara, 2019

Licensee PAGEPress, Italy

QUADERNI - Italian Journal of Medicine 2019; 7(1):56-58 della conta leucocitaria. Si può comunque verificare una situazione di leucopenia in assenza di neutropenia, tipicamente in caso di linfocitopenia. ${ }^{1}$

\section{Eziologia}

La neutropenia si distingue in congenita e acquisita.

\section{Neutropenia congenita}

Rara malattia (1/1.000.000 secondo il registro italiano delle neutropenie); si distinguono diverse forme di neutropenie congenite:

- isolate: i) con lesione genetica nota: ELA2 (autosomica dominante, sporadica) oppure HAX 1 (autosomica recessiva); ii) senza lesione genetica nota; associate ad altra condizione patologica: i) sindrome di Schwachman-Diamond; ii) sindrome di Pearson; iii) associate a malattie metaboliche quali glicogenosi, organico-acidosi, tirosinemia, sindrome di Barth, malattia di Gaucher; iv) associate a immunodeficit (Iper IgM, ipo-agammaglobulinemia X-linked, deficit isolato di IgA, disgenesia reticolare, neutropenia $\mathrm{X}$-linked...).

\section{Neutropenie acquisite}

Si distinguono diverse forme di neutropenie acquisite:

- Immunomediate: i) autoimmuni (neutropenia cronica idiopatica: non va incontro a remissione spontanea, tipicamente non si associa a infezioni significative, probabilmente grazie alla riserva granulocitaria midollare); ii) alloimmuni, neonatali; iii) neutropenia cronica benigna, nell'infanzia, si risolve spontaneamente con l'accrescimento; iv) neutropenia associata a patologie autoimmuni: LES, artrite reumatoide o sindrome di Felty, sclerodermia, sindrome di Sjogren, sindrome autoimmune linfoproliferativa, celiachia, cirrosi biliare primitiva, morbo di Crohn, associata ad attivazione del complemento;

- farmacoindotte (Tabella 2): i) immunomediate; ii) da soppressione midollare (farmaci comuni/neutropenia da chemioterapia);

- iatrogena (non farmacoindotta): i) in corso di emo- 
dialisi; ii) leucaferesi; iii) reazione trasfusionale;

- da tossine (mercurio, arsenico...);

- (post)infettive: da aumentato consumo/ipersplenismo: i) infezioni batteriche: Shigella, brucellosi, TBC, sepsi; ii) infezioni virali: HIV, morbillo, ebv, virus epatite, RSV, parvovirus, influenza; iii) parassitosi (malaria); iv) Rickettsia;

- da deficit nutrizionali: b12/folati/proteine/rame; raramente neutropenia isolata, più spesso associata a piastrinopenia ed anemia;

- da insufficienza midollare intrinseca od estrinseca: i) anemia aplastica; ii) mielodisplasia; iii) attivazione macrofagica primitiva o secondaria; iv) anemia di fanconi; v) mieloftisi;

- associata a patologie mielo/linfoproliferative: i) leucemia acuta (mieloide/linfoblastica); ii) leucemia mieloide cronica; iii) leucemia linfatica cronica (possibile neutropenia associata a linfocitosi); iv) leucemia mielomonociticacronica; v) linfomi; vi) leucemia a cellule capellute;

- da sequestro: i) tutti i casi di splenomegalia con

Tabella 1. Grado di neutropenia.

\begin{tabular}{ll}
\hline Grado & Valori di neutrofili $\left(\mathbf{x 1 0}^{\mathbf{9}}\right)$ \\
\hline Lieve & $1,0-1,5$ \\
\hline Moderato & $0,5-1,0$ \\
\hline Severo & $<0,5$ \\
\hline & $\begin{array}{l}\text { Fino all'anno di età si parla di neutropenia per valori } \\
\text { inferiori a } 1000 \text { neutrofili/mmc; la popolazione nera } \\
\text { ed altre etnie presenta un range di neutrofili sensibil- } \\
\text { mente più basso, fino a } 600 \text { neutrofili/mmc }\end{array}$ \\
\hline
\end{tabular}

ipersplenismo ( \pm anemia e/o piastrinopenia); ii) da sequestro in focolaio infettivo.

\section{Anamnesi}

È fondamentale raccogliere un'anamnesi accurata:

- anamnesi fisiologica: particolare attenzione a malattie virali, assunzione di farmaci in gravidanza e decorso del periodo neonatale (per quanto riguarda il neonato);

- anamnesi familiare: indagare l'origine geografica, eventuali altri casi noti di neutopenia;

- anamnesi patologica remota e prossima: indagare le patologie del paziente (autoimmunità, assunzione di farmaci, anamnesi di neoplasie, pregressi trattamenti chemio o radioterapici, infezioni recenti...). Importante inoltre valutare se la neutropenia si associa ad infezioni ricorrenti, più o meno gravi (candidosi, stomatiti, infezioni vie respiratorie, ascessi, infezioni urinarie). ${ }^{2}$

\section{Esame obiettivo}

L'esame obiettivo potrà risultare assolutamente normale o evidenziare epato/splenomegalia, linfoadenomegalie palpabili, segni di infezione in atto, malattie articolari.

\section{Esami ematochimici}

La leucopenia può essere evidenziata nel corso di accertamenti diagnostici (in caso ad esempio di episodi infettivi ricorrenti) oppure essere di occasionale riscontro a seguito dell'esecuzione di esami ematochimici.

Tabella 2. Farmaci potenzialmente in grado di causare neutropenia. ${ }^{2,3}$

\begin{tabular}{|c|c|}
\hline Analgesici/Fans & $\begin{array}{l}\text { Acetaminofenolo, acido acetilsalicilico, aminopirina, benoxaprofene, diclofenac, diflusinal, } \\
\text { dipyrone, fenoprofene, indometacina, ibuprofene, naprossene, fenilbutazone, piroxicam. }\end{array}$ \\
\hline Antipsicotici, ipnotici, sedativi e antidepressivi & $\begin{array}{l}\text { Clomipramina, clorpromazina, clozapina, diazepam, fluoxetina, alloperidolo, levopromazina, } \\
\text { mianserina, olanzapina, risperidone. }\end{array}$ \\
\hline Antiepilettici & Carbamazepina, etosuccimide, fenitoina, trimetiadone, acido valproico. \\
\hline Antitiroidei & Carbimazolo, metimazolo, perclorato di sodio, propiltiouracile. \\
\hline Cardiovascolari & $\begin{array}{l}\text { Acido acetilsalicilico, amiodarone, bepridil, captopril, cumarolici, dipiridamolo, digossina, } \\
\text { furosemide, idralazina, lisinopril, metildopamina, nifedipina, procainamide, propafenone, } \\
\text { propanololo, chinidina, ramipril, spironolattone, diuretici tiazidici, ticlopidina, acetazolamide. }\end{array}$ \\
\hline Antinfettivi & $\begin{array}{l}\text { Abacavir, aciclovir, amodiachina, atovaquone, cefalosporine, cloramfenicolo, clorguanide, } \\
\text { clorochina, clindamicina, dapsone, etambutolo, acido fusidico, gentamicina, idrossiclorochina, } \\
\text { isoniazide, linezolid, macrolidi, metronidazolo, minociclina, nitrofurantoina, norfloxacina, } \\
\text { penicillina, rifampicina, streptomicina, tetraciclina, cotrimossazolo, vancomicina. }\end{array}$ \\
\hline Miscellanea & $\begin{array}{l}\text { Acetilcisteina, allopurinolo, composti dell'arsenico, benzafibrato, calcio dobesilato, clorfenira- } \\
\text { mina, cimetidina, colchicina, mesalazina, metoclopramide, levodopamina, olanzapina, omepra- } \\
\text { zolo, ipoglicemizzanti orali, ranitidina, sulfasalazina, sulfonamidi, tamoxifene, retinoidi. }\end{array}$ \\
\hline
\end{tabular}




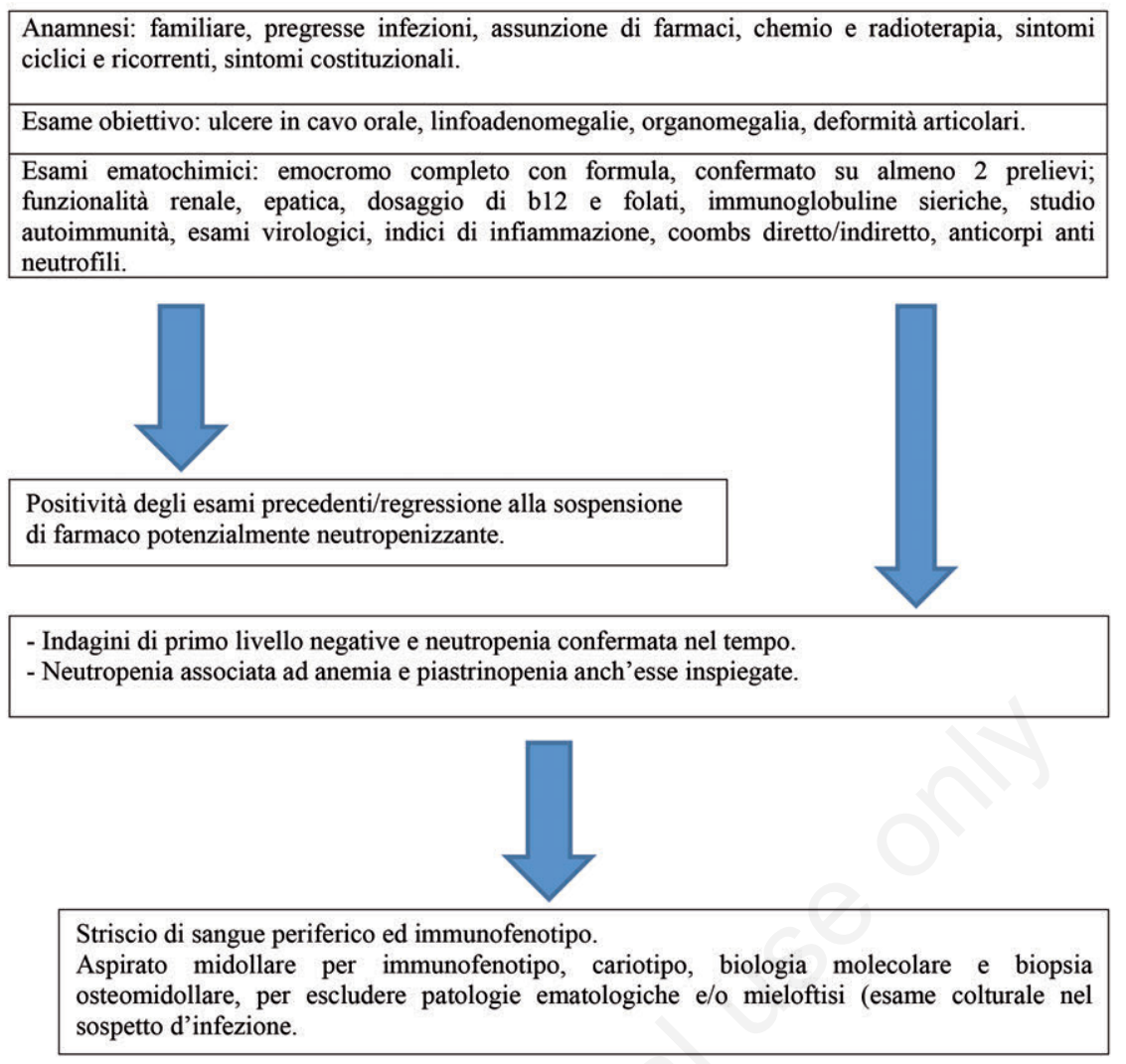

Figura 1. Come affrontare il paziente con neutropenia. ${ }^{2}$

Il dato andrà confermato almeno su un secondo esame emocromocitometrico; se confermata la leucopenia utile effettuare un controllo degli indici di funzionalità renale ed epatica, ionogramma, proteina $\mathrm{C}$ reattiva, dosaggio delle proteine totali, elettroforesi, $\mathrm{IgG}, \operatorname{IgA}$, IgM, indagini infettivologiche (virus epatite, herpes virus, EBV, HIV...) LDH, dosaggio di b12/folati, test di Coombs diretto e indiretto.

In seconda istanza indagare per l'autoimmunità (anticorpi anti transglutaminasi, anti endomisio, antigliadina, ANA, C3, C4, Ratest, pANCA, anticorpi antifosfolipidi...) (per quanto riguarda gli anticorpi anti neutrofili, considerata la bassa sensibilità del test si consiglia di ripetere l'esame fino a 4 volte nell'arco di 4-6 mesi) striscio di sangue periferico, immunofenotipo in caso di riscontro di blasti. ${ }^{2}$

\section{Le altre forme di leucopenia}

Le altre forme di leucopenia sono:

- Linfocitopenia: linfociti $<1500 / \mathrm{mmc}$ nell'adulto, $<3000 / m m c$ nel bambino. i) Forme congenite: malattie da immunodeficienza congenita, anomalie quali/quantitative della cellula staminale; ii) forme acquisite: infezioni (virali ma anche batteriche), patologie quali sarcoidosi; iii) forme iatrogene: secondarie a chemioimmunoterapia/radioterapia, terapia steroidea.

- Eosinofili: $<0,04 / \mathrm{mmc}$; cause frequenti: eccesso di glucocorticoidi (stress/iatrogeno/m. Cushing), significativo rilascio di epinefrina, stati infiammatori acuti.

- Basofili: $<0,01 / \mathrm{mmc}$, cause frequenti: eccesso di steroidi, infiammazione acuta, ipertiroidismo.

- Monociti: $<0,2 / \mathrm{mmc}$ somministrazione di steroide. L'approccio migliore per affrontare il paziente con neutropenia è riassunto in Figura $1{ }^{4}$

\section{Bibliografia}

1. Tura S, Baccarani M. Corso di malattie del sangue e degli organi emopoietici.

2. Fioredda F, Dufour C. Registro italiano delle neutropenie: Linee guida per l'inquadramento diagnostico e glossario delle neutropenie congenite ed acquisite.

3. Gibson C, Berliner N. How we evaluate and treat neutropenia in adults. August 2015.

4. Leukopenia (E. Birk-Urovitz) family and Community Medicine, University of Toronto. 


\title{
Come affrontare il paziente con trombocitosi
}

\author{
Lara Rebella, Rodolfo Tassara \\ SC Medicina 1 ed Ematologia, Ospedale San Paolo, Savona, Italia
}

\section{Introduzione}

Le piastrine (dette anche trombociti) fanno parte degli elementi figurati del sangue e la loro funzione è mediare il processo di emostasi e di coagulazione delle ferite. Le piastrine sono presenti nel sangue circolante in un numero che va da 150.000 a $450.000 \times 10^{3} / \mu \mathrm{L}$ ed hanno una vita media di 5-9 (anche 10) giorni: questo numero può tuttavia variare anche significativamente in condizioni fisiologiche particolari, come per esempio nell'esercizio fisico.

La normale conta piastrinica è compresa tra $150.000-450.000 \times 10^{3} / \mu \mathrm{L}$.

Si definisce trombocitosi o piastrinosi o trombocitemia un aumento oltre la soglia del range di normalità $\left(450 \times 10^{3} / \mu \mathrm{L}\right)$ del numero delle piastrine.

La trombocitosi viene distinta in primitiva (primaria) e secondaria (reattiva).

Tra le trombocitosi secondarie di rilievo vengono distinte le seguenti categorie:

- Trombocitosi fisiologiche: i) costituzionale; ii) esercizio fisico protratto ed intenso; iii) secondaria a parto.

- Trombocitosi reattive: i) anemia/perdita ematica: deficit di ferro, emorragia, emolisi; ii) infezioni: virali, batteriche, micobatteriche e fungina; iii) post-splenectomia, agenesia della milza, sequestro splenico; iv) malattie infiammatorie: neoplasie, malattie reumatologiche, trauma, reazioni farmacologiche.

I meccanismi che stanno alla base delle trombocitiosi reattive sono molteplici e includono cause che determinano alterazioni della proliferazione/maturazione dei megacariociti e cause che determinano un

Corrispondente: Lara Rebella, SC Medicina 1 ed Ematologia, Ospedale San Paolo, Savona, Italia.

Fax: +39.019.8404094.

E-mail: lararebella@inwind.it

Articolo pubblicato secondo la Creative Commons Attribution NonCommercial 4.0 License (CC BY-NC 4.0).

CC Copyright L. Rebella e R. Tassara, 2019

Licensee PAGEPress, Italy

QUADERNI - Italian Journal of Medicine 2019; 7(1):59-61 rilascio piastrinico accelerato o un loro ridotto turnover/sequestro.

Escluse tutte le forme di trombocitosi secondaria, si pone il sospetto diagnostico di trombocitosi primitiva causata da meccanismi intrinseci alla cellula; essa è clonale (maligna) e causata da una mutazione acquisita (somatica) di geni che regolano la trombopoiesi (ad es. JAK2, CALR o MPL). ${ }^{1}$

\section{Malattie ematologiche associate a trombocitosi}

- Trombocitemia essenziale;

- policitemia vera;

- mielofibrosi primaria;

- leucemia mieloide cronica;

- sindrome mielodisplastica;

- leucemia acuta mieloide.

Le cause di trombocitosi reattive e primarie sono riassunte rispettivamente in Tabella 1 e 2.

\section{Eziologia}

La trombocitosi può essere evidenziata nel corso di accertamenti diagnostici eseguiti per altre cause oppure essere di occasionale riscontro a seguito dell'esecuzione di esami ematochimici.

Tutti i pazienti con riscontro di trombocitosi devono ripetere un esame emocromocitometrico completo, essere sottoposti ad accurata anamnesi (ad es. recenti traumi, interventi chirurgici, storia di sanguinamento/emorragia, assunzione di farmaci/chemioterapia, storia di trombosi arteriose e/o venose, consumo di alcool o fumo) ed esame obiettivo (ad es. segni di infezione/infiammazione, sintomi inspiegabili quali febbre, calo ponderale, prurito, presenza di adenopatie o epatosplenomegalia). ${ }^{2}$

L'urgenza della valutazione è influenzata dal grado di trombocitosi, dalle condizioni cliniche e dalla presenza di altri sintomi. I pazienti che presentano sintomi quali flushing, prurito, febbre, perdita di peso e/o splenomegalia potrebbero avere una sindrome mieloproliferativa così come quelli che presentano trombosi in sedi inusuali (vene epatiche, vena porta, sindrome di Budd Chiari) o in siti multipli o trombosi in giovani pazienti ( $<45$ anni).

Il livello di trombocitosi da solo non è sufficiente a 
definire la causa o la gravità di malattia; è stato stimato che $\mathrm{i} 2 / 3$ dei pazienti con conta piastrinica $>1.000 .000 / \mathrm{mcL}$ era affetto da trombocitosi reattiva. ${ }^{3}$ Altri esami di laboratorio necessari all'inquadramento di una trombocitosi di natura da determinare comprendono lo studio dell'assetto marziale (dosaggio ferritina e indice di saturazione della transferrina), valutazione degli indici di flogosi (VES, PCR), esami ematochimici completi con dosaggio LDH ed elettroforesi delle proteine. I pazienti con sintomi vasomotori o splenomegalia o presenza di trombosi in sedi anomale dovrebbero essere valutati nel sospetto di una sindrome mieloproliferativa pertanto devono essere eseguiti: la ricerca di mutazione del gene JAK2, CALR, MPL e la ricerca del gene BCR-ABL, indagini citogenetiche e di biologia molecolare, biopsia osteomidollare (Figura 1). Sono di

Tabella 1. Cause di trombocitosi reattive.

\begin{tabular}{|c|c|}
\hline Malattie non neoplastiche & $\begin{array}{l}\text { Emorragia acuta } \\
\text { Anemia emolitica } \\
\text { Anemia da carenza marziale } \\
\text { Trattamento con vitamina b12 } \\
\text { Effetto rebound dopo terapia per piastrinopenia autoimmune }\end{array}$ \\
\hline Malattie neoplastiche & $\begin{array}{l}\text { Neoplasie metastatiche } \\
\text { Linfoma } \\
\text { Effetto rebound dopo trattamenti con agenti mielosoppressivi }\end{array}$ \\
\hline Malattie infiammatorie acute o croniche & $\begin{array}{l}\text { Disordini reumatologici, vasculiti } \\
\text { Malattie infiammatorie intestinali } \\
\text { Celiachia } \\
\text { Malattia di Kawasaki } \\
\text { Sindrome nefrosica }\end{array}$ \\
\hline Danno tissutale & $\begin{array}{l}\text { Ustioni termiche } \\
\text { Infarto acuto del miocardio } \\
\text { Traumi severi } \\
\text { Pancreatite acuta } \\
\text { Post operatorio, post splenectomia } \\
\text { Bypass coronarico }\end{array}$ \\
\hline Infezioni & $\begin{array}{l}\text { Infezioni croniche } \\
\text { Tubercolosi } \\
\text { Infezioni batteriche o virali acute }\end{array}$ \\
\hline \multicolumn{2}{|l|}{ Esercizio fisico } \\
\hline \multicolumn{2}{|l|}{ Reazioni allergiche } \\
\hline \multicolumn{2}{|l|}{ Splenectomia funzionale o chirurgica } \\
\hline Reazioni a farmaci & $\begin{array}{l}\text { Vincristina } \\
\text { Epinefrina, glucocorticoidi } \\
\text { Interleuchina B } \\
\text { Acido trans retinoico } \\
\text { Trombopoietina, agonisti recettoriali della trombopoietina }\end{array}$ \\
\hline
\end{tabular}

Tabella 2. Cause di trombocitosi primarie.

\begin{tabular}{ll}
\hline Trombocitemia essenziale & $\begin{array}{l}\text { La trombocitemia essenziale (TE) è una sindrome mieloproliferativa cronica che si manifesta con } \\
\text { trombocitosi e spesso si associa a sintomi vasogenici quali flushing, eritromelalgia e/o complicanze } \\
\text { trombotiche/emorragiche. La TE è di solito causata da mutazioni acquisite di JAK2, CALR o MPL. }\end{array}$ \\
\hline Policitemia vera & $\begin{array}{l}\text { La policitemia vera (PV) è una sindrome mieloproliferativa cronica che si manifesta con policitemia } \\
\text { spesso accompagnata a trombocitossi, complicanze trombotico emorragiche, splenomegalia, pru- } \\
\text { rito, flushing. La PV è per lo più associata a mutazione di JAK2. }\end{array}$ \\
\hline Mielofibrosi primaria & $\begin{array}{l}\text { La mielofibrosi primaria (PMF) è una sindrome mieloproliferativa cronica caratterizzata da fibrosi } \\
\text { midollare di grado variabile spesso accompagnata a trombocitosi, splenomegalia, complicanze } \\
\text { trombotico emorragiche e/o sintomi generali. Circa il 90\% dei pazienti affetti da mielofibrosi hanno } \\
\text { una mutazione a carico di JAK, CALR o MPL. }\end{array}$ \\
\hline Leucemia mieloide cronica & $\begin{array}{l}\text { La leucemia mieloide cronica (CML) è una sindrome mieloproliferativa in cui una specifica ano- } \\
\text { malia cromosomica, la traslocazione 9:22, genera un oncogene BCR-ABL. Raramente può asso- } \\
\text { ciarsi a trombocitosi ma tipicamente è caratterizzata dalla presenza di elementi immaturi mieloidi }\end{array}$ \\
nel sangue periferico. Si associa anche a splenomegalia e policitemia.
\end{tabular}




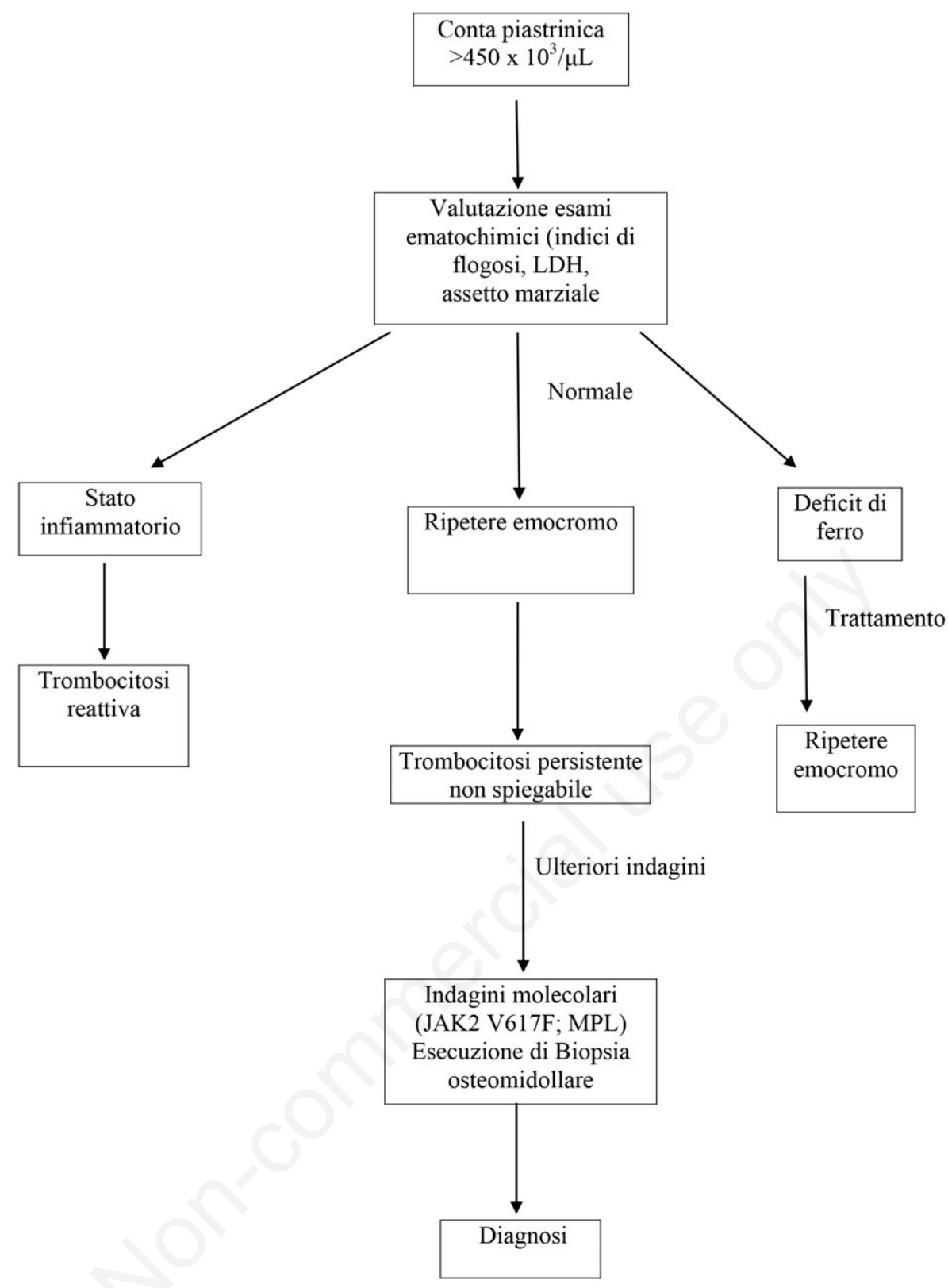

Figura 1. Algoritmo diagnostico per indagare il paziente affetto da trombocitosi. La determinazione di BCR-ABL è indicata solo nei pazienti che presentano all'emocromo elementi atipici e/o immaturi.

pertinenza ematologica i pazienti che presentano una delle mutazioni suddette o coloro che presentano all'emocromo blasti leucemici o forme immature. ${ }^{5}$

\section{Bibliografia}

1. Buss DH, Cashell AW. O'Connor ML, et al. Occurrence, etiology, and clinical significance of extreme thrombocytosis: a study of 280 cases. Am J Med 1994; 96:247.

2. Hutchinson CV, Stelfox P, Rees-unwin KS. Needle-like cryoglobulin crystals presenting as spurious thrombocytosis. Br J Haematol 2006;135:280.

3. Lawrence C, Atac B. Haematologic changes in massive burn injury. Critic Care Med 1992;20:1284.

4. Uppenkamp M, Makamora E, Petrasch S, Brittinger G. Thrombopoietin serum concentration in patient with reactive and myelooroliferative thrombocytosis. Ann Hematol 1998;77:217.

5. Harrison CN, Bareford D, Butt N. Guideline for investigation and management of adults and children presenting with a thrombocytosis. British Journal of Haematology, 2010;149:352-375. 


\title{
Policitemia vera o morbo di Vaquez
}

\author{
Eleonora Arboscello \\ Area Medica Critica, DEA IRCSS Policlinico San Martino, Genova, Italia
}

\section{Definizione ed epidemiologia}

La policitemia vera $(\mathrm{PV})$ è una malattia neoplastica della mielopoiesi caratterizzata dalla mutazione del gene JAK2 e dalla conseguente espansione clonale dell'eritrone e, nel $40 \%$ dei casi, della linea granulocitaria-macrofagica e megacariocitaria. ${ }^{1}$

Secondo i criteri WHO 2016 insieme alla trombocitemia essenziale (TE) e alla mielofibrosi primaria (MFP), fa parte delle neoplasie mieloproliferative croniche idiopatiche cromosoma Philadelphia BCR-ABL negative. $^{2}$

Il tasso di incidenza stimato in Europa è 0.4$2,8 \times 10^{5} /$ anno mentre per quanto riguarda il dato di prevalenza, esistono poche stime affidabili. È probabile però che il tasso di prevalenza sia in aumento a causa della diagnosi precoce e del miglioramento della gestione, fattori che determinato un prolungamento della sopravvivenza rispetto al passato.

La PV prevale in età adulto-avanzata; l'età mediana riportata alla diagnosi varia tra i 65 e 74 anni ed è più frequente e più grave nel sesso maschile, probabilmente perché il maschio dispone di maggiori riserve marziali che permettono al clone un'espansione più rapida e notevole del suo eritrone. ${ }^{3-6}$

\section{Patogenesi}

La PV è sostenuta da un'alterazione genetica scoperta nel 2005 e riguarda il gene JAK2. Si tratta di una mutazione puntiforme che comporta la sostituzione dell'aminoacido valida con l'aminoacido fenil-alanina

Corrispondente: Eleonora Arboscello, Area Medica Critica, DEA IRCSS Policlinico San Martino, Genova, Italia. E-mail: eleonora.arboscello@alice.it

Articolo pubblicato secondo la Creative Commons Attribution NonCommercial 4.0 License (CC BY-NC 4.0).

(C) Copyright E. Arboscello, 2019

Licensee PAGEPress, Italy

QUADERNI - Italian Journal of Medicine 2019; 7(1):62-68 a livello del cordone 617 (V617F) e determina un aumento dell'attività della proteina JAK2. Tale mutazione è presente nel $95-96 \%$ dei casi di $\mathrm{PV}$, nel rimanente 3-4\% dei casi si osservano, invece, mutazioni a carico dell'esone 12 del gene del JAK 2. Pertanto si riscontra una mutazione nel $99-100 \%$ dei pazienti affetti da $\mathrm{PV}^{3}$

La mutazione di JAK 2 conferisce alla cellula portatrice della mutazione medesima una sensibilità maggiore, rispetto alle cellule normali, alle citochine di tipo I (eritropoietina, G-CSF, GM-CSF, trombopoietina, interleuchina-3). A causa di queste proprietà, comuni ad altre sindromi mieloproliferative croniche come la TE, ma non riscontrabili negli individui normali o con policitemia secondaria paraneoplastica, il clone neoplastico sfugge alla regolazione a feed-back negativa mediata dall'eritropoietina ed espande progressivamente. È necessario anche ricordare che l'eritrone policitemico per svilupparsi ha bisogno di ferro come anche quello normale; quindi il principale fattore limitante l'espansione della massa eritrocitaria in corso di PV è costituito dal ferro disponibile nell'organismo. ${ }^{1}$

\section{Clinica}

L'aumento assoluto del numero degli eritrociti causa la comparsa dei segni e dei sintomi nel paziente. L'aumento della viscosità ematica e la conseguente riduzione del flusso sanguigno è correlata sia ai segni e ai sintomi cosiddetti minori sia ai sintomi cosiddetti maggiori (Tabella 1), secondari ad una condizione di ipossiemia tissulare e di aumentato rischio trombotico. ${ }^{1}$

In un terzo circa dei pazienti si aggiunge anche un prurito importante, soprattutto acquagenico, che alcuni autori hanno associato ad una condizione di iperistaminemia correlata all'espansione dell'eritrone. Tale interpretazione fisiopatologica è stata messa in discussione dopo il fallimento della terapia antistaminica.

Il paziente affetto da PV presenta un colorito rossovinoso che deve essere distinto da quello cianotico ed interessa soprattutto il volto e il palmo della mano.

Nel 20-30\% dei casi si osserva una splenomegalia mentre, assai più raramente si riscontra una epatosplenomegalia. 
In un terzo circa dei pazienti è possibile rilevare ipertensione arteriosa che poi scompare con la normalizzazione dell'ematocrito. ${ }^{1,3,4}$

\section{Laboratorio}

L'esame emocromocitometrico evidenzia concentrazioni di emoglobina $(\mathrm{Hb})$, un numero di globuli rossi (GR) e di ematocrito $(\mathrm{Ht})$ superiori rispetto ai valori normali. Le piastrine (PLT) sono aumentate, in genere tra 500.000 e $1.000 .000 /$ microL. In un terzo dei casi concomita un aumento dei globuli bianchi (GB), prevalentemente dei leucociti neutrofili.

La concentrazione di eriropoietina è in genere ridotta o comunque ai limiti inferiori della norma. ${ }^{1}$

Nei pazienti con PV la biopsia osteo-midollare mostra aumento delle tre linee emopoietiche correlate all'età, conseguente alla proliferazione globale dei precursori eritrocitari, granulociti e megacariocitari in proporzioni variabili. I megacariociti sono caratterizzati da un aspetto pleiomorfo, a causa della variabilità delle dimensioni con risconto di cellule da piccole a giganti, in assenza di anomalie maturative. Può essere presente una fibrosi reticolinica minima (grado 1), raramente di grado 2 .

Nella fase fibrotica post-policitemia si assiste ad un aumento della fibrosi reticolinica, alla comparsa di fasci grossolani di fibre collagene, spesso associata ad ipocellularità. Sempre in questa fase l'eritropoiesi e la granulopoiesi diminuiscono mentre compaiono megacariociti raggruppati in cluster spesso con nuclei ipercromatici e anormali.

Lo studio molecolare, eseguito su sangue periferico, evidenzia, nel 95\% dei casi, la presenza della mutazione JAK2 V617F dell'esone $14 \mathrm{e}$, in una minoranza di pazienti sono stati riscontrati altri tipi di mutazioni di JAK2 che interessano l'esone 12.,1,4

\section{Diagnosi}

Le più recenti acquisizioni di biologia molecolare hanno messo a punto nuovi criteri diagnostici per formulare la diagnosi di PV e per eseguire una differenziazione accurata con gli altri due sottotipi di neoplasie mieloproliferative. Una diagnosi accurata è fondamentale per definire la prognosi e il processo decisionale della terapia.

Non è accettabile utilizzare una etichetta diagnostica generica di malattia mieloproliferativa. I criteri diagnostici dell'WHO 2016 per la PV (Tabella 2), come per le altre malattie mieloproliferative, dovrebbero essere eseguiti rigorosamente, come riportato su tutte le linee guida internazionali. Per porre diagnosi di PV occorre la presenza di entrambe i criteri maggiori e di almeno uno dei criteri minori o il primo dei criteri maggiore e due criteri minori. Un iter diagnostico semplificato da seguire potrebbe essere quello riportato nella Figura 1.,7,8

La diagnosi differenziale deve essere posta con le policitemie secondarie e paraneoplastiche (Tabella 3), caratterizzate da un aumento dei valori sferici dell'eritropoietina. Questa può essere secondaria alla riduzione della pressione parziale di ossigeno $\left(\mathrm{pO}_{2}\right)$ o ad una inappropriata secrezione da parte di cellule tumorali. Tra le policitemie secondarie sono frequenti quelle riscontrate in corso di malattie dell'apparato respiratorio, di fumo di tabacco, di alterazioni congenite dell'apparato cardiovascolare con shunt destro-sinistro. Le policitemie paraneoplastiche sono rare, ma bisogna ricordare che un aumento inspiegato degli eritrociti può rappresentare la prima manifestazione della neoplasia. ${ }^{1}$

Tabella 1. Policitemia: sintomi e segni clinici.

\begin{tabular}{ll}
\hline Prurito & \\
\hline Disturbi del microcircolo cerebrale & $\begin{array}{l}\text { Cefalea } \\
\text { Vertigini } \\
\text { Acufeni } \\
\text { Disturbi visivi }\end{array}$ \\
\hline Disturbi circolatori arti inferiori & $\begin{array}{l}\text { Tromboflebiti } \\
\text { Claudicatio } \\
\end{array}$ \\
& Acrocianosi \\
& F. Raynaud \\
\hline Splenomegalia & \\
\hline Parestesie & \\
\hline
\end{tabular}

Tabella 2. Policitemia: criteri diagnostici WHO 2016.

\begin{tabular}{lll}
\hline Criteri maggiori & 1. & Emoglobina \\
& $>16,5 \mathrm{~g} / \mathrm{dL}$ (uomo) \\
& $>16,0 \mathrm{~g} / \mathrm{dL}$ (donna) \\
& o altra evidenza di aumento della massa eritrocitaria \\
& $\begin{array}{ll}\text { 2. } & \text { Presenza di JAK2N617F o di mutazione dell'esone } 12 \\
\text { 3. } & \text { Proliferazione trilineare a livello midollare }\end{array}$ \\
\hline Criteri minori & 1. & Bassi livelli di eritropoietina sierica \\
\hline
\end{tabular}




\section{Decorso e prognosi}

La sopravvivenza mediana è di circa 14 anni; sale a 24 anni nei pazienti di età $<60$ anni.

Il decorso clinico è bifasico ed è caratterizzato da una fase attiva e da una fase per così dire spenta; quest'ultima ricalca il quadro clinico della mielofibrosi.

Il decorso della PV è contrassegnato dalla comparsa di manifestazioni cliniche trombotiche, che costituiscono la causa più frequente di morbilità e di mortalità dei pazienti affetti da PV (Tabella 4).

Altre cause possibili di decesso sono rappresentate dalle malattie neoplastiche, tra cui la leucemia acuta e i tumori solidi, rispettivamente nel $15 \%$ e $14 \%$ dei casi.

Ogni paziente con nuova diagnosi di PV deve essere stratificato in base al rischio associato alla malattia e i sistemi di punteggio prognostico utilizzati per avviare il trattamento più indicato, si basano proprio sulla probabilità che i pazienti sviluppino complicanze trombotiche.

Lo score prognostico raccomandato per la stratificazione dei pazienti con PV si basa su due variabili: l'età $>60$ anni e l'anamnesi positiva per precedenti eventi trombotici.

Queste due variabili consentono di stratificare i pazienti in due classi di rischio, a basso e ad alto rischio. Oltre ai fattori di rischio precedentemente elencati, non va dimenticato che una conta leucocitaria $\geq 25 \times 10^{3} / \mathrm{L}$ e la mutazione JAK2V617F rappresentano ulteriori fattori di rischio trombotico, che permetterebbero di individuare nell'ambito dei pazienti con rischio basso, pazienti con rischio intermedio clinico.
Entrambi i gruppi di pazienti presentano alcune strategie comuni di trattamento, volte soprattutto a prevenire le complicanze trombotiche, come il controllo dei fattori di rischio modificabili, la somministrazione di acido acetilsalicilico a bassi dosaggi e il ricorso al salasso con lo scopo di mantenere l'ematocrito (Ht) $<45 \%$. Nei pazienti ad alto rischio è indicata, come trattamento di prima linea, la terapia citoriduttiva (Figura 2).

Non va comunque dimenticato che, a prescindere dalle due classi di rischio ben identificate, esiste un rischio intermedio clinico che deve essere ben valutato e gestito. In tali pazienti può essere avviata una terapia citoriduttiva.

Sono anche disponibili score per il calcolo della sopravvivenza globale dei pazienti affetti da PV, ma considerando la lunga sopravvivenza della malattia, non influenzano la scelta del trattamento. ${ }^{3-5,8,9}$

\section{Gestione e terapia}

Gli obiettivi del trattamento della PV sono quelli di ridurre il rischio di trombosi, di controllare i sintomi e forse di ridurre il rischio di progressione. Al momento attuale non è possibile raggiungere la guarigione. Tutti i pazienti devono essere opportunamente informati sul decorso della malattia e le possibili complicanze ad essa correlate.

La terapia della PV deve includere obiettivi a breve e a lungo termine.

Gli obiettivi a breve termine sono quelli di ridurre l'insorgenza e la recidiva di una manifestazione trombocita, mentre quelli a lungo termine sono di ridurre

Tabella 3. Policitemia: classificazione.

\begin{tabular}{llll}
\hline & Policitemie secondarie & Policitemie paraneoplastiche & Policitemia vera \\
\hline $\mathrm{pO}_{2}$ arteriosa & Ridotta & Normale & Normale \\
\hline Eritropoietina & Aumentata & Aumentata & Ridotta \\
\hline Cause & Alta montagna & Tumori renali & $\begin{array}{l}\text { Malattia primitiva delle cellule } \\
\text { staminali emopoietiche }\end{array}$ \\
& Malattie respiratorie e cardiovascolari & Tumori extra-renali eritropoietina secernenti & Mutato \\
\hline Jak2 & Non mutato & Non mutato &
\end{tabular}

Tabella 4. Policitemia vera: stratificazione del rischio e relativa terapia.

\begin{tabular}{lll}
\hline Categoria di rischio & Variabili di rischio & Terapia \\
\hline Rischio basso & $\begin{array}{l}\text { 1. Età }<60 \text { anni } \\
\text { 2. Anamnesi negativa per precedenti } \\
\text { eventi trombotici }\end{array}$ & $\begin{array}{l}\text { 1. Salassi } \\
\text { 2. Correzione dei fattori di rischio } \\
\text { cardiovascolari modificabili }\end{array}$ \\
\hline Rischio alto & $\begin{array}{l}\text { 3. Acido acetilsalicilico a basse dosi } \\
\text { 1. Età }>60 \text { anni }\end{array}$ & $\begin{array}{l}\text { 1. Terapia citoriduttiva } \\
\text { 2. Anamnesi positiva per precedenti } \\
\end{array}$ \\
& & $\begin{array}{l}\text { 2. Correzione dei fattori di rischio } \\
\text { modificabili }\end{array}$ \\
& $\begin{array}{l}\text { 3. Acido acetilsalicilico a basse dosi } \\
\text { 4. Salasso in caso di necessità }\end{array}$
\end{tabular}


l'evoluzione della malattia in mielofiobrosi, in sindrome mielodisplastica e leucemia acuta.

Ai fini di ridurre il rischio di trombosi è fondamentale controllare e gestire $\mathrm{i}$ fattori di rischio cardiovascolari (CV) modificabili in modo aggressivo, somministrare acido acetilsalicilico a basso dosaggio ed eseguire salassi con lo scopo di controllare l'ematocrito. Spesso rappresenta una terapia di emergenza alla diagnosi in pazienti con ematocrito molto alto e/o con segni e sintomi clinici di iperviscosità ma viene anche eseguita come terapia di mantenimento a lungo termine per mantenere i valori di ematocrito $<45 \%$. Infatti, un recente trial clinico randomizzato (CYTO$\mathrm{PV})^{10}$ ha dimostrato che l'ematocrito deve essere mantenuto strettamente al di sotto di questo valore per ridurre efficacemente il rischio trombotico.

L'acido acetilsalicilico a basso dosaggio rappresenta la seconda pietra miliare del trattamento, come dimostrato dallo Studio ECLAP, ${ }^{11}$ trial randomizzato in doppio cieco, controllato con placebo, in cui il braccio che prevedeva trattamento con acido acetilsalicilico ha raggiunto l'end point combinato che includeva la mortalità $\mathrm{CV}$, l'ictus non fatale e il trombo-embolismo venoso maggiore, in maniera statisticamente significativa.

Nei pazienti a basso rischio il trattamento di scelta prevede proprio la combinazione del controllo dei fattori di rischio $\mathrm{CV}$, la somministrazione di acido acetilsalicilico e il salasso, quando indicato. ${ }^{12-14}$ I pazienti con conta piastrina $>1500 \times 10^{9} / \mathrm{L}$ presentano un aumentato rischio emorragico per cui va sospesa la terapia con antiaggregante.

I pazienti ad alto rischio richiedono anche la somministrazione di una terapia citoriduttiva (Tabella 4).

L'idrossiurea (HU) rappresenta il farmaco citoriduttivo di prima scelta, che presenta buona efficacia e tolleranza nella maggior parte dei pazienti.

In relazione al profilo di sicurezza, non è stato peraltro dimostrato un rischio leucemogeno anche dopo esposizione prolungata al farmaco. ${ }^{15-19}$

In due Studi di fase II è stato dimostrato che anche l'inferferon-alfa induce un alto rischio di risposta ematologiche e riduce significativamente il clone maligno, ma tale farmaco non è stato approvato per il trattamento della PV, per quanto fosse riportato come terapia di prima linea nella Linee Guida dell'European LeukemiaNET. Al momento viene utilizzato come farmaco off-label.

Sono in corso attualmente due studi di fase III che confrontano l'idrossiurea con forme peghilate di interferon-alfa, che dovrebbero aiutare a definire meglio l'efficacia e la tolleranza di ciascun farmaco. ${ }^{18-20}$

In caso di fallimento/intolleranza al trattamento di prima scelta con idrossiurea, va contemplata con attenzione la seconda linea di terapia citoriduttiva (Figura 2) perché alcuni farmaci, come ad esempio il busulfano, possono aumentare il rischio di evoluzione leucemica. ${ }^{16,17}$

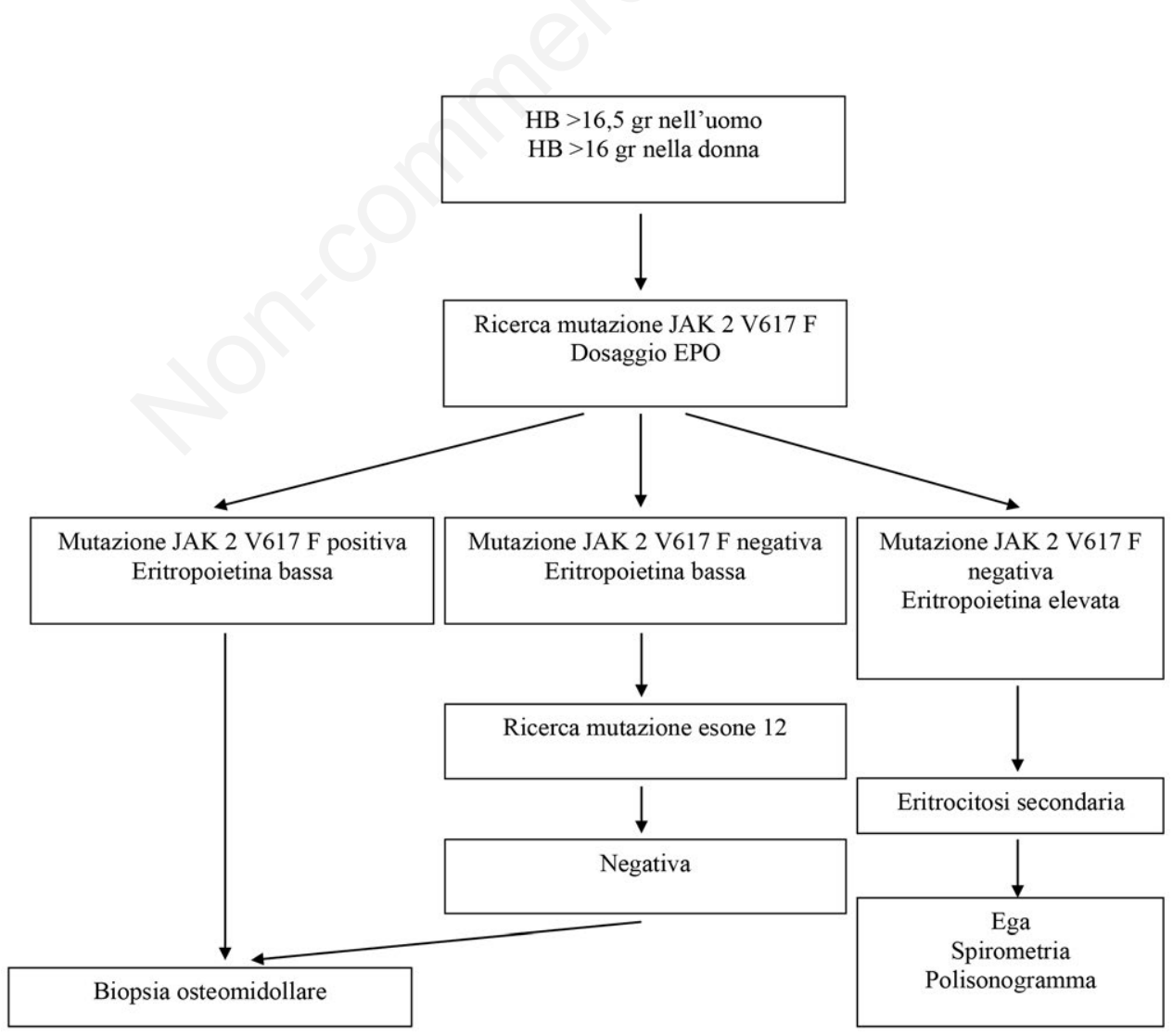

Figura 1. Poliglobulia: algoritmo diagnostico. 
Uno studio di fase III Response I, ha dimostrato che ruxolitinib, inibitore orale delle di JAK1 e JAK2, era superiore rispetto alla migliore terapia disponibile per controllare l'ematocrito al di sotto del $45 \%$ e per ridurre la splenomegalia. Ruxolitinib trova indicazione come terapia di seconda linea in caso di intolleranza/fallimento di idrossiurea (Figura 2). Un secondo studio di fase III Response II, ha poi rilevato che ruxolitinib è stato ben tollerato in tutti i pazienti in cui ha determinato la comparsa di anemia e piastrinopenia nel $40 \%$ dei casi, senza tuttavia anemia di grado severo. Altri eventi avversi segnalati in corso di terapia sono stati le infezioni, le neoplasie cutanee diverse dal melanoma, che costituiscono comunque un fattore di rischio per tutti i pazienti che si sottopongono a terapia con idrossiurea. ${ }^{21}$

\section{Follow-up a lungo termine e valutazione della risposta}

La valutazione clinica e laboratorista è in genere più frequente nelle fasi iniziali della gestione della malattia fino a quando non si raggiunge un tasso di salassi stabile e/ o una dose di farmaco efficace e ben tollerata.
Nei pazienti con PV asintomatica e ben controllata, le visite di follow-up possono essere programmate a intervalli di 1-3 mesi per determinare i fabbisogni di flebotomia. Addirittura nei pazienti con PV ad alto rischio che ricevono stabile dosaggio di idrossiurea e interferon-alfa, con necessità di rari salassi, può essere appropriato un intervallo di 4-6 mesi. La maggior parte dei pazienti mantiene la propria dose di HU stabile per diversi anni, sebbene in una minoranza di pazienti possa svilupparsi una mielosoppressione eccessiva che richiede un aggiustamento della dose. La valutazione della chimica di routine (compresi almeno test dei lipidi, glicemia, renale ed epatica) è raccomandata ad intervalli di 1 anno. Con cadenza inizialmente semestrale e poi annuale, è suggerito eseguire un'ecografia dell'addome per escludere la trombosi venosa subclinica o l'infarto della milza, la valutazione della splenomegalia può essere valutata con l'esame obiettivo ad ogni visita di follow-up. In tali occasioni sarà anche opportuno controllare i valori pressori, essendo l'ipertensione arteriosa un importante fattore di rischio $\mathrm{CV}$ non modificabie. A meno che non vi sia il sospetto di progressione della malattia in mielofibrosi non vi è alcuna indicazione a ripetere

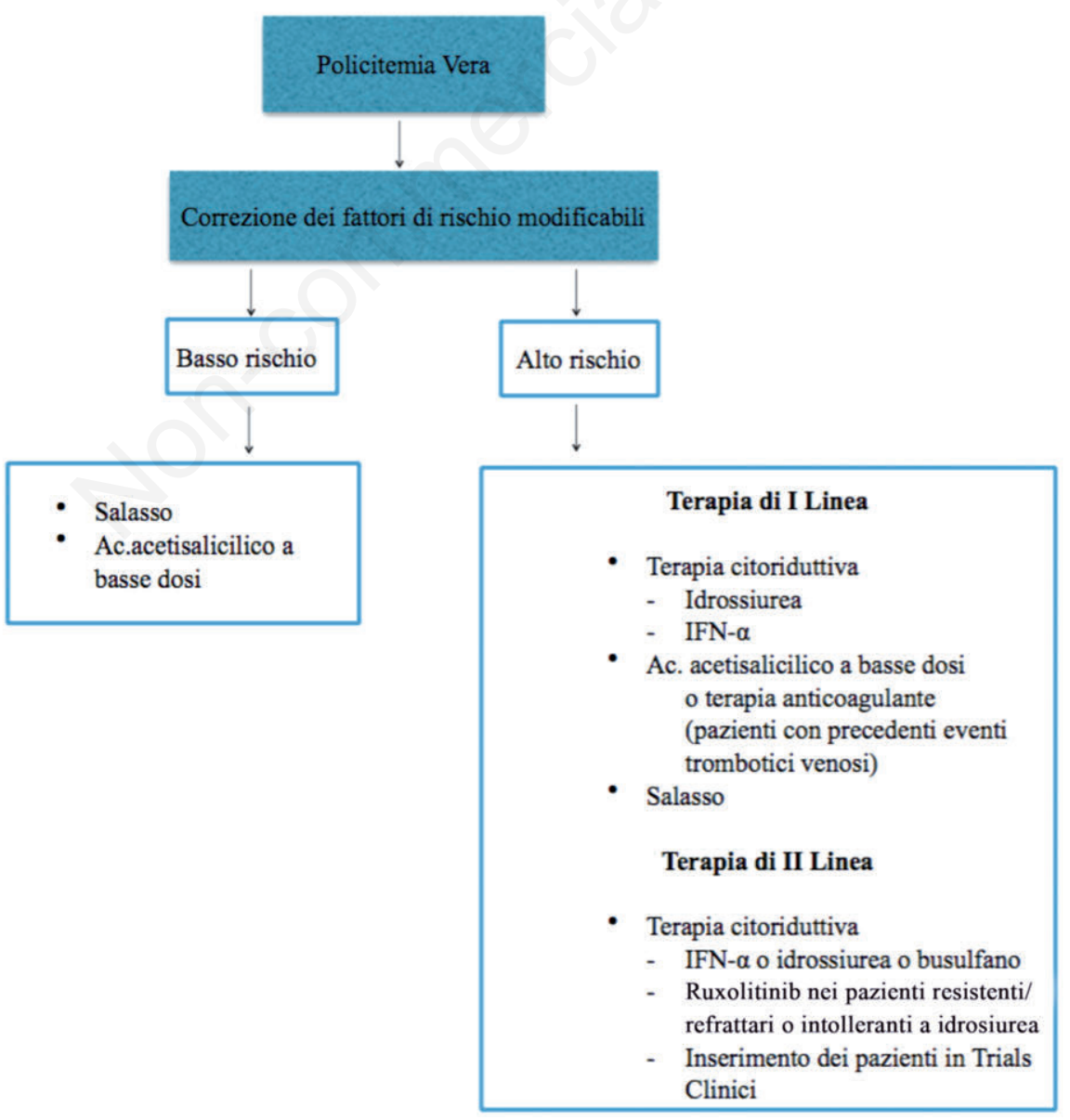

Figura 2. Policitemia vera: algoritmo terapeutico. 
periodicamente la biopsia osteo-midollare. Inoltre, al di fuori di uno studio clinico e con l'eccezione dei pazienti con IFN, non è neppure raccomandata una valutazione ripetuta del carico di mutazione.

In occasione delle visite di follow-up verrà valutata la risposta al trattamento, utilizzando criteri clinici e laboratoristi (Tabella 5). Inoltre, in caso di resistenza o in relazione alla comparsa di intolleranza alla terapia di prima scelta con idrossiurea, secondo criteri clinico-laboratoristici (Tabella 6), verrà posta indicazione alla terapia di seconda linea. Il fenomeno della resistenza HU o intolleranza è importante perché identifica un gruppo di pazienti con PV con prognosi infausta, che richiedono un cambio di trattamento e per i quali nuove terapie come gli inibitori JAK possono essere attraenti. , $^{3,422,23}$

\section{Policitemia vera in corso di gravidanza}

La letteratura attuale sugli esiti della gravidanza in MPN è scarsa e probabilmente soggetta a bias di se- gnalazione. Una gravidanza a termine sembra verificarsi nel 70\% dei pazienti. La gestione suggerita della gravidanza in MPN deriva principalmente da alcuni studi monocentrici. Viene per senso immaginare che la gestione della malattia deve essere ottimizzata prima del concepimento. L'idrossiurea deve essere sospesa con un periodo di wash-out adeguato. Se è necessaria una terapia citoriduttiva deve essere preso in considerazione l'inferferon-alfa. Salvo controindicazioni, tutte le donne dovrebbero ricevere un'aspirina a basse dosi durante tutta la gravidanza ed è possibile continuare a mantenere il livello di ematocrito entro un intervallo target adeguato alla gestazione, sufficiente per la gravidanza a rischio standard. Per una gravidanza ad alto rischio può essere preso in considerazione un trattamento addizionale comprendente la terapia citoriduttiva con interferon-alfa e l'eparina a basso peso molecolare. Il monitoraggio fetale è suggerito durante la gravidanza; le scansioni dovrebbero essere effettuate a 20 (con doppler delle arterie uterine), 26 e 34 settimane. Durante il travaglio vanno ri-

Tabella 5. Policitemia vera: criteri di risposta al trattamento.

Remissione completa

- Importante miglioramento dei sintomi, in particolare riduzione duratura della epatosplenomegalia OLTRE.

- Riduzione durata dell'ematocrito $<45 \%$ senza trattamento con salassi, della conta piastrinica $<400 \times 10^{9} / \mathrm{L}$ e dei globuli bianchi $<10 \times 10^{9} / \mathrm{L}$ OLTRE.

- Assenza di segni di progressione di malattia e di eventi trombotici o emorragici OLTRE.

- Remissione ematologica a livello del midollo osseo con cellularità nomale in relazione all'età, scomparsa di iperplasia trilineare e assenza di fibrosi reticulinica di grado $>1$.

Remissione parziale

- Importante miglioramento dei sintomi, in particolare riduzione duratura della epatosplenomegalia OLTRE.

- Riduzione durata dell'ematocrito $<45 \%$ senza trattamento con salassi, della conta piastrinica $<400 \times 10^{9} / \mathrm{L}$ e dei globuli bianchi $<10 \times 10^{9} / \mathrm{L}$ OLTRE.

- Assenza di segni di progressione di malattia e di eventi trombotici o emorragici OLTRE.

- Assenza di remissione ematologica a livello del midollo osseo con persistenza di iperplasia trilineare.

Nessuna risposta

- Non è soddisfatto alcun criterio di remissione parziale.

Progressione malattia

- Evoluzione di mielofibrosi post-PV, sindrome mielodisplastica, leucemia acuta.

Tabella 6. Policitemia vera: criteri di definizione di resistenza/intolleranza alla idrossiurea secondo European LeukemiaNEt.

- Necessità di salasso per raggiungere un ematocrito $<45 \%$ dopo 3 mesi di terapia con idrossiurea $2 \mathrm{~g} /$ die oppure

- Mieloproliferazione non controllata con conta piastrinica $>400 \times 10^{9} / \mathrm{L}$, globuli bianchi $>10 \times 10^{9} / \mathrm{L}$ dopo 3 mesi di terapia con idrossiurea 2 $\mathrm{g} /$ die oppure

- Fallimento nel ridurre la splenomegalia massima più del $50 \%$ valutata alla palpazione o fallimento nel ridurre i sintomi correlati alla splenomegalia dopo 3 mesi di terapia con idrossiurea $2 \mathrm{~g} / \mathrm{die}$

- Conta dei leucociti neutrofili $<1,0 \times 10^{9} / \mathrm{L}$, delle piastrine $<100 \times 10^{9} / \mathrm{L}$, con concentrazione dell'emoglobina $<10 \mathrm{~g} / \mathrm{dL}$ alla dose più bassa di idrossiurea necessaria per raggiungere una risposta parziale o completa oppure

- Presenza di ulcera a livello degli arti inferiori o di altro effetto collaterale non ematologico correlato alla idrossiurea come le manifestazione mucocutanee, i sitomi gastroenterici, le polmoniti, la febbre a qualunque dosaggio del farmaco. 
spettati i protocolli relativi all'interruzione dell'eparina a basso peso molecolare nello stesso tempo deve essere considerata la trombo-profilassi postpartum per 6 settimane. La trombosi infatti è stata documentata nel periodo postpartum e l'emocromo deve essere controllato più frequentemente in questo momento.

L'allattamento al seno è sicuro con aspirina a basso dosaggio, eparina e warfarin, ma è controindicato con la terapia citoriduttiva. Le decisioni sull'allattamento al seno durante il trattamento con dell'interferon-alfa dovrebbero essere prese su base individuale, dopo aver discusso su possibili rischi e benefici. ${ }^{3,24,25}$

\section{Bibliografia}

1. Tura S, Baccarani M. Corso di malattie del sangue e degli organi emolinfopoietici. Società Editrice Esculapio, quarta edizione 2007;170-175.

2. Amber A, et al. The 2016 WHO diagnostic criteria for polycythemia vera, essential thrombocythemia and myelofibrosis. Blood 2016;12:2391-2405.

3. Vannucchi AM, Barbui T, Cervantes F, Harrison C, Kiladjian J-J, Kröger N, Thiele J, Buske C, on behalf of the ESMO Guidelines Committee. Philadelphia chromosome-negative chronic myeloproliferative neoplasms: ESMO Clinical Practice Guidelines for diagnosis, treatment and follow-up. Annals of Oncology 26 (Supplement 5) 2015; v85-v99.

4. Tefferi A, Barbui T. Polycythemia vera and essential thromobocythemia update on diagnosis, risk stratification, and management. Am J Hematol 2017;92:95-108.

5. Swerdlow SH, Campo E, Harris NL, et al. WHO Classification of Tumors of Haematopoietic and Lymphoid Tissues. Lyon: International Agency for Research on Cancer, 2008.

6. Barosi G, Mesa RA, Thiele J, et al. Proposed criteria for the diagnosis of post-polycythemia vera and post-essential thrombocythemia myelofibrosis: a consensus statement from the International Working Group for Myelofibrosis Research and Treatment. Leukemia 2008;22:437-438.

7. Gianelli U, Bossi A, Cortinovis I, et al. Reproducibility of the WHO histological criteria for the diagnosis of Philadelphia chromosome-negative myeloproliferative neoplasms. Mod Pathol 2014;27:814-822.

8. Barosi G, Mesa R, Finazzi G, et al. Revised response criteria for polycythemia vera and essential thrombocythemia: an ELN and IWG-MRT consensus project. Blood 2013;121:4778-4781.

9. Tefferi A, Rumi E, Finazzi G, et al. Survival and prognosis among 1545 patients with contemporary polycythemia vera: an international study. Leukemia 2013; 27:1874-1881.

10. Scherber RM, Geyer HL, Dueck AC, Kosiorek HE, Finazzi G, Cavazzina R, Masciulli A, Scarano M, Vannucchi AM, Mesa RA, Barbui T. The potential role of hematocrit control on symptom burden among polycythemia vera patients: Insights from the CYTO-PV and
MPN-SAF patient cohorts. Leuk Lymphoma. 2017 Jun;58(6):1481-1487.

11. Finazzi G. A prospective analysis of thrombotic events in the European collaboration study on low-dose aspirin in polycythemia (ECLAP). Pathol Biol (Paris). 2004 Jun;52(5):285-8.

12. Barbui T, Barosi G, Birgegard G, et al. Philadelphianegative classical myeloproliferative neoplasms: critical concepts and management recommendations from $\mathrm{Eu}-$ ropean LeukemiaNet. J Clin Oncol 2011;29:761-770.

13. Marchioli R, Finazzi G, Landolfi R, et al. Vascular and neoplastic risk in a large cohort of patients with polycythemia vera. J Clin Oncol 2005;23:2224-2232.

14. Marchioli R, Finazzi G, Specchia G, et al. Cardiovascular events and intensity of treatment in polycythemia vera. N Engl J Med 2013;368:22-33.

15. Landolfi R, Marchioli R, Kutti J, et al. Efficacy and safety of low-dose aspirin in polycythemia vera. $\mathrm{N}$ Engl J Med 2004;350:114-124.

16. Finazzi G, Caruso V, Marchioli R, et al. Acute leukemia in polycythemia vera: an analysis of 1638 patients enrolled in a prospective observational study. Blood 2005; 105:2664-2670.

17. Björkholm M, Derolf AR, Hultcrantz M, et al. Treatment-related risk factors for transformation to acute myeloid leukemia and myelodysplastic syndromes in myeloproliferative neoplasms. J Clin Oncol 2011;29: 2410-2415.

18. Kiladjian JJ, Cassinat B, Chevret S, et al. Pegylated interferon-alfa-2a induces complete hematologic and molecular responses with low toxicity in polycythemia vera. Blood 2008;112:3065-3072.

19. Godfrey AL, et al. Hydroxycarbamide Plus Aspirin Versus Alone in patients with essential thrombocythemia age 40 to 59 years without high-risk feature. JCO 2018;78:8414.

20. Kiladjian JJ, Mesa RA, Hoffman R. The renaissance of interferon therapy for the treatment of myeloid malignancies. Blood 2011;117:4706-4715.

21. Vannucchi AM, Kiladjian JJ, Griesshammer M, et al. Ruxolitinib proves superior to best available therapy in a prospective, randomized, phase 3 study (RESPONSE) in patients with polycythemia vera resistant to or intolerant of hydroxyurea. EHA Annual Meeting 2014; LB2436.

22. Alvarez-Larrán A, Pereira A, Cervantes F, et al. Assessment and prognostic value of the European LeukemiaNet criteria for clinicohematologic response, resistance, and intolerance to hydroxyurea in polycythemia vera. Blood 2012;119:1363-1369.

23. Barosi G, Birgegard G, Finazzi G, et al. A unified definition of clinical resistance and intolerance to hydroxycarbamide in polycythaemia vera and primary myelofibrosis: results of a European LeukemiaNet (ELN) consensus process. Br J Haematol 2010;148:961-963.

24. Harrison CN, Robinson SE. Myeloproliferative disorders in pregnancy. Hematol Oncol Clin North Am 2011; 25:261-275.

25. Harrison C. Pregnancy and its management in the Philadelphia negative myeloproliferative diseases. $\mathrm{Br} \mathrm{J}$ Haematol 2005;129:293-306. 


\title{
Approccio all'adulto con piastrinopenia
}

\author{
Rodolfo Tassara, Luca Paris \\ Medicina 1 e Ematooncologia, Ospedale San Paolo, Savona, Italia
}

\section{Introduzione}

Si definisce piastrinopenia quella condizione clinica in cui la conta periferica delle piastrine è minore di $150.000 \mathrm{pts} / \mathrm{mmc}$.

La piastrinopenia può essere associata con una varietà di condizioni che possono essere asintomatiche o mettere a rischio di emorragie o di trombosi, anche pericolose per la vita. All'inizio, la causa della piastrinopenia può apparire tutt'altro che di facile identificazione ed il clinico si trova di fronte ad una situazione dalla prognosi imprevedibile perché non è prevedibile il trend della conta piastrinica.

L'importanza pratica di accertare una piastrinopenia è dovuta al fatto che: i) $1 / 3$ di tutte le consulenze ematologiche in ambito ospedaliero sono per piastrinopenie; ii) dal 5 al $10 \%$ di tutti i pazienti ospedalizzati sono piastrinopenici e nelle unità intensive il numero cresce al $35 \%$; iii) in generale un paziente piastrinopenico in ospedale è soggetto ad un tasso di mortalità due volte più elevato di quelli che non lo sono. ${ }^{1,2}$

È definita trombocitopenia una conta piastrinica inferiore alle 150.000 /microL e possiamo suddividerla in: i) lieve: PLT 100.000-150.000/ microL; ii) moderata: PLT 50.000-99.000/microL; iii) severa PLT $<50.000$.

Questo numero va comunque contestualizzato e valutato a seconda della malattia sottostante (in gravidanza anche 80.000 piastrine sono da considerare una piastrinopenia lieve; nella ITP si considera grave solo sotto le 30.000 piastrine). ${ }^{3-5}$

Corrispondente: Rodolfo Tassara, SC di Medicina Interna 1, Ospedale San Paolo, Savona, Italia.

E-mail: r.tassara@asl2.liguria.it

Articolo pubblicato secondo la Creative Commons Attribution NonCommercial 4.0 License (CC BY-NC 4.0).

CCopyright R. Tassara e L. Paris, 2019

Licensee PAGEPress, Italy

QUADERNI - Italian Journal of Medicine 2019; 7(1):69-75

\section{Richiamo fisiologico}

- Normali livelli piastrinici circolanti sono considerati da 150 a 450.000 PLT in Europa settentrionale (livelli lievemente inferiori nelle popolazioni del bacino del mediterraneo);

- $1 / 3$ delle piastrine sono sequestrate nella milza;

- l'emivita piastrinica varia dai 9 ai 10 giorni;

- la produzione piastrinica è compito dei megacariociti multi nucleati;

- dalle 15.000 alle 45.000 piastrine sono prodotte giornalmente per mantenere lo steady state;

- ci sono lievi oscillazioni della conta piastrinica anche legate alle stagioni;

- una piccola quota di individui (circa il $2,5 \%$ ha una conta piastrinica normale inferiore alle 150.000);

- la trombopoietina (TPO) è la proteina regolatoria primaria nella produzione di piastrine. Il gene della TPO si trova sul cromosoma 3. La TPO è espressa nel fegato, nel rene e nelle cellule della muscolatura liscia ed ha un'emivita plasmatica di 30 ore. Il recettore della TPO è il c-MPL che è presente sui megacariociti e sulle piastrine. La TPO cresce consensualmente al calo delle piastrine e declina quando i livelli di megacariociti e piastrine aumentano.

\section{Quando preoccuparsi del rischio di sanguinamento}

Il sanguinamento è variabile da soggetto a soggetto anche con lo stesso numero di piastrine ed è in relazione alla malattia sottostante.

Quelli che seguono possono essere alcuni punti di riferimento non esaustivi e non sostitutivi del giudizio clinico e della valutazione accurata e nel tempo del paziente: i) il sanguinamento chirurgico lo si può avere per un numero di PLT $<50.000$ (100.000 per la neurochirurgia, la cardiochirurgia e la chirurgia ortopedica maggiore); ii) sanguinamenti spontanei si possono avere più facilmente con PLT $<20.000-30.000$ ed in particolare $<10.000$; iii) un sanguinamento può essere meno probabile in una ITP rispetto ad altre condizioni a parità di piastrine.

Vanno inoltre considerate altre condizioni quali 
eventuali difetti di funzione piastrinica ed anomalie della coagulazione che possono favorire il sanguinamento.

\section{Quando preoccuparsi del rischio trombotico}

Raramente i pazienti con trombocitopenia sono a rischio di trombosi. Bisogna comunque avere presente le cause di piastrinopenia che mettono a rischio di trombosi perché, anche se rare, necessitano di un rapido riconoscimento ed una immediata presa in carico per instaurare la corretta terapia.

Elenchiamo le principali: i) trombocitopenia indotta da eparina (HIT): il 5\% dei soggetti che sono sottoposti a terapia/profilassi con eparina possono andare incontro ad una HIT (Heparin-induced thrmbocytopenia) che può portare a trombosi arteriose e/o venose. ${ }^{6}$ Va sospettata in caso di trombocitopenia in soggetto recentemente trattato con eparina, va sospesa l'eparina ed instaurate le terapie per prevenire i fatti trombotici; ii) sindrome da anticorpi antifosfolipidi: si sviluppa in soggetti con LES, cancro, infezioni o per assunzione di farmaci. Talora idiopatica. Va trattata con ASA o anticoagulanti e trattando la condizione clinica che la sottende; iii) coagulazione intravascolare disseminata (CID o DIC): si sviluppa prevalentemente in pazienti con cancro o sepsi; iv) microangiopatie trombotiche: la porpora trombotica tombocitopenia (TTP), la sindrome emolitico-uremica (HUS) o la microangiopatia trombotica indotta da farmaci (DITMA) sono associate a trombi dei piccoli vasi in tutti gli organi. Una diagnosi rapida è necessaria per iniziare la terapia al più presto; v) emoglobinuria parossistica notturna (PNH): causata dalla perdita di glicosilfosfatidilinositolo della membrana cellulare. Può presentarsi con trombosi dei vasi addominali e cerebrali con anemia emolitica e/o citopenie. Esiste trattamento specifico e salvavita.

\section{Meccanismi fisiopatologici causa di trombocitopenia}

\section{Alterazioni del midollo osseo}

- S. mielodisplastiche;

- infezioni/sepsi di solito con anemia e leucopenia;

- deficit nutrizionali;

- da farmaci;

- nella ITP c'è anche una ridotta produzione in quanto gli anticorpi antipiastrine agiscono anche da anticorpi antimegacariociti.

\section{Distruzione o consumo piastrinico}

- Accelerata distruzione piastrinica (e megacariocitaria) può essere dovuta ad anticorpi sia nella ITP primitiva che secondaria ad altre patologie autoim- muni; anche i farmaci possono determinare la formazione di anticorpi antipiastrine;

- s. di Evans: anticorpi anti piastrine e anemia emolitica autoimmune (può associarsi anche neutropenia autoimmune);

- DIC/TTP/HUS: consumo piastrinico per la formazione di trombi.

\section{Diluizione}

- Massive trasfusioni e/o infusioni di liquidi.

\section{Redistribuzione/splenomegalia}

- Splenomegalia e/o congestione splenica per ipertensione portale (cirrosi, epatopatia alcolica): si determina piastrinopenia senza riduzione della massa piastrinica totale.

\section{Pseudotrombocitopenia}

- Aggregazione in vitro da EDTA;

- aggregazione in vitro da carenza di anticoagulante;

- aggregazione in vitro da inibitori della glicoproteina IIb/IIIa (che peraltro può dare anche vera trombocitopenia);

- piastrine giganti conteggiate come leucociti.

\section{Cause comuni di trombocitopenia}

\section{Trombocitopenia immune primitiva}

È una causa comune di moderata/severa piastrinopenia in adulti asintomatici senza compromissione della linea rossa e bianca. È mediata da anticorpi. La diagnosi è prevalentemente di esclusione per cui oltre all'emocromo è utile eseguire uno striscio periferico e gli esami per escludere cause virali o di altra origine. ${ }^{7,8}$

\section{Farmaci}

\section{Trombocitopenia immune farmaco indotta}

Tutti i farmaci possono dare trombocitopenia ma alcuni sono maggiormente responsabili (vedi Tabella $1 \mathrm{e}$ sito www.ouhsc.edu/platelets). ${ }^{9-11}$

La trombocitopenia si sviluppa in poche ore se c'è stata una precedente esposizione al farmaco o in 1 o 2 settimane se è un nuovo farmaco. Di solito si risolve in 5/7 giorni dopo la sospensione del farmaco.

\section{Eparina}

Gli anticorpi antipiastrine causano attivazione piastrinica determinando trombosi venose ed arteriose.

Manifestazioni cliniche tipiche sono: i) comparsa di piastrinopenia in un soggetto in terapia con eparina nei precedenti 5-10 giorni; ii) una caduta delle piastrine del 50\%; iii) trombosi venose e/o arteriose; iv) lesioni necrotiche cutanee nel sito di iniezione della 
eparina; v) reazione sistemica acuta dopo la somministrazione di eparina. ${ }^{12}$

Va sospesa subito l'eparina e sostituita con un anticoagulante diverso.

\section{Terapia citotossica o radioterapia}

La chemioterapia o la radioterapia inducono una prevedibile, dose-dipendente mielosoppressione a ca- rico delle tre linee cellulari del sangue. La piastrinopenia è spesso di più difficile recupero. ${ }^{13}$

\section{Farmaci da banco, integratori, cibi e bevande}

Bevande contenenti chinino (acqua tonica, Schweppes bitter lemon), noci, infusi di erbe, farmaci da banco possono essere causa di trombocitopenia e devono essere ricordati nella valutazione anamnestica. ${ }^{14-16}$

Tabella 1. Farmaci associati a piastrinopenia isolata.

\begin{tabular}{|c|c|}
\hline Farmaco & Meccanismo \\
\hline Abciximab & Piastrinopenia immune farmaco indotta \\
\hline Acetaminofene & Piastrinopenia immune farmaco indotta; (anticorpi contro un metabolita del farmaco) \\
\hline Alemtuzumab & Sindrome simil-ITP (immune thrombocytopenia) \\
\hline Amiodarone & Piastrinopenia immune farmaco indotta \\
\hline Antibiotici betalattamici (penicilline, cefalosporine) & Piastrinopenia immune farmaco indotta \\
\hline Carbamazepina & Piastrinopenia immune farmaco indotta \\
\hline Ceftriaxone & Piastrinopenia immune farmaco indotta \\
\hline Daptomicina & Soppressione midollo osseo (dose-dipendente) \\
\hline Eptifibatide & Piastrinopenia immune farmaco indotta \\
\hline Etambutolo & Piastrinopenia immune farmaco indotta \\
\hline Furosemide & Piastrinopenia immune farmaco indotta \\
\hline Sali d'oro & Soppressione midollo osseo \\
\hline Aloperidolo & Piastrinopenia immune farmaco indotta \\
\hline Eparine & Anticorpi che attivano le piastrine e determinano anche trombosi \\
\hline Ibuprofene & Piastrinopenia immune farmaco indotta \\
\hline Irinotecan & Piastrinopenia immune farmaco indotta \\
\hline Levofloxacina & Piastrinopenia immune farmaco indotta \\
\hline Linezolid & Soppressione midollo osseo (dose-dipendente) \\
\hline Vaccini per morbillo, epatite, rosolia & Sindrome simil-ITP \\
\hline Mirtazapine & Piastrinopenia immune farmaco indotta \\
\hline Naproxene & Piastrinopenia immune farmaco indotta; (anticorpi contro un metabolita del farmaco) \\
\hline Oxaliplatino & Piastrinopenia immune farmaco indotta \\
\hline Penicillina & Piastrinopenia immune farmaco indotta \\
\hline Fenitoina & Piastrinopenia immune farmaco indotta \\
\hline Piperacillina & Piastrinopenia immune farmaco indotta \\
\hline Chinidina & Piastrinopenia immune farmaco indotta \\
\hline Chinino & $\begin{array}{l}\text { Piastrinopenia immune farmaco indotta (può dare anche microangiopatia trombotica } \\
\text { e/o altre citopenie) }\end{array}$ \\
\hline Ranitidina & Piastrinopenia immune farmaco indotta \\
\hline Rifampicina & Piastrinopenia immune farmaco indotta \\
\hline Simvastatina & Piastrinopenia immune farmaco indotta \\
\hline Sulfonamidi & Piastrinopenia immune farmaco indotta \\
\hline Suramina & Piastrinopenia immune farmaco indotta \\
\hline Tirofiban & Piastrinopenia immune farmaco indotta \\
\hline Trimetoprim-sulfametossazolo & Piastrinopenia immune farmaco indotta; Anticorpi anti sulfametossazolo \\
\hline Acido valproico & Soppressione midollo osseo (dose-dipendente) \\
\hline $\begin{array}{l}\text { Vancomicina (parenterale o anche presente } \\
\text { nel cemento per protesi in ortopedia) }\end{array}$ & Piastrinopenia immune farmaco indotta \\
\hline
\end{tabular}




\begin{abstract}
Alcool
Può essere causa di trombocitopenia per tossicità diretta sul midollo, per indurre deficit nutrizionali e vitaminici o per l'ipersplenismo che spesso accompagna le malattie epatiche.
\end{abstract}

\section{Deficit nutrizionali}

Carenza di Vit. B12, acido folico, rame possono essere causa di lieve pancitopenia ma anche di piastrinopenia isolata. I pazienti possono essere asintomatici o manifestare sintomi legati alla anemia e/o a turbe neurologiche. Maggiormente colpiti i soggetti vegani, quelli che ingeriscono troppo zinco, chi ha malassorbimento a seguito di patologie gastrointestinali autoimmuni o a seguito di chirurgia bariatrica o altra chirurgia addominale in carenza di supplementazione.

\section{Infezioni}

Vari tipi di infezione possono dare piastrinopenia con meccanismo di distruzione immuno-mediata, soppressione midollare o consumo piastrinico. ${ }^{17}$

- Virali: molte infezioni virali possono dare trombocitopenie transitorie che si risolvono spontaneamente. In caso di persistenza dell'infezione come nel caso del virus $\mathrm{C}$ la trombocitopenia può persistere.

- HIV: va ricordata ed il test per l'HIV va sempre eseguito nello screening della trombocitopenia.

Le cause della trombocitopenia nell'HIV possono essere: i) tossicità diretta del virus sui megacariociti; ii) una forma simil ITP chiamata PHAT (primary HIVassociated thrombocytopenia); iii) infezioni opportunistiche secondarie.

- Infezioni batteriche: i) infezioni batteriche protratte; ii) Helicobacter pylori; iii) leptospirosi, brucellosi, anaplasmosi, punture di zecche; iv) malaria, babesiosi. ${ }^{18,19}$

- Sepsi: i) per diretta soppressione midollare, che è spesso accompagnata da altre citopenie; ii) DIC; iii) consumo piastrinico; iv) distruzione piastrinica. ${ }^{20-22}$

\section{Ipersplenismo dovuto a malattie epatiche croniche}

Una malattia cronica del fegato con ipertensione portale e splenomegalia congestizia (ipersplenismo) può essere causa di piastrinopenia lieve o moderata (60.000-100.000/microL). ${ }^{23,24} \mathrm{Il}$ numero totale di piastrine è normale ma una grossa quota è sequestrata dalla milza.

\section{Malattie reumatologiche/autoimmuni}

- LES (nel 25-50\% dei casi)

- Sindrome da anticorpi antifosfolipidi

- Artrite reumatoide

\section{Gravidanza}

Circa il 5-10\% delle donne gravide presenta una lieve trombocitopenia nella fase tardiva della gravidanza, chiamata anche trombocitopenia gestazionale, asintomatica, che si risolve dopo il parto, senza rischio di sanguinamento o di trombocitopenia fetale. Deve essere condotta una normale gravidanza. Se le piastrine invece sono sotto le 70.000/microL devono essere prese in considerazione altre cause di trombocitopenia coma la ITP. Trombocitopenie più severe, specie se accompagnate da insufficienza renale, ipertensione, anemia emolitica microangiopatica devono essere gestite in modo più attento ed aggressivo per la possibilità di trovarsi di fronte ad una HELLP (hemolysis, elevated liver enzymes, low platelet count) Syndrome, una pre-eclampsia o una TTP (poropora trombotica trombocitopenica).

\section{Alterazioni del midollo osseo}

Molte malattie primitive del midollo osseo possono dare piastrinopenia, di solito con altre anomalie della serie rossa e/o bianca. Una valutazione da parte di un ematologo ed una mielobiopsia diventano di fondamentale importanza. Ricordiamo: i) le sindromi mielodisplastiche; ii) anemia aplastica; iii) leucemia acuta; iv) EPN (emoglobinuria parossistica notturna).

\section{Neoplasie}

Le neoplasie possono presentarsi con piastrinopenia a causa di: i) CID; ii) infiltrazione o soppressione neoplastica del midollo (linfomi, leucemia, tumori solidi); iii) microangiopatia trombotica. ${ }^{25,26}$

\section{Microangiopatie trombotiche}

- TTP o PTT (porpora trombotica trombocitopenica) possono essere presenti o no febbre, insufficienza renale, deficit del SNC, anemia emolitica che comporrebbero la PENTADE della PTT;

- SEU (sindrome emolitica uremica) di solito con presenza di danno renale;

- microangiopatie trombotiche da farmaci (DITMA drug-induced thrombotic microangiopathy).

\section{Malattie congenite delle piastrine} (di solito diagnosticate nel bambino)

- Malattia di Von Willebrand tipo 2B;

- Sindrome di Wiskott-Aldrich;

- Sindrome di Alport;

- Anomalia di May-Hegglin;

- Sindrome di Fanconi;

- Sindrome di Bernard-Soulier;

- Sindrome trombocitopenia e assenza del radio.

\section{Approccio al paziente piastrinopenico}

L'approccio al paziente con piastrinopenia può prendere in considerazione 3 presentazioni cliniche di- 
verse: i) paziente ambulatoriale con piastrinopenia, asintomatico; ii) paziente con piastrinopenia associata ad una altra condizione clinica nota; iii) paziente con piastrinopenia ospedalizzato con patologia acuta.

\section{Anamnesi}

- Familiare: diatesi emorragica, piastrinopenia o malattie autoimmuni $\rightarrow$ forme congenite o immuni.

- Fisiologica: i) sesso femminile $\rightarrow$ piastrinopenie immuni, TMA (microngiopatia trombotica); ii) sesso femminile $\rightarrow$ alterazioni ciclo mestruale, meno-metrorragie; iii) gravidanza $\rightarrow$ piastrinopenie immuni, gravidiche, TMA; iv) gravidanza, poliabortività $\rightarrow$ APS (malattia autoimmune); v) età neonatale $\rightarrow$ forme alloimmuni; vi) età pediatrica $\rightarrow$ forme congenite, post-virali o vaccinali, leucemie; vii) anziani $\rightarrow$ forme linfoproliferative, farmaci, mielodisplasie; viii) nazionalità $\mathrm{e}$ provenienza $\rightarrow$ forme virali, batteriche, parassitarie; ix) oliguria, aumento ponderale, urine ipercromiche $\rightarrow$ TMA, PNH (emoglobinuria parossistica notturna); x) potus, abitudini sessuali, tossicodipendenza, pregresse trasfusioni $\rightarrow$ forme secondarie a $\mathrm{HCV}, \mathrm{HIV}$; xi) recente vaccino rosolia $\rightarrow$ postvaccinale; xii) deficit dietetici (vegetariani, vegani, chirurgia bariatrica) $\rightarrow$ deficit B12 e/o folico

- Farmacologica: i) eparine, anti IIb-IIIa, sulfamidici, barbiturici, antiaritmici; ii) chemioterapici $\rightarrow$ farmacomediata; iii) anticoagulanti, antiaggreganti $\rightarrow$ aumento del rischio emorragico; iv) FANS anche presi in modo intermittente; v) farmaci da banco, erbe (albero della Cinchona), farmaci prescritti per altri membri della famiglia presi dal paziente; vi) particolare attenzione va posta ai farmaci contenenti chinino (per la malaria, per i crampi) e bevande contenenti chinino (acqua tonica, bitter lemon, gin and tonic, jello shots, shocktails).

- Patologica: i) diatesi emorragica $\rightarrow$ sanguinamenti post-chirurgici, ematuria, melena, cefalea, epistassi, petecchie ecc.; ii) infezioni in atto: vie respiratorie, vie urinarie, ecc.; iii) recente chemioterapia e/o radioterapia, neoplasie metatastatiche $\rightarrow$ CID, forme farmacomediate; iv) malattie ematologiche o reumatologiche.

\section{Esame obiettivo}

- Segni di sanguinamento: muco-cutanei (petecchie, porpora, ecchimosi), epistassi, tratto gastroenterico, SNC, vie urinarie e retroperitoneo;

- la presenza di petecchie palatine è indice di gravità della piastrinopenia;
- febbre $\rightarrow$ sepsi, TTP, leucemie, malattie linfoproliferative;

- $\quad$ ittero $\rightarrow$ TMA;

- edema $\rightarrow$ insufficienza renale acuta da TMA;

- esantemi $\rightarrow$ infezioni virali;

- segni di trombosi venosa o arteriosa $\rightarrow$ sindrome da anticorpi antifosfolipidi (APS), emoglobinuria parossistica notturna (EPN), trombocitopenia da eparina (HIT);

- segni di interessamento neurologico $\rightarrow$ emorragia a carico del SNC o TTP;

- linfoadenomegalia e splenomegalia $\rightarrow$ sindromi linfoproliferative, leucemie, m. infettiva, m. autoimmune;

- epatomegalia o epato-splenomegalia $\rightarrow$ malattia epatica.

\section{Test diagnostici}

- Una piastrinopenia senza altri segni e con clinica silente va sempre ricontrollata per evitare di eseguire esami inutili; ${ }^{27-31}$

- Prelievo in citrato ed EDTA per escludere le forme spurie: i) una conta piastrinica $<50.000 \mathrm{plt} / \mathrm{mmc}$ va ricontrollata immediatamente; ii) una conta piastrinica con Plt tra le 50.00 e le $100.000 / \mathrm{mmc}$ e paziente asintomatico va ricontrollata dopo 1-2 settimane; iii) una conta piastrinica con Plt tra le 100.000 e le $149.000 / \mathrm{mmc}$ va ricontrollata dopo 1 o più mesi. Fa eccezione il paziente che assume un nuovo farmaco da poco o che ha alterazioni anche dei globuli rossi e /o bianchi.

- Esami di laboratorio: i) emocromo con formula, reticolociti; ii) PT-INR, aPTT, test di Coombs diretto (se c'è associata anemia); iii) antitrombina III, fibrinogeno, d-dimero, aptoglobina, LDH; iv) urea, creatinina, ioni, enzimi epatici, bilirubina, proteine con elettroforesi; v) test per HCV, HIV, Helicobacter pylori, infezioni virali; vi) test per autoimmunità (LES, anticorpi antifosfolipidi).

- Striscio di sangue periferico: permette di confermare la presenza di piastrinopenia e fornisce informazioni sulla morfologia di tutti i componenti ematici: i) una piastrinopenia accompagnata da alterazioni quali-quantitative della serie bianca o rossa deve far sospettare una malattia ematologica o emato-oncologica; ii) la presenza di schistociti può orientare verso una TMA - microangiopatia trombotica; iii) la sferocitosi $\rightarrow$ sferocitosi congenita o anemia emolitica; iv) corpi di Howell-Jollyà post-splenectomia o paziente con iposplenismo; v) leucocitosi $\rightarrow$ infezione; vi) displasia dei G.B. $\rightarrow$ leucemia acuta o mielodisplasia; vii) neutrofili ipersegmentati $\rightarrow$ deficit di B12 e/o folico.

- Biopsia osteomidollare (esame da eseguire a cura dello specialista ematologo): indicata in presenza 
di forte sospetto clinico di disordine midollare primitivo.

- ECG: identifica la presenza di sofferenza ischemica del miocardio in caso di TMA, CAPS o HIT.

- $\mathrm{Rx}$ torace: esclude la presenza di focolai broncopneumonici associati o marcate linfoadenomegalie mediastiniche.

- Ecotomografia addominale: per ricerca eventuale splenomegalia e/o adenomegalie.

- TAC torace e/o addome: di secondo livello per stadiazione eventuale malattia linfoproliferativa $o$ neoplasia solida.

- TAC cerebrale: da eseguire in presenza di sintomatologia a carico del SNC.

- Ecodoppler venoso-arterioso arti: nel sospetto di HIT o APS.

\section{Cosa fare}

\section{Emergenze trombocitopeniche}

- Sanguinamento in paziente con severa trombocitopenia $(<50.000 / \mathrm{mmc})$;

- Necessità di procedura invasiva in paziente con trombocitopenia;

- Gravidanza con severa trombocitopenia;

- Sospetta trombocitopenia da eparina (HIT);

- Sospetta porpora trombotica trombocitopenica (PPT), sindrome emolitico-uremica (HUS) o microangiopatia trombotica farmaco-indotta (DITMA);

- Sospetta leucemia acuta, anemia aplastica o altre cause di insufficienza midollare;

- Infezione/sepsi;

- DIC.

In questi casi è necessario che il paziente sia ricoverato e attentamente sorvegliato e trattato da un internista/ematologo esperto.

\section{Trombocitopenia asintomatica, incidentale}

- Trombocitopenia immune ITP;

- Malattia epatica occulta;

- Infezione da HIV;

- Sindrome mielodisplastica;

- Malattie congenite non diagnosticate;

- Farmaci e farmaci da banco.

Nella piastrinopenia moderata (tra 100.000 e $150.000 \mathrm{Plt} / \mathrm{mmc}$ ) non è necessario fare ulteriori esami sino a quando non si evidenzino nuove alterazioni cliniche o di laboratorio.

Bisogna ricordare che in uno studio osservazionale a sei mesi di distanza 1' $88 \%$ dei pazienti avevano sempre la piastrine sotto il valore di $150.000 / \mathrm{mmc}$ senza ulteriori segni di malattia e a 5 anni il $66 \%$ dei pazienti vedevano risolto il problema della piastrinopenia senza che si fosse evidenziato alcuna malattia a supporto quindi di una diagnosi di ITP.

\section{Principi generali di trattamento}

- Ai pazienti con piastrinopenia con valori sotto le $50.000 \mathrm{Plt} / \mathrm{mmc}$ và raccomandato di non praticare sport a rischio (boxe, rugby, arti marziali, calcio).

- Valutare attentamente le eventuali terapie antiaggreganti/anticoagulanti tenendo presente i rischi ed i benefici ricordando che la piastrinopenia non protegge di per sé da eventi trombotici arteriosi o venosi e pertanto che la sospensione dei farmaci antitrombotici andrà valutata per $\mathrm{Plt} / \mathrm{mmc}<50.000$.

- Non assumere aspirina, FANS e farmaci da banco.

- In caso di interventi o procedure invasive andrà valutata la possibilità di somministrare steroidi e/o immunoglobuline o concentrati piastrinici (l'anestesista ed il chirurgo hanno in questo caso l'ultima parola).

- La gestione di un sanguinamento acuto va sempre gestita con la trasfusione di piastrine.

Il trattamento della piastrinopenia sarà quello della causa che l'ha generata ed a queste si rimanda (corticosteroidi e/o immunoglobuline seguite poi da splenectomia o TPO-mimetici per l'ITP, eradicazione dell'Helicobacter pylori, trattamento della infezione da HIV o da HCV, trattamento della infezione batterica o virale, trattamento della epatopatia con ipersplenismo, sospensione del farmaco reputato colpevole della piastrinopenia, trattamento della malattia autoimmune/reumatologica, trattamento della malattia ematologica o emato-oncologica, trattamento della microangioatia trombotica).

\section{Conclusioni}

Il paziente con piastrinopenia è un paziente, spesso ansioso, che mette o trasmette ansia al medico che non ha esperienza nel gestire abitualmente questo tipo di alterazione dell'emocromo. Per tale motivo si è cercato di inquadrare il problema cercando di dare dei suggerimenti per analizzare le possibili cause della piastrinopenia onde poter aiutare nel fare la diagnosi al più presto, dove è necessario farlo, ma anche nel confortare sul fatto che spesso solo l'osservazione ed il controllo dell'emocromo, e del paziente, nel tempo possono portare ad una diagnosi o alla remissione del quadro ematologico senza aver ingenerato ulteriore ansia e senza avere intrapreso un percorso diagnostico complesso e inutile.

\section{Bibliografia}

1. Arnold DM, Lim W. A rational approach to the diagnosis and management of thrombocytopenia in the hospitalized patient. Semin Hematol 2011;48:251.

2. Greinacher A, Selleng S. How I evaluate and treat 
thrombocytopenia in the intensive care unit patient. Blood 2016;128:3032.

3. Buckley MF, James JW, Brown DE, et al. A novel approach to the assessment of variations in the human platelet count. Thromb Haemost 2000;83:480.

4. Dowling MR, Josefsson EC, Henley KJ, et al. Platelet senescence is regulated by an internal timer, not damage inflicted by hits. Blood 2010;116:1776.

5. Stasi R, Amadori S, Osborn J, et al. Long-term outcome of otherwise healthy individuals with incidentally discovered borderline thrombocytopenia. PLoS Med 2006; 3:e24.

6. Warkentin TE. Heparin-induced thrombocytopenia in critically ill patients. Crit Care Clin 2011;27:805.

7. Arnold DM, Nazy I, Clare R, et al. Misdiagnosis of primary immune thrombocytopenia and frequency of bleeding: lessons from the McMaster ITP Registry. Blood Adv 2017;1:2414.

8. Neunert C, Lim W, Crowther M, et al. The American Society of Hematology 2011 evidence-based practice guideline for immune thrombocytopenia. Blood 2011; 117:4190.

9. Rousan TA, Aldoss IT, Cowley BD Jr, et al. Recurrent acute thrombocytopenia in the hospitalized patient: sepsis, DIC, HIT, or antibiotic-induced thrombocytopenia. Am J Hematol 2010;85:71.

10. Reese JA, Li X, Hauben M, et al. Identifying drugs that cause acute thrombocytopenia: an analysis using 3 distinct methods. Blood 2010;116:2127.

11. O'Donnell E, Shepherd C, Neff A. Immune thrombocytopenia from vancomycin in orthopedic cement. Am J Hematol 2007;82:1122.

12. Williamson DR, Albert M, Heels-Ansdell D, et al. Thrombocytopenia in critically ill patients receiving thromboprophylaxis: frequency, risk factors, and outcomes. Chest 2013;144:1207.

13. West KA, Anderson DR, McAlister VC, et al. Alloimmune thrombocytopenia after organ transplantation. $\mathrm{N}$ Engl J Med 1999;341:1504.

14. Azuno Y, Yaga K, Sasayama T, Kimoto K. Thrombocytopenia induced by Jui, a traditional Chinese herbal medicine. Lancet 1999;354:304.

15. Ohmori T, Nishii K, Hagihara A, et al. Acute thrombocytopenia induced by jui, a traditional herbal medicine. J Thromb Haemost 2004;2:1479.

16. Arnold J, Ouwehand WH, Smith GA, Cohen H. A young woman with petechiae. Lancet 1998;352:618.

17. Mantadakis E, Farmaki E, Buchanan GR. Thrombocytopenic purpura after measles-mumps-rubella vaccina- tion: a systematic review of the literature and guidance for management. J Pediatr 2010;156:623.

18. Patel U, Gandhi G, Friedman S, Niranjan S. Thrombocytopenia in malaria. J Natl Med Assoc 2004;96:1212.

19. Zammarchi L, Stella G, Mantella A, et al. Zika virus infections imported to Italy: clinical, immunological and virological findings, and public health implications. J Clin Virol 2015;63:32.

20. Hui P, Cook DJ, Lim W, et al. The frequency and clinical significance of thrombocytopenia complicating critical illness: a systematic review. Chest 2011;139:271.

21. Strauss R, Wehler M, Mehler K, et al. Thrombocytopenia in patients in the medical intensive care unit: bleeding prevalence, transfusion requirements, and outcome. Crit Care Med 2002;30:1765.

22. Vanderschueren S, De Weerdt A, Malbrain M, et al. Thrombocytopenia and prognosis in intensive care. Crit Care Med 2000;28:1871.

23. Aster RH. Pooling of platelets in the spleen: role in the pathogenesis of "hypersplenic" thrombocytopenia. J Clin Invest 1966;45:645.

24. Mendes FD, Suzuki A, Sanderson SO, et al. Prevalence and indicators of portal hypertension in patients with nonalcoholic fatty liver disease. Clin Gastroenterol Hepatol 2012;10:1028.

25. Montague N, Blackwelder P, Alsayegh H, et al. Platelet satellitism and dual surface immunoglobulin light-chain expression in circulating splenic marginal zone lymphoma cells. Ann Diagn Pathol 2013;17:117.

26. Bobba RK, Doll DC. Platelet satellitism as a cause of spurious thrombocytopenia. Blood 2012;119:4100.

27. Savage RA. Pseudoleukocytosis due to EDTA-induced platelet clumping. Am J Clin Pathol 1984;81:317.

28. Payne BA, Pierre RV. Pseudothrombocytopenia: a laboratory artifact with potentially serious consequences. Mayo Clin Proc 1984;59:123.

29. Garcia Suarez J, Calero MA, Ricard MP, et al. EDTAdependent pseudothrombocytopenia in ambulatory patients: clinical characteristics and role of new automated cell-counting in its detection. Am J Hematol 1992; 39:146.

30. Vicari A, Banfi G, Bonini PA. EDTA-dependent pseudothrombocytopaenia: a 12-month epidemiological study. Scand J Clin Lab Invest 1988;48:537.

31. Podda GM, Pugliano M, Femia EA, et al. The platelet count in EDTA-anticoagulated blood from patients with thrombocytopenia may be underestimated when measured in routine laboratories. Am J Hematol 2012; 87:727. 


\section{La gestione delle infezioni nel paziente oncoematologico}

Anna Lisa Garlaschelli, Francesco Artom

Medicina 1, AO San Giuseppe, Cairo Montenotte (SV), Italia

\section{Introduzione}

Le infezioni rappresentano un'importante causa di mortalità, morbosità ed incremento dei costi nei pazienti affetti da patologie oncoematologiche. La gestione della problematica infettiva richiede la conoscenza dei fattori di rischio peculiari del paziente ematologico, delle patologie infettive di più frequente riscontro e le scelte terapeutiche ad esse associate ed inoltre delle misure profilattiche atte a ridurne l'incidenza.

\section{Fattori predisponenti}

Il rischio infettivo differisce in ogni paziente e dipende da diversi fattori, modificabili e non. I fattori non modificabili sono dati dalle alterazioni del sistema immunitario, che dipendono non solo dalle terapie immunosoppressive, ma sono anche intrinseche alla patologia ematologica di base; le comorbidità del paziente e gli eventuali danni da terapia come le alterazioni delle barriere anatomiche come mucositi ed enteriti. I fattori modificabili sono la presenza di presidi tipo accessi venosi centrali o cateteri vescicali (CV); altri fattori di cui bisogna tenere conto, e ad oggi di particolare rilevanza, sono la colonizzazione con batteri resistenti e l'epidemiologia del contesto in cui si opera.

Inoltre di importanza fondamentale è la condivisione della problematica con lo specialista oncoematologo che ha in cura il paziente che potrà delucidare sulle terapie in atto e gli eventuali rischi infettivi peculiari ad esse connessi.

Corrispondente: Anna Lisa Garlaschelli, Medicina 1, AO San Giuseppe, ASL 2 Savona, Italia.

Tel.: +39.340.5024615.

E-mail: a.garlaschelli@asl2.liguria.it

Articolo pubblicato secondo la Creative Commons Attribution NonCommercial 4.0 License (CC BY-NC 4.0).

CCopyright A.L. Garlaschelli e F. Artom, 2019

Licensee PAGEPress, Italy

QUADERNI - Italian Journal of Medicine 2019; 7(1):76-82

\section{Alterazioni del sistema immunitario}

Le alterazioni del sistema immunitario possono riguardare uno solo o più componenti dello stesso; i nostri elementi difensivi principali sono dati da granulociti neutrofili, immunità cellulo-mediata, immunità umorale e milza.

I granulociti neutrofili sono la prima linea di difesa contro i micro-organismi patogeni; si possono osservare sia alterazioni in termini quantitativi, come nelle neutropenie, sia qualitativi, con deficit della fagocitosi o della chemiotassi e conseguente maggior rischio di infezione. Difetti di questo tipo si associano sia a chemioterapie che terapia a radiante, con impatto diverso in base all'area irradiata ed alla dose; difetti qualitativi si associano alle terapie steroidee ed a patologie ematologiche, come ad esempio le leucemie acute e le sindromi mileodisplastiche.

L'immunità cellulo-mediata agisce eliminando patogeni intracellulari e cellule infettate da virus attraverso Natural Killer e linfociti T; alterazioni di questo sistema si osservano in patologie quali i linfomi, nei pazienti trapiantati e come risultato di trattamenti citotossici in corso di chemioterapia.

L'immunità umorale è responsabile del riconoscimento e distruzione dei patogeni extracellulari e della produzione degli anticorpi.

In patologie come il mieloma multiplo e la leucemia linfocitica cronica questa funzione è alterata; radio e chemioterapie possono portare ad ipogammaglobulinemia.

La milza è strettamente correlata all'immunità e l'asplenia, sia post chirurgica, che funzionale, porta ad un aumentato rischio di infezioni da batteri capsulati come come Streptococcus pneumoniae ed Haemophilus influenzae e Neisseria meningitidis; la splenectomia può anche portare ad una ridotta produzione di fattori del complemento; deficit isolati di fattori del complemento, anche in assenza di splenectomia, aumentano il rischio di infezioni da menigococco., ${ }^{1,2}$

\section{Alterazioni delle barriere anatomiche}

Cute e mucose, quando integre, rappresentano le principali barriere protettive del nostro corpo e sono normalmente colonizzate da una flora residente peculiare per ogni sede (Tabella 1). 
La loro interruzione o malfunzionamento porta ad un maggior rischio di infezione sia da patogeni esterni che da parte della flora residente. Si intuisce facilmente come un CVC costituisca una facile via d'accesso al torrente ematico per batteri della cute; infatti le infezioni catetere correlate sono principalmente dovute a stafilococchi coagulasi negativi, abituali colonizzati della pelle. ${ }^{3}$

I pazienti ematologici assumono spesso antibiotici e questo, oltre a curare le infezioni, porta a selezionare batteri resistenti nella flora residente o facilitare infezioni quali le coliti da Clostridium difficile ${ }^{4}$ questi pazienti assumono anche antiacidi per alleviare gli effetti collaterali delle terapie con riduzione del $\mathrm{pH}$ gastrico e facilitazione alla colonizzazione dell'intestino da parte della flora del cavo orale e viceversa. Inoltre l'integrità fisica delle loro barriere è di frequente alterata da trattamenti citotossici o radianti con mucositi del cavo orale $\mathrm{o}$ enteriti. Lesioni o aumentata permeabilità delle mucose facilita le infezioni da parte della flora locale. ${ }^{5}$

\section{Altri fattori}

Le comorbidità con i loro peculiari deficit immunitari, come accade ad esempio nel diabete mellito, o fattori di rischio ad esse connesse si sommano ai precedenti elementi citati; lo stato nutrizionale è un altro fattore importante; la patologia ematologica ed i trattamenti possono portare ad uno stato ipercatabolico e calo ponderale; in caso di supporto parenterale si osserva un incremento del rischio di sepsi da Candida, ${ }^{6}$ mentre un supporto enterale può incrementare l'incrementare il rischio di polmoniti ab ingestis.

Un argomento di particolare rilevanza negli ultimi anni è la colonizzazione da batteri multiresistenti. Il paziente ematologico è particolarmente coinvolto in quanto attivo frequentatore dell'ambiente ospedaliero ed assume inoltre o in profilassi o a scopo terapeutico, una grande quantità di antibiotici durante la sua storia medica. La colonizzazione con batteri resistenti quali enterobatteri ESBL (extended spectrum beta lactamasis), MRSA (methicillin resistant Staphylococcus au- reus), KPC (Klebsiella pneumoniae carbapenemasi produttrice) o Psudomonas aeruginosa ed Acinetobacter spp multiresistenti lo mettono a rischio di infezioni causate da questi stessi batteri.

Le infezioni da multiresistenti hanno una mortalità elevata in quanto insensibili alle abituali terapie empiriche. ${ }^{7,8}$

\section{Concetti chiave}

- Il rischio infettivo del paziente ematologico varia da caso a caso.

- Difetti di numero o funzione dei granulociti aumenta il rischio di infezioni batteriche.

- I deficit di immunità cellulo-mediata aumentano il rischio di infezioni da batteri in genere, soprattutto intracellulari, tra cui anche quelle da Micobatteri e di infezioni virali.

- I deficit di immunità umorale aumentano il rischio di infezioni da patogeni extracellulari.

- L'aspenia post chirurgica o funzionale aumenta il rischio di infezione da batteri capsulati.

- Le singole colonizzazione da batteri resistenti portano ad un aumentato rischio di infezione dagli stessi.

- Fattori di rischio come presenza di presidi terapeutici o alterazioni delle barriere anatomiche devono essere conosciuti e considerati così come la storia terapeutica ematologica.

\section{Agenti eziologici}

Le cause di infezione, così come nel paziente immunocompetente, sono rappresentate da batteri, virus ed in misura minore funghi; più rare le infezioni parassitarie.

Le peculiarità del paziente determinano alcune differenze fondamentali con una maggiore insorgenza di infezioni da batteri resistenti e da agenti associati alla presenza di presidi quali i CVC anche in pazienti domiciliari.

Il deficit immunitario, anche se in forme differenti

Tabella 1. Flora commensale umana per sede anatomica.

\begin{tabular}{ll}
\hline Sede anatomica & Flora commensale \\
\hline Cute & Stafilococchi, Streptococchi, Propionebatteri, Corinebatteri, Acinetobacter \\
\hline Faringe e cavità nasali & Stafilococchi, Streptococchi, Haemophili, Branamella catharralis, Nesseria, Mycoplsama, Corinebatteri \\
\hline Stomaco & Lieviti, Helicobacter pylorii, alcuni lattobacilli \\
\hline Intestino tenue & Candida, Lattobacilli, Enterobatteri, Bacteroides \\
\hline Intestino crasso & Escherichia coli, Enterobacter, Lattobacilli, Streptococchi, Pseudomonas, Fusobaterium, Bacteroides, Klebsiella, Proteus \\
\hline Uretra & Streptococchi, Bacteroides \\
\hline Vagina & Lattobacilli, Streptococchi, Candida, Corinebatteri \\
\hline
\end{tabular}


di caso in caso, rende queste persone prone ad infezioni da microrganismi scarsamente patogeni per l'individuo sano, meglio noti come opportunisti come Pneumocystis jiroveci o Cryptococcus neoformans.

\section{Batteri}

I batteri sono i più comuni agenti eziologici delle infezioni nel paziente ematologico, gli stafilococchi coagulasi negativi (ad esempio S. epidermidis) sono quelli più frequentemente isolati dalle emocolture; anche se una parte di essi sono verosimilmente dovuti a contaminazione; gli altri isolati sono sostanzialmente costituiti da Enterobatteri, streptocchi ed MRSA, ma anche Pseudomonas aeruginosa, Acinetobacter spp ed altre eziologie meno frequenti..$^{9,10}$

La profilassi con ciprofloxacina aumenta il rischio di infezioni da gram-positivi, così come la presenza di CVC. ${ }^{11}$

\section{Virus}

La diagnostica delle infezioni virali, rispetto alle batteriche, è assai più povera; i virus di più frequente riscontro sono gli Herpes virus, sia HSV (herpes simplex virus) che CMV (citomegalovirus) che VZV (varicella zoster virus), più spesso come riacutizzazioni, ma anche come prima infezione ed i virus epatitici; ${ }^{12}$ l'infezione da virus influenzale può dare forme particolarmente impegnative.

\section{Funghi}

I funghi patogeni più comuni sono Candida spp, Aspergillo, Pneumocystis jiroveci, e più raramente Criptococcus neoformans e funghi dell'ordine Mucorales.

Nel paziente immunocompromesso, in particolare ematologico, possono causare forme invasive ad elevata mortalità, la cui diagnosi è spesso difficile e ritardata.

La diagnosi di certezza richiede l'isolamento in coltura da tessuti o l'identificazione in campioni bioptici. ${ }^{13}$

La candidemia (isolamento di Candida da emocolture) è la micosi invasiva di più frequente riscontro; mentre sono più rare le localizzazioni agli organi con focolai settici. ${ }^{14}$

Candida colonizza frequentemente la pelle, il cavo orale, l'intestino ed il tratto genitale femminile ed il fattore di rischio principale per le candidemie è rappresentato da un'interruzione delle barriere come avvine in presenza di un CVC o in corso di mucositi.

Clinicamente indistinguibile da una sepsi batterica, la diagnosi si basa sulle metodiche di laboratorio: il gold standard è rappresentato dalla positività su emocolture anche se la sensibilità si aggira intorno al 50$70 \%$; è pertanto importante che vengano raccolti più campioni; ${ }^{15}$ test di più recente introduzione come il beta-D-glucano o metodiche di biologia molecolare possono essere d'aiuto ma non sono disponibili presso tutti i centri. ${ }^{16}$

Il secondo fungo di più comune riscontro è l'Aspergillo, si tratta di un micro-organismo ubiquitario che viene contratto attraverso l'inalazione e come forma principale determina una polmonite con lesioni peculiari; ${ }^{17,18}$ nelle forme più avanzate si può avere disseminazione ad altri organi quali in particolare reni ed encefalo; il fattore di rischio per l'Aspergillosi invasiva è una neutropenia profonda e prolungata. La diagnosi di certezza richiede l'identificazione colturale o istologica su campioni di tessuto; vista la difficoltà ad eseguire accertamenti bioptici in pazienti spesso pancitopneici, risultano di grande importanza la determinazione del galattomannano, sia su BAL che su sangue e del beta-D-glucano, entrambi componenti della parete cellulare fungina ma con diverse specificità; quest'ultimo è infatti comune a molti funghi e pertanto meno specifico per Aspergillus. ${ }^{19} \mathrm{La}$ TC del torace fornisce elementi fondamentali per avvalorare il sospetto clinico, con immagini che vanno da infiltrati con alone periferico a vetro smerigliato a più tipiche cavitazioni; queste spessonon risultano visibili nei pazienti neutropenici e possono compaire in ritardo con l'immunoricostituzione; recentemente è stato introdotto l'utilizzo dell'angioTC polmonare per la ricerca di segni di angioinvasività che possono avvalorare il sospetto di Aspergillosi invasia. ${ }^{20}$

Altri funghi rilevanti sono Pneumocystis jiroveci, responsabile di polmoniti e Cryptococcus neoformas che determina soprattutto meningiti, meno frequentemente polmoniti; negli ultimi anni sono emersi come causa di micosi invasive anche gli Zygomiceti, agenti di sinusiti e polmoniti. ${ }^{21}$

\section{Parassiti}

Il parassita di più comune riscontro nelle infezioni nel paziente ematologico, in particolare nel trapiantato è Toxoplasma gondii, agente eziologico della neurotoxoplasmosi, forma patologica estremamente grave, solitamente dovuta ad una riattivazione di un'infezione contrattata in precedenza. ${ }^{22}$

Alle nostre latitudini le altre parassitosi sono di scarsa importanza clinica in quanto poco diffuse, merita comunque menzione lo Strongiloides stercoralis, elminta presente in Italia, che può dare forme disseminate nell'immunocompromesso; l'ipereosinofilia deve far sorgere il sospetto clinico in associazione a colite, anche emorragica, tosse con infiltrati polmonari; da notare che in forme di immunosoppressione particolarmente severa l'ipereosinofilia può essere assente..$^{23}$

L'aumento dei flussi migratori è destinato a condurre ad un aumento delle delle parassitosi, che devono comunque essere prese in considerazione nei pazienti provenienti da aree endemiche. 


\section{Concetti chiave}

- Le infezioni di più frequente riscontro nel paziente oncoematologico sono quelle ad eziologia batterica.

- Le forme di immunosoppressione più severa possono associarsi ad infezioni da agenti meno comuni, noti come opportunisti.

- L'aumento delle migrazioni e dei viaggi in paesi con differente clima ed epidemiologia, portano all'emergenza di infezioni da agenti tropicali in passato estremamente rare.

\section{Forme cliniche}

La gestione delle infezioni nelle immunosoppressioni iatrogene più profonde, come si osservano ad esempio nel paziente trapiantato, è normalmente condivisa tra lo specialista ematologo ed infettivologo, tuttavia spesso altri specialisti si trovano a dover gestire episodi febbrili in corso di trattamenti chemioterapici.

\section{Neutropenia febbrile}

La problematica di più frequente riscontro è la neutropenia febbrile.

$\mathrm{Si}$ intende per neutropenia un numero assoluto di neutrofili $\leq 500 \mathrm{cell} / \mathrm{mm}^{3}$ e per neutropenia profonda $\leq 100 \mathrm{cell} / \mathrm{mm}^{3}$.

Si intende per febbre una singola misurazione di temperatura orale $\geq 38,3^{\circ} \mathrm{C}$ oppure $\geq 38^{\circ} \mathrm{C}$ peristente per almeno 1 ora.

L'approccio al paziente richiede una strategia che comprende decidere se il paziente necessita di un ricovero e quali antibiotici utilizzare, ovvero identificare i pazienti critici e che richiedono un trattamento aggressivo.

I pazienti con neutropenia profonda o attesa superiore ai 7 giorni o con comorbidità sono abitualmente considerati ad alto rischio ed avviati a ricovero ospedaliero. $^{24}$

Esistono degli score validati che possono essere d'aiuto nel processo decisionale come il MASCC score (multinational association for supportive care in cancer) o il CISNE (clinical index of stable febrile neutropenia), entrambi ideati per identificare i pazienti low risk candidabili ad una terapia domiciliare. ${ }^{25}$

La diagnostica si basa principalmente sull'esecuzione di emocolture seriate; sia da periferico che da CVC in caso ne sia presente uno, con esecuzione di almeno 1 set (flacone aerobi e flacone anaerobi) per ogni via dell'accesso centrale. ${ }^{8}$

Altri accertamenti colturali o metodiche molecolari dovrebbero essere guidate da sintomi di richiamo d'organo o specifici sospetti. Spesso gli episodi febbrili si risolvono con terapia empirica e gli accertamenti colturali risultano negativi; la percentuale di positività delle emocolture in corso di neutropenia febbrile si aggira intorno al $30 \%$.

Gli esami ematochimici, oltre alle funzionalità d'organo, devono comprendere gli indici di flogosi come PCR e procalcitonina.

Nei pazienti a basso rischio, gestiti in ambulatorio, la scelta terapeutica ricade su un fluorochinolonico (da evitare in caso di profilassi con gli stessi) o amoxicillina-clavulanato, ${ }^{26}$ la gestione domiciliare implica un monitoraggio stretto e continuativo del paziente con possibilità di rivalutazioni quotidiane.

Nei pazienti ospedalizzati viene abitualmente utilizzata come terapia empirica una cefalosporina antipseudomonas (cefepime), piperacillina-tazobactam o un carbapenemico; ${ }^{27}$ l'associazione di un agente anti MRSA (vancomicina/daptomicina/linezolid) non è routinaria ma trova indicazione in presenza di CVC, infezioni tessuti molli o polmonari oltre che nei pazienti critici (Tabella 2).

La conoscenza di eventuali colonizzazioni da bat-

Tabella 2. Trattamento empirico della neutropenia febbrile.

\begin{tabular}{|c|c|c|c|}
\hline Categoria & Eziologie & Trattamento empirico & Note \\
\hline $\begin{array}{l}\text { Adulti basso rischio: } \\
\text { Neutropenia attesa } \\
<7 \text { giorni, nessuna comorbidità, } \\
\text { paziente stabile, possibilità di } \\
\text { terapia orale }\end{array}$ & $\begin{array}{l}\text { Bacilli gram negativi aerobi; } \\
\text { streptococchi viridanti }\end{array}$ & $\begin{array}{l}\text { Ciprofloxacina }+ \text { amoxicillina } \\
\text { clavulanatotrattare fino a conta } \\
\text { assoluta neutrofili } \\
>1000 \text { cell } / \mathrm{mm}^{3}\end{array}$ & $\begin{array}{l}\text { In caso di allergia a beta lattamici } \\
\text { considera clinidamicina }\end{array}$ \\
\hline $\begin{array}{l}\text { Adulti alto rischio: } \\
\text { Neutropenia attesa } \\
>7 \text { giorni, neutropenia profonda, } \\
\text { comorbidità }\end{array}$ & $\begin{array}{l}\text { Bacilli gram negativi aerobi, } \\
\text { Pseudomonas; Streptococchi } \\
\text { virudanti R a cefalosporine; } \\
\text { MRSA }\end{array}$ & $\begin{array}{l}\text { Cefepime o cefalosporina } \\
\text { anti pseudomonas; pip/tazo } \\
\text { IMIpene/meropenem } \\
\text { Aggiungere vancomicina } \\
\text { in caso di sospetto di infezione } \\
\text { associata a CVC }\end{array}$ & $\begin{array}{l}\text { Nel paziente critico considera di } \\
\text { associare aminoglicoside e } \\
\text { vancomicna ed echinocandina }\end{array}$ \\
\hline $\begin{array}{l}\text { Febbre e neutropenia persistenti } \\
\text { dopo } 5 \text { giorni di terapia } \\
\text { antibiotica empirica }\end{array}$ & $\begin{array}{l}\text { Candida, Aspergillus, VRE, } \\
\text { Gram negativi resistenti }\end{array}$ & $\begin{array}{l}\text { Aggiungere Echinocandina o } \\
\text { voriconazolo }\end{array}$ & $\begin{array}{l}\text { Se utilizzata Amfotericina } \mathrm{B} \text { la } \\
\text { forma lipidica è meglio tollerata }\end{array}$ \\
\hline
\end{tabular}


teri resistenti (ESBL, MRSA, VRE, KPC ed altre) obbliga a prendere in considerazione l'aggiunta precoce di farmaci mirati al trattamento empirco.

La terapia dovrebbe essere modificata non prima di 72 ore; salvo in neutropenie che durano da più di 7 giorni; nel paziente clinicamente stabile l'antifungino dovrebbe essere aggiunto solo dopo 4-7 giorni di terapia antibiotica senza risposta.

La durata della terapia antibiotica nelle neutropenie febbrili senza identificazione di una fonte o di un'eziologia è piuttosto controversa, ma abitualmente si protrae fino alla ripresa della funzionalità midollare e risoluzione della neutropenia. ${ }^{8,24}$

\section{Altre sindromi}

Le infezioni polmonari sono gravate da un'alta mortalità nel paziente ematologico; il basso numero di neutrofili può ridurre sia i sintomi che i reperti radiologici in caso di polmonite; oltre ad $i$ comuni batteri che causano polmonite nei pazienti immunocompetenti, nei pazienti con neutropenie prolungate o terapie aggressive devono essere presi in considerazione agenti eziologici particolari o quali Aspergillus o Pnemocystis jiroveci o forme virali come il Citomegalovirus.

In questi pazienti lo studio TC del polmone deve sempre affiancare la radiografia tradizionale che risulta poco sensibile in questi pazienti. ${ }^{28}$

Altre infezioni che, nei pazienti più compromessi possono mettere a rischio di vita sono le sinusiti; oltre alle eziologie tradizionali devono essere tenute in considerazione forme fungine più rare come quelle da $\mathrm{Mu}-$ corales che richiedono un approccio aggressivo basato sull'associazione di terapia chirurgica ed antifungina.

Le infezioni del gastroenterico annoverano, tra le altre, esofagiti da Candida, esofagiti e coliti da CMV, stomatiti da HSV. ${ }^{29}$

Le infezioni del sistema nervoso centrale, oltre alle forme batteriche includono encefaliti da virus della famiglia degli Herpes, le forme da Toxoplasma e Criptococco, le forme da JC virus e le localizzazioni encefaliche in corso di micosi invasive.

\section{Concetti chiave}

- Lo screening dei pazienti con infezione e l'identificazione dei soggetti a rischio che necessitano di ospedalizzazione per il trattamento è di fondamentale importanza; score come il MASCC ed il CISNE possono essere d'ausilio al giudizio del clinico.

- La scelta della terapia empirica si basa sui fattori di rischio e sulle condizioni cliniche del paziente; la terapia del paziente critico deve essere a spettro più ampio possibile.

- La durata del trattamento in assenza di identificazione di un focus infettivo o di un agente eziolo- gico dovrebbe durare fino a risoluzione della neurtopenia o, in caso di neutropenie prolungate, fino alla stabile risoluzione del fatto clinico.

\section{Prevenzione}

\section{Misure ambientali}

Per ridurre il rischio di trasmissione delle infezioni in ospedale devono essere impiegate varie misure di controllo come elementi fondamentali delle precauzioni di isolamento, tra le quali il lavaggio delle mani è riconosciuto come la misura singola più efficace.

Le altre precauzioni prevedono l'utilizzo dei dispositivi di protezione individuale (DPI); adeguate procedure di decontaminazione, pulizia, disinfezione e/o sterilizzazione di presidi e attrezzature; pulizia, sanificazione e disinfezione di superfici e ambiente; corretta gestione e trasporto dei campioni di materiali biologici; educazione sanitaria a degente e visitatori. ${ }^{30}$

Una revisione pubblicata nel 2008 da Lancet Infectious Diseases afferma che la combinazione di terapia antibiotica profilattica, barriere di isolamento e controllo della qualità dell'aria riduce significativamente il tasso di mortalità nei pazienti oncologici immunocompromessi a causa della chemioterapia o del trapianto di cellule staminali emopoietiche nella misura del $40 \%$ a 30 giorni dal trattamento. ${ }^{31}$ La prevenzione delle infezioni passa quindi anche attraverso misure ambientali e comportamentali: per i pazienti neutropenici, ad esempio, sarà importante ventilare le stanze di degenza ed evitare la presenza di lavori di costruzione o manutenzione nell'ospedale, osservare misure di prevenzione comportamentale quali: lavaggio delle mani; acqua e altre bevande; preparazione del cibo; piante, giochi, animali; igiene della cute e del cavo orale. Come già sottolineato, le infezioni rappresentano anche un'importante complicanza correlata all'uso dei CVC e gli infermieri hanno un ruolo fondamentale sia nella gestione dell'accesso venoso centrale, che nell'informazione e nell'educazione dell'utente.

\section{Profilassi farmacologica}

Si basa su diversi tipi di farmaci, alcuni atti a correggere difetti del sistema immunitario del paziente, come le immunoglobuline o i fattori di crescita granulocitari che determinando un più rapido recupero dei neutrofili, riducono la durata della neutropenia e conseguentemente il rischio di infezioni; altri sono invece propriamente agenti anti infettivi.

Questi ultimi sono antibiotici, anti virali ed antifungini che vengono somministrati per il periodo in cui il paziente è a rischio particolarmente elevato di infezioni, come nelle chemioterapie intensive o nei pazienti trapiantati.

La prevenzione delle infezioni batteriche durante 
le neutropenia prolungata si basa principalmente sull'utilizzo di ciprofloxacina o levofloxacina; la profilassi delle infezioni fungine sull'uso di fluconazolo o posaconazolo; altri farmaci che vengono utilizzati sono il trimethoprim sulfametossazolo per la prevenzione della polmonite da $P$. jiroveci; altri farmaci vengono utilizzati per prevenire riattivazioni virali come ad esampio acyclovir.

Se utilizzate in gruppi particolari di pazienti le profilassi sono in grado di ridurre l'incidenza di specifiche infezioni, ma si associano ad un'aumentata emergenza di infezioni da forme resistenti.

Risulta intuitivo che in caso di infezione in paziente in profilassi farmacologica, l'agente scelto per la terapia deve necessariamente differire da quello utilizzato in profilassi.

La profilassi delle infezioni nel paziente immunocopromesso comprende anche un'accurata pianificazione del calendario vaccinale. ${ }^{32}$

\section{Vaccinazioni}

Le indicazioni sono differenti per le diverse patologie ematologiche, ma in generale i vaccini vivi attenuati sono controindicati e deve essere posta attenzione anche nella vaccinazione dei familiari con gli stessi perchè potrebbero trasmettere la patologia al congiunto.

Oltre ai vaccini comunemente consigliati alla popolazione generale i pazienti ematologici devono essere sottoposti a vaccinazione anti influenzale ed a vaccinazioni contro batteri specifici, in particolare l'anti pneumococcica, associata alle altre vaccinazioni contro i capsulati in caso di asplenia.

Al fine di ottenere una risposta soddisfacente la vaccinazione dovrebbe essere pianificata ed avvenire prima dell'inizio delle terapie immunosoppressive.

Il vaccino anti-influenzale è indicato e da somministrare al di fuori del trattamento chemioterapico, ma la risposta immunitaria potrebbe essere ridotta; alcuni esperti per tale motivo consigliano di praticare una dose di richiamo a breve distanza.

Anche il vaccino antipneumococcico dovrebbe essere somministrato a distanza da trattamenti chemioterapici; dei vaccini disponibili deve essere somministrato prima il 13-valente e, a distanza di 812 settimane il 23-valente.

I pazienti non immuni per epatiti A e B dovrebbero essere vaccinati, ma anche in questo caso la risposta può essere ridotta. ${ }^{33}$

\section{Concetti chiave}

- Il lavaggio delle mani è la forma più efficace ed economica di prevenzione delle infezioni.

- Le misure di isolamento ambientale sono da applicare solo in casi selezionati.
- La profilassi anti infettiva deve essere applicata solo in casi selezionati, tipicamente nelle forme di immunosoppressione più severa e duratura.

- La valutazione dello stato vaccinale deve essere effettuata alla diagnosi di patologia oncoematologica ed il programma vaccinale inserito nel programma terapeutico del paziente.

\section{Conclusioni}

Il rischio infettivo nei pazienti oncoematologici è senza dubbio considerevole ed i soggetti più fragili e critici spesso sono quelli a rischio delle infezioni più disparate, compresi patogeni opportunisti e micosi invasive, rendendo il processo diagnostico terapeutico particolarmente difficoltoso.

Un'accurata valutazione clinico anamnestica e dei dati laboratoristico-strumentali e la collaborazione con lo specialista ematologo o oncologo di riferimento sono un importante ausilio; nonostante questi accorgimenti la mortalità per infezione nel paziente ematologico rimane comunque elevata.

\section{Bibliografia}

1. Van der Meer J. Defects in host defence mechanisms. In RubinR, Young LS eds. Current Approaches in the Compromised Host. New York: Plenum; 1994: 33-66hes in the Compromised Host. New York: Plenum; 1994:33-66.

2. De Paw BE, Donnelly JP. Infections in the immunocompromised host: general principles. In: Mandell, Douglas and Bennett's Principles and practice of infectious diseases, $5^{\text {th }}$ ed., Churchill Livingstone, London 2000; 3079-90.

3. Wolf HH, et al. Central venous catheter-related infections in hematology and oncology: Guidelines of the Infectious Diseases Working Party (AGIHO) of the German Society of Hematology and Oncology (DGHO). Annal Hematol 2008 Nov;87(11):863-76.

4. Revolinski SL, et al. Clostridium difficile in Immunocompromised Hosts: A Review of Epidemiology, Risk Factors, Treatment, and Prevention.Clin Infect Dis. 2018 Oct 3. doi: 10.1093/cid/ciy845.

5. Roth RR, James WD. Microbial ecology of the skin. Annu Rev Microbiol. 1988;42:441-464.

6. Vergara T, et al. Exposition to total parenteral nutrition increases the risk of catheter-related bloodstream infection Rev Chilena Infectol 2016 Dec;33(6):603-608.

7. Chen CY, et al. Trends and antimicrobial resistance of pathogen causing bloodstream infectios amog febrile neutropenic adults with hematological malignacy. J Formos Med Ass 2004;103:526-32.

8. Averbuch D, et al. Targeted therapy against multiresistant bacteria in leukemic and hematopoietic stem cell transplant recipients: guidelines of the 4th European conference on infections in leukemia (ECIL-4, 2011). Haematologica 98(12): 1836-1847. doi:10.3324/haematol.2013.091330.

9. Wisplinghoff H, Cornely OA, Moser S, Bethe U, Stutzer 
H, Salzberger B, Fatkenheuer G, Seifert H. (2003) Outcomes of nosocomial bloodstream infections in adult neutropenic patients: a prospective cohort and matched case-control study. Infect Control Hosp Epidemiol 24(12):905-911.

10. Kirchhoff LV, Sheagren JN. (1985) Epidemiologyandclinicalsignificance of blood cultures positive for coagulase-negative staphylococcus. Infect Control: IC 6(12):479-486.

11. Heinz WJ, et al. Diagnosis and empirical treatment of fever of unknown origin (FUO) in adult neutropenic patients: guidelines of the Infectious Diseases Working Party (AGIHO) of the German Society of Hematology and Medical Oncology (DGHO). 2017; Ann Hematol 96:1775-1792.

12. Ullmann AJ. Infectious diseases in allogeneic haematopoietic stem cell transplantation: prevention and prophylaxis strategy guidelines 2016. Ann Hematol. 2016;95:1435-1455.

13. Schmiedel Y, Zimmerli S. Common invasive fungal diseases: an overview of invasive candidiasis, aspergillosis, cryptococcosis, and Pneumocystis pneumonia Swiss Med Wkly. 2016;146:w14281.

14. Bennett JE, Dolin R, Blaser MJ. Mandell, Douglas, and Bennett's Principles and Practiceof Infectious Diseases. 8thed. Philadelphia: Elsevier Saunders; 2015.

15. Clancy CJ, Nguyen MH. Finding the "missing 50\%" of invasive candidiasis: how nonculture diagnostics will improve understanding of disease spectrum and transform patient care. Clin Infect Dis. 2013;56(9):1284-92.

16. Theel ES, Doernb CD. Beta-D-Glucan Testing Is Important for Fungal Diagnosis Journal of Clinical Microbiology 2013;51(11)3478-3483.

17. Alastruey-Izquierdo A, Mellado E, Pelaez T, et al. Population-based survey of filamentous fungi and antifungal resistance in Spain (FILPOP Study). Antimicrob Agents Chemother. 2013;57(7):3380-7.

18. Anaissie EJ, Stratton SL, Dignani MC, et al. Pathogenic Aspergillus species recovered from a hospital water system: a 3-year prospective study. Clin Infect Dis. 2002;34(6):780-9.

19. Pfeiffer CD, Fine JP, Safdar N. Diagnosis of invasive aspergillosis using a galactomannan assay: a metaanalysis. Clin Infect Dis. 2006;42(10):1417-27.

20. Stanzani M, Lewis R, Fiacchini M, et al. A risk prediction score for invasive mold disease in patients with hematological malignancies. PLoS One 8: e75531etaanalysis. Clin Infect Dis. 2006;42(10):1417-27.

21. Ruhnke M, Schwartz S. Recent developments in the management of invasive fungal infections in patients with oncohematological diseases Ther Adv Hematol 2016, Vol. 7(6) 345-359.

22. Schmidt-Hieber M, et al. CNS Infections in Patients with Hematological Disorders (including allogeneicstem-celltransplantation) Guidelines of the Infectious Diseases Working Party (AGIHO) oftheGermanSocietyofHematologyand MedicalOncology(DGHO). 2016. Annal of Oncology 27:1207-1225.

23. Fabiani S, et al. Allogeneic hematopoietic stem cell transplant recipients and parasitic diseases: A review of the literature of clinical cases and perspectives to screen and follow-up active and latent chronic infections. 2017; Transpl Infect Dis. 19:e12669.

24. Fraifeld AG, Bow EJ, Kent A, et al. Clinical Practice Guideline for the Use of Antimicrobial agent in Neutropenic Patient with Cancer: 2010 Update by the Infectious Diseases Society of America. CID 2011:52(4) e56-e93.

25. Klastersky J, et al. The Multinational Association for Supportive Care Cancer risk index: a multinational scoring system for identifying low risk neutropenic cancer patients. J Clinic Oncol 2000;18:3038-51.

26. Klastersky J. Management of fever in neutropenic patients with different risks of complications. Clin Infect Dis 2004; 39(Suppl 1):S32-7.

27. Johnson MP, Ramphal R. Beta-lactam-resistant Enterobacter bacteremia in febrile neutropenic patients receiving monotherapy. J Infect Dis 1990;162:981-3.

28. Shorr AF, at al. Pulmonary infiltrates in the non-HIV-infected immunocompromised patient: etiologies, diagnostic strategies, and outcomes. Chest 2004;125: 260-271.

29. Vehreschild MJGT, et al. Diagnosis and management of gastrointestinal complications in adult cancer patients: evidence-based guidelines of the Infectious Diseases Working Party (AGIHO) of the German Society of Hematology and Oncology (DGHO)Annals of Oncology 24:1189-1202,2013.

30. Garner JS, et al. The Hospital Infection Control Practices Advisory Committee (HICPAC). Guideline for isolation precautions in hospital. Hospital Infect Control Hosp Epidemiol 1996;17(1):53-80.

31. Schlesinger A, et al. Infection-control interventions for cancer patients after chemotherapy: a systematic review and meta-analysis. The Lancet Infectious Diseases 2008; DOI:10.1016/S1473-3099(08)70284-6.

32. Silva-Pinto A, et al. Protocol for the prevention of Infections Related to the treatment of Hematological Malignancies. Acta Med Port 2018 Jun; 31 (6):347-361.

33. Rieger CT, et al. Anti infective vaccination strategy in patient with hematologic malignasis or solid tumorosGuideline of the Infectious Diseases Working Party (AGIHO) of German Socety for Hematology and medical Oncology (DGHO)Annals of Oncology 2018;29 (6) 1354-1365. 


\title{
La gammopatia di origine indeterminata
}

\author{
Silvana Timitilli, Maurizio Cavalleri, Marco Scudeletti \\ Medicina Interna I, PO Sestri Levante, ASL 4 Chiavarese, Chiavari (GE), Italia
}

\section{Introduzione}

Si definisce MGUS ${ }^{1}$ (monoclonal gammopathy of undetermined significance) uno dei disordini clonali pre-maligni più comuni, caratterizzato dalla presenza di una componente monoclonale di natura immunoglobulinica (IgG, gA o IgM ma anche, sebbene raramente, costituita esclusivamente da catene leggere libere $\mathrm{k}$ o l).

Questa situazione è pressoché costantemente di riscontro occasionale e asintomatica. Non interferisce (non deve interferire) con la qualità della vita del soggetto.

I criteri per la diagnosi di MGUS sono: i) presenza di una componente monoclonale serica inferiore ai 3 $\mathrm{g} / \mathrm{dL}$; ii) assenza di danni d'organo; iii) presenza di plasmacellule monoclonali midollari $<10 \%$.

La prevalenza del MGUS è del 3\% nella popolazione di età superiore ai 50 anni e del $5 \%$ nella popolazione di età superiore ai 70 anni per arrivare a una percentuale di oltre il $7 \%$ negli ultraottantenni ${ }^{1,2}$ (Figura 1).

Ciò che conferisce alle gammopatie monoclonali di significato indeterminato una rilevanza clinica è la sua possibilità/probabilità di: i) progressione delle caratteristiche proliferative verso il mieloma multiplo smoldering, mieloma multiplo, malattia di Waldenstrom, sindromi linfoproliferative croniche $(90 \%$ dei casi); ii) sviluppo di danno d'organo causato dalla proteina monoclonale quali amiloidosi AL, light chains deposition disease ( $L C D D$ ) ed altre rare condizioni (10\% dei casi) (Figura 2$)$.

Il rischio di trasformazione complessivo in mie-

Corrispondente: Silvana Timitilli, Medicina Interna I, PO Sestri Levante, ASL 4 Chiavarese, Chiavari (GE), Italia.

E-mail: silvana.timitilli@asl4.liguria.it

Articolo pubblicato secondo la Creative Commons Attribution NonCommercial 4.0 License (CC BY-NC 4.0).

CCopyright S. Timitilli et al., 2019

Licensee PAGEPress, Italy

QUADERNI - Italian Journal of Medicine 2019; 7(1):83-88 loma multiplo è stimato intorno all' $1 \%$ annuo ${ }^{3}$ e rimane stabile negli anni.

L'elevata prevalenza del MGUS rispetto alla popolazione e la non chiarezza esistente sulle modalità di follow up di tale condizione, ha generato finora notevoli problemi di gestione nella pratica clinica.

\section{Diagnosi}

La diagnosi di MGUS è basata sulla presenza di tutti i seguenti parametri: i) presenza di componente monoclonale di entità $<$ a $3 \mathrm{gr} / \mathrm{dL}$; ii) presenza di plasmacellule midollari $<10 \%$; iii) assenza di segni $\mathrm{CRAB}^{4-6}$ (Tabella 1).

Esistono diverse categorie di M-GUS, con diverse possibilità evolutive: le prime tre sono le più frequenti: ${ }^{7-9}$ i) non-IgM M-GUS; ii) light chain M-GUS o M-GUS a catene libere leggere (la cui componente monoclonale è costituita esclusivamente da catene leggere libere k o 1); iii) IgM M-GUS; iv) plasmocitoma solitario; v) plasmocitoma solitario con minimo coinvolgimento midollare; vi) amiloidosi da catene leggere sistemica.

I criteri diagnostici sono rappresentati dalla Tabella 2 alla $4 .^{10}$

\section{Fattori di rischio di progressione maligna}

L'importanza clinica dell'MGUS è data dalla possibilità che possa progredire verso una forma maligna. Le caratteristiche di presentazione e di evoluzione della malattia nel primo anno di follow-up sono molto utili per predire il rischio di trasformazione da MGUS a malattia sintomatica (Tabella 5). I principali fattori di rischio predittivi di trasformazione maligna sono correlati alla carica tumorale: la percentuale di plasma cellule midollari e la quantità di componente monoclonale: $>15 \% \mathrm{e}>15 \mathrm{gr} / \mathrm{L}$, probabilità di progressione a 10 anni 16,5 e $6,1 \%$ rispettivamente, alle caratteristiche biologiche del clone plasmacellulare: isotipo catene pesanti $\operatorname{Ig} \mathrm{A} / \mathrm{IgM}>\operatorname{IgG}$, produzione catene leggere con determinazione del rapporto FLC ratio, presenza di proteinuria Bence Jones, anomalie citogentiche del clone plasmacellulare (neuploide $>$ diploide).

A questi fattori principali vanno aggiunti la per- 
centuale di plasmacellule clonali rispetto a quelle policlonali e la riduzione delle immunoglobuline policlonali nel siero.

M-GUS non-IgM e light chain possono progredire in mieloma multiplo o disordini correlati a plasmacellule monoclonali mentre i pazienti con M-GUS IgM possono progredire in malattia di Waldenstrom, linfoma non Hodgkin o altre sindromi linfoproliferative croniche.

I pazienti con MGUS hanno un rischio di sviluppare mieloma multiplo sette volte superiore alla popolazione normale. Il rischio di evoluzione è dell' $1 \%$ per anno, in modo costante. Data l'età mediana di insorgenza e il rischio della popolazione generale di sviluppare un mieloma multiplo, la grande maggioranza dei portatori di MGUS non svilupperanno mai un mieloma multiplo o altra patologia correlata.

Nel 99\% dei casi la progressione della MGUS è predetta da un incremento della componente monoclonale $^{3}$ (Figura 3).

\section{Stratificazione del rischio di progressione}

Esistono due sistemi di stratificazione di rischio: uno sviluppato dal PETHEMA, basato sull'analisi immunofenotipica delle plasmacellule monoclonali, e quello sviluppato dalla Mayo Clinic, maggiormente validato e diffuso, che identifica tre fattori di rischio maggiori: ${ }^{4}$ i) concentrazione della componente monoclonale $>1,5 \mathrm{gr} / \mathrm{dL}$; ii) isotipo non-IgG; iii) rapporto delle catene leggere libere sieriche (free light chainsFLC ratio) anormale $(<0,26 \mathrm{o}>1,65)$.

Sulla base di questi parametri sono state codificate 4 classi di rischio con diversa, significativa, tendenza all'evoluzione (Tabella 3) (Figura 4). ${ }^{4}$

La stadiazione determina il follow up che ha lo scopo di individuare i pazienti a rischio di evoluzione in mieloma multiplo ed eventualmente di sottoporli a trattamento prima che sviluppino danno d'organo (CRAB), secondo i nuovi criteri diagnostici del mieloma multiplo. ${ }^{10}$ La stadiazione ha anche lo scopo di individuare persone con minima o nulla probabilità di progressione e conseguentemente di non medicalizzarli e di non sprecare risorse sanitarie.

Infine il follow up ha anche lo scopo di individuare i pazienti a rischio di sviluppare amiloidosi $\mathrm{AL}$ e di trattarli prima dello sviluppo di danni d'organo irreversibili.

\section{Esami per stadiazione e follow-up}

Esami di base obbligatori in caso di riscontro di componente monoclonale IgG ed IgA: i) elettroforesi

Tabella 1. Criteri CRAB.10

\begin{tabular}{lll}
\hline $\mathbf{C}$ & Calcio & Calcio serico $>11 \mathrm{mg} / \mathrm{dL}$ o sopra i limiti della norma \\
\hline $\mathbf{R}$ & Insufficienza renale & Creatinina serica $>2 \mathrm{mg} / \mathrm{dL}$ o eGFR $<40 \mathrm{~mL} / \mathrm{min}$ \\
\hline $\mathbf{A}$ & Anemia & Emoglobina $<10 \mathrm{gr} / \mathrm{dL} \mathrm{o}<2 \mathrm{gr} / \mathrm{dL}$ normale \\
\hline $\mathbf{B}$ & Bone lytic lesion & Radiografia scheletro convenzionale, TC o PET-TC \\
\hline
\end{tabular}

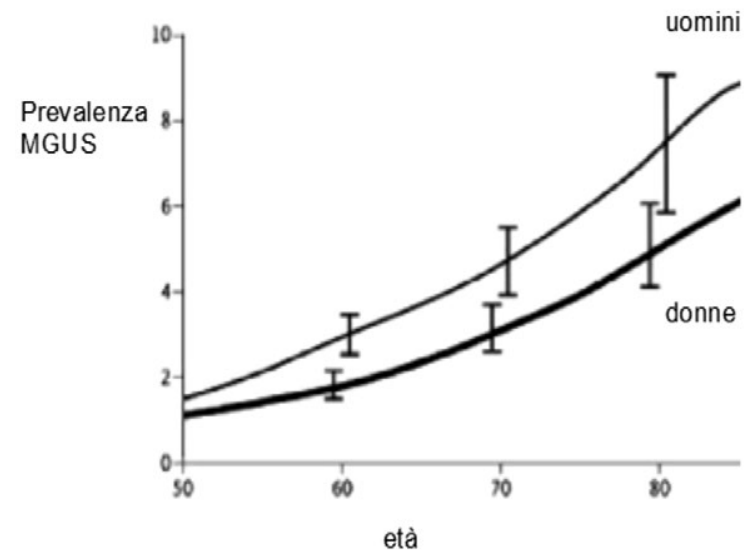

Figura 1. Prevalenza di MGUS secondo età e sesso. ${ }^{3}$

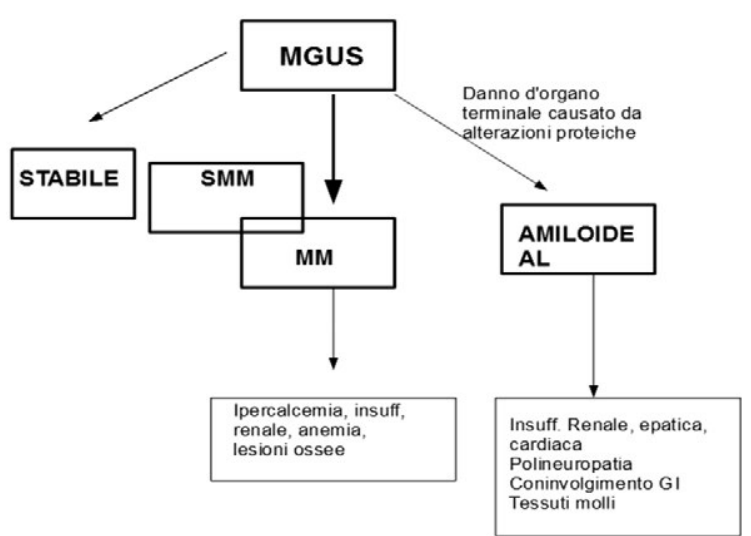

Figura 2. Evoluzione dell'M-GUS. ${ }^{9}$ 
proteine con dosaggio componente monoclonale (mandatoria la definizione quantitativa della componete monoclonale); ii) immunosottrazione o immunofissazione siero; iii) determinazione catene leggere libere sieriche (free light chains, FLC); iv) emocromo con formula; v) funzione renale (creatinina sierica, eGFR, calcemia); vi) esame urine ed analisi del sedimento con dosaggio proteinuria (immunofissazione urinaria e albuminuria solo in presenza di proteinuria); vii) proteinuria delle 24 ore, creatinina, azotemia; viii) calcemia; ix) GOT, GPT, GGT, ALP, bilirubina.
La immunofissazione dovrebbe essere eseguita anche in presenza di ipogammaglobulinemia.

In seguito alla stadiazione si dovrà eseguire aspirato midollare e biopsia ossea nei pazienti in classe di rischio intermedio 2 e alto. Anche se il mieloaspirato è sufficiente, la biopsia ossea aggiunge il vantaggio di un dato più accurato nell'identificazione delle plasmacellule clonali. In ogni caso eseguendo entrambi può accadere che vi sia diversità nell'entità dell'infiltrato: in questo caso va considerato il valore più alto. ${ }^{7}$ Lo studio citogenetico con l'ibridazione fluorescente in

Tabella 2. Criteri diagnostici e classificazione IMWG per le MGUS.

\begin{tabular}{|c|c|c|c|}
\hline & Definizione & Tasso di progressione & Eventi di progressione \\
\hline $\begin{array}{l}\text { Gammapatia monoclonale } \\
\text { di incerto significato } \\
\text { non-IgM }\end{array}$ & $\begin{array}{l}\text { - Proteine monoclonali sieriche }(\text { non } \mathrm{IgM})<30 \mathrm{~g} / \mathrm{L} \\
\text { - Plasmacellule clonali midollari }<10 \% \\
\text { - Assenza di danno d'organo come ipercalcemia, } \\
\text { insufficienza renale, anemia, lesioni ossee }(\mathrm{CRAB}) \\
\text { o amiloidosi attribuibile al disordine proliferativo } \\
\text { delle plasmacellule }\end{array}$ & $1 \%$ anno & $\begin{array}{l}\text { Mieloma multiplo, } \\
\text { plasmocitoma } \\
\text { solitario, amiloidosi } \\
\text { immunoglobulina correlata } \\
\text { (AL-AHL-AH) }\end{array}$ \\
\hline $\begin{array}{l}\text { Gammopatia monoclonale } \\
\text { di incerto significato IgM }\end{array}$ & $\begin{array}{l}\text { - Proteine monoclonali sieriche }(\operatorname{IgM})<30 \mathrm{~g} / \mathrm{L} \\
\text { - Infiltrazione midollare linfoplasmacellulare }<10 \% \\
\text { - Nessuna evidenza di anemia, sintomi costituzionali, } \\
\text { iperviscosità, linfoadenopatia o altro danno d'organo } \\
\text { attribuibile al disordine linfoproliferativo }\end{array}$ & $1,5 \%$ per anno & $\begin{array}{l}\text { Macroglobulinemia di } \\
\text { Waldentrom, amiloidosi } \\
\text { immunoglobulina correlata } \\
\text { (AL, AHL, AH) }\end{array}$ \\
\hline $\begin{array}{l}\text { Gammopatia di incerto } \\
\text { significato a catene leggere }\end{array}$ & $\begin{array}{l}\text { - Rapporto FLC anomalo }(<0,26 \mathrm{o}>1,65) \\
\text { - Livello aumentato della catena leggera coinvolta } \\
\text { (aumento di } \kappa \text { FLC in pazienti con rapporto }>1,65 \\
\text { e aumento } \lambda \text { FLC in quelli con rapporto }<0,26) \\
\text { - Nessuna espressione di catene pesanti } \\
\text { all'immunofissazione } \\
\text { - Assenza di danno d'organo (CRAB) o amiloidosi } \\
\text { - Plasmacellule clonali midollari }<10 \% \\
\text { - Concentrazione di proteine monoclonali nelle urine } \\
\text { (Bence Jones) }<500 \mathrm{mg} / 24 \mathrm{~h}\end{array}$ & $0,3 \%$ per anno & $\begin{array}{l}\text { Mieloma multiplo a catene } \\
\text { leggere, amiloidosi AL }\end{array}$ \\
\hline Plasmocitoma solitario & $\begin{array}{l}\text { - Lesione solitaria dell'osso e del tessuto molle } \\
\text { con evidenza di plasmacellule clonali alla biopsia } \\
\text { - Midollo normale, senza evidenza di plasmacellule } \\
\text { clonali } \\
\text { - Skeletal surgery nella norma e RMN oTC della } \\
\text { colonna e del bacino nella norma (eccetto che per } \\
\text { la lesione primaria solitaria) } \\
\text { - Assenza di danno d'organo (CRAB) o amiloidosi }\end{array}$ & Circa $10 \%$ entro 3 anni & Mieloma multiplo \\
\hline $\begin{array}{l}\text { Plasmicitoma soltario con } \\
\text { minimo coinvolgimento } \\
\text { midollare }\end{array}$ & $\begin{array}{l}\text { - Lesione solitaria dell'osso e del tessuto molle con } \\
\text { evidenza di plasmacellule clonali alla biopsia }<10 \% \\
\text { - Skeletal surgery nella norma e RMN o TC della } \\
\text { colonna e bacino nella norma } \\
\text { - Assenza di danno d'organo (CRAB) }\end{array}$ & $\begin{array}{l}60 \% \text { (osso) } \\
20 \% \text { (tessuti molli) } \\
\text { entro } 3 \text { anni }\end{array}$ & Mieloma multiplo \\
\hline $\begin{array}{l}\text { Amiloidosi da catene } \\
\text { leggere }\end{array}$ & $\begin{array}{l}\text { - Presenza di sindrome sistemica amiloido-correlata } \\
\text { (esempio: coinvolgimento epatico, renale, } \\
\text { cardiaco, gastrointestinale, nervi periferici) } \\
\text { - Colorazione positiva al Congo red in qualunque } \\
\text { tessuto (grasso aspirato, midollo, biopsia d'organo) } \\
\text { - Evidenza di correlazione con catene leggere } \\
\text { attraverso esame diretto della massa amiloide con } \\
\text { analisi MS o immunoelettroscopia } \\
\text { - Evidenza di disturbo proliferativo delle } \\
\text { plasmacellule monoclonali (proteine monoclonali } \\
\text { in plasma e urine, FLC ratio anomalo, plasmacellule } \\
\text { clonali nel midollo) }\end{array}$ & Non disponibile & $\begin{array}{l}\text { Mieloma multiplo in alcuni } \\
\text { pazienti }\end{array}$ \\
\hline
\end{tabular}


situ (FISH) è di scarsa utilità perché possono esserci alterazioni sia nelle MGUS che nel MM e non è stato ancora definito il loro significato; comunque gli studi citogenetici raramente mostrano anomalie cariotipiche nelle MGUS a causa del basso indice proliferativo e al numero limitato di plasmacellule.

Nei casi con rapporto $\mathrm{k} / \lambda$ (free light chains), indipendentemente dall'entità della alterazione eseguire NT-proBNP e proteinuria/albuminuria delle $24 \mathrm{~h}$ (screening di danno d'organo da amiloidosi). L'esecuzione di disfunzione cardiaca (NT-proBNP) e alterazione renale (albuminuria) in presenza di FLC ratio alterato ha la finalità di valutare una fase iniziale di amiloidosi $\mathrm{AL}$, in considerazione che fino all' $83 \%$ dei pazienti affetti da tale patologia presenta un'alterazione di tale rapporto e del fatto che la prognosi dei pazienti trattati in fase pre-sintomatica individuata dai marcatori di danno d'organo è migliore di quella dei pazienti sintomatici. La presenza di anormalità di tali esami, in assenza di altre cause, rappresentano un elemento di sospetto per cui bisogna proseguire nel protocollo diagnostico delle amiloidosi. ${ }^{8,11,12}$

Esami di base obbligatori in caso di riscontro di componente monoclonale IgM: agli esami sopra elencati si deve aggiungere dosaggio delle LDH, esecuzione di radiografia del torace ed ecografia dell'addome e pelvi.

Il follow up andrà eseguito a seconda del rischio di progressione: i) rischio basso: $1^{\circ}$ anno ogni 6 mesi e poi ogni 2 anni; ii) rischio intermedio $1: 1^{\circ}$ anno ogni 6 mesi e poi ogni anno; iii) rischio intermedio 2: ogni 6 mesi; iv) rischio alto: ogni 3-4 mesi.

Alla luce della recente revisione dei criteri diagnostici per il MM asintomatico (Tabella 4), si evidenzia l'importanza del monitoraggio osseo della MGUS. Le modifiche più importanti riguardano la definizione del mieloma asintomatico ad alto rischio. Ai vecchi CRAB sono stati aggiunti 3 nuovi parametri costituendo gli SLIM (plasmocytosis, light chains ratio, RM). L'adozione dei nuovi criteri per l'inizio della terapia, soprattutto se ne è presente uno solo, deve comunque essere valutata con prudenza e caso per caso. Di seguito vengono riportati alcuni chiarimenti del panel di esperti sullo studio della malattia ossea.

La RMN (Whole body o spinale) è raccomandata per lo staging iniziale.

Tabella 3. Stratificazione di rischio di progressione secondo Rajkumar e rischio di evoluzione in mieloma multiplo in 20 anni. $^{4}$

\begin{tabular}{llll}
\hline $\begin{array}{l}\text { Numero fattori } \\
\text { di rischio presenti }\end{array}$ & Categoria di rischio & $\begin{array}{l}\text { Rischio assoluto evoluzione } \\
\text { in mieloma multiplo } \\
\text { a 20 anni (\%) }\end{array}$ & $\begin{array}{l}\text { Rischio assoluto evoluzione in mieloma multiplo a } \\
\mathbf{2 0} \text { anni corretto per decesso per cause competitive (\%) }\end{array}$ \\
\hline Nessuno & 5 & 2 \\
\hline 1 & Basso & 21 & 10 \\
\hline 2 & Intermedio-basso & 37 & 18 \\
\hline 3 & Intermedio-alto & 58 & 27 \\
\hline
\end{tabular}

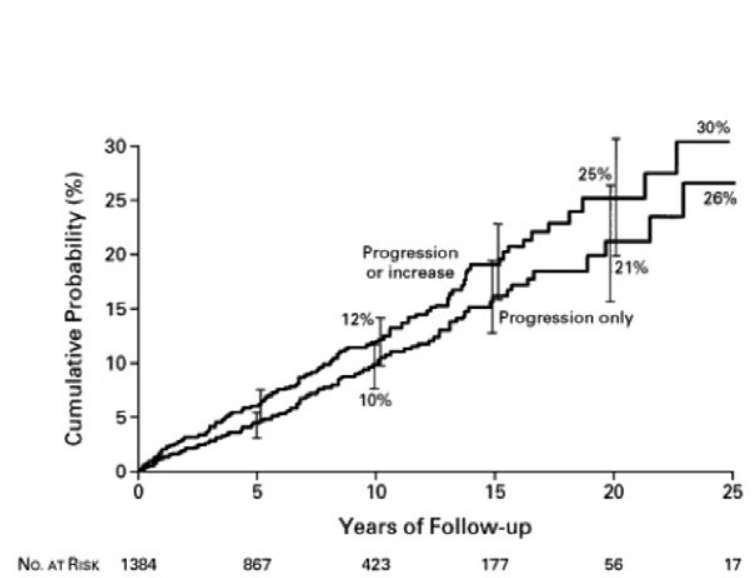

Figura 3. Rischio di progressione in mieloma multiplo di pazienti con diagnosi di MGUS. ${ }^{3}$

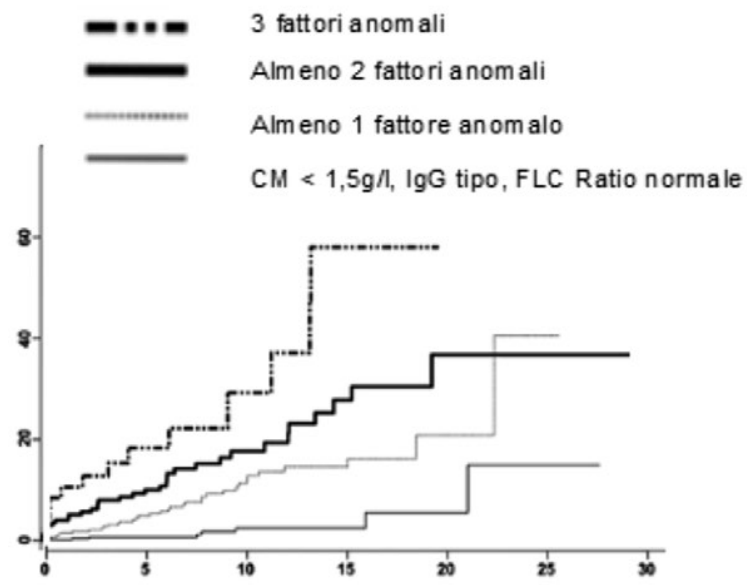

Figura 4. Rischio di evoluzione in mieloma multiplo di portatori di MGUS secondo la stratificazione di Rajkumar. ${ }^{4}$ 
Tabella 4. Revisione dei criteri diagnostici per il mieloma asintomatico e sintomatico.

Evidenza di danno d'organo attribuibile al sottostante disordine plasmacellulare $(\mathrm{CRAB})^{\mathrm{a}}$
Specificatamente

- Ipercalcemia: calcio sierico $>0,25 \mathrm{mml} / \mathrm{L}(1 \mathrm{mg} / \mathrm{dL})$ maggiore del limite normale $\mathrm{o}>2,75 \mathrm{mmol} / \mathrm{L}$ $(11 \mathrm{mg} / \mathrm{dL})$

- Insufficienza renale: clearance della creatinina $<40 \mathrm{~mL} /$ minuto $^{\mathrm{b}}$ o creatinina sierica $>177 \mathrm{mmol} / \mathrm{L}$ $(2 \mathrm{mg} / \mathrm{dL})$

- Anemia: valore di emoglobina ridotto di $2 \mathrm{~g} / \mathrm{dL}$ sotto il limite normale o valore $<10 \mathrm{~g} / \mathrm{dL}$ - Lesioni ossee: una o più lesioni litiche alla Rx scheletro, TC o PET-TC ${ }^{c}$

Uno o più dei seguenti marker bioumorali di malignità

- Infiltrato plasmacellulare clonale midollare $>60 \%$

- Rapporto catene leggere patologiche/non patologiche $>100$

$\cdot>1$ lesione focale alla RMN

a La clonalità deve essere definita mostrando la restrizione clonale $\mathrm{k} / \lambda$ con la citometria a flusso, con biopsia ossea; in caso di discrepanza fra mieloaspirato e biopsia ossea deve essere considerato il valore più alto; ${ }^{b}$ misurata o stimata con formule validate; ${ }^{c}$ se l'infiltrato midollare di plasmacellule clonali è $<10 \%$, è richiesta la presenza di lesioni ossee per distinguere il mieloma dal plasmocitoma solitario con minimo interessamento midollare.

Tabella 5. Malattie rare correlate a una MGUS.

\begin{tabular}{|c|c|c|}
\hline LCCD (HCDD) & $\begin{array}{l}\text { - Catene leggere } \mathrm{k}(>90 \%) \\
\text { - Sindrome nefrosica, insufficienza renale }\end{array}$ & $\begin{array}{l}\text { - Albuminuria, riduzione della filtrazione glomerulare, } \\
\text { ematuria }\end{array}$ \\
\hline Sindrome POEMS & $\begin{array}{l}\text { - IgG }(>90 \%) \\
\text { - Neuropatia periferica (demielinizzante) } \\
\text { - Organomegalia (epatomegalia, splenomegalia, } \\
\text { linfoadenomegalia) } \\
\text { - Endocrinopatia (adrenergica, gonadica, pancreatica, } \\
\text { paratiroide, ipofisaria, tiroide) } \\
\text { - Modificazioni cutanee (alterazioni riferite a tessitura, } \\
\text { e spessore pigmenti cutanei; modificazioni della quantità } \\
\text { di peli corporei o della loro trama; angiomi a ciliegia) } \\
\text { - Ascite, effusione pleurica, edema periferico } \\
\text { - Malattia di Castelman } \\
\text { - Papilledema } \\
\text { - Lesioni ossee scleroticheVEGF elevato } \\
\text { - Trombocitosi, diatesi trombotica, policitemia }\end{array}$ & $\begin{array}{l}\text { - Segni di neuropatia: torpore, parestesia, debolezza o } \\
\text { alterazioni del bilancio associate a } \operatorname{IgG} \lambda\end{array}$ \\
\hline $\begin{array}{l}\text { Sindrome di } \\
\text { Fanconi acquisita }\end{array}$ & $\begin{array}{l}\text { - Catene leggere k (circa } 100 \% \text { ) } \\
\text { - Proteinuria tubulare, glicosuria, } \\
\text { aminoaciduria, acidosi, ipofosfatemia, ipocalcemia, } \\
\text { ipouricemia } \\
\text { - Insufficienza renale } \\
\text { - Osteomalacia }\end{array}$ & $\begin{array}{l}\text { - Glicosuria con normale glicemia } \\
\text { - Ipouricemia non in trattamento con allopurinolo } \\
\text { o acido acetilsalicilico }\end{array}$ \\
\hline $\begin{array}{l}\text { Crioglobulinemia: } \\
\text { tipo I (proteina M } \\
\text { singolatipo II } \\
\text { (IgM monoclonale } \\
\text { + IgG policlonale) }\end{array}$ & $\begin{array}{l}\text { - Vasculite cutanea } \\
\text { - Astenia } \\
\text { - Neuropatia } \\
\text { - Insufficienza renale }\end{array}$ & $\begin{array}{l}\text { - Orticaria fredda, porpora agli arti inferiori, } \\
\text { Fenomeno di Raynaud, acrocianosi, ulcere agli arti } \\
\text { inferiori associate ad artralgie }\end{array}$ \\
\hline Sleromioedema & $\begin{array}{l}\text { - Principalmente IgG } \\
\text { - Indurimento cutaneo diffuso } \\
\text { - Malattia polmonare ostruttiva, ipertensione polmonare } \\
\text { - Sindrome neuro-dermatologica (convulsioni e coma } \\
\text { preceduti da febbre), rara }\end{array}$ & $\begin{array}{l}\text { - Depositi cutanei di mucina a lenta progressione } \\
\text { in assenza di malattia tiroidea e i presenza di } \operatorname{IgG} \lambda\end{array}$ \\
\hline Sindrome di Schnitzler & $\begin{array}{l}\text { - } \operatorname{IgM\kappa }(80 \%) \\
\text { - Dermatosi urticaria neutrofila cronica con CRP e SA } \\
\text { elevati } \\
\text { - Artralgie, dolore osseo } \\
\text { - Linfonodi, milza e fegato ingrossati } \\
\text { - Amiloidosi AA, rara }\end{array}$ & 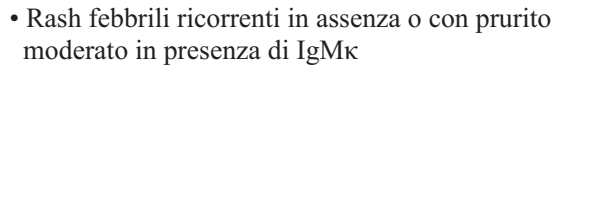 \\
\hline Neuropatie & - Neuropatia periferica (spesso demielinizzante) & $\begin{array}{l}\text { - Insorgenza di parestesie e/o disestesie, mancanza di } \\
\text { equilibrio, andatura atassica }\end{array}$ \\
\hline Xantomatosi & $\begin{array}{l}\text { - IgG }(80 \%) \\
\text { - Lesioni xantomatose cutanee } \\
\text { - Lesioni extracutanee (orbitali, BM, linfonodi, tendini, } \\
\text { mucosa) }\end{array}$ & $\begin{array}{l}\text { - Papule e macule gialle } \\
\text { - Noduli o placche da gialli a violacei } \\
\text { (nello xantogranuloma necrobiotico) }\end{array}$ \\
\hline $\begin{array}{l}\text { Malattia da agglutinina } \\
\text { fredda }\end{array}$ & - Anemia emolitica & $\begin{array}{l}\text { - Acrocianosi, fenomeno di Raynaud } \\
\text { - Falso aumento dell'MCV e riduzione degli RBC alla } \\
\text { conta eritrocitaria completa }\end{array}$ \\
\hline
\end{tabular}


Nei pazienti che presentano infiltrazione diffusa, o nei quali è presente una lesione isolata $(<5 \mathrm{~mm})$, è utile eseguire un controllo a 3-6 mesi.

La presenza di lesioni evidenziate con TC o TCPET può essere considerata un criterio per iniziare un trattamento anche in assenza di evidenza alla $\mathrm{Rx}$ scheletro.

L'osteoporosi, in assenza di mieloma conclamato, non è considerata sufficiente per porre diagnosi di malattia ossea da mieloma.

\section{Considerazioni conclusive e key point}

- Nelle MGUS bisogna adottare un approccio diagnostico adeguato al rischio evolutivo. Se la MGUS viene definita a baso rischio evolutivo il follow up può essere svolto anche dal medico di famiglia.

- I soggetti con MGUS non a basso rischio, vanno monitorati con NT-pro-BNP per identificare precocemente una amiloidosi cardiaca.

- Nell'inquadramento e monitoraggio della malattia ossea, la LDTC è una più valida alternativa alla radiografia dello scheletro.

- Allo stato attuale una MGUS non va trattata; la nuova classificazione del mieloma ha definito alcuni parametri (SLIM) che aiutano a identificare i pazienti con smoldering mieloma ad alto rischio evolutivo verso un mieloma sintomatico $(80 \%$ a 2 anni): in questi casi è giustificato iniziare precocemente una terapia del mieloma adattata in base a età e comorbidità.

\section{Bibliografia}

1. Kyle RA, Rajkumar SV. Monoclonal gammopathy of undetermined significance and smoldering multiple myeloma. Curr Hematol Malig Rep 2010;5:62-9.
2. Kyle RA, Therneau TM, Rajkumar SV, et al. Prevalence of monoclonal gammopathy of undetermined significance. N Engl J Med 2006;354:1362-9.

3. Kyle RA, Therneau TM, Rajkumar SV, et al. A longterm study of prognosis in monoclonal gammopathy of undetermined significance. N Engl J Med 2002;346: 564-9.

4. Rajkumar SV, Kyle RA, Therneau TM, et al. Serum free light chain ratio is an independent risk factor for progression in monoclonal gammopathy of undetermined significance. Blood 2005;106:812-7.

5. Durie BG, Kyle RA, Belch A, et al. Myeloma management guidelines: a consensus report from the Scientific Advisors of the International Myeloma Foundation. Hematol J 2003;4:379-98.

6. Group IMW. Criteria for the classification of monoclonal gammopathies, multiple myeloma and related disorders: a report of the International Myeloma Working Group. Br J Haematol 2003;121:749-57.

7. Rajkumar SV, Dispenzieri A, Kyle RA. Monoclonal gammopathy of undetermined significance, Waldenstrom macroglobulinemia, AL amyloidosis, and related plasma cell disorders: diagnosis and treatment. Mayo Clin Proc 2006;81:693-703.

8. Merlini G, Palladini G. Differential diagnosis of monoclonal gammopathy of undetermined significante. Hematology 2012.

9. Van de Donk NWCJ, Palumbo A, Johnsen HE, et al. The clinical relevance and management of monoclonal gammopathy of undeterminated significant and related disorders: recommendations from the European Myeloma Network. Haematol Jun 2014;99(6):984-996.

10 Rajkumar V, et al. International Myeloma Working Group updated criteria for the diagnosis of multiple myeloma. Lancet Oncol 2014;15:e538-48.

11. Merlini G, et al. Systemic light chain amyloidosis: an update for treating physicians. Blood, 2013;121:51245130.

12. van de Donk NW, Mutis T, Poddighe PJ, Lokhorst HM, Zweegman S. Int J Lab Hematol. 2016 May;38 Suppl 1:110-22. doi: 10.1111/ijlh.12504. Epub 2016 May 9. 


\title{
La malattia di Gaucher
}

\author{
Marina Cavaliere \\ SC Medicina 1 ed Ematologia, Ospedale San Paolo, Savona, Italia
}

\section{Definizione}

La malattia di Gaucher è una malattia metabolica congenita dovuta all'accumulo di un particolare glicosfingolipide, il glucosil-ceramide, all'interno dei lisosomi presenti nei macrofagi.Essa fa parte delle malattie lisosomiali malattie in cui un particolare metabolita viene accumulato all'interno di cellule deficitarie dell'enzima deputato al suo catabolismo. Sono note 45 diverse malattie lisosomiali, tutte rare ma, nell'insieme, hanno una prevalenza di 1:5000 persone. $\mathrm{E}$ fondamentale conoscerle in quanto per alcune di esse esistono terapie che sono tanto più efficaci quanto più precocemente vengono cominciate.

\section{Epidemiologia}

La malattia di Gaucher è panetnica, ha un'ereditarietà autosomica recessiva legata al cromosoma $1 . \mathrm{La}$ prevalenza della malattia di Gaucher nella popolazione generale è compresa tra 1:40.000 e 1:60.000. È più comune nella popolazione ebrea ashkenazita $(\sim 1: 850)$.

\section{Genetica}

Il gene $G B A$, sul cromosoma 1, che codifica per la glucocerebrosidasi acida, è lungo $7 \mathrm{~KB}$ e presenta 11 esoni che possono essere soggetti a mutazioni funzionalmente significative: sono ad oggi note circa $300 \mathrm{mu}-$ tazioni. Non sono state ancora identificate correlazioni genotipo-fenotipo: la malattia di Gaucher è caratterizzata da una notevole variabilità in termini di espressione

Corrispondente: Marina Cavaliere, SC Medicina 1 ed Ematologia, Ospedale San Paolo, Savona, Italia.

Tel.: +39.019.8404551 - Fax: +39.019.8404583.

E-mail: marinacavaliere@libero.it

Articolo pubblicato secondo la Creative Commons Attribution NonCommercial 4.0 License (CC BY-NC 4.0).

CCopyright M. Cavaliere, 2019

Licensee PAGEPress, Italy

QUADERNI - Italian Journal of Medicine 2019; 7(1):89-93 clinica e i pazienti presentano un ampio spettro di fenotipi, alcuni di essi presentando sintomi sin dall'infanzia, tipicamente nelle forme più severe, altri possono rimanere paucisintomatici fino all'età adulta.

La glucocerebrosidasi acida scinde il glucosilceramide (o glucocerebroside) in ceramide e glucosio.

Il glucosilceramide è un componente del doppio strato fosfolipidico delle membrane cellulari.

\section{Fisiopatologia}

Il deficit dell'enzima lisosomiale $\beta$-glucosidasi acida porta all'accumulo di glucosilceramide nei lisosomi principalmente nelle cellule della linea dei monociti/macrofagi, con conseguente disfunzione multiorgano progressiva che coinvolge principalmente il sistema reticoloendoteliale.

Perché proprio il sistema reticolo endoteliale? Perché è il sistema deputato all'eliminazione delle celle senescenti del tessuto a più rapido ricambio cellulare del nostro organismo: il sistema emopoietico, e abbiamo visto che il glucosilceramide è un componente delle membrane cellulari. Gli altri tessuti a rapido ricambio: le mucose, la cute, i capelli, espellono all'esterno dell'organismo le cellule morte o senescenti, mentre ciò non accade alle cellule del sangue.

Gli organi principalmente coinvolti dalla malattia di Gaucher saranno quindi: la milza, il fegato, il midollo osseo e, di conseguenza, l'osso.

\section{Sottotipi della malattia di Gaucher}

I sottotipi della malattia di Gaucher a seconda delle manifestazioni cliniche sono:

- Non-neuronopatica (tipo 1): prevalenza da 1:50.000 a 1:100.000 a livello mondiale; prevalenza nella popolazione ebrea ashkenazita 1:850; manifestazione clinica possibile a qualsiasi età.

- Neuronopatica (tipo 2 e tipo 3): i) acuta (tipo 2): manifestazione nel primo anno di vita con un'aspettativa di vita fino a 2 anni; ii) cronica (tipo 3): manifestazione nella prima infanzia; ${ }^{1}$ iii) la malattia di Gaucher neuronopatica ha una prevalenza $<1: 100.000 .^{2}$

La classificazione e le principali caratteristiche della malattia di Gaucher sono riportate in Tabella 1. 
Comunque, nonostante le classificazioni formulate per favorire gli approcci diagnostici e terapeutici, la malattia di Gaucher presenta un continuum fenotipico.

\section{Quadro clinico}

La malattia di Gaucher presenta manifestazioni cliniche molto eterogenee ma che possiamo raggruppare in: i) coinvolgimento viscerale; ii) manifestazioni ematologiche; iii) sintomi neurologici; iv) coinvolgimento osseo.

Il coinvolgimento viscerale è praticamente sempre presente e si evidenzia con splenomegalia ed epatomegalia. La splenomegalia può essere imponente (il $38 \%$ dei pazienti presenza un volume splenico di circa 15 volte superiore alla norma, mentre solo il $14 \%$ dei pazienti ha una splenomegalia di dimensioni inferiori a 5 volte la norma) così come l'epatomegalia (il 53\% dei pazienti presenta un volume epatico compreso tra 1,25 e 2,5 volte superiore rispetto alla norma).

L'anemia e la piastrinopenia sono le manifestazioni ematologiche più comuni, associate all'incremento della frazione gamma dell'elettroforesi con sviluppo di componenti monoclonali al suo interno. Un variabile grado di anemia è presente nel $65 \%$ dei pazienti, mentre le piastrine sono superiori a $120.000 / \mathrm{nmv}$ nel $40 \%$ dei pazienti e circa il $14 \%$ dei pazienti ha valori di piastrine inferiori a $60.000 / \mathrm{mmc}$.

I sintomi neurologici sono variabilissimi e passano da semplici disturbi deglutitori e strabismo a manifestazioni parkinsoniane o epilettiche fino a gravi turbe neuromuscolari con retroflessione perenne del capo e degenerazione neurologica progressiva con morte precoce. Sono comunque tipiche delle forme più gravi e di interesse prevalentemente pediatrico.

Il coinvolgimento osseo è associato all'infiltrazione del midollo osseo da parte delle cellule di Gau- cher. Il meccanismo o i meccanismi fisiopatologici precisi non sono ben noti. L'entità del coinvolgimento scheletrico e della progressione della malattia varia notevolmente. Come per le manifestazioni generali della malattia, l'entità e la gravità del coinvolgimento scheletrico nella malattia di Gaucher non possono essere predette in base al genotipo GBA del paziente. Gli effetti sullo scheletro sono l'aspetto più invalidante della malattia di Gaucher e condizionano negativamente la qualità della vita. I pazienti possono essere interessati da: crisi ossee (15-20\% dei pazienti), dolore osseo cronico ( $>50 \%$ dei pazienti), fratture patologiche, collasso delle articolazioni secondario a osteonecrosi.

La fisiopatologia del danno osseo nella malattia di Gaucher non è completamente nota. Alla base delle complicanze sembrano essere coinvolti diversi meccanismi: i) infiltrazione: le cellule di Gaucher penetrano nell'osso e nel midollo osseo; ii) l'espansione midollare dovuta all'infiltrazione delle cellule di Gaucher potrebbe causare occlusione e compressione vascolare e aumentare la pressione intraossea, sebbene non esistano dati diretti per dimostrarlo; iii) anche $\mathrm{i}$ meccanismi con i quali le cellule di Gaucher rimpiazzano le normali cellule del midollo osseo, causando edema e ischemia, non sono noti; iv) accumulo di glucocerebrosidi, che può alimentare processi infiammatori inibendo l'attività degli osteoblasti, inducendo l'attivazione e la formazione di osteoclasti.

Una volta stabilitasi, l'osteonecrosi è irreversibile e spesso progredisce a complicanze invalidanti, che possono richiedere interventi di chirurgia ortopedica per il ripristino funzionale e l'attenuazione del dolore. L'osteopenia può contribuire all'osteoporosi e aumentare il rischio di fratture patologiche e di collasso delle articolazioni. Gli obiettivi terapeutici nella malattia di Gaucher includono la prevenzione, stabiliz-

Tabella 1. Classificazione e principali caratteristiche della malattia di Gaucher.

\begin{tabular}{|c|c|c|c|}
\hline & TIPO 1 & TIPO 2 & TIPO 3 \\
\hline & Non neuronopatica & Neuronopatica acuta & Neuronopatica cronica \\
\hline Prevalenza & $\begin{array}{c}\text { Panetnica } \\
\text { 1:50.000-1:100.000 } \\
\text { (ebrei Ashkenaziti: } 1: 850 \text { ) }\end{array}$ & \multicolumn{2}{|c|}{$\begin{array}{c}<1: 100.000 \\
\text { Panetnica }\end{array}$} \\
\hline Età alla presentazione & Qualsiasi & Primo anno di vita & Infanzia \\
\hline Durata della vita & Variabile & $<2$ anni & $<40$ anni \\
\hline Malattia primaria della SNC & Assente & Grave & Da lieve a grave \\
\hline Visceromegalie & Da lieve a grave & Da moderata a grave & Da lieve a grave \\
\hline Anomalie ematologiche & Da lievi a gravi & Gravi & Da lievi a gravi \\
\hline Anomalie scheletriche & Da lievi a gravi & Assenti & Da lievi a moderate \\
\hline
\end{tabular}


zazione e inversione della progressione della patologia scheletrica. I bambini sembrano beneficiare più rapidamente dalla terapia enzimatica sostitutiva, il che sottolinea l'importanza di trattare precocemente la malattia di Gaucher, con l'obiettivo di far regredire la malattia esistente, di raggiungere il picco di massa ossea e di prevenire lo sviluppo di una patologia grave o irreversibile.

\section{Diagnosi della malattia di Gaucher}

Gli ematologi svolgono un ruolo essenziale nella diagnosi della malattia di Gaucher. In un'indagine rivolta ai pazienti, l' $^{\prime} 6 \%$ \% $(\mathrm{n}=98)$ degli intervistati ha riferito di aver consultato un ematologo o un oncoematologo nel tentativo di ottenere una diagnosi. Purtroppo però, In un'indagine rivolta a ematologi e oncoematologi, solo il $20 \%$ ha preso in considerazione la malattia di Gaucher nella sua diagnosi differenziale. Questo è tanto più preoccupante quando ricordiamo che la diagnosi e il trattamento precoci della malattia di Gaucher sono essenziali per prevenire o far regredire le complicanze gravi della malattia. Sono stati riportati ritardi diagnostici di più di 10 anni in pazienti con sintomi legati alla malattia di Gaucher. La malattia di Gaucher è una patologia progressiva e, se non trattata, può portare a:i) morte prematura dovuta a complicanze emorragiche; ii) ipertensione polmonare; iii) malattia epatica; iv) sepsi; v) ritardo/mancanza di crescita; vi) complicanze derivanti dalla progressione della malattia ossea; vii) impatto sulla qualità della vita.

Comunque circa i $2 / 3$ dei pazienti ricevono la diagnosi entro l'età di 20 anni e quasi la metà dei pazienti prima dei 10 anni. Tra i pazienti con malattia di tipo 1 che ricevono la diagnosi prima dell'età di 10 anni, il $68 \%$ ha ricevuto la diagnosi prima dei 5 anni.

\section{Quali pazienti devono essere sottoposti a test per la malattia di Gaucher?}

I pazienti con splenomegalia elo trombocitopenia devono essere sottoposti a test per la malattia di Gaucher quando siano state escluse le seguenti patologie: i) neoplasie ematologiche maligne; ii) anemia emolitica; iii) talassemia; iv) porpora trombocitopenica immune; v) splenomegalia dovuta a ipertensione portale.

I pazienti con splenomegalia elo trombocitopenia devono essere sottoposti a test per la malattia di Gaucher nel caso in cui sia stata loro diagnosticata una delle seguenti condizioni: i) splenomegalia idiopatica o senza causa nota; ii) trombocitopenia idiopatica o senza causa nota; iii) trombocitopenia idiopatica atipica o non responsiva; iv) sanguinamento e lividi inspiegabili; v) iperferritinemia inspiegabile con saturazione normale della transferrina.

\section{Test diagnostici}

Per ottenere una diagnosi affidabile di malattia di Gaucher, non sono necessari né sufficienti esami citoistologici del midollo osseo. La malattia di Gaucher può essere diagnosticata o esclusa con un dosaggio enzimatico ( $\beta$-glucosidasi acida) su campioni di sangue. Questo test dell'attività enzimatica può essere eseguito su una goccia di sangue essiccato (DBS). I risultati di tale dosaggio su DBS sono altamente indicativi per la malattia di Gaucher, ma è necessaria un'analisi su campioni di sangue intero per confermare la diagnosi. Il metodo di riferimento per la diagnosi definitiva di malattia di Gaucher è rappresentato dai dosaggi enzimatici su campioni di sangue. La misurazione della $\beta$-glucosidasi acida può essere integrata con un'analisi mutazionale del gene GBA1 ( $\beta$ glucosidasi acida).

Diagnosi differenziale tra malattia di Gaucher e neoplasie ematologiche è riportata in Tabella 2.

\section{Terapie della malattia di Gaucher}

\section{Terapia enzimatica sostitutiva $v s$ terapia di riduzione del substrato}

Una adeguata terapia deve vedere combinati interventi sintomatici (e.g., supporto al dolore, procedure ortopediche, supplemento di ferro e bifosfonati) e terapie specifiche per la malattia: terapia enzimatica sostitutiva (ERT) o terapia di riduzione del substrato (SRT). Una cura ottimale prevede un regolare followup con un team multidisciplinare con esperienza nel trattamento della malattia di Gaucher.

\section{La terapia enzimatica sostitutiva}

La ERT è la cura standard per la malattia di Gaucher. L'imiglucerasi è stato il primo farmaco indicato per l'uso come terapia enzimatica sostitutiva a lungo termine, in pazienti con diagnosi confermata di malattia di Gaucher non neuropatica (tipo 1) o neuropatica cronica (tipo 3), i quali evidenzino inoltre significative manifestazioni cliniche non neurologiche della malattia. La somministrazione è parenterale e deve essere ripetuta ogni 2 settimane. Il dosaggio è individualizzato e dipende dalla gravità della malattia e dalla presenza di fattori di rischio aggiuntivi per la progressione della patologia ossea. ${ }^{3}$ Per raggiungere l'effetto terapeutico, le manifestazioni ossee richiedono un trattamento a lungo termine a dosaggi elevati. I pazienti con interessamento scheletrico significativo o altri fattori di rischio devono essere trattati con terapia ad alte dosi (60 $\mathrm{U} / \mathrm{kg} / 2$ settimane). I pazienti giovani devono essere trattati con terapia ad alte dosi per promuovere il raggiungimento di un adeguato picco di densità minerale ossea durante questo periodo critico. 
Tabella 2. Diagnosi differenziale tra malattia di Gaucher e neoplasie ematologiche.

\begin{tabular}{|c|c|c|c|c|c|c|c|}
\hline & $\begin{array}{l}\text { Malattia } \\
\text { di Gaucher }\end{array}$ & Leucemia & $\begin{array}{c}\text { Mieloma } \\
\text { multiplo }\end{array}$ & $\begin{array}{c}\text { Leucemia } \\
\text { a cellule } \\
\text { capellute }\end{array}$ & $\begin{array}{c}\text { Leucemia } \\
\text { mieloide } \\
\text { cronica }\end{array}$ & $\begin{array}{c}\text { Linfoma } \\
\text { non-Hodgkin }\end{array}$ & Mielofibrosi \\
\hline Età di esordio tipico (anni) & $0-80$ & $\begin{array}{l}<5 \text { bambini } \\
>60 \text { adulti }\end{array}$ & $65-70$ & $>50$ & $>50$ & $>70$ & $>50$ \\
\hline Dolore osseo & $\bullet$ & $\bullet$ & $\bullet$ & & $\bullet$ & $\bullet$ & $\bullet$ \\
\hline Sanguinamenti/ecchimosi & • & • & • & • & • & • & • \\
\hline Astenia & - & - & - & - & • & - & - \\
\hline Splenomegalia & $\bullet$ & $\bullet$ & Poco comune & - & $\bullet$ & $\bullet$ & $\bullet$ \\
\hline Epatomegalia & • & - & Poco comune & - & $\bullet$ & $\bullet$ & • \\
\hline Ritardo crescita/pubertà ritard & data $\bullet$ & - (bambino) & no & no & no & no & no \\
\hline $\begin{array}{l}\text { Cellule di Gaucher } \\
\text { alla BOM }\end{array}$ & Raggruppate & $\begin{array}{c}\text { A volte } \\
\text { pseudo cellule } \\
\text { di Gaucher }\end{array}$ & $\begin{array}{c}\text { A volte } \\
\text { pseudo cellule } \\
\text { di Gaucher }\end{array}$ & no & $\begin{array}{c}\text { A volte } \\
\text { pseudo cellule } \\
\text { di Gaucher }\end{array}$ & $\begin{array}{c}\text { A volte } \\
\text { pseudo cellule } \\
\text { di Gaucher }\end{array}$ & $\begin{array}{c}\text { A volte } \\
\text { pseudo cellule } \\
\text { di Gaucher }\end{array}$ \\
\hline
\end{tabular}

Gli obiettivi terapeutici sono di raggiungere un'aspettativa e qualità di vita normale e di ridurre il rischio di sequele a lungo termine clinicamente significative I benefici del trattamento sono estremamente rapidi per alcuni tipi di sintomi, mentre per altri la correzione, anche solo parziale, richiede anni di terapia.

I punti chiave sono: i) la ERT riduce le dimensioni di milza e fegato, migliora o normalizza la trombocitopenia e l'anemia, migliora o normalizza la densità minerale ossea e il carico del midollo osseo e riduce o elimina il dolore osseo e le crisi ossee; ii) la malattia ossea e la conseguente disabilità sono importanti cause di morbilità a lungo termine nei pazienti con malattia di Gaucher. Il conseguimento e il mantenimento di una BMD nella norma sono importanti obiettivi terapeutici per tutti i pazienti con malattia di Gaucher; ${ }^{3}$ iii) il miglioramento a livello midollare e scheletrico in risposta alla terapia enzimatica sostitutiva è più lento delle risposte viscerali ed ematologiche.

L'imiglucerasi è utilizzata da oltre 20 anni, essendo stata approvata nel 1994 negli Stati Uniti e nel 1997 in Europa; dal 2010 è disponibile anche la velaglucerasi alfa.

\section{La terapia di riduzione del substrato}

Essa ha il grande vantaggio di permettere una terapia orale. Il farmaco più ampiamente utilizzato oggi è l'eliglustat che si è dimostrato efficace rispetto al placebo nel trattamento di pazienti naive. Ha raggiunto tutti gli endpoint di efficacia in uno studio di fase 3 controllato con placebo (riduzione volume splenico ed epatico, miglioramento dei valori di emo- globina e piastrine). In uno studio in cui pazienti stabilizzati con ERT venivano randomizzati a proseguire la ERT o a passare a SRT, eliglustat ha dimostrato di non essere inferiore a imiglucerasi nel mantenere la stabilità del paziente. Il confronto tra eliglustat e imiglucerasi nei pazienti naive ha mostrato risultati comparabili nei parametri ematologici e viscerali. Eliglustat ha migliorato la densità minerale ossea da livelli di osteopenia a livelli normali dopo 4 anni di trattamento. Eliglustat è oggi l'unica terapia orale di prima linea per adulti affetti da malattia di Gaucher di tipo 1 con qualsiasi capacità di metabolismo: metabolizzatori lenti (poor metabolisers), metabolizzatori intermedi (intermediate metabolisers) o metabolizzatori estensivi (extensive metabolisers) per CYP2D6. La dose raccomandata dipende dalle capacità metabolizzanti: i) è $84 \mathrm{mg}$ di eliglustat due volte al giorno nei metabolizzatori intermedi o metabolizzatori estensivi per CYP2D6; ii) $84 \mathrm{mg}$ di eliglustat una volta al giorno nei metabolizzatori lenti per CYP2D6. Se una dose viene omessa, la dose prescritta deve essere assunta all'orario successivo previsto; la dose successiva non deve essere raddoppiata; iii) miglustat: approvata da EMA nel 2002 e da FDA nel 2003, ha indicazioni un po' più limitate: può essere utilizzata solo se la terapia enzimatica sostitutiva non sia disponibile o sia controindicata.

\section{Obiettivi terapeutici}

Gli obiettivi terapeutici nella malattia di Gaucher includono obiettivi ematologici, viscerali e in merito alla patologia ossea (vedi Tabelle 3-5). 
Tabella 3. Obiettivi terapeutici ematologici.

\begin{tabular}{|c|c|c|}
\hline Pazienti & Goal & Range di tempo \\
\hline \multicolumn{3}{|l|}{ Piastrinopenia } \\
\hline Tutti i pazienti & Piastrine sufficienti per ridurre l'emorragia & 1 anno \\
\hline Pazienti splenectomizzati & Normalizzazione della conta piastrinica & 1 anno \\
\hline \multicolumn{3}{|c|}{ Pazienti non splenectomizzati } \\
\hline Piastrinopenia moderata & Conta piastrinica ai limiti inferiori della normalità & Secondo anno \\
\hline Piatrinopenia severa & Progressivo aumento ma non normalizzazione & Secondo anno \\
\hline \multicolumn{3}{|l|}{ Anemia } \\
\hline Femmine adulte e bambini & $\mathrm{HB} \geq 11 \mathrm{gr} / \mathrm{dL}$ & 1-2 anni \\
\hline Pazienti maschi $>12$ anni & $\mathrm{HB} \geq 12 \mathrm{gr} / \mathrm{dL}$ & 1-2 anni \\
\hline Tutti i pazienti & $\begin{array}{l}\text { Eliminata la dipendenza dalle trasfusioni di sangue } \\
\text { Ridurre l'astenia } \\
\text { Mantenere i miglioramenti dei livelli di } \mathrm{Hb}\end{array}$ & \\
\hline
\end{tabular}

Tabella 4. Obiettivi terapeutici viscerali.

\begin{tabular}{llr}
\hline Pazienti & Goal & Range di tempo \\
\hline Epatomegalia & & \\
\hline Tutti i pazienti & Diminuzione del $20-30 \%$ & $1-2$ anni \\
& Diminuzione del $30-40 \%$ & $3-5$ anni \\
\hline Splenomegalia & & 1 anno \\
\hline Tutti i pazienti & Diminuzione del 30-50\% & $2-5$ anni \\
& Diminuzione del $50-60 \%$ & \\
\hline
\end{tabular}

Tabella 5. Obiettivi terapeutici ossei.

\begin{tabular}{lll}
\hline Pazienti & Goal & Range di tempo \\
\hline Tutti i pazienti & $\begin{array}{l}\text { Ridurre o eliminare il dolore osseo } \\
\text { Prevenire le crisi ossee } \\
\text { Prevenire osteonecrosi e il collasso subcondrale dell'articolazione }\end{array}$ \\
\hline Pazienti pediatrici & Ottenere una crescita ed una maturazione normale e il picco ideale di massa ossea \\
\hline Pazienti adulti & Aumentare la densità minerale ossea corticale e trabecolare & Secondo anno \\
& Migliorare ulteriormente e normalizzare la densità minerale ossea & $3-5$ anni \\
\hline
\end{tabular}

\section{Bibliografia}

1. Kaplan P, Baris H, De Meirleir L, et al. Revised recommendations for the management of Gaucher disease in children. Eur J Pediatr 2013;172:447-58.
2. Grabowski GA, Petsko GA, Kolodny EH. Gaucher disease. In: Valle D, Beaudet AL, Vogelstein B, Kinzler KW, Antonarakis SE, Ballabio A, Gibson K, Mitchell G, eds. New York, NY: McGraw-Hill; 2014.

3. Cheson BD. Clinical advances in hematology \& oncology. Clin Adv Hematol Oncol 2012;10:8. 


\section{APPENDICE \\ Come affrontare i pazienti con...}

\section{1) Piastrinopenia}

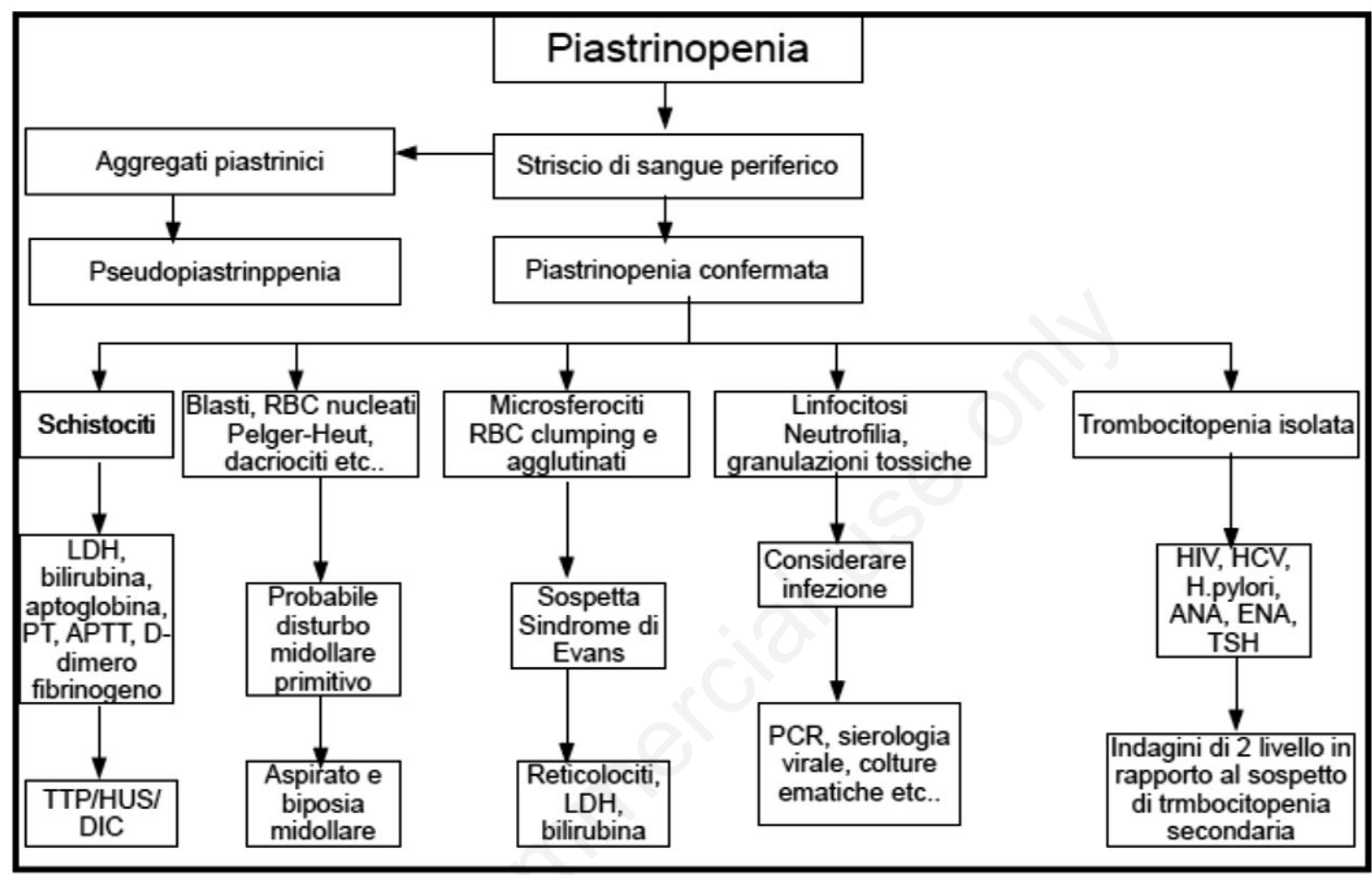


2) Piastrinosi

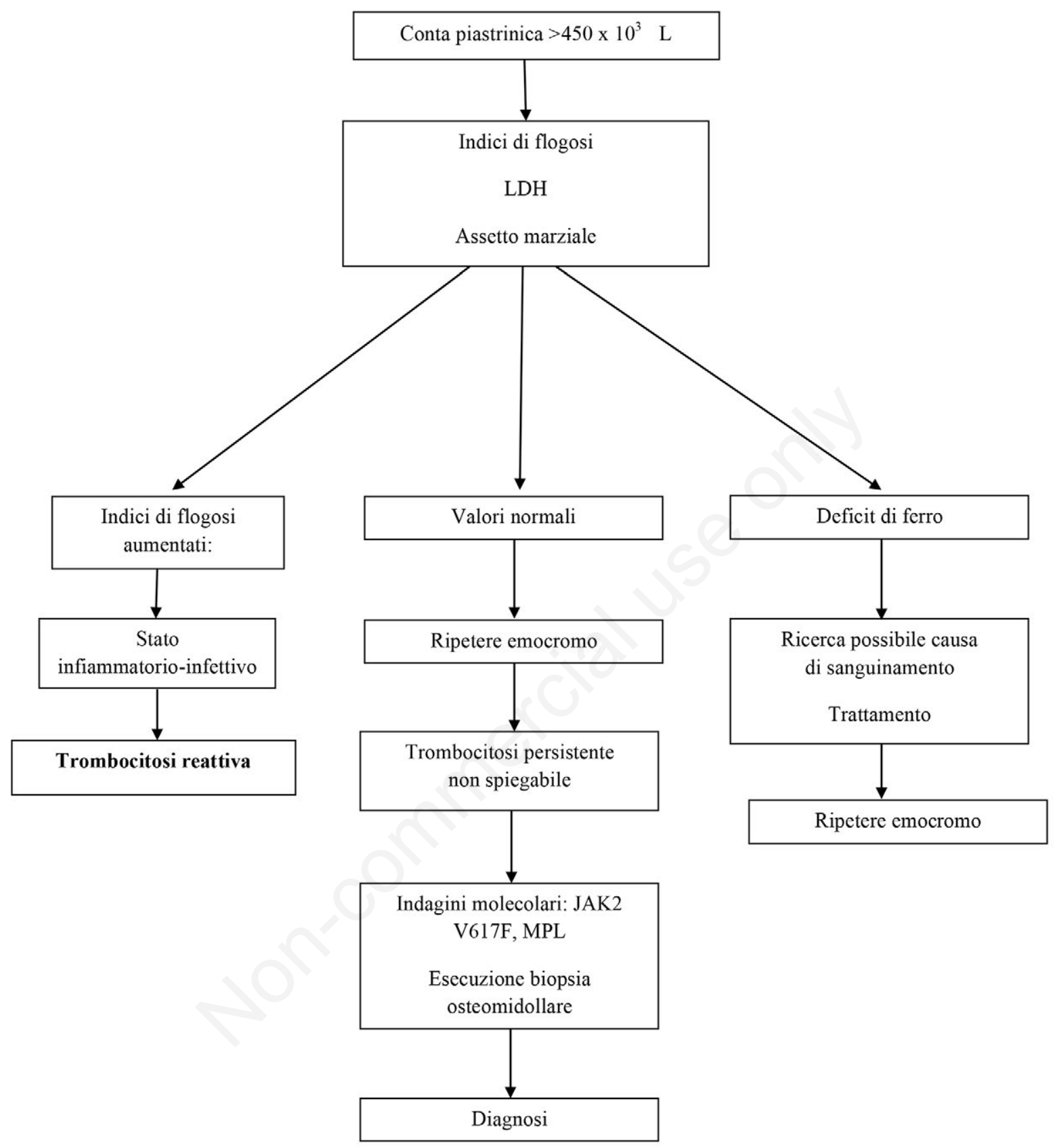




\section{3) Poliglobulia}

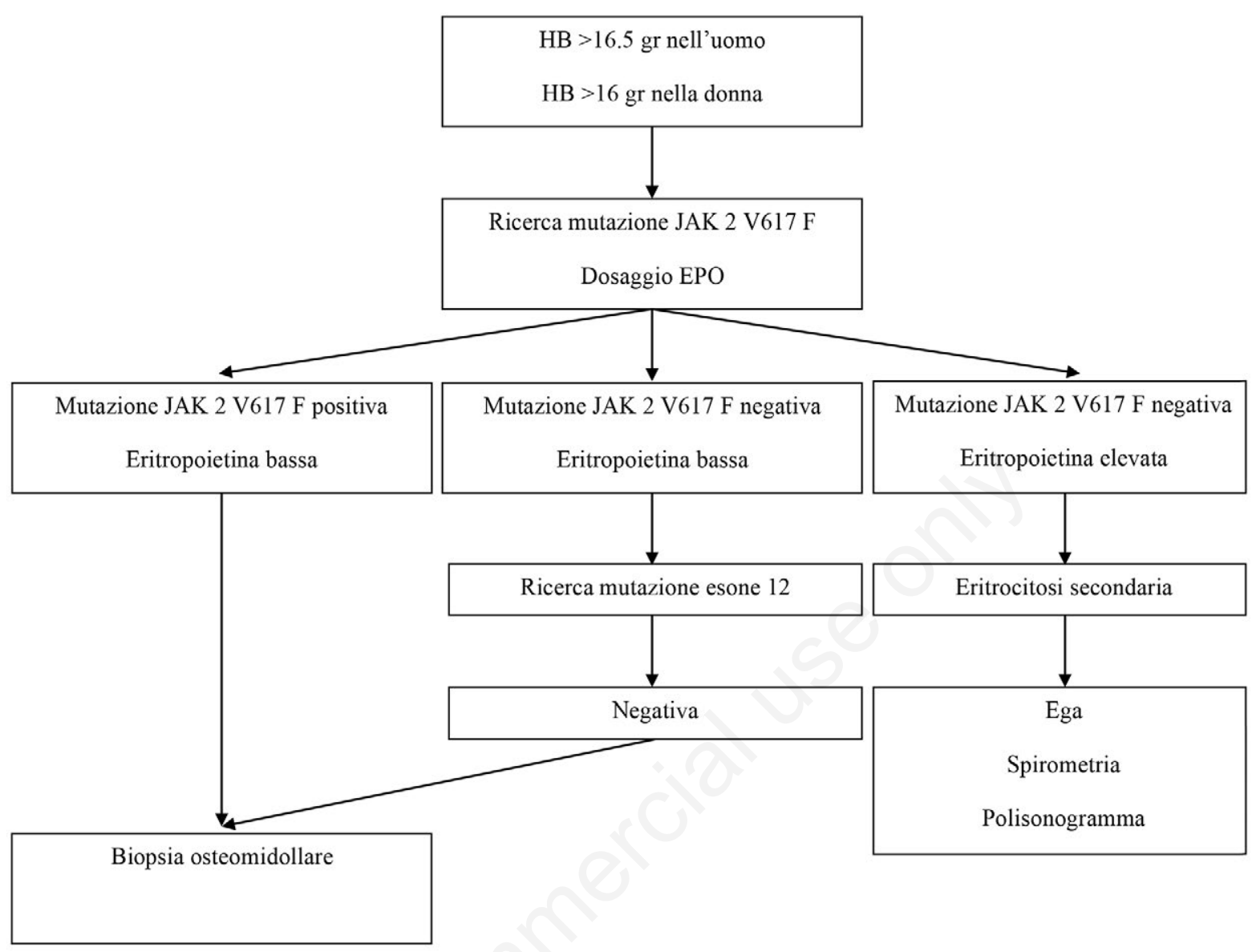




\section{4) Linfocitosi}

Anamnesi accurata: indagare in merito a patologie reumatiche, autoimmuni, tireopatie, morbo celiaco, asplenia/splenectomia, epatopatie, terapia farmacologica, ecc.

Quadro clinico: sintomi quali febbre/febbricola, recenti infezioni, ecc.

Esame obiettivo: presenza di adenomegalie, epatosplenomegalia.

Esami di laboratorio: PCR, VES, TSH, test di autoimmunità, esami sierologici, ecc.

Esami strumentali: ecografia, TC.

Escluse cause di linfocitosi reattiva, quando la linfocitosi è confermata e significativa $(\mathrm{L}>5.000 / \mathrm{mcL})$ e/o quando il quadro clinico è fortemente suggestivo per malattia ematologica (linfoadenomegalie, epato-splenomegalia, sintomi specifici), il medico internista dovrà orientarsi verso malattie linfoproliferative e quindi programmare uno studio dell'immunofenotipo su sangue periferico

\section{L'immunofenotipo potrà mettere in evidenza la presenza di una malattia ematologica}

(la patologia di maggiore frequenza è la leucemia linfatica cronica ma esistono anche linfomi leucemizzati, leucemie acute).

Talvolta invece la linfocitosi potrà essere etichettata come Linfocitosi $\mathrm{B}$ monoclonale. 


\section{5) Neutropenia}

Anamnesi:
familiare, pregresse infezioni, assunzione di farmaci, chemio e radioterapia, sintomi ciclici e ricorrenti, sintomi costituzionali.

Esame obiettivo:

ulcere in cavo orale, linfoadenomegalie, organomegalia, deformità articolari.

Esami ematochimici:

emocromo completo con formula, confermato su almeno 2 prelievi; funzionalità renale, epatica, dosaggio di b12 e folati, immunoglobuline sieriche, studio autoimmunità, esami virologici, indici di infiammazione, coombs diretto/indiretto, anticorpi anti neutrofili

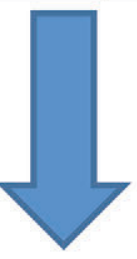

Positività degli esami precedenti/regressione alla sospensione di farmaco potenzialmente neutropenizzante

- Indagini di primo livello negative e neutropenia confermata nel tempo.

- Neutropenia associata ad anemia e piastrinopenia anch'esse inspiegate.

Striscio di sangue periferico ed immunofenotipo.

Aspirato midollare per immunofenotipo, cariotipo, biologia molecolare e biopsia osteomidollare, per escludere patologie ematologiche e/o mieloftisi (esame colturale nel sospetto di infezione). 


\section{6) Splenomegalia}

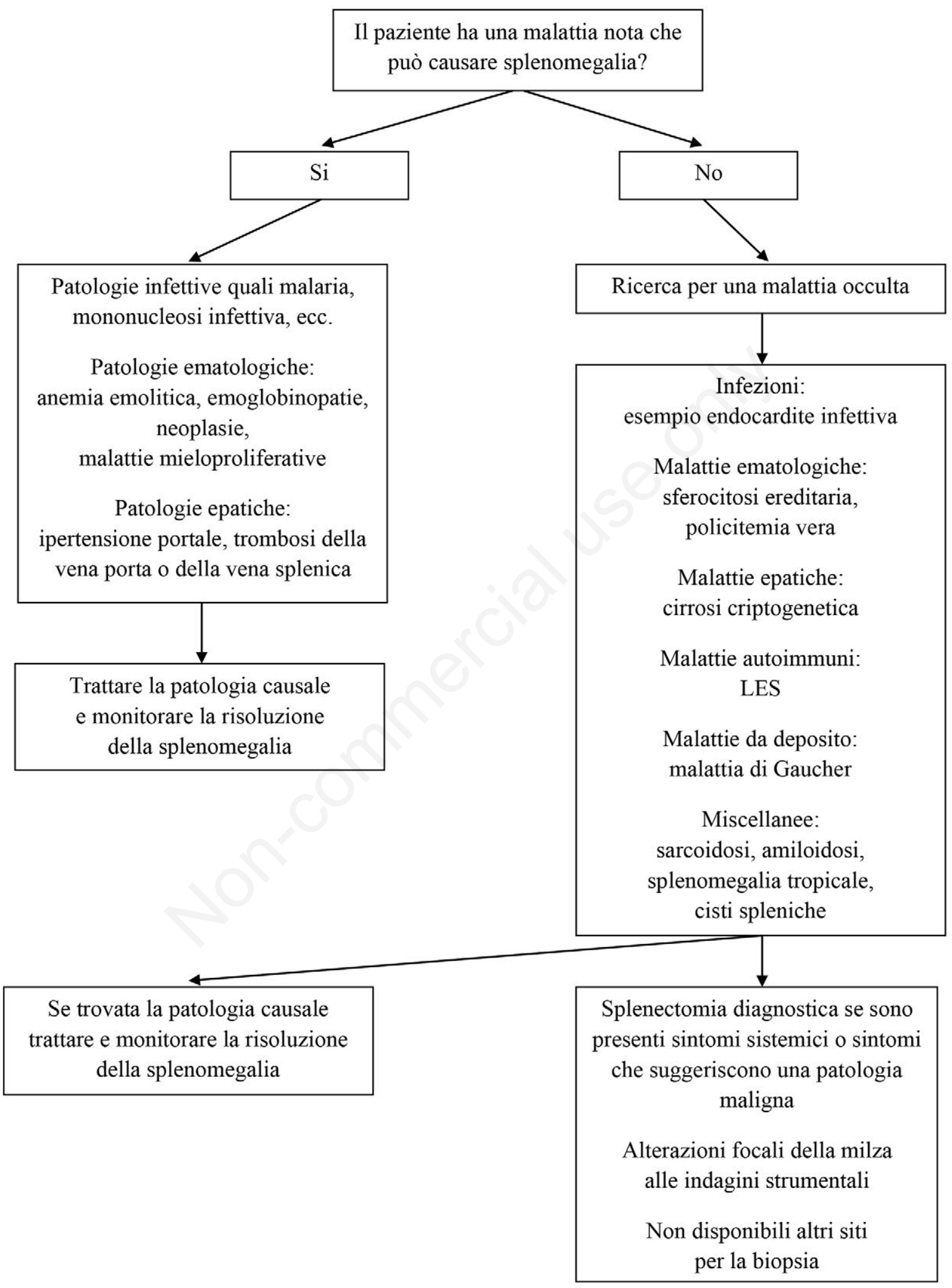




\section{7) Linfoadenomegalie}

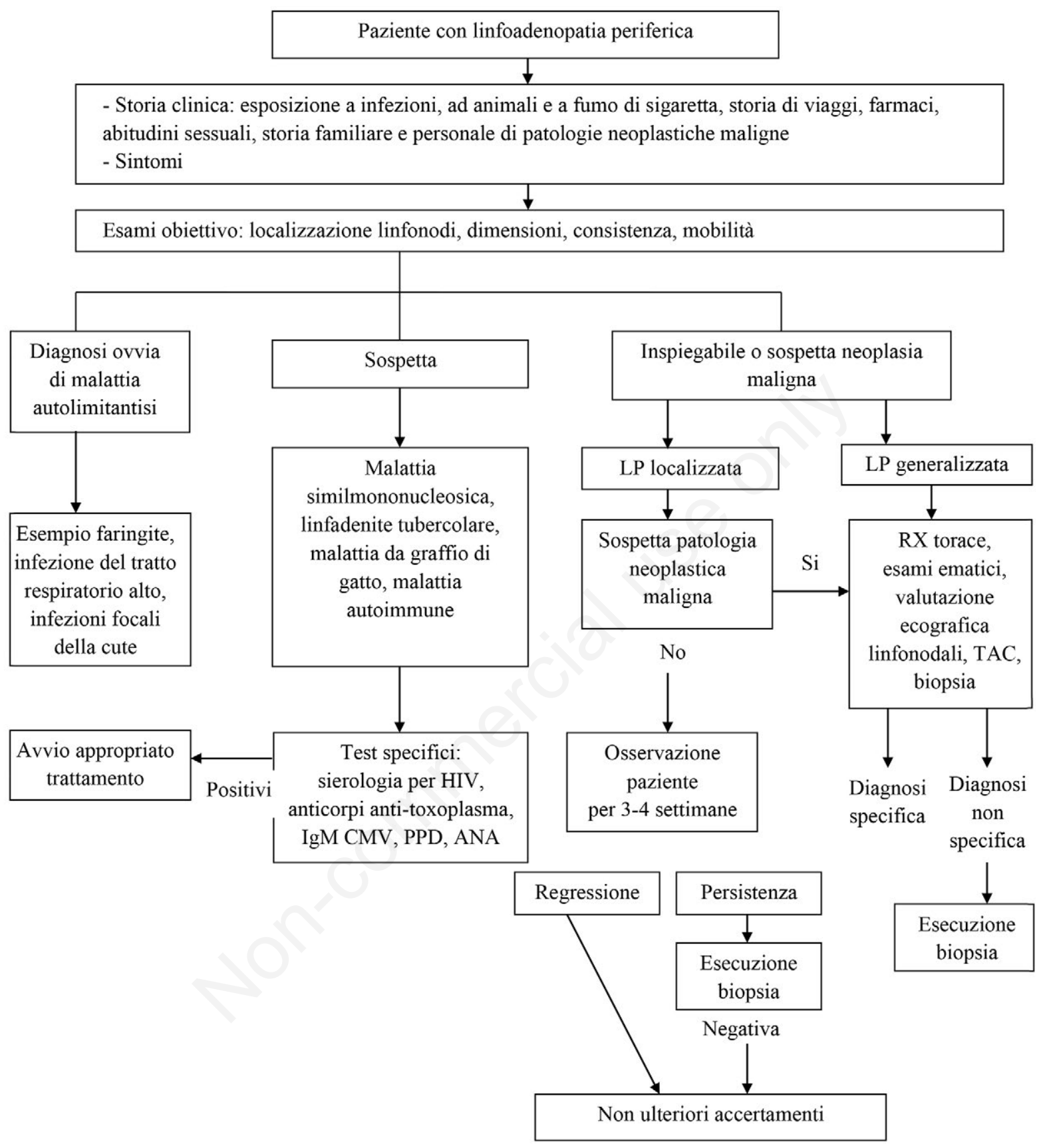




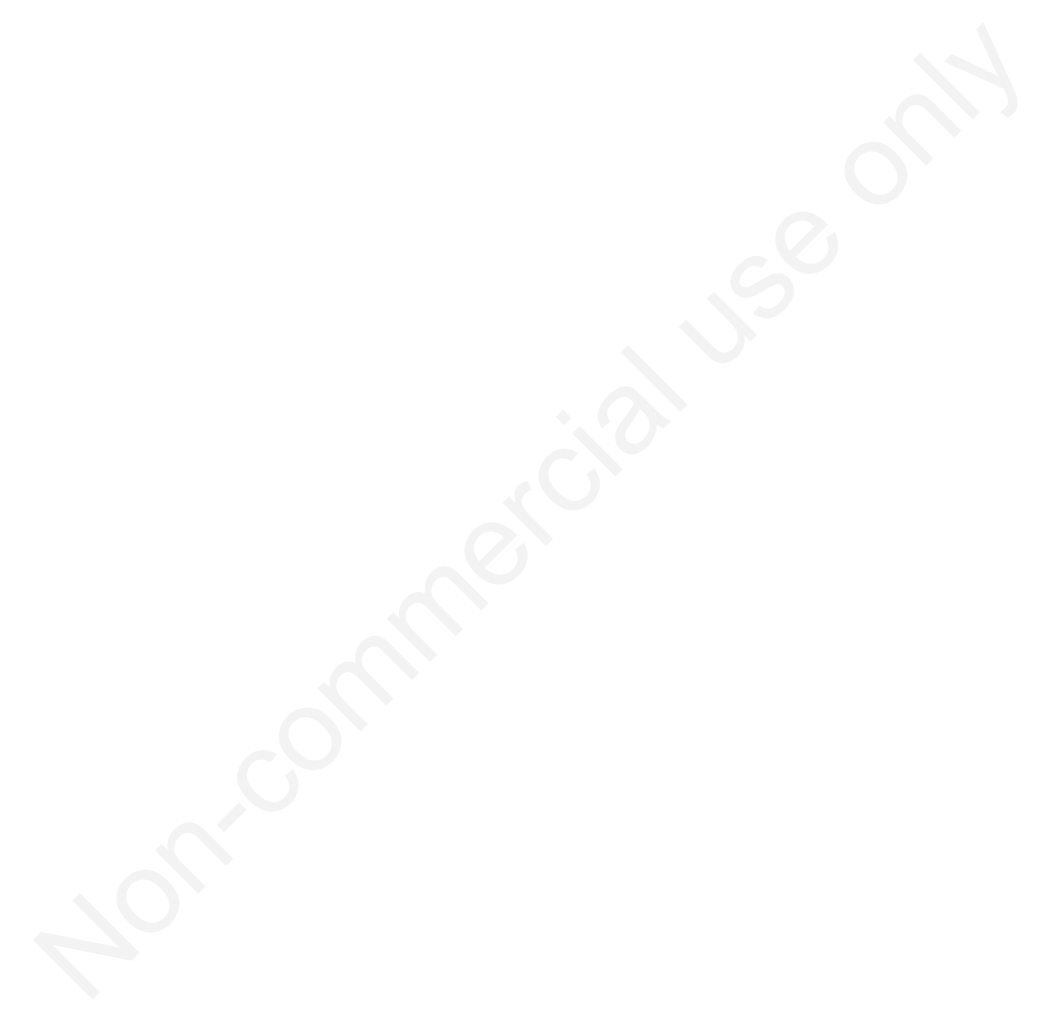




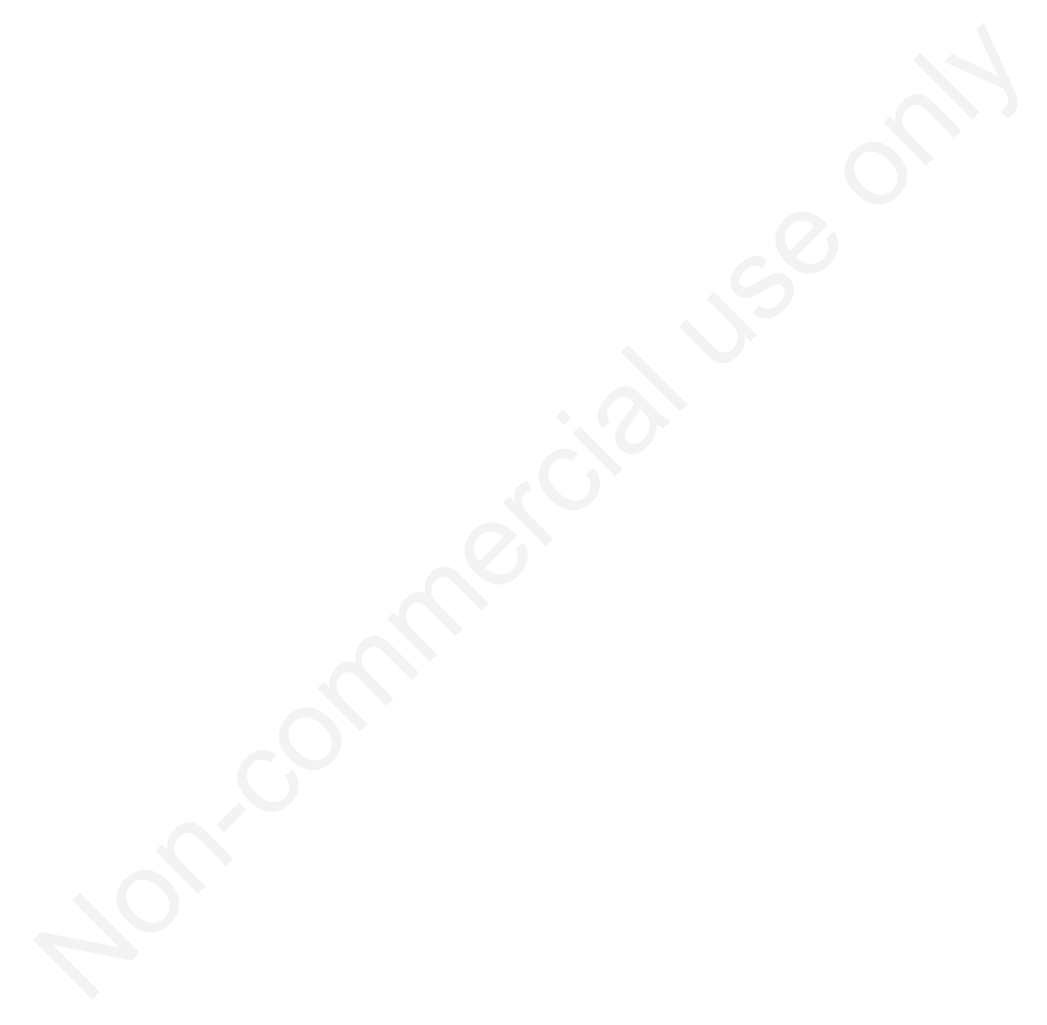




\section{LINEE GUIDA PER GLI AUTORI}

I Quaderni dell 'Italian Journal of Medicine (Quaderni ITJM), costituiscono una collana supplementare solo online annessa alla rivista Italian Journal of Medicine contenente lavori solo in lingua italiana.

I Quaderni ITJM pubblicano:

- Monografie ad hoc individuate dal Presidente FADOI, dal Consiglio Direttivo, dal Board Scientifico o dall'Editor in Chief dell'Italian Journal of Medicine, in funzione del contesto scientifico-istituzionale attuale.

- Monografie ad hoc su temi di particolare rilevanza scientifica a cura della Commissione FADOI Giovani.

- Traduzioni in italiano di alcuni lavori pubblicati sui numeri standard dell'Italian Journal of Medicine, di particolare interesse per la comunità scientifica.

\section{STESURA DEI LAVORI}

I lavori dovranno essere redatti in modo conforme alle linee guida sotto riportate:

- I manoscritti devono essere scritti interamente in lingua italiana, su documento di Word, con carattere Times New Roman/Arial, dimensione 12, formato A4, interlinea doppia e margini $2,54 \mathrm{~cm}$

Parole totali: $\max$ 4000; Sommario/Abstract: $\max 250$ parole; Bibliografia: min 40 voci; Tabelle e Figure: $3 / 5$ totali (le tabelle non devono superare n. 1 pagina del documento in Word).

- La strutturazione del contenuto deve attenersi agli standard internazionali per la Rassegna (Review): i) Abstract riassuntivo dell'intero lavoro; ii) Introduzione al tema trattato; iii) Criteri e strumenti di ricerca (criteri di inclusione/esclusione, banche dati consultate, ...); iv) i successivi paragrafi devono illustrare le più recenti scoperte scientifiche nel settore; v) Conclusioni; vi) Bibliografia.

- La prima pagina deve riportare: i) titolo (in stampatello minuscolo), senza acronimi; ii) nome e cognome per esteso di ciascun autore; iii) affiliazione(i) di ciascun autore, numerate con numeri arabi iv) eventuali ringraziamenti; v) nome e indirizzo postale completi dell'autore corrispondente, corredati da telefono, fax, e-mail; vi) da 3 a 5 parole chiave, separate da virgola. La seconda pagina può riportare: i) contributi degli autori, e.g. informazioni relative a contributi sostanziali delle persone coinvolte nello studio (http://www.icmje.org/\#author); ii) dichiarazione relativa a potenziali conflitti d'interesse; iii) ulteriori informazioni (e.g. fondi, esposizioni durante conferenze...).

- In caso di utilizzo di tabelle, queste devono essere tutte numerate con numeri arabi e citate nel testo in ordine consecutivo (e.g. NON nominare le tabelle come Tabella $1 \mathrm{~A}, 1 \mathrm{~B}, \ldots$ o $1.0,1.1, \ldots$ ). Le tabelle devono essere presentate in formato editabile. Ciascuna tabella deve essere corredata da una breve didascalia; in caso di abbreviazioni, riportare una nota a piè di CIASCUNA tabella che spieghi TUTTE le abbreviazioni presenti in ognuna.

- In caso di utilizzo di figure, queste devono essere inviate in formato tiff o .jpg, allegate al manoscritto in singoli files, secondo le seguenti specifiche:

i) a colori (salvate in modalità CMYK): minimo 300 dpi di risoluzione;

ii) in bianco e nero: minimo $600 \mathrm{dpi}$ di risoluzione;

iii) minimo $17,5 \mathrm{~cm}$ di larghezza.

Ciascuna figura deve essere corredata da una breve didascalia.

$N B$ : In caso di Tabelle/Figure riprese e/o modificate da altri lavori già pubblicati, sarà cura degli autori accertarsi se tali materiali siano o meno coperti da copyright e procurarsi i permessi necessari per la riproduzione. Tali permessi dovranno essere allegati alla versione definitiva del lavoro. L'ufficio editoriale si riserva la facoltà di rimuovere Tabelle/Figure coperte da copyright, se sprovviste dei necessari permessi.

- In caso di utilizzo di abbreviazioni, la prima volta che esse sono citate è necessario scrivere per esteso la definizione+abbreviazione tra parentesi tonde [e.g. risonanza magnetica $(\mathrm{RMN})]$, a seguire si dovrà riportare solo l'abbreviazione (unica eccezione: nei titoli e nelle didascalie di tabelle e figure NON si utilizzano abbreviazioni).

\section{BIBLIOGRAFIA}

Le voci bibliografiche devono essere formattate secondo lo stile Vancouver.

Nella sezione Bibliografia, le voci bibliografiche devono essere numerate consecutivamente nell'ordine in cui appaiono per la prima volta nel testo (NON in ordine alfabetico) e, nel testo, devono essere indicate con numeri arabi in apice. Voci bibliografiche riferite a comunicazioni personali o dati non pubblicati devono essere incorporate nel testo e NON inserite tra le voci numerate [e.g. (Wright 2011, dati non pubblicati) o (Wright 2011, comunicazione personale)]. Le voci bibliografiche nella sezione Bibliografia devono tassativamente essere preparate come segue:

i) più di 3 autori, citare 3 autori, et al. Se il lavoro contiene solo 4 autori, citarli tutti e 4 ;

ii) titolo del lavoro in stampatello minuscolo;

iii) nome della rivista, senza punti, abbreviato secondo gli standard internazionali; in caso di dubbi sulla corretta abbreviazione, fare riferimento ai seguenti siti:

a. ISI Journal Abbreviations Index (http://library.caltech.edu/ reference/abbreviations/);

b. Biological Journals and Abbreviations (http://home.ncifcrf. gov/research/bja/);

c. Medline List of Journal Titles (ftp://ftp.ncbi.nih.gov/pubmed/J_Medline.txt);

iv) inserire l'anno di pubblicazione subito dopo il nome della rivista, seguito da punto e virgola;

v) NON inserire giorno o mese di pubblicazione;

vi) citare solo il volume, seguito dai due punti (NON citare il fascicolo tra parentesi);

vii) abbreviare le pagine, e.g. 351-8

Per accertarsi di aver correttamente formattato le voci bibliografiche, confrontarle con le citazioni in PubMed (http://www.ncbi. nlm.nih.gov/pubmed).

Esempi (prestare attenzione anche alla punteggiatura):

Articolo standard su Rivista

Halpern SD, Ubel PA, Caplan AL. Solid-organ transplantation in HIV-infected patients. N Engl J Med 2002;347:284-7.

Proceedings

Christensen S, Oppacher F. An analysis of Koza's computational effort statistic for genetic programming. In: Foster JA, Lutton E, Miller J, Ryan C, Tettamanzi AG, eds. Genetic programming. EuroGP 2002: Proceedings of the 5th European Conference on Genetic Programming, 2002 Apr 3-5, Kinsdale, Ireland. Berlin: Springer; 2002. pp 182-91.

Articoli i cui autori sono Organizzazioni

Diabetes Prevention Program Research Group. Hypertension, insulin, and proinsulin in participants with impaired glucose tolerance. Hypertension 2002;40:679-86.

Libri

Murray PR, Rosenthal KS, Kobayashi GS, Pfaller MA. Medical microbiology. 4th ed. St. Louis, MO: Mosby; 2002. (CITAZIONE DEL LIBRO INTERO)

Meltzer PS, Kallioniemi A, Trent JM. Chromosome alterations in human solid tumors. In: Vogelstein B, Kinzler KW, eds. The genetic basis of human cancer. New York, NY: McGraw-Hill; 2002. pp 93113. (CITAZIONE DI UN CAPITOLO)

\section{MODALITÀ D'INVIO DEI LAVORI}

Monografie

Gli Autori dovranno fare riferimento all'Editor-in-Chief o alle persone da lei designate nelle lettere di invito a scrivere gli articoli programmati.

Per gli articoli inviati da giovani internisti, gli Autori dovranno fare riferimento alla Dr.ssa Paola Gnerre (e-mail: pgnerre@yahoo.it) e agli eventuali altri referenti da lei designati, nelle prime fasi di stesura dei manoscritti, revisioni e correzioni. 


\section{QUADERNI}

dell'Italian Journal

of Medicine

La Dr.ssa Gnerre raccoglierà poi le versioni definitive dei lavori di ciascuna monografia e provvederà all'invio di tutti i materiali all'ufficio editoriale.

I lavori solo nella loro versione definitiva e approvata dalla Commissione FADOI Giovani dovranno pervenire all'ufficio editoriale già pronti per l'impaginazione e immediata pubblicazione (già corredati da eventuali permessi per la riproduzione di tabelle e immagini redatti secondo le presenti linee guida).

Traduzioni

Previo invito dell'Editor-in-Chief, gli Autori dovranno far pervenire all'ufficio editoriale la versione tradotta in italiano, al seguente indirizzo e-mail: paola.granata@pagepress.org

Il file in formato Word dovrà essere formattato secondo gli standard editoriali della rivista ufficiale ed essere già pronto per impagina- zione e immediata pubblicazione (corredato da eventuali permessi per la riproduzione di tabelle e immagini).

Si prega di inviare le eventuali tabelle in formato editabile e le figure in alta definizione secondo gli standard sopra riportati.

\section{NOTA PER GLI AUTORI}

I lavori pubblicati sui Quaderni ITJM non verranno indicizzati, ma saranno liberamente disponibili in un'apposita sezione del sito FADOI (http://www.fadoi.org/) e della rivista ufficiale.

Gli Autori i cui lavori siano accettati per la pubblicazione sui Quaderni ITJM e che fossero interessati a vederli pubblicati anche sulla rivista ufficiale, dovranno sottomettere attraverso il sito dell'ITJM (www.italjmed.org) la versione (già tradotta) in inglese e redatta in modo conforme alle linee guida della rivista; seguiranno poi la procedura di selezione tramite peer review e, se accettati, saranno inseriti nel piano editoriale standard.

\section{STAFF EDITORIALE}

Paola Granata, Journal Manager

paola.granata@pagepress.org

Claudia Castellano, Production Editor

Tiziano Taccini, Technical Support
PUBBLICATO DA

PAGEPress Publications

via A. Cavagna Sangiuliani 5

27100 Pavia, Italy

T. +39.0382 .464340$

F: +39.0382 .34872$

\section{agepress}

www.pagepress.org info@pagepress.org

\section{QUADERNI - ITALIAN JOURNAL OF MEDICINE}

Tutti gli articoli pubblicati sui QUADERNI - Italian Journal of Medicine sono redatti sotto la responsabilità degli Autori. La pubblicazione o la ristampa degli articoli della rivista deve essere autorizzata per iscritto dall'editore. Ai sensi dell'art. 13 del D.Lgs 196/03, i dati di tutti i lettori saranno trattati sia manualmente, sia con strumenti informatici e saranno utilizzati per l'invio di questa e di altre pubblicazioni e di materiale informativo e promozionale. Le modalità di trattamento saranno conformi a quanto previsto dall'art. 11 del D.Lgs 196/03. I dati potranno essere comunicati a soggetti con i quali PAGEPress intrattiene rapporti contrattuali necessari per l'invio delle copie della rivista. Il titolare del trattamento dei dati è PAGEPress Srl, via A. Cavagna Sangiuliani $5-27100$ Pavia, al quale il lettore si potrà rivolgere per chiedere l'aggiornamento, l'integrazione, la cancellazione e ogni altra operazione di cui all'art. 7 del D.Lgs 196/03.

https://www.italjmed.org/index.php/ijm/quad 
PAGEPress - Scientific Publications

Via A. Cavagna Sangiuliani, 5 - 27100 Pavia - Italy

Phone +390382 $464340-$ Fax +39 038234872

www.pagepress.org 